SCHOOL OF CIVIL ENGINEERING

JOINT HIGHWAY RESEARCH PROJECT

JHRP-74-15- /

DESTINATION CHOICE MODELLING AND THE DISAGGREGATE ANALYSIS OF URBAN TRAVEL BEHAVIOR

Joseph A. Ansah

,

Joseph A. Ansah 
Digitized by the Internet Archive in 2011 with funding from

LYRASIS members and Sloan Foundation; Indiana Department of Transportation 
DESTINATION CHOICE MODELLING AND THE DISAGGREGATE ANALYSIS OF URBAN TRAVEL BEHAVIOR

TO: J. F. McLaughlin, Director Joint Highway Research Project

August 28, 1974

Project: C-36-69I

FROM: H. I. Michael, Associate Director File: 3-7-9 Joint Highway Research Project

The attached Report "Destination Choice Modelling and the Disaggregate Analysis of Urban Travel Behavior" is the Final Report on Phase II of the HPR Part I Research Study titled "A Micro-Analysis of the Effects of Household Socio-Economic Characteristics and Individual Attitudes in Trip Generation". The report has been authored by Joseph A. Ansah, Graduate Fellow on our staff under the direction of Professors G. T. Satterly and K. C. Pillai.

The report is an extensive theoretical analysis of proposed methods and claimed benefits of disaggregate analysis for trip generation. A method of such analysis on the basis of limited application to Indianapolis data appears to have much promise.

Although some additional research is warranted in this area, and in fact some recommended, this report is submitted as the Final Report on this study. If and when additional research is proposed in this area it will be submitted as a new study.

The Report is submitted as fulfillment of the objectives of Phase II of the research. A number of technical papers from Phase II are anticipated in order to obtain good distribution of the results. These will be forwarded as prepared. The Report will also be submitted to ISHC and FHWA for their review, comment and similar acceptance.

Respectfully submitted,

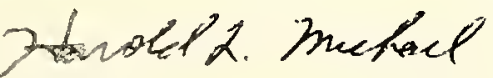

Harold L. Michael

Associate Director

HLM:jal

CC: W. I. Dolch
R. L. Eskew
G. D. Gibson
W. H. Goetz
M. J. Gutzwiller
G. K. Hallock

M. L. Hayes
C. W. Lovell
G. W. Marks
R. F. Marsh
R. D. Miles
G. T. Satterly

C. F. Scholer

M. B. Scott

H. R. J. Walsh

E. J. Yoder

S. R. Yoder

G. K. Hallock 
Final Report

\section{DESTINATION CHOICE MODELLING AND THE DISAGGREGATE \\ ANALYSIS OF URBAN TRAVEL BEHAVIOR}

by

Joseph A. Ansah

Graduate Fellow

Joint Highway Research Project

Project No.: $\mathrm{C}-36-69 \mathrm{I}$

File No.: $3-7-9$

Prepared as Part of an Investigation

Conducted by

Joint Highway Research Project

Engineering Experiment Station

Purdue University

In cooperation with the

Indiana State Highway Commission

and the

U.S. Department of Transportation

Federal Highway Administration

The opinions, findings and conclusions expressed in this publication are those of the authors and not necessarily those of the Federa I Highway Administration. 
TECHNICAL REPORT STANDARD TITLE PAGE

\begin{tabular}{|c|c|}
\hline 2. Government Accousion No. & 3. Recipient's Colalog No. \\
\hline \multirow{2}{*}{$\begin{array}{l}\text { 4. Tillo ond Subtillo } \\
\text { DESTINATION CHOICE MODELLING AND THE } \\
\text { DISAGGREGATE ANALYSIS OF URBAN TRAVEL } \\
\text { BEHAVIOR }\end{array}$} & $\begin{array}{l}\text { 5. Report Dote } \\
\text { August } 1974\end{array}$ \\
\hline & $\begin{array}{l}\text { 6. Performino Organization Codo } \\
\mathrm{C}-36-69 \mathrm{I}\end{array}$ \\
\hline $\begin{array}{l}\text { 7. Author(s) } \\
\text { Joseph A. Ansah }\end{array}$ & $\begin{array}{l}\text { 8. Performing Orgenizotion Roport No. } \\
\text { JHRP }-74-15\end{array}$ \\
\hline \multirow{3}{*}{$\begin{array}{l}\text { 9. Performing Orgonizotion Nome ond Addras } \\
\text { Joint Highway Research Project } \\
\text { Civil Engineering Building } \\
\text { Purdue University } \\
\text { West Lafayette, Indiana } 47907\end{array}$} & 10. Work Unit No. \\
\hline & $\begin{array}{l}\text { 11. Controct or Gront No. } \\
\text { HPR-1 (12) Part I }\end{array}$ \\
\hline & \multirow[t]{2}{*}{ 13. Type of Report and Period Covered } \\
\hline \multirow{2}{*}{$\begin{array}{l}\text { 12. Sponsoring Agency Nome ond Addres: } \\
\text { Indiana State Highway Commission } \\
100 \text { North Senate Avenue } \\
\text { Indianapolis, Indiana } 46204\end{array}$} & \\
\hline & 14. Sponagring $\AA^{6}$ fncy Codo \\
\hline
\end{tabular}

15. Supplementory Notes Federal Highway Administration. Research Study titled "A MicroAnalysis of the Effects of Household Socio-Economic Characteristios 16. Absiroc and Individual Attitudes in Trip Generation".

This research postulates a destination choice methodology that can be incorporated in an operational set of models of urban travel behavior. The model formulation presented has provision for making aggregate forecasts of types of travel behavior that the current quality of data can allow.

The belief that disaggregate models developed with traditional sampling designs require smaller samples is not theoretically supported. It is argued that separate sampling, (analogous to stratified sampling) be used to achieve such savings in sample size.

The multinomial logit model was found to be impractical and of low predictive power in modelling the choice of specific shopping destinations.

A multinomial response relation model that is proposed indicated that it is more pragmatic, given current data quality, to predict types of shopping destination choice behavior. Additional market segmentation was found to be worthwhile in model development. There was the indication that only a few attitudinal factors were necessary. Empirical investigations with the methodology yielded encouraging results.

The extension of destination choice modelling as a logistic discrimination problem is also discussed.

17. Koy Word: Logistic Discrimination; 7 18. Distributlon Stotement

Destination Choice Modelling;

Functional Shopping Destinations

Multinomial Response Relation

Model; Disaggregate Modelling;

Multinomial Logit Model; Separate Sampling.

\begin{tabular}{|l|c|c|c|}
\hline 19. Security Cloceif. (of this report) & 20. Security Cloself. (of thio poge) & 21. No. of Poget & 22. Price \\
Unclassified & Unclassified & 274 & \\
\hline
\end{tabular}

Form DOT F $1700.7(8.69)$ 


\section{ACKNOWLEDGEMENTS}

The author wishes to express his deep appreciation and gratitude to Professors Gilbert T. Satterly and K. C. Sreedharan Pillai for their counsel. during the course of this research and for their critical review of the manuscript.

The author is very thankful to professor Harold L. Michael for his guidance during the conception of the research problem, and for his review of the manuscript. Many thanks are due to Profossor Robert D. Miles for reviewing the manuscript.

Special thanks go to Dr. Edward Kannel who planned and collected the basic data used in the study. The author is thankful to Messrs. Sweson Yang and Leonard Kenne for making some data and material available from the Indianapolis Department of Metropolitan Development. The cooperation of Mr. George Barker of the Indiana State Highway Department in allowing the author to use some aerial photographs of the Indianapolis area is appreciated.

The author is grateful to Professors Moshe Ben-Akiva and Peter Stopher for giving the author some logit model computer prograns and their comments during the conception of the research problem. The comments and encouragenent of Doctors Tom Lisco, Gregory Nicholaidis, Ricardo Dobson, Donald Constantino, Pat Burnett and Stein Hansen and many others at various stages of the study are appreciated. 
The author is thankful to the Government of Ghana, The AfricanAmerican Institute, Purdue University, and the Joint Highway Research Project for making his graduate study and research possible. Particular thanks go to Mrs. Kenneth Moll and Mrs. Becky Fagan for typing the manuscript. 
TABLE OF CONTENTS

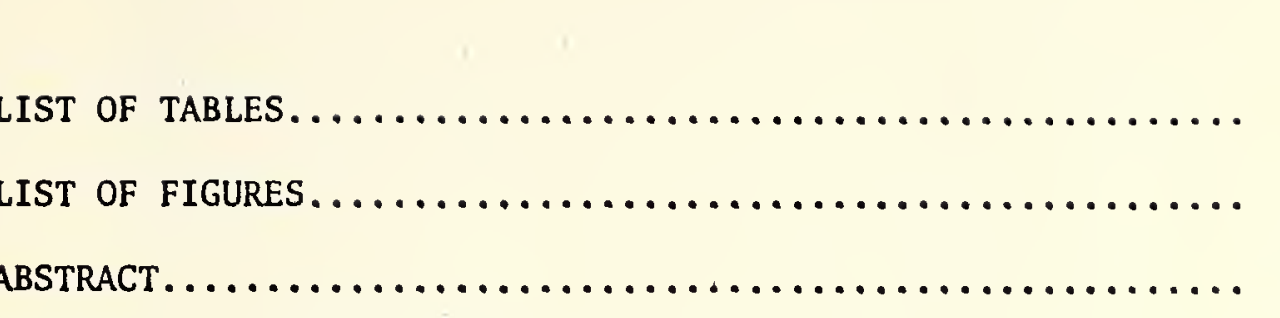

Page

vii

xiii

xviii

CHAPTER 1. INTRODUCTION....................... 1

Research Objectives........................ 4

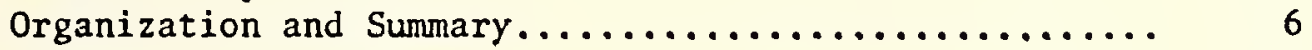

CHAPTER 2, DESTINATION CHOICE MODELLING FOR PRIMARY

URBAN TRAVEL BEHAVIOR....................... 10

Destination Choice Unclouded by Mode Choice.......... 10

Destination Choice Set Definition.................. 12

Model Development with Prior Consideration of

Agregation............................. 16

The Use and Methodological Implications of

Attitudinal Data.......................... 20

CHAPTER 3. GENERALIZED PROBABILISTIC CHOICE MODELLING...... 23

Probabilistic Choice Theory..................... 23

Estimating the Conditional Logit Model.............. 27

Some Fundamental Assumptions in Estimating the Conditional Logit Model..................... 34

Summary................................. 36

CHAPTER 4. EMPIRICAL ANALYSIS USING SOME CURRENT

DISAGGREGATE METHODOLOGY..................... 38

Introduction. .......................... 38

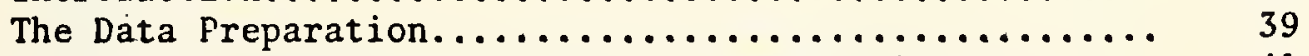

Supplementary Data Collection and Preparation......... 41

Application of the Multinomial Logit Model in

the Prediction of Specific Shopping Destinations....

Specific Destination Choice Models................ 50

Summary................................ 62 
CHAPTER 5. DESTINATION CHOICE MODELLING WITH PRIOR CONSIDERATION OF A SAMPLING FRAMEWORK FOR

AGGREGATE PREDICTION....................

Multinomial Response Law and its Estimation......... A Specific Applied Discussion of the Multinomial

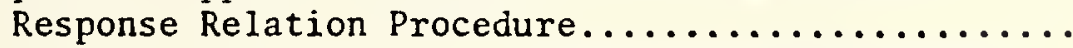

Multinomial Response Relation Model and Destination

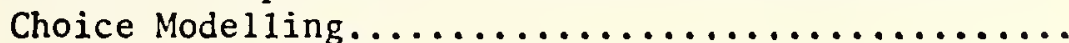

Logistic Discrimination...................

Estimation When Sampling From a Mixture of

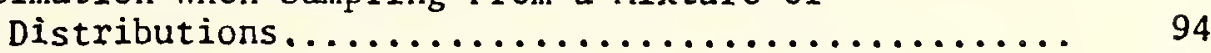

Estimation Under Separate Sampling of Populations..... 94

Choosing Between Mixture and Separate Sampling........ 100

Methodology for Data for This Research.............. 102

Large Sample Maximum Likelihood Estimators and

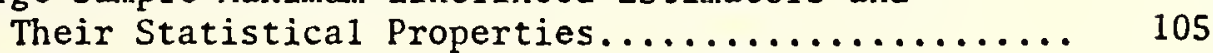

Summary............................... 112

CHAPTER 6. ATTITUDINAL CONSIDERATIONS IN DESTINATION

CHOICE MODELLING. ........................

Description of Available Successive Category Data....

Sorne Approaches for Successive Category Data........

The Reproduction of Attitudinal Orientation

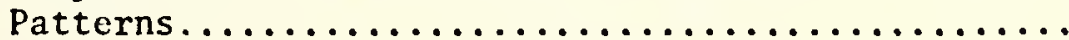

Introduction of Tables That Present Models for

Predicting Attitudinal Orientation Patterns.......

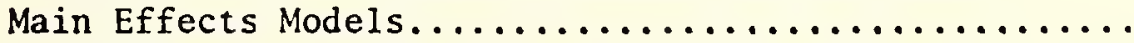

Models With Main Effects and 1,1 Interactions........

Models With Main Effects and 1,2 or 2,1

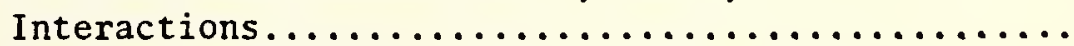

Models With Main Effects and 22 Interactions........

Models With Main Effects 1,1 and 2,2

Interactions ........................

Deductions From the Models...................

Summary ..............................

CHAPTER 7. ESTIMATION WITH PROPOSED FUNCTIONAL DESTINATION CHOICE MODELLING FRAMEWORK...............

Prediction of Functional Shopping Destinations Defined With Respect to Retail Floor Area and Line Haul Travel Time by Attitudinal Factor Market Segments.......................... The Effectiveness of Attitudinal Factors for

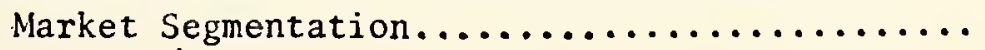


Page

Prediction of Functional Shopping Destinations Defined With Respect to Retail Floor Area and Airline Distance by Attitudinal Factor Market

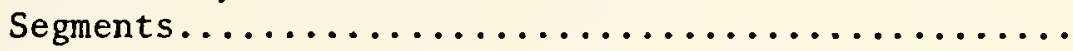

Prediction of Functional Shopping Destinations for Approachability Market Segments..............

The Feasibility of Having Attitudinal and

Approachability Factors in the Same Model for

Functional Shopping Destination Prediction........

Testing the Hypothesis That the Attitudinal Market

Segments Used in Functional Destination Choice

Represent Different Behavioral Populations........

Testing the Equality of Two Covariance

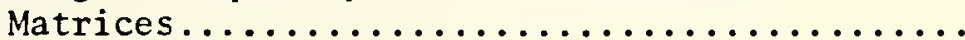

Testing the Equality of Two Parameter

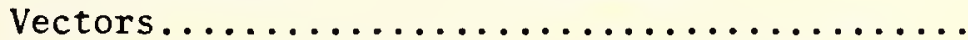

Testing the Hypothesis That Two Attitudinal Market

Segment Multinomial Response Relation Model

Parameter Vectors Have the Same Multivariate

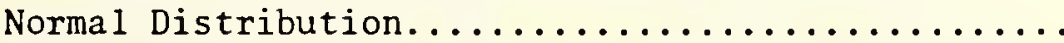

The Use of Travel Data on Zonal Shopping Destination

Choice to Provide an Approximate Verification of

Some Assumptions Used in Functional Destination

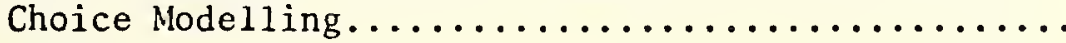

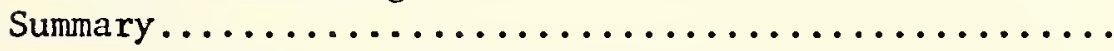

190

191

CHAPTER 8. CONCLUSIONS AND RECOMMENDATIONS............ 194

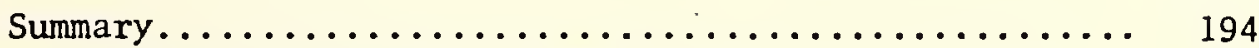

Major Conclusions and Recommendations............. 198

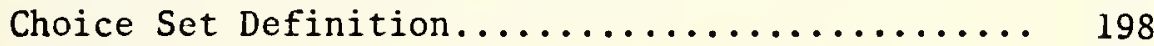

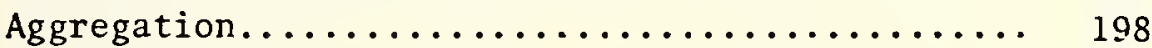

Attitudinal Orientation................... 199

Predictive Performance of the Conditional Logit

Model and the Multinomial Response Relation Model

for Modelling Actual and Functional Shopping

Destination Choices, Respectively..............

Reduction of Data Requirements and the Need for

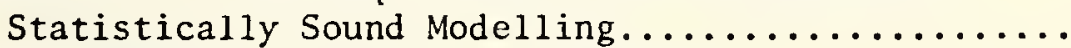

199

Recommendations for Further Research............. 200

LIST OF REFERENCES........................ 202

APPENDIX A............................. 210

APPENDIX B............................... 229 


\section{LIST OF TABLES}

Tab 1e

Page

3.1 Minimum Sample Size to Validate Normal Approximation in Binomial Sampling for Proportions.......

4.1 Average Household Income Distribution for Survey

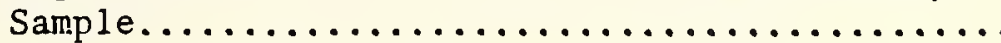

4.2 Occupation of Head of Household..............

$4.3 \quad$ Education of Respondents................. 47

4.4 Age Distribution of Head of Household, 1971....... 47

$4.5 \quad$ Family Status of Household in $1971 \ldots \ldots \ldots \ldots \ldots \ldots$

4.6 Multinomial Logit Model Variables............... 48

4.7 Predictive Accuracy of Conditional Logit Model

in Specific Shopping Destination Choice

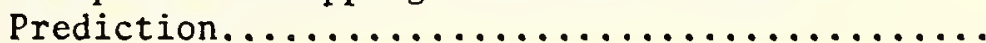

4.8 Summary of Conditional Logit Model Estimation

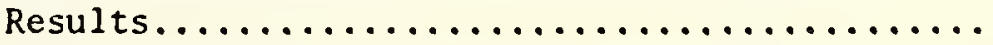

6.1 Attitudinal Ratings of Factors Important in

Selection of Shopping Destination..........

6.2 Shopping Destination Choice Factors Considered

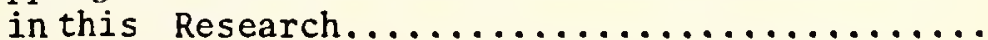

6.3 Correlation Matrix for 7 Shopping Destination

Choice Factors........................ 122

$6.4 x^{2}$-Values in 2 -Way Tables - Case I............ 134

$6.5 . x^{2}$ - Values in 2 -Way Tables - Case II ........... 136

$6.6 x^{2}$-Values in 2-Way Tables, Main Effects Only Case III - $2 \times 2$ Cross-Classification, D.F. $=1$ in all Cases........................ 138

$6.7 X^{2}$ - Values in 2-Way Tables - Case I, Interactions... 140 
Table

Page

$6.8 x^{2}$-Values in 2-Way Tables - Case II, Interactions........................ 141

6.9 Attitudinal Orientation Pattern Prediction Tables - Case III, Main Effects Models.........

6.10 Attitudinal Orientation Pattern Prediction Table - Case I, Main Effects Mode1............

6.11 Attitudinal Orientation Pattern Prediction Table - Case II, Main Effects Model...........

6.12 Attitudinal Orientation Pattern Prediction Tables - Main Effects + 1,1 Interaction

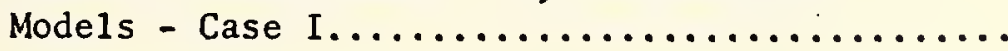

6.13 Attitudinal Orientation Pattern Prediction Tables - Main Effects + 1,1 Interaction Models - Case III.......................

6.14 Attitudinal Orientation Pattern Prediction Tables - Main Effects + 2,2 Interaction

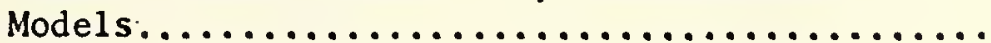

6.15 Attitudinal Oriertation Pattern Prediction Tables - Main Effects $+1,1$ Interaction Models - Case I.......................

6.16 Attitudinal Orientation Pattern Prediction Tables - Main Effects $+1,1$ Interaction Models - Case II........................

7.1 Prediction of Functional Destination Choice Frequencies for the Total Sample With Respect to Retail Floor Area and Line Haul Travel Time..........................

7.2 Prediction of Functional Destination Choice Frequencies for the Total Sample With Respect to Retail Floor Area and Airline Distance......

7.3 Likelihood Ratio Goodness-of-fit $x^{2}$ Values for Fitting KFL $x$ TCLS Contingency Tables......

7.4 Functional Destination Choice Predictions by Market Segments - KFL x TCLS - Many Employees ...

7.5 Functional Destination Choice Predictions by Market Segments - KFL x TCLS - Wide Selection... 
Table

Page

7.6 Functional Destination Choice Predictions Market Segments - KFL x TCLS - Uncongested

Roads...........................

7.7 Functional Destination Choice Predictions by Market Segments - KFL x TCLS - Several Stores...

7.8 Functional Destination Choice Predictions by Market Segments - KFL x TCLS - Quick Parking....

7.9 Functional Destination Choice Predictions by Market Segments - KFL x TCLS - Close to Home.....

7.10 Functional Destination Choice Predictions by Market Segments - 1,1 Interaction Included

- KFL x TCLS - Many Employees................

7.11 Functional Destination Choice Predictions by Market Segments - 1,1 Interaction Included

- KFL $x$ TCLS - Wide Selection................

7.12 Functional Destination Choice Predictions by Market Segments - 1,1 Interaction Included

- KFL x TCLS - Uncongested Roads..............

7.13 Functional Destination Choice Predictions by Market Segments - 1,1 Interaction Included

- KFL $\times$ TCLS - Several Stores...............

7.14 Functional Destination Choice Predictions by Market Segments - 1,1 Interaction Included

- KFL $x$ TCLS - Quick Parking...............

7.15 Functional Destination Choice Predictions by Market Segments - 1,1 Interaction Included

- KFL x TCLS - Close to Home................

7.16 Likelihood Ratio Goodness-of-fit $x^{2}$ Values for Fitting KFL $x$ DCLS Contingency Tables........

7.17 Functional Destination Choice Predictions by Market Segments - KFL x DCLS - Many

Employees.........................

7.18 Functional Destination Choice Predictions by Market Segments - KFL x DCLS - Wide Selection 
Tables

7.19 Functional Destination Choice Predictions by Market Segments - KFL x DCLS - Uncongested

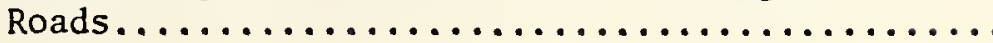

7.20 Functional Destination Choice Predictions by Market Segments - KFL x DCLS - Several Stores...

7.21 Functional Destination Choice Predictions by Market Segments - KFL x DCLS - Quick Parking....

7.22 Functional Destination Choice Predictions by Market Segments - KFL x DCLS - Close to Home.............................

7.23 Functional Destination Choice Predictions by Market Segments - KFL x TCLS Approachability......................

7.24 Functional Destination Choice Predictions by Market Segments - KFL x DCLS Approachability.....................

7.25 Prediction of the Joint Relationship Between "Many Employees" (SC1) and Approachability

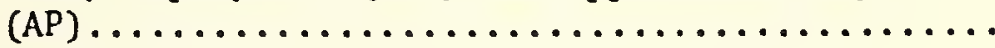

7.26 Prediction of the Joint Relationship Between "Wide Selection" (SD1) and Approachability

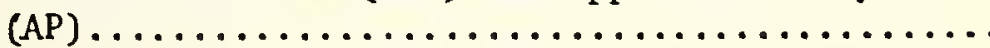

7.27 Prediction of the Joint Relationship Between "Shortest Time" (SE1) and Approachability

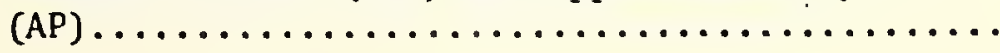

7.28 Prediction of the Joint Relationship Between "Uncongested Roads" (SH1) and Approachability (AP).

7.29 Prediction of the Joint Relationship Between "Several Stores" (SK1) and Approachability

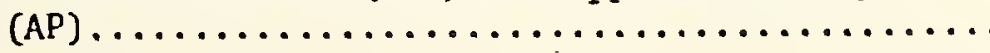

7.30 Prediction of the Joint Relationship Between "Quick Parking" (SL1) and Approachability (AP) .

7.31 Prediction of the Joint Relationship Between "Close to Home" (SN1) and Approachability (AP) 
Table

Page

7.32 Testing the Hypothesis that Two Attitudinal Orientation Market Segments Display Different

Patterns in Their Response to Functional

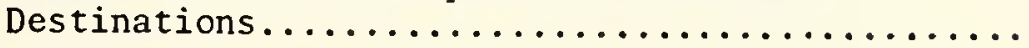

Appendix

Table

A.1 Sample Calculations for a Multinomial Response

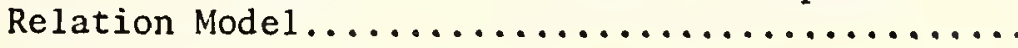

B.1 Response Prediction for Functional Destinations

Defined by the Crossing of Zonal Retail Floor

Area (FLAC) and Airline Distance (DALC).........

B. 2 Response Prediction for Functional Destinations

Defined by the Crossing of Zonal Retail

Employment and Airline Distance............

B.3 Likelihood Ratio Goodness-of-fit $X^{2}$ Values in

Predicting Responses of the Total Sample to

Functional Destinations Defined in $5 \times 5$

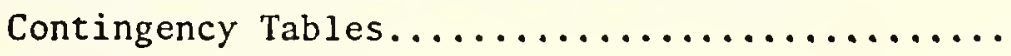

B.4 Likelihood Ratio Goodness-of-fit $x^{2}$ Values in

Predicting Responses of Subsample to Functional

Destinations Defined in $3 \times 3$ Contingency Tables...

B.5 Response Prediction for Functional Destinations Defined by the Crossing of Zonal Retail Floor Area and Airline Distances - Total Raw Sample

- Avg. Income $\$ 7001$ - $\$ 8000 \ldots \ldots \ldots \ldots \ldots \ldots \ldots \ldots$

B.6 Response Prediction for Functional Destinations

Defined by the Crossing of Zonal Retail Employment and Airline Distance - Total Raw Sample

- Avg. Income $\$ 7001-\$ 8000 \ldots \ldots \ldots \ldots \ldots \ldots \ldots \ldots$

B.7 Response Prediction for Functional Destinations Defined by the Crossing of Zonal Retail Floor Area and Airline Distance - Floor Area > 50,000 sq. ft. - Avg. Income $\$ 7001$ - $\$ 8000, \ldots \ldots \ldots \ldots$

B. 8 Response Prediction for Functional Destinations Defined by the Crossing of Zonal Retail Employment and Airline Distance - Floor Area

$>50,000 \mathrm{sq}$. ft. - Avg. Income $\$ 7001-\$ 8000 \ldots \ldots$ 
B.9 Response Prediction for Functional Destinations Defined by the Crossing of Zonal Retail Floor Area and Airline Distance - Floor Area $>50,000 \mathrm{sq}$. ft. - Avg. Income $>\$ 8000 \ldots \ldots$

B.10 Response Prediction for Functional Destinations Defined by the Crossing of Zonal Retail Employment and Airline Distance - Floor Area $>50,000 \mathrm{sq}$. ft. - Avg. Income $>\$ 8000 \ldots \ldots$.

B.11 Response Prediction for Functional Destinations Defined by the Crossing of Zonal Retail Floor Area and Airline Ristance - Airline Distance $>1.0$ unit - Avg. Income $>\$ 8000 \ldots \ldots$.

B.12 Response Prediction for Functional Destinations Defined by the Crossing of Zonal Retail Employment and Airline Distance - Airline Distance $>1.0$ unit - Avg. Income $>\$ 8000 \ldots \ldots$.

B.13 Response Prediction for Functional Destinations

Defined by the Crossing of Zonal Retail

Floor Area and Airline Distnace - Floor

Area $>50,000 \mathrm{sq}$. ft. - Airline Distance

$>1.0$ unit - Avg. Income $>\$ 8000 \ldots \ldots \ldots \ldots \ldots$.

B.14 Response Prediction for Functional Destinations

Defined by the Crossing of Zonal Retail

Employment and Airline Distance - Floor

Area $>50,000 \mathrm{sq}$. ft. - Airline Distance

$>1.0$ unit - Avg. Income $>\$ 8000 \ldots \ldots \ldots \ldots \ldots$.

B.15 Functional Zonal Destination Choice Models

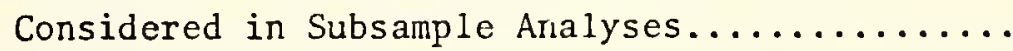




\section{LIST OF FIGURES}

Figure

Page

4.1 Directions of Approach to a Shopping Area......... 46

4.2 Correlation Matrix for Logit Model Variables........ 51

5.1 Illustration of Classifications Defining ' $X$ ' and

'A' Matrices for Crossed Designs.............. 83

5.2 Frequency Distribution of Reported Travel Time in 1971 Survey......................... 88

5.3 Perspective of Aggregate Travel Demand Prediction Considering a Broad Range of Factors........... 90

6.1 Successive Category Questionnaire on Shopping Destination Choice..................... 116

6.2 Frequency Distributions for the Response Categories of Seven Destination Choice Factors........... 123

6.3 2-Way Contingency Tables Representing Attitudinal

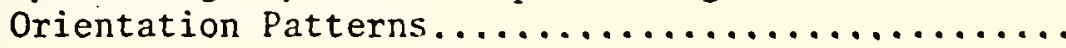

7.1 Functional Shopping Destination Categories Defined by Retail Floor Area and Line Haul Travel

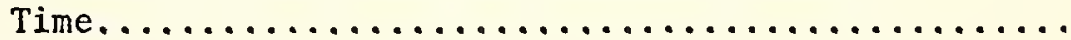

7.2 Functional Shopping Destination Categories Defined by Retail Floor Area and Airline Distance.........

Appendix

Figure
A. 1

Functional Destination Classification Defined by Zonal Retail Floor Area and Interzonal Airline Distance for Average Origin Zone Income of $\$ 7001-\$ 8000 \ldots \ldots \ldots \ldots \ldots \ldots \ldots \ldots \ldots$

B.1 Response Frequency Distributions for Functional Shopping Destination Choice - FLAC x DALC........ 234

B.2 Response Frequency Distributions for Functional Shopping Destination Choice - EMPC $\times$ DALC........ 
Figure

B.3 Functional Zonal Shopping Destination Categories

Defined by Retail Floor Area and Airline

Distance............................ 239

B.4 Functional Zonal Shopping Destination Categories

Defined by Retail Employment and Airline

Distance. 


\section{LIST OF TERMS AND EXPRESSIONS}

\section{USED IN TEXT}

Aggregate Models - Aggregate models deal with the behavior of a group of individuals or households where the grouping may be geographical (traffic zone or census tract) or demographic (total population, labor force or high income families).

Aggregation - An aggregation scheme is a means of making forecasts for a larger unit or group using predictions made for a smaller unit. An example is the prediction of the use of public transit for a zone from a mode split model that predicts choice of mode for individuals.

Approachability - An indication of how well a shopping area is served by a highway network.

Attitudinal Orientation - A classification that an individual can be associated with by virtue of his attitudes relating to certain factors that influence a given item of travel behavior.

Contingency Table - Another expression for a cross-classification table.

Destination Choice Set - The group of alternative destinations that are relevant to an individual household or group of households.

Disaggregate Models - Disaggregate models develop travel models for individuals in the very general sense.

Efficient Sampling - This is a sampling procedure that captures all items of travel behavior without using an excessive sample size.

Functional Shopping Destination - A classification of shopping destination choice behavior defined with respect to shopping area attraction measures and their spatial separation from househoids.

Likelihood Ratio $\chi^{2}$ - A goodness-of-fit criterion that is explained on page 226 in Appendix A. 
Logistic Discrimination - This is a discrimination procedure that uses the logistic distribution as against the classical approach that uses the multivariate normal distribution.

Market Segment - A subdivision of a travel population that is defined on the basis of a socio-economic, attitudinal or other attribute. An example is a group of individuals from high income suburban zones who rely solely on the automobile and who do not consider travel cost as important.

Maximum Likelihood - A statistical parameter estimation procedure that maximizes the joint probability of occurence for a sample. The procedure is discussed in Chapter 5.

Mixed Distribution Logistic Discrimination - This refers to logistic discrimination based on a sample drawn from a mixture of the populations for which the discrimination model is being developed.

Multinomial Logit Model - A model used mostly in recent work on travel mode choice. It is discussed in Chapters 3 and 4.

Multinomial Response Relation (MRR) Model - This is a model suggested in this research. It is discussed in Chapter 5 with application in Chapters 6 and 7. An example estimation is given in Appendix A.

Separate Sampling - This is analogous to stratified sampling in that data collection is done by sampling the choice of each travel behavior alternative instead of leaving it to chance in random sampling. A secondary source of estimating the proportions of the alternatives in the total population is needed.

Symbols
$A \subset B$ - Implies $A$ is a subset of $B$
$t \in A$ - Indicates $t$ is an element of the set $A$
$x<y-x$ is less than $y$
$x \leq y-x$ is less than or equal to $y$
$x>y-x$ is greater than $y$
$x \geq y-x$ is greater than or equal to $y$
$x \in A-x$ belongs to the set $A$
$\infty$ - infinity 
$\Gamma$ - Denotes the gamma function

$\stackrel{\sim}{M}$ - Matrix $\underset{\sim}{M}$

${\underset{\sim}{X}}^{\prime}$ - Transpose of Matrix $\underset{\sim}{X}$

$\underset{\sim}{x^{T}}$ - Transpose of Matrix $\underset{\sim}{x}$

$\mathrm{n}$

$\prod_{i=1}-a_{1} \times a_{2} x \ldots a_{n}$

$E(X)$ - Statistical expectation on $X$

$\otimes$ - Kronecker Product discussed in Chapter 5.

$\underset{\dot{x} \tilde{m}}{\mathrm{~A}}-\operatorname{mxn} \operatorname{matrix} \underset{\sim}{\mathrm{A}}$ mx̃n

$\underset{\mathrm{p} \tilde{x} 1}{\mathrm{~V}}-\mathrm{p} \times 1$ vector $\underset{\sim}{\mathrm{V}}$ 
ABSTRACT

Ansah, Joseph, A., Ph. D., Purdue University, August, 1974. Destination Choice Modelling and The Disaggregate Analysis of Urban Travel Behavior. Major Professors: Gilbert $T$. Satterly and K. C. Sreedharan Pillai.

This research postulates a destination choice methodology that can be incorporated in an operational set of models of urban travel behavior. The model formulation presented has a prior provision for making aggregate forecasts of types of travel behavior that the current quality of data can allow.

The belief that disaggregate models developed with traditional sampling designs require smaller samples than aggregate models is not supported. This belief is a result of the lack of any research that has, at least theoretically, specified a framework for making aggregate predictions prior to disaggregate model development. It is argued that separate sampling (analogous to stratified sampling) be used to develop models without using excessive samples.

Empirical analyses were carried out on shopping destination choice in the Indianapolis area, using specific shopping areas instead of zones. A sample of automobile users was used.

The multinomial logit model was found to be impractical and of low predictive power in modelling the choice of specific shopping destinations. 
A multinomial resporse relation model that is proposed, indicates that it is more pragmatic, given the current data quality, to predict types of shopping destination choice behavior. Attitudinal market segmentation was found to be worthwhile in model development. There was the indication that only few attitudinal factors were necessary. Empirical investigations with the methodology yielded encouraging results. Certain interaction effects had to be included in some of the models developed.

The extension of destination choice modelling as a logistic discrimination problem is also discussed. 


\section{CHAPTER 1}

\section{INTRODUCTION}

In order to have travel demand models that are relevant and valid in the urban setting, some desirable properties that a suitable modelling approach should include are:

1. The incorporation of transportation, socio-economic, and activity system effects as well as the attitudinal orientation of travellers.

2. The consideration of competition among choices at each decision level.

3. A structure based on behavioral as well as theoretical and a priori grounds.

4. Provision for the computation of a valid equilibrium between demand and supply.

5. Feasibility of statistical estimation and computational efficiency.

That the present urban transportation planning (UTP) package of travel demand models cannot meet most of the above conditions is well documented $[1,2,3,4,5,6], *$ Both workers on trip generation $[1,6,7,8$,

* Numbers in square parenthesis refer to reference material listed at the end of the report. 
$9,10]$ and on modal split $[11,12,13,14,15]$ have recommended, for reasons briefly given here, that disaggregate models be developed. Disaggregate models at one extreme analyze the travel behavior of individuals while aggregate models at another extreme deal with variables representing averages or totals for large groups of entities (e.g., households in a traffic zone) in their group's travel behavior predictive models. Since conventional trip generation models do not consider transportation variables they work, on the assumption that trip frequency is independent of changes in the transportation system. Most available large scale.modal split functions, among other shortcomings, have either ignored all the door-to-door components of travel time and cost or they have aggregated them in ways that limit the applications of the modelling approach. The route assignment procedure tends to be mechanical since it cannot interact with the demand functions by virtue of the latter being devoid of transportation policy variables.

Manheim [5] has discussed requirements to be met by travel demand models relating to relevance, validity, testability, compatibility and feasibility. Ben-Akiva [17] has pointed out the need to have a behavioral assumption on a priori grounds, relating to the structure of the models. Under the relevance criterion the models should discern differences among alternative transportation strategies, recognize the existence of different market segments and also serve toward the evaluation of the alternative strategies. Some examples of transportation strategies whose impacts the model should detect are:

(i) Ramp-metering and lane reversal operations for improving 
traffic flow and reducing the usage of alternative local roads in populated areas.

(ii) The increase of parking prices at certain times of the day or the restriction of automobiles from certain areas at different times of the day.

The above examples relate to an auto-oriented travel market segment. Further classification may be on the basis of income, social class, stage of life cycle, etc. Several researchers have recommended or used market segmentation in both disaggregate and aggregate analyses $[5,19,20,21,22,23,24]$. The demand that models be valid is not questioned. The lack of sufficient data is often used as an excuse for the insufficient realization of validity. Reasonable evidence of validity from limited available data would not only help in justifying further data coilection, but the sampling can be better designed if the limited analysis has improved the researcher's understanding of the system in question.

The requirement that a travel demand model exhibit compatibility implies that the travel demand should be allocated to the network consistent with the services that the transportation facilities can provide and the travellers' perception of such services. The demand is often computed with a supply configuration assumed. Though some exact procedures for computing equilibrium have been proposed, the underlying assumptions and their level of empirical testing have not rendered them operational [25, 26]. A few iterative procedures are available for obtaining an approximate equilibrium in aggregate modelling $[27,28]$. 
It is necessary that demand models be feasible and meet current time, financial and manpower constraints. In the extreme situation. one would seek to have causal models. The farthest causal analysis has been taken in transportation planning is at best explanatory $[10$, 34] in its use in studying factors that affect trip generation and the length of a work trip. Though it has been argued that observations on human populations cannot be analyzed with the classical tools for experimental studies $[29,30,31,32,33]$, improved statistical tools can be used to handle the limited size and quality of available travel survey data. If one has to use lower level (e.g. probabilittic) models it has to be ensured that their structure is behavioral. Ben-Akiva [17] has extensively discussed why a direct demand model is behaviorally more satisfactory. Computational feasibility may occasionally require that an indirect or recursive formulation be used.

Research Objectives

In a previous study, Kannel [10] examined the trip generation behavior of a relatively stable group of households (the residents had not relocated over a period of seven years). The household trip generation regression equations developed could only explain under forty percent of the variation in trip generation. It is unlikely that regression models using similar variables for less stable socioeconomic groups can achieve better results. It is necessary that other analytical tools be considered for modelling not only trip generation, but other travel decisions like destination and route choices at an operationally feasible level. Such an endeavor would require a comprehensive and costly data collection effort. 
The development of feasible analytical tools must precede a massive expenditure of manpower and fiscal resources. Research work using present data with some promise for shedding light on useful analytical techniques can, therefore, be a very valuable guide to decision makers with regard to future directions in travel demand modelling. The principal concern of this research is the development of an operational framework for modelling urban shopping destination choice behavior.

Current disaggregate approaches are so clouded by mode choice considerations that it is hard to tell their effectiveness in predicting destination choices directly. Arbitrarily selected sets of alternative shopping destination alternatives are used for individuals, a procedure that is impractical on a large scale. Provided there is information on the geographical coordinates of households and shopping area locations, even at the sub-zonal centroid level, eirline distances and shopping area attraction measures can be used to develop a more consistent procedure for selecting shopping destination choice sets. Notwithstanding the choice set definition problem for spatial choices, the aggregation problems associated with determining aggregate predictions from the current formulation of disaggregate models is mainly a result of the failure to specify an aggregation methodology prior to disaggregate model development. This research effort uses functional shopping area classifications of conceptual destination choice alternatives in model development.

One major expectation in disaggregate modelling is a saving in data collecticn in operational applications. Disaggregate models, in 
addition, attempt to consider as many travel market segments as possible. A random sample is likely to under-represent some of the less common market segments. With a conscious effort to represent each market segment, a suitable sampling scheme, tied to the modelling theory, can be utilized to cover all the relevant market segments without making the total sample size prohibitive.

The major objectives of this study were:

1. To investigate the modelling of shopping destination choices for an essentially auto-committed group of households at the disaggregate level.

2. To attempt to incorporate attitudinal indices in the modelling of types of shopping destination choice.

3. To determine, from the estimation and application problems encountered in the study, how data can be efficiently collected and analyzed for operational transportation planning.

Organization and Summary

Chapter 2 discusses the problem of destination choice modelling in a spatial context, unclouded by mode choice effects. The issue of destination choice set definition is considered with the proposal that a functional destination classification be adopted in order to develop practical travel behavior models. The aggregation problem is discussed. Some inconsistencies and possible analytical problems in some recently proposed approaches are also discussed. It is maintained that a framework, not necessarily operational because of data 
collection problems, for aggregation should be a prerequisite for the development of a compatible disaggregate model. With the qualitative and categorical nature of most of the data currently available it is proposed that an experimental design-based approach be used to set up a modelling framework that simultaneously considers different travel segments in a given choice situation. Some methodological implications of introducing attitudiaal factors into the disaggregate modelling scenario is also discussed.

Chapter 3 briefly introduces the disaggregate modelling approach highlighted by recent research work $[13,16,17]$. Some underlying assumptions in model parameter estimation and their interpretation are discussed.

Chapter 4 presents the results of empirical analysis based on the theory and concepts discussed in Chapter 3.

A detailed justification is given in Chapter 5 to the concept of functional destinations introduced in Chapter 2. A Multinomial Response Relation methodology is presented that accounts for the different travel market segments and their response to travel choice alternatives.

In the context of a common choice set for all individuals, an equivalence is readily established between the choice context multinomial logit modelling approach and a recently developed logistic discrimination approach.

A major advantage of the multinomial response relation approach is the ability provided for the investigation of interaction among qualitative variables that classify travel market segments or travel 
choice categories. The classifications can be revised to minimize such interactions. Estimates of travel market segment shares of travel behavioral responses can be obtained from a mail or telephone survey. These estimated proportions can then be used in a separate sampling logistic discrimination that is eventually proposed as a procedure to be adopted in an operational transportation study.

The theory behind separate sampling logistic discrimination is elaborated on and its discriminant function estimation is related to that of the mixed distribution unconstrained discrimination situation. Approaches for including attitudinal information in the market segmentation are presented in Chapter 6 . By virtue of the nature of the information on attitudes to hypothetical shopping areas (See Figure 6.1) no extensive scaling is possible. With the nature of the data not allowing the use of classical successive category analytical techniques, contingency table methods are used to organize the available attitudinal data prior to its use in market segmentation for multinomial response relation analysis.

Chapter 7 gives the empirical investigation with the methodologies developed in Chapter 5 and 6. Models for various market segments are discussed. Some multivariate testing is conducted on the need for attitudinal market segmentation.

Chapter 8 draws conclusions from the study.' The major proposals are:

1. The adoption of a systematic definition of travel choice sets, considering common functional destination alternatives. 
2. The use of a multinomial response approach as a vehicle for developing an aggregation scheme linked with an appropriate sample survey design.

3. The separate sampling of travel market segments at activitymarket segment interfaces and the recommendation that disaggregate analysis be considered in the framework of separate sampling logistic discrimination. 


\section{CHAPTER 2}

DESTINATION CHOICE MODELLING FOR

PRIMARY URBAN TRAVEL BEHAVIOR

\section{Destination Choice Unclouded by Mode Choice}

The viewing of urban travel behavior in a choice framework instead of the traditional demand approach can be taken as the current state of the art in disaggregate modelling. The urban traveller has been considered as a consumer choosing among alternative trip frequencies, periods of day, modes of travel, destinations, and routes at different decision levels or simultaneously. The dominance of mode choice considerations in most of such traveller choice considerations in most of such traveller choice models $[13,16,17,20,41,42]$ is readily detected. The spatial context of destination or route choice behavior warrants a treatment that has not been operationally implicit in current methods of disaggregate analysis.

Spatial choices of destinations and routes at a micro level involve different specific choice sets for individuals depending on their geographical location and the time of day. The attraction measures of spatial opportunity sets also involve a lot of factors most of which are qualitative. It is the willingness of current disaggregate modelling approaches $[16,17]$ to use arbitrarily selected specific but gross destination choice sets of different sizes for different individauls that poses intractable problems in terms of 
operational practicability and analytical feasibility. It is quite easy for one to get carried away by endless theoretical excursions in travel behavior analysis and over-generalize the models, losing sight of the ultimate objectives of urban transportation planning. An example is the recommendation that models include linked trips, the variation of destination choice sets with time of day and various considerations that arise in local travel, when one is still unable to adequately analyze the one-way travel from the home to the first destination. The functional classification in an urban highway network should be instructive here. Transportation engineers experience greater congestion problems with higher class roads: facilities like freeways, expressways and major arterial streets. Travel on local streets is not as critical as that on some higher type facilities. Even on the arterial network it is the traffic movement in major corridors that is of major interest. Problems involving local travel and sections of arterial streets where traffic volumes taper off in magnitude fall within the capability of traffic operations and need not be considered by travel behavior models until travel on the primary arterial network has been adequately analyzed.

It is the issues briefly cited in this section and the need to develop interim or "compromising" operational models of urban travel behavior that will dictate the choice of methodology to be presented in this report. The concentration on destination choice is only to allow a detailed consideration of the ramifications in the analysis of this spatial travel choice so that it can be more effectively incorporated in a model considering all relevant travel choices. 
The choice of the shopping trip purpose is not only a result of the nature of available data but also because shopping travel is next in importance to work travel in many urban areas,

\section{Destination Choice Set Definition}

An immediate problem that arises in modelling destination choices is that of defining the sets of alternatives to be considered by different individuals or groups of people. Gravity, intervening opportunity, or more general entropy models as well as utility models of interzonal trip distribution $[55,56,57,58,59]$ assume a common set of physical destinations for all individuals i.e. each individual within a given zone is said to consider every other zone in the city as a potential destination. Notwithstanding the gross measure of attraction implied in considering zones as destinations, some destinations are more likely to be selected than others. If the different dimensions of attraction of activity centers were to be fully considered the total number of distinct alternatives would be prohibitive even for aggregate trip distribution procedures. The claim that groups of people in zones consider zones as destination alternatives is more parsimonious than the expectation that individuals considered in disaggregate models $[16,17]$ consider zones or even districts as alternative destinations. The rejection of the assumption that individuals have a common physical destination choice set is implied in work done by urban geographers in the individual's cognition and information field $[60,61]$ and by currently proposed disaggregate modelling techniques $[16,17]$. 
It is quite inconsistent to advocate disaggregate analysis at the behavioral unit - the individual or household - and yet grossly aggregate the specific destinations that individuals consider. Urban travel related disaggregate destination choice modelling has so far been confined to samples taken from just one or two geographic sectors of a city for which the set of zonal shopping destinations is arbitrarily limited. The arbitrary selection of alternative destination sets, even in the form of zones using zonal retail employment as the attraction measure, is a very tedious process even when considering a couple of sectors. It is operationally impractical to attempt to suggest such a procedure for a larger number of individuals located all over a given metropolitan area. If the different retail activities and the multiple classifications of retail center types were to be considered, the situation becomes exceedingly complex. The alternative shopping destinations faced by individuals depend on the location of the individual relative to the total set of alternatives in the urban area at a given time of day, the socio-economic class, the attitudinal orientation of the individual, and the categories of destinations more likely to fall within the individual's consideration. Other factors include the familiarity of the individual with the urban area $[51,60$, 61] as well as the cost of travel and ease of travel to each shopping area. The present state of knowledge about destination choice behavior and the data collection and analytical problems cannot permit an adequate consideration of all the above factors in defining destination choice sets for an operational model for destination choices for primary urban trave1. 
To operationalize the choice set definition for individuals under present circumstances the use of some approximate and indirect techniques is inevitable. Hanson [61] suggested the consideration of grocery stores falling into distance rings centered on the individual's location. This approach is, however, too simplified for urban transportation planning. It is possible to use some concepts in information theory $[105,106,107]$ to bound choice sets for individuals given suitable data. The main idea is to select shopping areas that are likely to induce primary urban travel (i.e. travel that will use major arterials of interest to transportation engineers). Having identified such shopping areas they are classified from the point of view of each individual household's relative location, the attraction measures for the shopping areas and the ease of approach to the latter from different directions. A relative entropy computed from each individual's deduced classification table determines the degree to which different categories of shopping areas are readily available to the individual. Depending on whether the relative entropy approaches unity or zero, the individual is likely to have a large or smali choice set of shopping areas.

A way to get around the individual destination choice set definition problem is to develop functional classifications of destinations so that each individual or market segment faces the same set of functional categories of destinations. Factors that can be used operationally for shopping area categorization with respect to auto travel may include airline distance, level of free parking availability, the number of retail outlets, and the ease of shopping area approach 
from different directions. Even the functional classification of shopping areas on two or three of these factors is not a trivial matter. The limits of categorization of the essentially qualitative factors involved cannot be so easily determined. It is possible to test for independence among the ways of classification in order to achieve mutually exclusive functional classifications. If several interactions are detected it will be necessary to revise the ways of categorization or to transform the definitions of the factors used for the classification. The specific set of physical alternatives that fall into the functional destination category that an individual or market segment is predicted to select, can be identified relative to the individual's location. For example, if the functional category is associated with medium airline distance from home, a high level of free parking, and a wide availability of different retail outlets, the physical set of destinations for an individual includes all shopping areas within a medium airline distance range with the corresponding levels of free parking and availability of retail outlets. Computer simulation can be used to further assign individuals to specific physical destinations in the absence of a better procedure for doing so $[65,80]$. The sample size needed to conduct disaggregate modelling using such functional destinations may not be as small as many researchers have been hoping, but, more importantly, this approach better prepares the travel behavior analyst to deal with a problem like aggregation more effectively. The functional destination approach makes the analysis of destination choices more systematic, making possible the adaptation of statistical methods like multinomial 
response relation analysis $[66,67]$ for the analysis of market segments that can be identified in the sampling sense as different strata for which a travel survey has to be designed. It will be further proposed in this research that the different travel market segments should be sampled separately, preferably at activity centers. This, in principle, is not a new idea in transportation planning [68, 69, 70]. A familiar disadvantage in the use of a single sample involving a mixture of market segments is the attempt to do modal choice analysis in a travel survey only to find out that a negligible percentage of the sample were. in a position to trade between modes of travel. The contribution of this study will be in the presentation of a statistical methodology that handles discrimination with separate sampling. The use of multinomial response relation approach, using a single sample from old survey data or a mail survey provides estimates of separate sampling population proportions needed in the separate sampling discrimination approach. It will be shown in Chapter 5 that, in the framework of a common set of functional destinations, a multinomial choice model is equivalent to a multi-population discrimination problem. It is the availability of theoretical work to extend the mixed distribution sampling discrimination estimation problem to the separate sampling situation that dictates the preference for viewing the problem as one in statistical discrimination.

Model Development With Prior Consideration of Aggregation

In order to make aggregate forecasts of travel behavior, a means of accomplishing this must be developed whether one starts with an 
aggregate or disaggregate set of models for a given travel survey sample data. Several problems that can be encountered in the process have been discussed by Talvitte [71]. Only the determination of aggregate forecasts from disaggregate models will be discussed in this section. Recent workers on such aggregation $[71,72]$ have proposed the development of an aggregate forecasting model from a disaggregate model, which is an easy matter if linearity prevails, However, making aggregate forecasts can be considered a complex sampling problem where disaggregate models are used for prediction within a given sample design based on a rigorous experimental design classification scheme,both for the travel market segments and travel choices. The sampling approach to aggregation will be recommended, particularly for spatial choices. In a multiple choice situation the probability of choice of an alternative can be expressed as [36]:

$$
p_{i k}=\frac{e^{g\left(x_{i k}\right)}}{\sum_{1=1} e^{g\left(x_{i l}\right)}}
$$

where $P_{i k}=$ the probability that an individual $i$ chooses alternative $k$ out of a total of $K$ alternatives. $g\left(x_{i 1}\right)=a$ function (usually assumed linear) of the variables or factors for alternative 1 that affect the choice decision. This function has been called the utility function. Though the author prefers to call it a discriminant function, the name "utility" will be used only to maintain a uniformity of terminology. 
Assuming that all individuals within a given travel market segment of size $M$ attach the same importance to rationalizing the decision, as the model implies, the likelihood of each individual behaving rationally is $1 / M$. Using a Taylor's series expansion up to second order terms on the individual's cumulative distribution function in equation (1), Talvitte suggested that the aggregate share of the alternative $k$ be expressed as [71]:

$$
\begin{aligned}
\hat{\mathrm{P}}_{\mathrm{k}}=\overline{\mathrm{P}}_{\mathrm{k}}\left[1+\sum_{1=1}^{\mathrm{k}} \operatorname{Var}\left(g\left(x_{1}\right)\right) \cdot\left(\overline{\mathrm{P}}_{1}-\theta\right) \cdot\left(\overline{\mathrm{P}}_{1}-\frac{1}{2}\right)\right] \\
\text { where } \theta=1 \quad \text { when } t=k \\
\theta=0 \quad \text { otherwise } \\
\hat{\mathrm{P}}_{\mathrm{k}}=\text { aggregate share of alternate } \mathrm{k} \text { in a market segment } \\
\overline{\mathrm{P}}_{\mathrm{k}}=\text { value of } \mathrm{P}_{\mathrm{k}} \text { evaluated at the mean of } \mathrm{G}(\mathrm{x}),
\end{aligned}
$$

$P_{k}$ and $G(x)$ being general expressions.

$P_{i k}$ and $g\left(x_{i}\right)$ in equation 2.1 are values taken by $P_{k}$ and $G(x)$ respectively for individual $i$.

$\operatorname{Var}\left(g\left(x_{i}\right)\right)=$ variance of the utility function in the market for alternative 1 :

$x$ in $g(x)$ is a vector of socio-economic, level of service and activity system variables.

The evaluation of the mean and variance of the utility function is a difficult problem, as has been discussed by Talvitte [71]. Essentially, assuming activity system variables to be constant, Talvitte's discussion assumes the canonical correlation between the set of socio-economic variables and the set of level of service variables is negligible, leaving room for the possibility of correlation among 
variables within either set. The choice model of equation 2.1 must be the first to consider the existence of correlation or interaction among variables or factors. Purely analytical approaches, even assuming all the components of $x$ are continous variables with a multivariate distribution, can easily get out of hand, even if one uses well-developed multivariate normal distribution theory $[16,73,74]$, this being the very reason why the multimonial logit model was postulated. A further point of observation is that it is only in mode choice related situations that one has a respectable number of independent variables that condition choice behavior. With the introduction of attitudinal orientation into the mode choice analysis, an important qualitative dimension is introduced. Purely analytical approaches to the aggregation problem cannot handle situations where qualitative factors conditioning choice behavior cannot be ignored.

Within the framework of disaggregate analysis suggested by recent works that have considered spatial choices, one would have to look for sub-market segments that have the same set of spatial alternatives before an analytical aggregation scheme can be used. This approach is only a step away from trying to predict the choice of each household or block of households, which is obviously an impractical task.

It has been suggested [75] that building separate models for different market segments can help resolve some of the aggregation problems. This requires a rigorous definition of market segments with both homogeneous population characteristics and travel behavioral and attitudinal orientations. 
Some difficulties and possible inconsistercies in analytical approaches to the aggregation problem have been discussed above. The predominance of categorical and qualitative factors in travel choice behavior, particularly for spatial choice, and the requirement for a rigorous definition of homogeneous categories of travel market segments, further complicate the aggregation problem. A reasonable approach is an experimental design method that provides a link to a complex sampling design that can be used for aggregate predictions of distinct types of travel behavior. This is the basis for recommending the multinomial response relation procedure mentioned earlier in this chapter and presented in detail in Chapter 5. A major requirement of such a statistical approach is that one rigorously define the ways of classification of the rravel market and a systematic specification of direct alternatives, like modes, and conceptual spatial alternatives, like functional shopping destinations, discussed in the previous section. Drawing an analogy with methods like factor analysis, multidimensional scaling and principal component analysis for reducing the dimensionality of problems in many fields $[49,54,76,77]$, the concept of functional spatial alternatives should not be too hard to accept.

Though this research was not concerned with aggregation models, the above discussion has been necessitated by the basic requirement that disaggregate models be tied with a suitable aggregation framework.

The Use and Methodological Implications of Attitudinal Data

The need to add attitudinal data to socio-economic, transportation and activity system variables in analyzing travel behavior is well 
documented $[10,21,23,43,44,45,46]$. Two questions that may be asked relate to how attitudinal data should be used and whether they are important separately or in combination with other variables and factors.

There has been the use of attitudinal indices for the definition of utility "functions" for groups that individuals may belong to, relative to a given item of travel behavior $[23,45,47]$. The work along these lines has been based either explicitly or indirectly on Lancaster's thesis [48], that it is the intrinsic properties of a good that give satisfaction and not the good per se. The implications of this in modal choice has been discussed by Allen and Isserman [23] . The assumption is made that an individual behaves rationally in that he maximizes the utility associated with the attributes, physical or subjective, posed by transportation alternatives. Compared with the substantial work done on attitudinal and perception considerations in modal choice behavior $[10,21,23,43,44,78,79]$, similar work on destination choice has been mostly limited [75]. Making reference to others' work, Burnett[75] points out that "socio-economic characteristics do not appear to be highly correlated with cognition, preference formation and overt choice behavior". There is the need to incorporate the individual's perception or attitude towards travel choices directly. Recent work on the perception of shopping places $[75,61]$ indicates that very few complex attributes are used by individuals to assess alternatives. These attributes do not appear to bear any clear relationship to the size and distance variables assumed to be important by traditional models of destination choice [58, 81]. 
Some recently developed multi-dimensional scaling techniques have been applied in some studies of travel behavior $[54,77]$. Their appeal is supposed to be in the hope that they can provide a monotonic scale of measurement that could be used to predict individual preferences. These multi-dimensional scaling procedures are not only expensive and difficult to implement, but the nature of their data requirements can be too involved in the context of operational travel surveys even for short range purposes. Considerable effort will be needed to develop a methodology appropriate for different kinds of travel decisions $[51,53,82,84]$. It is appropriate, at least for the preliminary work on attitudes on primary shopping travel, to use simpler uni-dimensional scaling techniques $[10,85,86]$ as a means of introducing attitudinal data in the analysis of destination choice. A contingency approach for attitudinal orientation pattern prediction is discussed in Chapter 6. 
CHAPTER 3

GENERALIZED PROBABILISTIC CHOICE MODELLING

Much of the recent work on disaggregate modelling of travel choices $[13,16,17]$ has been based on probabilistic choice theory. The theory is generalized in the sense that physically distinct choice sets of different sizes have been considered for individuals. The foundations of probabilistic choice theory are in the works of Luce, Suppes, Arrow and Marschak and it has been discussed in recent travel-choice behavior literature $[39,87]$. Some of the following discussion that introduces some aspects of probabilistic choice theory is drawn from a presentation by Hansen [88].

\section{Probabilistic Choice Theory}

Luce's basic choice axiom defines $T$ of a finite subset of $V$ such that, for every $S \subset T, P_{S}$ is defined.

(i) If $\mathrm{P}_{x y}(x, y) \neq 0,1$ for all $x, y \in T$, then $\mathrm{P}_{T}(\mathrm{R})=\mathrm{P}_{S}(R) \cdot \mathrm{P}_{T}(\mathrm{~S})$.

(ii) If $P_{x y}(x, y)=0$ for some $x, y \in T$, then for every $S \subset T$

$$
P_{T}(S)=P_{T-(x)}(S-(x)) .
$$

In the above, $A \subset C$ implies $A$ is a subset of $C$. Subscripts refer to the set for which the probability is defined. The notation $P_{x y}(x, y)$ is the probability that $x$ is chosen over $y$.

The Luce model can be shown to imply the existence of a ratio scale that is unique up to a positive scalar multiplication and is 
independent of any assumptions about the structure of the set of alternatives when one is confined to a local region $T$ in $V$. The Existence Theorem [39] is as follows:

"Suppose that $T$ is a finite subset of $V$, that $P_{X Y}(x, y) \neq 0,1$ for all $x, y \in T$, and that axiom 1 holds for $T$ and $i t s$ subsets, then there exists a positive real-valued function $U$ on $T$, which is unique up to multiplication by a positive constant, such that for every $\mathrm{S} \subset \mathrm{T}$

$$
P_{S}(x)=\frac{U(x)}{\sum_{y \in S} U(y)} "
$$

The existence theorem deals with each subset in $V$ in which pairwise discriminations are imperfect (i.e. al1 $P(x, y) \neq 0,1$ ). Supposing $R$ and $\mathrm{S}$ are two overlapping subsets of $\mathrm{V}$ over which $\mathrm{U}$-functions are defined. Arbitrary scale constants can be chosen so that a single scale will prevail over the overlap region. Luce [39] has given sufficient conditions for merging local U-scales together to form a single scale over the whole set $V$.

According to Marschak [87] "U ${ }^{(2)}$, a real-valued random function on $X$ is called a 'random utility indicator' in the binary sense if for every $x \neq y$,

$$
P\left(U_{x}^{(2)} \geq U_{y}^{(2)}\right)=P_{x y}(x, y) "
$$

Special random utility indicators are introduced by Marschak [87] in the following decreasing order of generality:

- A real-valued function $w$ on $x$ is called a weak utility function if $w_{x} \geq w_{y}$ when and only when $P_{x y}(x, y) \geq \frac{1}{2}$

- A real-valued function $V$ on $X$ is called a, strong utility function if there exists a monotone increasing function $\phi_{v}$ such that $\phi_{v}\left(V_{x}-v_{y}\right)$ $=P_{x y}(x, y) ; \phi_{V}(0)=\frac{1}{2}$

- A positive-valued function $U$ on $X$ is called a strict utility 
function in the binary sense if $P_{x y}(x, y)=\frac{U_{x}}{U_{x}+U_{y}}$

In this sense, Luce's [39] U-functions are "strict utility functions". Assuming that conditions for random and strong utility functions are satisfied, a random function $\varepsilon_{\mathrm{x}}$ can be defined as a random component of $\mathrm{U}_{\mathrm{X}}^{(2)}$ as follows:

$$
U_{x}^{(2)}=V_{x}+\varepsilon_{x} \text { where } E\left(\varepsilon_{x}\right)=0
$$

The random $\varepsilon_{\mathrm{x}}$ 's are assumed to be independently distributed and to contain the effects of the choice situation upon utility which one is unable to measure. This results in the following binary choice probability of alternative $x$

$$
\begin{aligned}
P_{x y}(X, Y) & =P_{x y}\left(V_{x}+\varepsilon_{x}>V_{y}+\varepsilon_{y}\right) \\
& =P_{x y}\left(\varepsilon_{y}-\varepsilon_{x}<V_{x}-V_{y}\right)
\end{aligned}
$$

Attention will now be focussed on the distribution of the random variables $\varepsilon_{y}$ and $\varepsilon_{x}$ as well as $\varepsilon^{*}=\varepsilon_{y}-\varepsilon_{x}$.

With $V_{x}$ and $V_{y}$ linear in their unknown parameters, it has been shown that a variety of probability distribution functions (p.d.f.) are consistent with the underlying random model of individual utility maximization for binary choice [88]. The most useful distribution has been the logistic distribution [16]. This is obtained when:

$$
\begin{aligned}
& P\left(\varepsilon_{i} \leq t\right)=e^{-e^{-t}} \\
& f\left(\varepsilon_{i}\right) \text {, the p.d.f. of } \varepsilon_{i} \text { is given by } \\
& f\left(\varepsilon_{i}\right)=e^{-\varepsilon_{i}} e^{-e^{-\varepsilon_{i}}} \\
& \quad-\infty \leq \varepsilon_{i} \leq \infty
\end{aligned}
$$


The following relationships are defined:

$$
\varepsilon=\varepsilon_{y}-\varepsilon_{x} \quad \text { and } \quad w=\varepsilon_{y}
$$

where $\varepsilon_{y}$ and $\varepsilon_{x}$ have the p.d.f. given in equation 3.6. The Jacobian of transformation in equation 3.7 is unity. The joint p.d.f of $\varepsilon$ and $w$ is $g(\varepsilon, w)=e^{\varepsilon-2 w} e^{-e^{\varepsilon-w}} \cdot e^{-e^{-w}}$

$$
\begin{aligned}
& =\mathrm{e}^{\varepsilon-2 \mathrm{w}} \cdot \mathrm{e}^{-\mathrm{e}^{-\mathrm{w}\left(1+\mathrm{e}^{\varepsilon}\right)}},-\infty \leq \varepsilon \leq \infty \\
& -\infty \leq \mathrm{w} \leq \infty \\
& \text { substituting } \mathrm{s}=\mathrm{e}^{-\mathrm{w}} \quad 0 \leq \mathrm{s} \leq \infty \\
& g_{1}(\varepsilon)=\mathrm{e}^{\varepsilon} \int_{0}^{\infty} \mathrm{se}^{-\mathrm{s}\left(1+\mathrm{e}^{\varepsilon}\right)} \mathrm{ds}
\end{aligned}
$$

put $v=s\left(1+e^{\varepsilon}\right)$ whereby $\frac{d s}{d v}=\frac{1}{1+e^{\varepsilon}}$

$$
\begin{aligned}
g_{1}(\varepsilon) & =\frac{-e^{\varepsilon}}{\left(1+e^{\varepsilon}\right)^{2}} \int_{0}^{\infty} v e^{-v} d v \\
& =\frac{-e^{\varepsilon}}{\left(1+e^{\varepsilon}\right)^{2}} r_{2}=\frac{-e^{\varepsilon}}{\left(1+e^{\varepsilon}\right)^{2}}
\end{aligned}
$$

from which

$$
P\left(\varepsilon \leq \varepsilon^{*}\right)=\frac{1}{1+e^{\varepsilon^{*}}}
$$

Substituting $\varepsilon^{\star}=\varepsilon_{y}-\varepsilon_{x}$

$$
p_{x y}(x, y)=\frac{e^{v}}{e^{V x}+e^{V y}}
$$

Defining $e^{V}$ as the explicit form for the positive-valued $U$ in Luce's choice model, it is seen that the logit model is consistent with 
Luce's ratio scale and Marschak's strict utility function [87].

The binary logit model can be extended to the multinomial logit model $[13,16]$ in the multiple choice situation as:

$$
\mathrm{P}_{J}(i)=e^{V_{i}} / \sum_{j=1}^{J} e^{v_{j}}
$$

where $\mathrm{P}_{\mathrm{J}}(\mathrm{i})$ is the probability of choosing alternative $i$ out of a choice set of dimension $J$.

The model has been referred to as an explicit form of the strict utility function in the multiple choice setting [87]. The assumption of a reciprocal exponential distribution for the random component $\varepsilon_{i}$ can be shown to be equivalent to the axiom of independence from irrelevant alternatives implied in Luce's choice axiom.

Thus the odds of choosing alternative $i$ over alternative $k$ are independent of other alternatives. It is noted that

$$
\frac{P_{J}(i)}{P_{J}(k)}=\frac{e^{V_{i} / D}}{e^{V_{k} / D}}=e^{v_{i}-v_{k}}
$$

where $D=\sum_{j=1}^{J} e^{V_{j}}$.

The multinomial logit follows as:

$$
\log \frac{\mathrm{P}_{J}(\mathrm{i})}{\mathrm{P}_{\mathrm{J}}(\mathrm{k})}=\mathrm{V}_{\mathrm{i}}-\mathrm{V}_{\mathrm{k}}
$$

Estimating the Conditional Logit Model

This section explores the implications of the selected linear utility function in a conditional logit model from the point of view 
of statistical inference on the parameters of the linear utility function estimated by the method of maximum likelihood. Since several references will be made to a paper by McFadden [36] a notation compatible with that in this paper will be adopted.

$A_{t}$ is defined as the set of alternatives and $J_{t}$ the number of alternative choices for case $t$ where $t=1,2, \ldots, \mathrm{T}$.

The linear utility function $v_{i}$ in the previous section has an equivalent here, denoted by $b(i)=B\left(\underset{\sim}{X_{i}}, \underset{\sim}{\theta}\right)$ where $\underset{\sim i}{X_{i}}$ is a vector of variables (of dimension $K$ ) contributing to the utility function for alternative $i \in A_{t} \cdot K$ is the number of variables and $\theta$ is a vector of unknown parameters defining $b(i)=\underset{\sim}{X_{i}^{\prime}} \underset{\sim}{\theta}$.

For $i \in A_{t}, t=1, \ldots, T$ we define a variable $f_{i}$ such that $f_{i}=1$ if alternative $\mathbf{i}$ is chosen and $\mathbf{f}_{\mathbf{i}}=0$ otherwise. Thus

$$
\sum_{i=A_{t}} f_{i}=1 \text {. }
$$

Using the logit model, the probability that alternative $i$ is chosen is given by

where $D_{t}=\sum_{j \in A_{t}} e^{\dot{x}_{j}^{\prime} \stackrel{\theta}{\sim}}$.

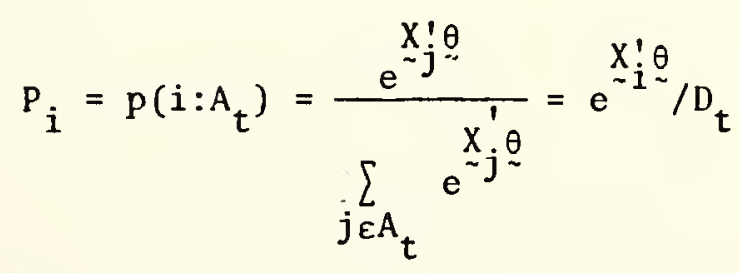

The likelihood of a given sample is given by

$$
L_{s}=\prod_{t=1}^{T} \prod_{i \in A_{t}} P\left(i: A_{t}\right)^{f_{i}}
$$




$$
=\prod_{t=1}^{T} \prod_{i \varepsilon A_{t}} P_{i} f_{i}
$$

Let the $\log$ of the likelihood function be $\log \left(\mathrm{L}_{S}\right)=L(\theta)$

$$
L(\theta)=\sum_{t=1}^{T} \sum_{i \varepsilon A_{t}} f_{i} \log P_{i} .
$$

One can define a vector $\underset{\sim j i}{z}=\underset{\sim j}{x_{j}}-\underset{\sim i}{x_{i}}$ in which case $P_{i}=\left[\sum_{j \in A_{t}} e^{z j i \stackrel{\theta}{\sim}}\right]^{-1}$

$$
\begin{aligned}
& \partial \log P_{i} / \partial \underset{\sim}{\theta}=\frac{\sum_{j \varepsilon A_{t}} \underset{\sim j i}{Z i} e^{Z j i \underset{\sim}{\theta} \stackrel{\theta}{Z}}}{\sum_{j \in A_{t}} e^{\sim j i} i_{\sim}^{\prime}} \\
& =\sum_{j \notin A_{t}} P_{j} \stackrel{Z}{\sim} j i \\
& =\left[\mathbb{X}_{i} \sum_{j \in A_{t}} P_{j}-\sum_{j \in A_{t}} P_{j}{\underset{\sim}{\sim j}}^{X_{j}}\right] \\
& =\left[{\underset{\sim}{X}}_{i}-{\underset{\sim}{X}}_{t}\right]
\end{aligned}
$$

where $\bar{X}_{t}=\sum_{j \in A_{t}} P_{j \sim t} X_{t}$

$$
\begin{aligned}
& \frac{\partial^{2} \log P_{i}}{\partial \underbrace{\theta}_{\sim}{ }^{\prime}}=\frac{\partial}{\partial \theta_{\sim}^{\prime}}\left[{\underset{\sim}{X}}_{i}-\sum_{j \in A_{t}} P_{j}{\underset{\sim j}{X}}_{j}\right] \\
& =\frac{\partial}{\partial \underset{\sim}{\theta}}\left[-\sum_{j \in A_{t}} P_{j} \stackrel{x}{j}_{j}\right] \\
& =-\sum_{j \in A_{t}}{\underset{\sim}{x}}_{j} P_{j}\left(\partial \log P_{j} / \partial \underline{\sim}^{\prime}\right)
\end{aligned}
$$

Since $P_{j} \partial \log P_{j} / \partial{\underset{\sim}{\prime}}^{\prime}=\partial P_{j} / \partial{\underset{\sim}{\prime}}^{\prime}$.

It then follows that 


$$
\begin{aligned}
& \frac{\partial^{2} \log P_{i}}{\partial \underbrace{}_{\sim} \theta^{\prime}}=-\sum_{j \varepsilon A_{t}} x_{j} P_{j}\left(x_{j}^{X}-x_{t}^{\prime}\right) \\
& =-\sum_{j \in A_{t}} \underset{j}{X} P_{j}{\underset{x}{j}}_{j}^{\prime}+\left(\sum_{j \in A_{t}} P_{j \sim j}{\underset{X}{j}}_{j}\right) \bar{x}_{t}^{\prime}
\end{aligned}
$$

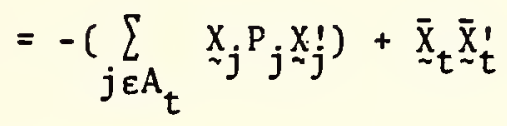

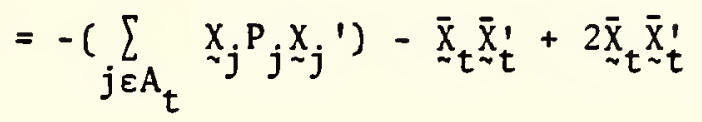

$$
\begin{aligned}
& =-\sum_{j \varepsilon A_{t}}\left({\underset{\sim j}{x}}_{j}-{\underset{\sim}{x}}_{t}^{\bar{x}^{\prime}}\right)^{\prime} P_{j}\left({\underset{\sim j}{x}}_{j}-{\underset{\sim}{\bar{x}_{t}}}^{\prime}\right)^{\prime},
\end{aligned}
$$

using the fact that $\sum_{j \varepsilon A_{t}} P_{j}=1$. Differentiating equn. (3.14) and using (3.15) and (3.16),

$$
\begin{aligned}
\frac{\partial L}{\partial \theta} & =\sum_{t=1}^{T} \sum_{i \varepsilon A_{t}} f_{i}\left({\underset{\sim}{x}}_{i}-\bar{x}_{\tau}\right) \\
& =\sum_{t=1}^{T} \sum_{i \in A_{t}} f_{i} \underset{\sim}{x_{i}}-\sum_{t=1}^{T}{\underset{\sim}{x}}_{t}^{\bar{x}_{t}}
\end{aligned}
$$

using $\sum_{i \varepsilon A_{t}} f_{i}=1$

and

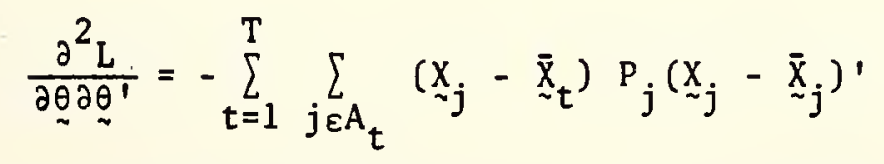

The maximum likelihood method is a way of estimating the parameter vector $\underset{\sim}{\theta}$. This is accomplished by maximizing $L$, which if it exists must require $\partial^{2} L / \partial \underset{\sim}{\theta} \partial \theta^{\prime}$ to be negative definite $[36,89]$. McFadden [36] discussed conditions for such negative definiteness, as well as 
necessary and sufficient conditions for the existence of a vector maximizing $L(\theta)$.

The above development in connection with the multinomial logit model has a built-in constraint: $\sum_{j \in A_{t}} P_{i}=1$. For this reason the parameters of a general $b(i)=\theta_{1}+X_{i 2}{ }^{\theta}{ }^{+} \ldots+X_{i k}{ }^{\theta} k$ cannot be estimated uniquely, the dimension of the estimation space being reduced by the number of constraints. This is noticed by considering a general linear form of $b(i)$ in equation (3.18) where the first row of $\underset{\sim}{\mathrm{x}}$ is unity in which case $\partial^{2} L / \partial \underset{\sim}{\theta}{ }_{\sim}^{\prime}$ will have a zero first row, making it singular. If the constant term in $b(i)$ is not zero then all parameters estimated are confounded with the effect of $\theta_{1}$, the constant term. Another way of viewing this problem is that the response probabilities determined with the logit model are invariant under change of location of the logits. The parameter corresponding to the general mean (constant term in $b(i)$ ) is indeterminate. There are very serious implications in this fact in the use of logit model parameters for computing quantities like elasticities and the value of travel time.

Proofs about some statistical properties of the conditional logit model require that ${\underset{\sim}{\mathrm{X}}}_{j}$ have a continuous non-degenerate distribution. It is possible to establish such proofs [86, 89, 90] for categorical variables by a suitable reparameterization of the model so that the rows of $\left({\underset{\sim}{X}}_{1}^{X},{\underset{\sim}{2}}_{2}, \ldots,{\underset{\sim}{T}}_{\mathrm{T}}\right)$ are linearly independent. A usual procedure for such reparameterization is to exclude one category of the categorical variables so that unique estimates of categorical parameters are no longer available even if the constant term, $\theta_{1}$, in $b(i)$ is zero [86, 90]. In a situation where $\theta_{1}$ is not necessarily zero and there is a 
mixture of categorical and continuous variables in $x_{j}$ the parameters are confounded with the effects of both the mean and excluded category effects. For example, defining $x_{j i}$ as the $i$ th. component of $x_{j}$, if $x_{j 2}$ is continuous and $x_{j 3}$ and $x_{j 4}$ are two categories of a 3-category variable with category $x_{j 5}$ excluded, the parameters estimated will be $\left(\theta_{1}+\theta_{2}+\theta_{5}\right),\left(\theta_{1}+\theta_{3}+\theta_{5}\right)$ and $\left(\theta_{1}+\theta_{4}+\theta_{5}\right)$. Hypotheses about individual parameters are thus not testable. Suitable testable contrasts can be developed. An example is $\left(\theta_{1}+\theta_{4}+\theta_{5}\right)-\left(\theta_{1}+\theta_{3}+\theta_{5}\right)=$ $\theta_{4}-\theta_{3}$. Elasticities and other values can be computed from the estimated parameters only through suitable functions of estimable functions $[92,93]$. By introducing time and cost variables in ranges, the effects of time and cost over different ranges can be tested for equality. It is then possible to determine unconfounded values of travel time over intervals where time and cost effects are constant. The reference to the value of travel time is only a result of the wide use of logit models in mode choice analysis.

That the previous discussion can help clarify the way the estimated parameters of the logit model can be used is not sufficient if such a model is going to be a source of policy making in the transportation area. Proper statistical inference that can be made about the parameters of the model depends on the statistical properties of large sample of maximum likelihood estimators. Though extensive sensitivity analyșes would be needed to make conclusive statements, care must be taken for sample sizes used to allow such desirable properties of maximum likelihood estimators to be used. 
As discussed in Chapter 5, parameters under maximum likelihood estimation have a joint distribution which is asymptotically multivariate normal in large samples. Table 3.1 , shows the minimum total sample size in the smaller class required to use the normal approximation in sampling for the proportion in the smaller class, $p$, in a binary situation. In a typical mode choice problem the transit users fall in the smaller class whilst auto users are in the larger class. In several cities, p, hardly exceeds 0.1 in which case a reasonable sample size should be around 600 . Considering

Table 3.1 MINIMUM TOTAL SAMPLE SIZE TO VALIDATE NORMAL APPROXIMATION IN THE BINOMIAL SAMPLING FOR PROPORTIONS (Adapted from Cochran [64])

Proportion in Smaller of Two C1asses Minimum Total Sample Size

$\begin{array}{lr}0.5 & 30 \\ 0.4 & 50 \\ 0.3 & 80 \\ 0.2 & 200 \\ 0.1 & 600 \\ 0.05 & 1400\end{array}$

that disaggregate mode choice logit models estimate several parameters that determine the probability of each individual belonging to either class, and the intractability of small sample maximum likelihood estimation where there are more than two classes and where one is interested in estimating models for different market segments, larger (but not excessive) sample sizes would be required. How to use a larger sample in disaggregate analysis of urban travel behavior efficiently in the 
sense of a well designed sample survey, without necessarily collecting as much data as in previous transportation studies is discussed in detail in Chapter 5.

Some Fundamental Assumptions in Estimating the Conditional Logit Model.

In his exposition on the statistical properties of the conditional logit estimator, McFadden [36] defined the $\log$ of the likelihood function (see equation 3.14 ) as $L(T, \underset{\sim}{\theta})=\sum_{t=i}^{T} \lambda(t, \underset{\sim}{\theta})$ where

$$
\lambda(t, \theta)=\sum_{j \in A_{t}} f_{j} \log P_{j} \quad t=1, \ldots, T
$$

Defining $\underset{\sim}{\lambda}=\partial \lambda / \partial{\underset{\sim}{\theta}}^{\theta}$ and $\lambda \underset{\sim}{\theta} \underline{\sim}^{\prime}=\partial^{2} \lambda / \partial \underset{\sim}{\theta}{ }^{\prime}$

$$
\begin{aligned}
& E \lambda_{\sim} \underset{\sim}{t}(t, \underset{\sim}{\theta})=\sum_{j \in A_{t}}\left(\partial P{ }_{j} / \partial \underset{\sim}{\theta}\right){\underset{\sim}{~}}^{o}=0 \\
& L(T, \underset{\sim}{\theta}) \text { is maximized at }{\underset{\sim}{\theta}}^{o} .
\end{aligned}
$$

$\mathrm{L}(\mathrm{T}, \underset{\sim}{\theta})$ is maximized for $\partial \mathrm{L}(\mathrm{T}, \underset{\sim}{\theta}) /\left.\underset{\sim}{\theta}\right|_{\sim} ^{0}=0$

The expected value of $\lambda_{\underset{\theta}{\theta}}^{\prime}$ is defined as

$$
\begin{aligned}
& \stackrel{\Omega}{\tau}_{t}=-\sum_{j \in A_{t}} P_{j}\left(\partial^{2} \log P_{j} / \partial \dot{\sigma}_{\sim}^{\prime}\right) \\
& \underset{\sim j}{E}\left(\Omega_{\sim t}\right) \text { is defined as } \Omega_{\sim *}\left(J_{t}\right)
\end{aligned}
$$

and a matrix $\underset{\sim}{\Omega}$ is defined as

$$
\stackrel{\Omega}{\sim}=\sum_{J=2}^{J} \nu_{J} \Omega_{\mathrm{t}}(J)
$$

where $\frac{1}{T} \Omega_{\sim}^{-1}$ is the asymptotic covariance matrix of $\underset{\sim}{\hat{\theta}}$ and $\nu_{J}$ is the relative frequency with which $J_{t}=J$ is observed. 
Equation (3.22) implies that each observation with $\mathrm{J}$ alternatives is necessarily drawn from the same subsample for the purpose of pooling to estimate $\Omega$. Just as it is untenable to expect individuals or cases to have the same set of physical spatial alternatives $[16,17]$ it is unreasonable to imply in such pooling that individuals with the same number of physical alternatives belong to the same subsample. If one is willing to consider each individual case to have a different set of alternatives one should be prepared to statistically let several observations for the individual constitute a subsample in which case $\Omega$ is estimated by $\frac{1}{\mathrm{~T}} \sum_{t=1}^{\mathrm{T}} \Omega_{t}$. The estimate for $\underset{\sim}{\Omega}$ in equation (3.22), - though statistically invalid, would only serve the purpose of an information matrix in maximum likelihood estimation (89). Its use for statistical inference would be incorrect. It is more parsimonious, for example, in destination choice modelling, to consider clusters of households with the same set of physical alternatives so one can define $\Omega_{\star}(1)$ for the 1 th cluster location which will go into pooling the estimates of $\underset{\sim}{\Omega}$ from different clusters. This amounts to the analysis of market segments where the segmentation is geographical. While this is theoretically possible, there are so many physical destinations and so many clusters of households that can have the "same" constrained set of physical choice sets that one can quickly run into operational problems. In the context of functional destinations discussed in Chapters 2 and 5, a conscious attempt is made to reduce such unnecessary complexity in dealing with physical alternatives directly.

The arbitrary selection of unchosen alternatives in situations where information on such alternatives is not available could cause 
further problems in the form of judgemental bias, If it is possible, repeated observations for each individual should go into the estimation of $\Omega_{\sim} ;$ this is virtually impossible unless physical experimental conditions prevail. The generalized alternative set modelling approach without repeated measurements on individuals is invalid statistically if one is not prepared to accept all the underlying assumptions in the estimation procedure as discussed above. It is only under repeated observations under which an individual chooses among different alternatives with some relative frequency distribution that one can develop a model for predicting which one alternative the individual would select under a given situation. Since it is impossible to do this for each individual and it is obviously not what was intended in the proposition of the generalized choice set approach, there is a serious need to revise the whole analytical procedure.

\section{Sunmary}

Some aspects of probabilistic choice theory leading to the binary logit choice model and its extension to the multiple choice setting are discussed. Some assumptions necessary for maximum likelihood estimation of the conditional multinomial logit model, as developed by McFadden, and statistical inferences on the parameters are also discussed. It is also indicated that although the theoretical development behind the estimation of the covariance matrix of the conditional logit model parameters assumes the estimate is pooled over estimates for different choice set sizes, the actual estinate considers all the units as belonging to the same group. It is maintained that the 
over-generalization implied in using variable destination alternative choice sets for different individuals stifles both the covariance matrix estimation procedure and further complicates any possible. analytical aggregation techniques. 


\section{CHAPTER 4 \\ EMPIRICAL ANALYSIS USING SOME \\ CURRENT DISAGGREGATE METHODOLOGY}

\section{Introduction}

This chapter first discusses the background, collection and preparation of the data base used for some empirical analyses in this chapter. and later chapters.

The empirical analyses presented in this chapter examine the predictive performance of the multinomial logit model, presented in Chapter 3, for specific shopping destination areas. A difference between the models discussed and others on shopping destination choices is that the latter have been connected with travel mode choice considerations and have considered alternative destinations as zones or districts. The analysis presented in this chapter involves automobile users and the destinations are specifically identifiable combinations of shopping centers and retail outlets. Models developed using different variables and their combinations are presented. The effect of significant correlation between some of the variables or the predictive ability of the resulting models is also discussed.

A subsample of the data sample available was used to estimate the multinomial logit models discussed in this cahpter. The objective was to conduct a modest empirical analysis to investigate the performance of this disaggregate modelling approach. One useful purpose 
that the analysis served was to indicate the general effectiveness of the available variables for deveioping alternative models for functional shopping destination choice as presented in Chapter 7.

\section{The Data Preparation}

The data in this research were derived from a home-interview survey in Indianapolis, Indiana organized by Kannel [10], supplemented with additional data collection and preparation. Kannel collected home interview and attitudinal data from a sample of 357 single-family households in the fall of 1971, the households having maintained their residential location for a period of at least seven years. The Indianapolis metropolitan area with a population of about 744,748 in 1970 had conducted a conventional transportation study during the fall of 1964. A five percent sample of households was taken for the home interview portion of the study from which a total of 10,532 interview forms were completed.

A major objective of Kannel's research was to monitor trip generation changes between 1964 and 1971. It was necessary to use households that had remained at the same address so influences of changes in household location relative to the transportation system would not distort the results of the study. In order to minimize the differences in travel behaviour that might be due to differences in life style of families living in different types of dwelling units, only single family dwelling units were used in Kannel's survey. Since trip generation was a major concern in Kannel's work it was necessary to obtain a gcod representation of variables like family income, auto ownership and family size in his sample selection. The list of 
single-family dwelling units that had reported their income in 1964 totalled 4,300. A systematic one in four sampling procedure was used to obtain a basic list of households. Each family in this list was checked against the listings in the 1971 Indianapolis telephone directory to determine which households were still at their 1964 addresses. The aim was to obtain a list of potential households that would yield about 400 completed interviews. Though an initial sample of 400 households was selected to be interviewed, a list of additional households was developed to replace refusals from households in the original list.

Although a conscious effort was made to represent different combinations of family size, family income and auto ownership, the results of the 1971 survey reported only three percent of the trips being made by suburban or city bus lines. Thus the sample essentially represents a group committed to the automobile. In addition to conventional origin-destination information, attitudinal data was obtained in structured and unstructured forms. The structured responses were in the form of paired comparison and successive categorical techniques to evaluate individual attitudes to various attributes of modal, shopping destination and route choices. The unstructured part of the questionnaire obtained data on trip length and cost characteristics for the work trip. The shopping trip was investigated with respect to the time of day of travel, mode of travel, length of trip and reason for a destination selection for a shopping trip made during a previous one week period. The work in the present research on shopping destination choice modelling will be centered around the 
portion of Kannel's survey on a recent shopping trip made and the successive categories data on factors influencing the choice of shopping destinations.

of the 357 completed interviews obtained by Kannel the principal respondent was male in 162 households and female in 195 households. Respondent characteristics that may help in interpreting results in model development relate to age, income and occupation. The average age of the head of household was 52 years with a median education attainment of 11.8 years. The family income and occupational categories are shown in Tables 4.1 and 4.2 respectively. Tables 4.3 to 4.5 present information on educational leve1, age and family status distributions.

Supplementary Data Collection and Preparation

With the aid of publications, maps, aerial photographs and other material from the Indianapolis Department of Metropolitan Development, the Indiana Chamber of Commerce, the Indianapolis Star and the Indiana State Highway Department additional data collection and preparation were carried out to develop a complete data set for this research. Having identified the location and checked the zonal area codes for the 1971 sample households, the shopping destinations of those who responded to a probe into a recent shopping trip were determined. A land-use map and addresses of major shopping centers or clusters of major shopping outlets were used to identify the most likely destination using the description of the closest intersection to the shopping destination selected by the respondent. The most reasonable route for each such trip was identified after a careful examination 
Table 4.1. Average Household Income Distribution for Survey Sample.

\begin{tabular}{lcc}
\hline Income Stratifications & \multicolumn{2}{c}{1971} \\
\cline { 2 - 3 } Louseholds & Percent \\
\hline 4,000 to 4,999 & 14 & 5.9 \\
5,000 to 5,999 & 20 & 3.9 \\
6,000 to 6,999 & 25 & 5.6 \\
7,000 to 7,999 & 20 & 7.0 \\
8,000 to 9,999 & 38 & 5.6 \\
10,000 to 11,999 & 49 & 10.7 \\
12,000 to 14,999 & 61 & 13.7 \\
15,000 to 17,999 & 45 & 17.1 \\
18,000 to 23,999 & 31 & 12.6 \\
Greater than 24,000 & 33 & 9.7 \\
\hline
\end{tabular}


Table 4.2. Occupation of Head of Household

\begin{tabular}{lcc}
\hline & \multicolumn{2}{c}{1971} \\
\cline { 2 - 3 } & Number & Percent \\
\hline Professional & 43 & 12.0 \\
Managers & 32 & 9.0 \\
Clerical & 23 & 6.5 \\
Salesman & 40 & 11.2 \\
Craftsman & 75 & 21.0 \\
Operatives & 31 & 8.7 \\
Service Personnel & 16 & 4.5 \\
Retired or Unemployed & 68 & 19.1 \\
\multicolumn{1}{l}{ Total } & 357 & 100.0 \\
\hline
\end{tabular}


of a network map with the assistance of a person familiar with the Indianapolis area. Using travel speed study results between 1970 and 1972,typical speeds were estimated for different categories of road after which travel time determinations were made to alternative shopping destinations.

Complete information was available for only the major shopping areas listed in publications on retail outlets in the Indianapolis area obtained from the Indianapolis Star and the Chamber of Commerce. Thirty-eight shopping destination areas were identified, each consisting of one major shopping center or a collection of shopping centers and other retail outlets. Information compiled for each shopping area included the floor area, the number of parking spaces, the number of discount stores, the number of grocery stores and the number of other retail outlets and the distance of the shopping area from downtown Indianapolis.

Having restricted the analysis to travel to major shopping areas that are more likely to attract major volumes of primary urban travel, the sample size useful for destination choice modelling was reduced to about 220-households. Out of a subsample of 120 selected from the original sample of 357 households 87 were found to have all the information needed to develop a disaggregate model for predicting specific destination choices with respect to travel to major shopping areas.

A LARR-V digitizer was used to specify the geographic coordinates for each household and the center of each shopping destination area. The coordinates enabled airline distances from 
households to shopping centers and the bearing of each household from each shopping area to be computed. Four directions of approach to each shopping area were defined as illustrated in Figure 4.1. The bearing of approach of each household to a shopping area allowed the direction of approach to be quickly determined. From the highway network configuration, the limited information on 24-hour link volumes, the number of arterials of approach and the number of intersections on different routes, it was possible to assign subjective ratings of ease of approachability from each direction to each shopping center. In practice, where the number of shopping areas may be high, a more objective determination of such an approachability measure would be needed.

Three additional alternative shopping destinations were selected for each household to provide four alternatives for each household. Travel time, airline distance, the level of approachability and shopping opportunity measures were assembled for alternative destinations for each household, manually and with the aid of appropriate computer programs. Cost data were not collected since with auto travel the travel cost is highly correlated with the travel time and also because most of the parking reported for the shopping areas was free. The variables for which there was sufficient variation over the subsample of 87 to allow a meaningful application of the multinomial logit modelling approach are given in the following table: 


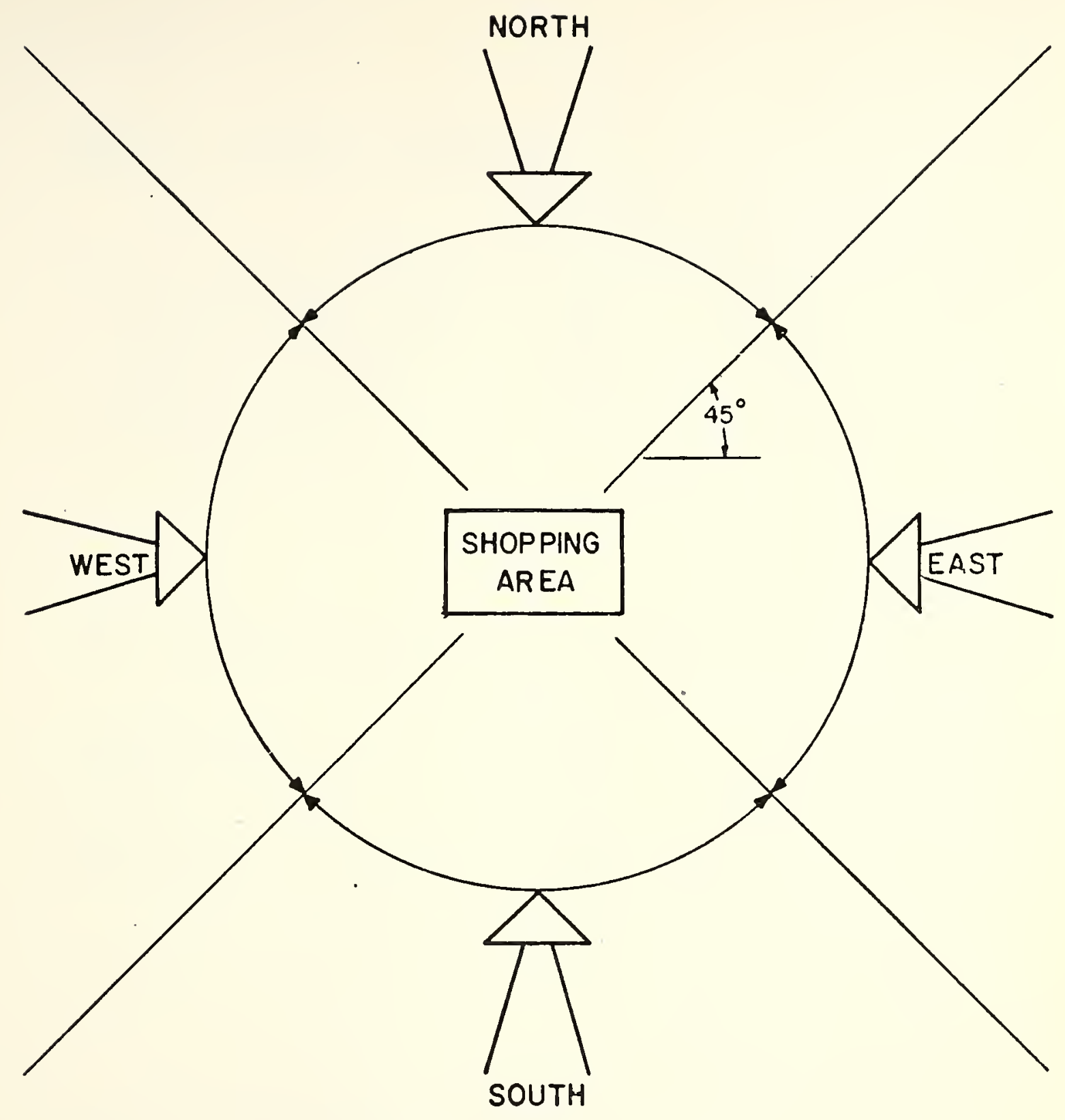

FIGURE 4.I DIRECTIONS OF APPROACH TO A SHOPPING AREA 
Table 4.3. Education of Respondents

\begin{tabular}{llc}
\hline & $\begin{array}{c}\text { Number of } \\
\text { Respondents }\end{array}$ & $\begin{array}{c}\text { Percent of } \\
\text { Respondents } \\
\text { in Group }\end{array}$ \\
\hline 1) Eight grade or less & 43 & 12 \\
2) Two years of High School & 48 & 14 \\
3) High School Graduate & 139 & 39 \\
4) Two years of College & 59 & 17 \\
5) College Graduate & 33 & 9 \\
6) Graduate Work & 22 & 3 \\
7) Vocational School & 12 & 6
\end{tabular}

Table 4.4. Age Distribution of Head of Household, 1971

\begin{tabular}{lcc} 
& $\begin{array}{c}\text { Number in } \\
\text { Age Group }\end{array}$ & $\begin{array}{c}\text { Percent in } \\
\text { Age Group }\end{array}$ \\
\hline Less than 35 & 22 & 6 \\
35 to 44 & 59 & 17 \\
45 to 54 & 115 & 33 \\
55 to 64 & 95 & 27 \\
65 and over & 66 & 19
\end{tabular}

Table 4.5. Family Status of Households in 1971

Percent of Households
in Group

Married with school age

children 43

Married without school age children

Not married 
Table 4.6. Multinomial Logit Model Variables

FLA - Retail Floor Area in 1000 sq. $\mathrm{ft}$.

PRK - Number of Parking Spaces

TL - Line Haul Trave1 Time

TA - Line Haul Travel Time plus adjustments for congestion and delays at trip origin and destination

DAL - Airline Distance

AP - Approachability Rating 1. Poor

2. Moderate

3. Good

Application of the Multinomial Logit Model in the Prediction of Specific Shopping Destinations

Objections were raised in Chapters 2 and 3 with regard to operationalizing the multinomial logit model as currently applied in spatial travel demand analysis with respect to

1. The destination choice set definition

2. A feasible determination of aggregate predictions

3. The estimation of and inferences about model parameters.

It was indicated in Chapter 3 that parameter estimates would still be feasible in spite of the non-compliance with all the necessary statistical conditions for proper inferences on the parameters. The remainder of this Chapter will illustrate why parameter estimation is possible for the problem at hand and discuss the performance of the multinomial logit model in predicting the choice of specific shopping 
destination alternatives with various combinations of variables. The empirical investigation will also serve as a useful guide in the selection of variables for use in the development of models for the prediction of the choice of functional travel destinations discussed in Chapter 7. The estimation program used was obtained from Moshe BenAkiva [17].

In short, the objection to the covariance matrix estimated for the parameters raised in Chapter 3 amounts to the fact that although the final estimate is supposed to be pooled over estimates for different choice set sizes, the estimate actually computed disregards this fact and derives an estimate that considers all the units as belonging to the same group. This, of course, assumes that the number of alternatives is a valid basis for grouping with respect to the estimation of the covariance matrix. On the application discussed in this chapter it just happens that the same number of alternatives was selected for each household so the problem with the covariance matrix does not arise.

The estimated models discussed for shopping destination area choice are based on the following relationship in which the parameters $\hat{\theta}_{q}$ are estimated.

$$
\log \frac{P_{j}}{P_{i}}=\sum_{q=1}^{k}\left(X_{j_{q}}-X_{i_{q}}\right)_{\hat{\theta}_{q}}
$$

where $P_{j}=$ predicted probability of choosing alternative $j$

$P_{i}=$ predicted probability of choosing alternative $i$, the actually chosen alternative 


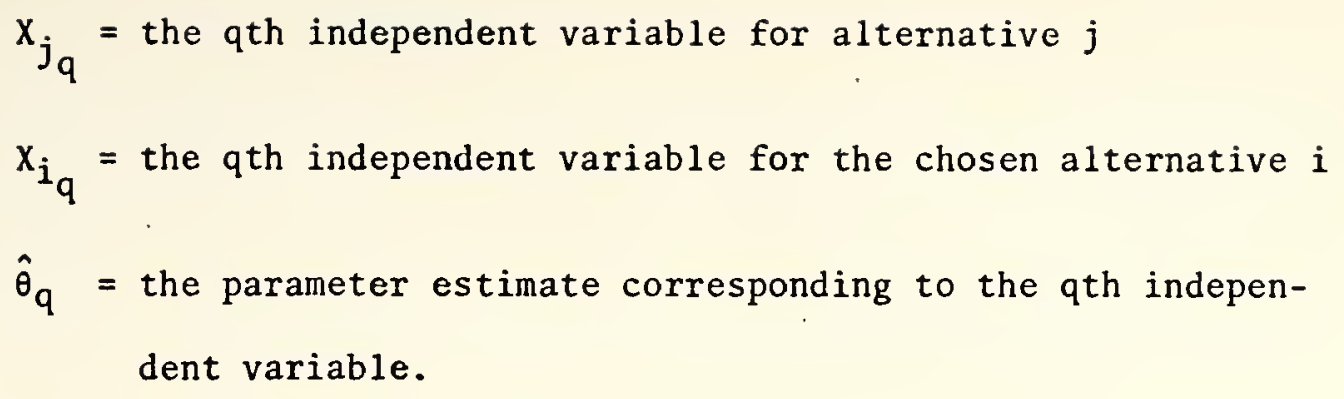

Specific Destination Choice Mode1s

Figure 4.2 shows the correlation matrix for the variables assumed to act as continuous variables in the modelling discussed in this chapter. It was anticipated that the appearance of any pair of significantly correlated variables in the same model would have a confounding effect on the predictive effectiveness of the model. Table 4.7 shows the number of times the multinomial logit model developed with each variable or combination of variables correctly predicts the actually chosen alternative. A summary of the parameter estimation results is given in Table 4.8 .

Considering single variables alone, the number of correct predictions in Table 4.7 ranges from 42 for Line Haul Travel Time (TL) to 25 for Airline Distance (DAL) out of the total of 87 households considered. As expected, every correct prediction made for travel time that allows for terminal times (TA) was made by Line Haul Travel Time (TL), the latter making five more correct predictions. The same comparison can be established between Floor Area (FLA) and the Parking Spaces Available (PRK) with Floor Area making more correct predictions.

When pairs of variables that are not significantly correlated were used very little or no improvement in prediction accuracy was 


\begin{tabular}{|c|c|c|c|c|c|c|}
\hline & $F L A$ & TL & TA & DAL & PRK & TOT \\
\hline FLA & - & 0.2949 & 0.3071 & 0.1802 & 0.7335 & 0.8169 \\
\hline$T L$ & & - & 0.9773 & 0.7865 & 0.0570 & 0.1408 \\
\hline TA & & & - & 0.7643 & 0.0311 & 0.1287 \\
\hline DAL & & & & 一 & 0.0064 & 0.0485 \\
\hline PRK & & & & & - & 0.8088 \\
\hline TOT & & & & & & - \\
\hline
\end{tabular}

FIGURE 4.2 CORRELATION MATRIX. FOR LOGIT MODEL VARIABLES 
Toble 4.7 Predictive Accurocy of Conditionol Logit Modol ${ }^{0, b}$ in Specific Shopping Desfination Choice Prediction

\begin{tabular}{|c|c|c|c|c|c|c|c|}
\hline \multirow{2}{*}{$\begin{array}{r}\text { Hous hold } \\
\text { Number }\end{array}$} & \multicolumn{7}{|c|}{ Sel of Explonotory Vorinbles } \\
\hline & $T L$ & TA & $F L A$ & PRK & TOT & DAL & FLA,OAL \\
\hline 1 & & & $x$ & $x$ & & $x$ & $x$ \\
\hline 2 & $x$ & & & & $x$ & & \\
\hline 3 & $\bar{x}$ & $x$ & & & $x$ & & \\
\hline 4 & & & & & & & \\
\hline 5 & & & & 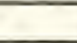 & & $x$ & \\
\hline 6 & & & $x$ & $x$ & & $\bar{x}$ & $x$ \\
\hline 7 & & & & & & $x$ & \\
\hline 8 & 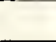 & 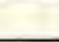 & 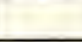 & & $x$ & & \\
\hline 9 & & & & & & $x$ & \\
\hline 10 & $x$ & $x$ & & & & & \\
\hline I I & $x$ & $x$ & & & $x$ & & \\
\hline 12 & & & $x$ & $x$ & & $x$ & $x$ \\
\hline 13 & & & $x$ & & & $x$ & $x$ \\
\hline 14 & & & & & & & \\
\hline 15 & $x$ & $x$ & $x$ & $x$ & $x$ & & $x$ \\
\hline 16 & & 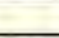 & $x$ & $x$ & $x$ & $x$ & $x$ \\
\hline 17 & $x$ & $x$ & $x$ & $x$ & $x$ & & $x$ \\
\hline 18 & $x$ & $x$ & $x$ & $x$ & $x$ & & $x$ \\
\hline 19 & $x$ & & $x$ & $x$ & & & $x$ \\
\hline 20 & & & $x$ & $x$ & & & $x$ \\
\hline 21 & $x$ & $x$ & $x$ & $\bar{x}$ & $x$ & & $x$ \\
\hline 22 & $x$ & $x$ & $x$ & $x$ & $x$ & & $x$ \\
\hline 23 & $x$ & $x$ & $x$ & $x$ & $x$ & & $x$ \\
\hline 24 & & & & & & & \\
\hline 25 & & & $x$ & & & $x$ & $x$ \\
\hline 26 & & & $x$ & & & & $x$ \\
\hline 27 & $x$ & $x$ & & & & & \\
\hline 28 & $x$ & $x$ & & & & & \\
\hline 29 & $x$ & $x$ & $x$ & & $x$ & & $x$ \\
\hline 30 & & & $x$ & & $x$ & & $x$ \\
\hline 31 & & & $x$ & & $x$ & & $x$ \\
\hline 32 & & & $x$ & & $x$ & & $x$ \\
\hline 33 & $x$ & $x$ & $x$ & & $x$ & & $x$ \\
\hline 34 & & & $x$ & & $x$ & & $x$ \\
\hline 35 & $x$ & $x$ & $x$ & 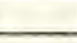 & $x$ & & $x$ \\
\hline 36 & 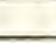 & & & $x$ & & $x$ & \\
\hline 37 & & & $x$ & & $x$ & & $x$ \\
\hline 38 & $x$ & $x$ & & 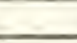 & & & \\
\hline 39 & & & & $x$ & & $x$ & \\
\hline 40 & & & & & $x$ & & \\
\hline 41 & & & $x$ & $x$ & & $x$ & $x$ \\
\hline 42 & $x$ & $y$ & & & & $x$ & \\
\hline 43 & & & $x$ & . & & $x$ & $x$ \\
\hline 44 & & & $x$ & $x$ & & $x$ & $x$ \\
\hline
\end{tabular}

- The Legend for the Voriobles in Toble, $4 \cdot 6$ 'x'Indicolos Correcl Prodiclion 
Table $4 \cdot 7$ Conl.

\begin{tabular}{|c|c|c|c|c|c|c|c|}
\hline \multirow{2}{*}{$\begin{array}{l}\text { Household } \\
\text { Number }\end{array}$} & \multicolumn{7}{|c|}{ Set of Explonatory Voriobles } \\
\hline & $T L$ & TA & $F L A$ & PRK & TOT & DAL & FLA,DAL \\
\hline 45 & & & $x$ & $x$ & & $x$ & $x$ \\
\hline 46 & & & $x$ & $x$ & & $x$ & $x$ \\
\hline 47 & & & $x$ & $x$ & & $x$ & $x$ \\
\hline 48 & & & $x$ & $x$ & & $x$ & $x$ \\
\hline 49 & $x$ & $x$ & & & & & \\
\hline 50 & $x$ & $x$ & $x$ & $x$ & & $x$ & $x$ \\
\hline 51 & $x$ & $x$ & & & & & \\
\hline 52 & $x$ & $x$ & & & & & \\
\hline 53 & $x$ & $x$ & $x$ & $x$ & & & $x$ \\
\hline 54 & & & $x$ & & & $x$ & $x$ \\
\hline 55 & & & & & $x$ & $x$ & $x$ \\
\hline 56 & $x$ & $x$ & & & & & \\
\hline 57 & & & & $x$ & $x$ & & \\
\hline 58 & $x$ & $x$ & & $x$ & & & \\
\hline 59 & & & & & & & \\
\hline 60 & $x$ & $x$ & & & & & \\
\hline 61 & $x$ & & & $x$ & $x$ & & \\
\hline 62 & $x$ & $x$ & & & & & \\
\hline 63 & & & & & & & \\
\hline 64 & $x$ & $x$ & & & & & \\
\hline 65 & $x$ & $x$ & & $x$ & & & \\
\hline 66 & & & & & & & \\
\hline 67 & & & & & $x$ & & \\
\hline 68 & & & & $x$ & & & \\
\hline 69 & & & & & $x$ & & \\
\hline 70 & $x$ & $x$ & & & & & \\
\hline 71 & & & & & & $x$ & \\
\hline 72 & & & & & & $x$ & \\
\hline 73 & $x$ & $x$ & & & & & \\
\hline 74 & & & $x$ & & $x$ & $x$ & $x$ \\
\hline 75 & & & $x$ & $x$ & $x$ & & $x$ \\
\hline 76 & & & & & & & \\
\hline 77 & $x$ & $x$ & $x$ & $x$ & $x$ & & $x$ \\
\hline 78 & $x$ & $x$ & & & & & \\
\hline 79 & $x$ & $x$ & & & & & \\
\hline 80 & $x$ & $x$ & $x$ & $x$ & $x$ & & $x$ \\
\hline 81 & $x$ & & & & & & \\
\hline 82 & $x$ & $x$ & & & & & \\
\hline 83 & $x$ & $x$ & & $x$ & & & \\
\hline 84 & $x$ & $x$ & $x$ & $x$ & $x$ & & $x$ \\
\hline 85 & $x$ & $x$ & $x$ & $x$ & $x$ & & $x$ \\
\hline 86 & 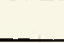 & & & $x$ & $x$ & & \\
\hline 87 & $x$ & $x$ & $x$ & $x$ & $x$ & 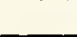 & $x$ \\
\hline & 42 & 37 & 40 & 35 & 33 & 25 & 41 \\
\hline
\end{tabular}

The Legend for tha Variobles in Toble 4.6 
Table 4.7 Cont.

\begin{tabular}{|c|c|c|c|c|c|c|}
\hline \multirow{2}{*}{$\begin{array}{c}\text { Household } \\
\text { Number }\end{array}$} & \multicolumn{6}{|c|}{ Sel of Explanalory Voriobles } \\
\hline & FLA,AP3 & TL,PRK & $T L, \triangle P 3$ & TA, PRK & TA, TOT & TA,AP 3 \\
\hline 1 & $x$ & & & & & \\
\hline 2 & & $x$ & $x$ & $x$ & $x$ & $x$ \\
\hline 3 & & $x$ & $\bar{x}$ & $x$ & $x$ & $x$ \\
\hline \multicolumn{7}{|l|}{4} \\
\hline \multicolumn{7}{|l|}{5} \\
\hline 6 & $x$ & $x$ & & $x$ & & \\
\hline \multicolumn{7}{|l|}{7} \\
\hline \multicolumn{7}{|l|}{8} \\
\hline 9 & & & & & & $x$ \\
\hline \multicolumn{7}{|l|}{10} \\
\hline 11 & & $x$ & $x$ & $x$ & $x$ & $x$ \\
\hline 12 & $x$ & & & $x$ & & \\
\hline 13 & $x$ & & & & & \\
\hline \multicolumn{7}{|l|}{14} \\
\hline 15 & $x$ & $x$ & $x$ & $x$ & $x$ & $x$ \\
\hline 16 & $x$ & & & & & \\
\hline 17 & $x$ & $x$ & $x$ & $x$ & $x$ & $x$ \\
\hline 18 & $x$ & $x$ & $x$ & $x$ & $x$ & $x$ \\
\hline 19 & $x$ & $x$ & $x$ & $x$ & $\bar{x}$ & $\bar{x}$ \\
\hline 20 & $x$ & & & & & \\
\hline 21 & $x$ & & $x$ & $x$ & $x$ & $x$ \\
\hline 22 & $x$ & $x$ & $x$ & $x$ & $x$ & $x$ \\
\hline 23 & $x$ & $x$ & $x$ & $x$ & $x$ & $x$ \\
\hline 24 & & $x$ & & & & \\
\hline 25 & $x$ & & & & & \\
\hline 26 & $x$ & & & & & \\
\hline 27 & & & $x$ & & & $x$ \\
\hline 28 & & & $x$ & & & $x$ \\
\hline 29 & $x$ & $x$ & $x$ & $x$ & & $x$ \\
\hline 30 & $x$ & $x$ & & $x$ & $\dot{x}$ & \\
\hline 31 & $x$ & $x$ & & & $x$ & \\
\hline 32 & $x$ & $x$ & & & $x$ & \\
\hline 33 & $x$ & $x$ & $x$ & $x$ & $x$ & $x$ \\
\hline 34 & $x$ & & & & $x$ & \\
\hline 35 & $x$ & $x$ & $x$ & $x$ & $x$ & $x$ \\
\hline \multicolumn{7}{|l|}{36} \\
\hline 37 & $\bar{x}$ & & & & $x$ & \\
\hline 38 & & & $x$ & & & $x$ \\
\hline \multicolumn{7}{|l|}{39} \\
\hline 40 & & $x$ & $x$ & $x$ & $x$ & $x$ \\
\hline 41 & $x$ & & & & & \\
\hline \multicolumn{7}{|l|}{42} \\
\hline 43 & $x$ & & & & & \\
\hline 44 & $x$ & $x$ & & $x$ & & \\
\hline
\end{tabular}

The Legend for the Voriostes in

Table $4 \cdot 6$

' $x$ ' Indicatos Correcl Prodictlon 
Toble 4.7 Cont

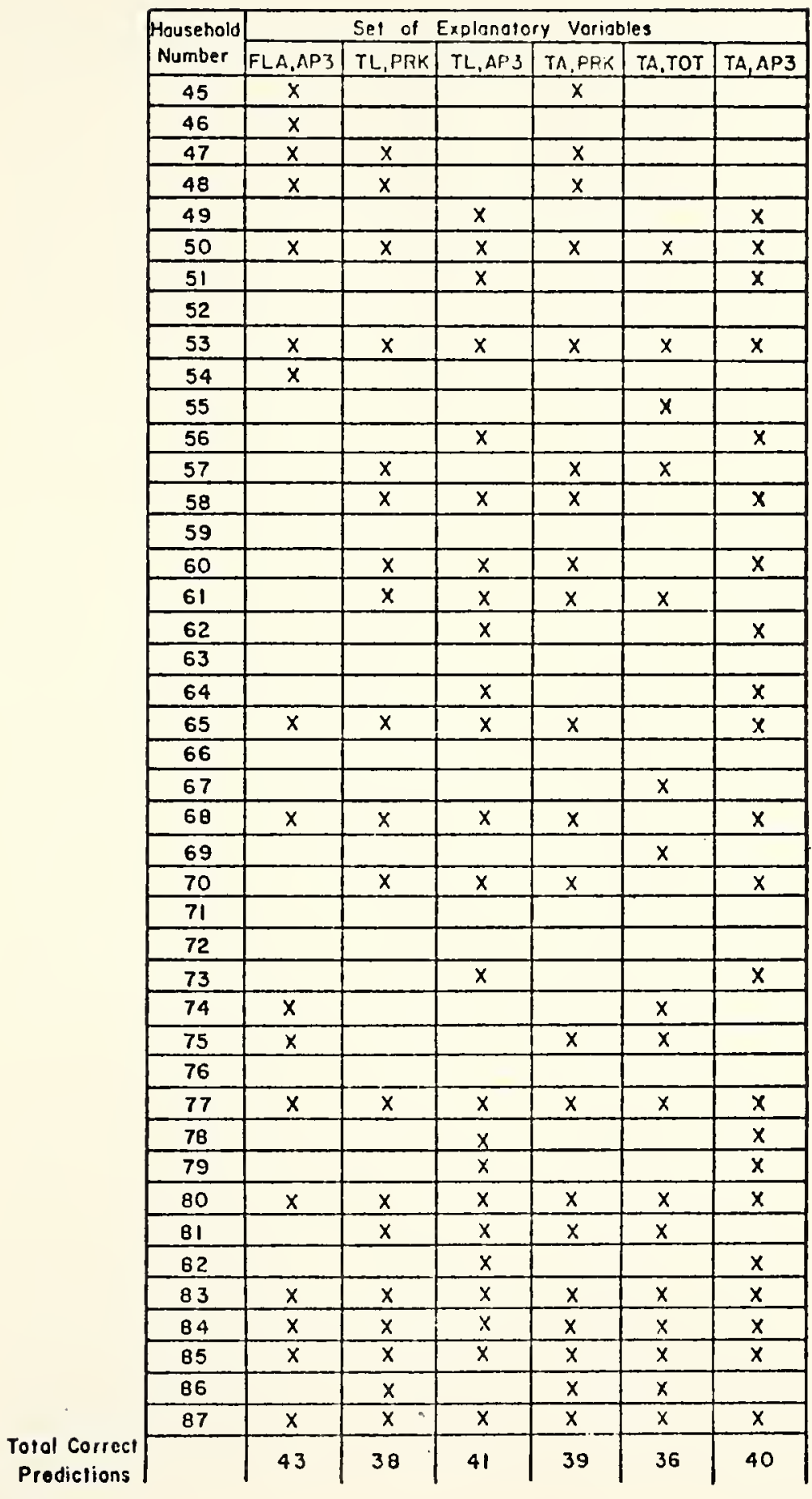

The Legend for the Variobles in

Toble 4.6

' $x$ 'Indicales

Correct Prodicilon 
Toble 4.7 Conl.

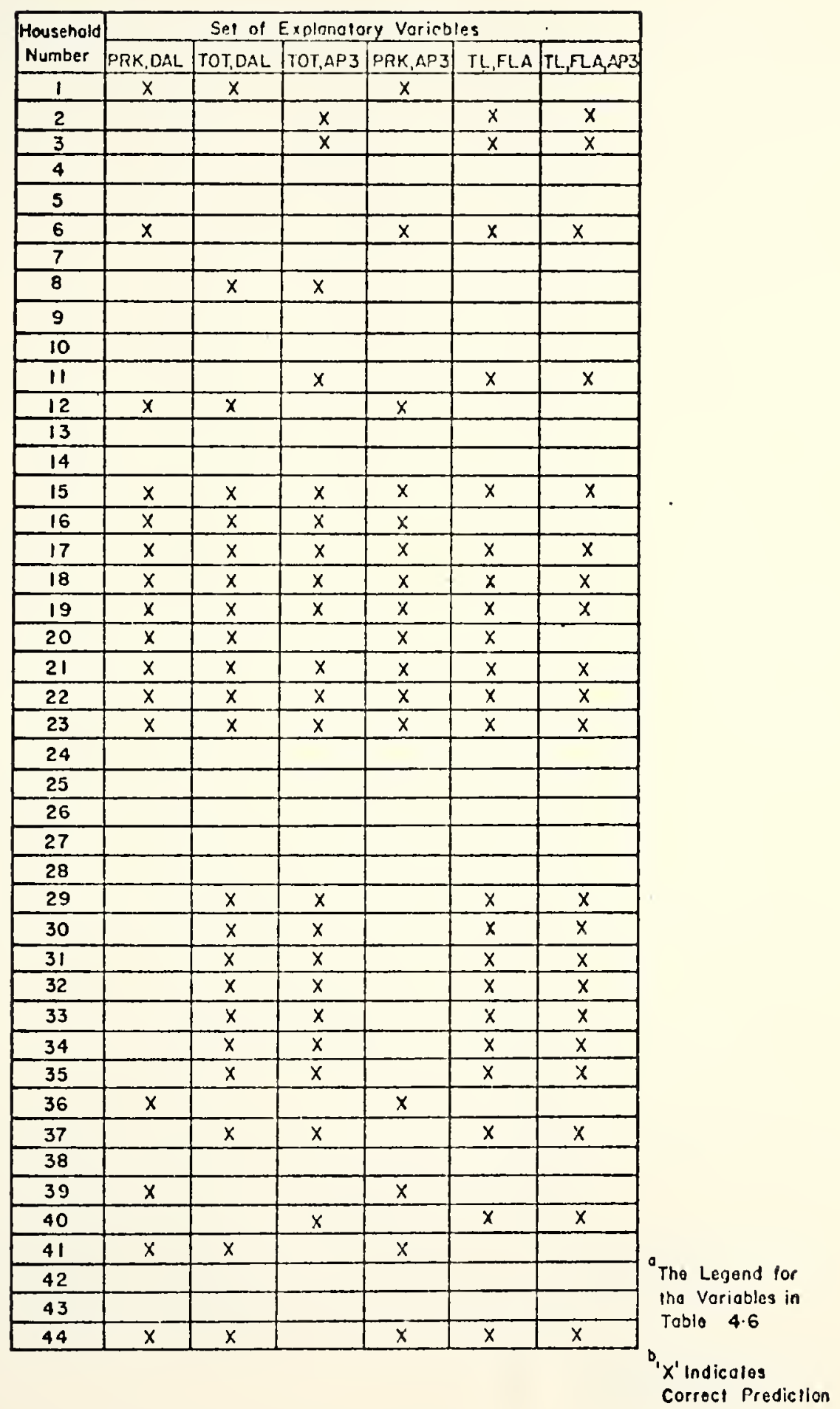


Toble 4.7 Cont

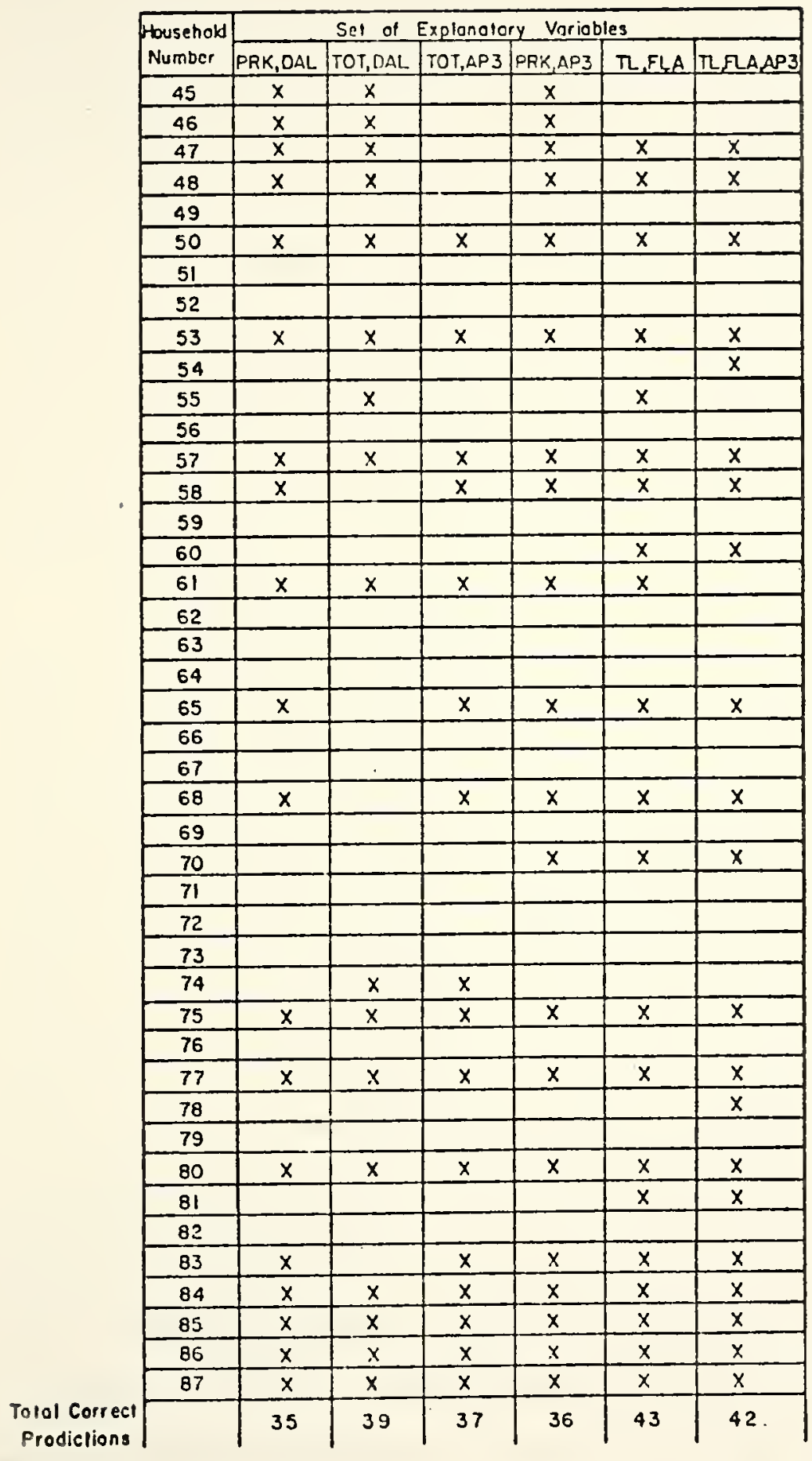

The Legend for the Voriables in Toble 4.6 
achieved, as shown in Table 4.7. Considering the correct predictions made by single variables, one gets the impression that if Line Haul Travel Time (TL), and Floor Area (FLA) act independently the two of them in a single model should produce more correct predictions. It was anticipated that since the correlation between these two variables is significant such an optimistic expectation would not materialize. This can be verified in Table 4.7. Similar remarks can be made about Line Haul Travel Time (TL) and Airline Distance (DAL) acting in the same model since these two variables are significantly correlated and do not always make the same actual predictions when they act separately.

The approachability measures turned out to be in categories 2 or 3 (i.e. medium or good approachability) because no household in the subsample taken had a rating of 1 (poor approachability) with respect to its approachability to any of its alternative destinations. The models developed to combine the approachability measures as dummy variables with other variables do give the same results as those obtained in the absence of the approachability measure. This indicates that the ease of approach to the shopping centers did not really pose any serious problems for the households concerned. This confirms the fact that no particular effort was reported to have been made by the households to avoid congestion by making shopping trips during off-peak periods. Another contributing factor is that the subsample covered households from some two or three adjacent sectors which probably resulted in the households involved being relatively located with respect to the highway network in a similar manner. 
Table 4.8. Summary of Conditional Logit Model Estimation Results

\begin{tabular}{|c|c|c|c|}
\hline $\begin{array}{l}\text { Explanatory } \\
\text { Varlables }^{a}\end{array}$ & Parameter Estimate ${ }^{b}$ & Likel lhood & $\begin{array}{l}-2 \times \text { Log Like- } \\
\text { lihood } \\
\text { Ratio }\end{array}$ \\
\hline $\mathrm{TL}$ & $-0.0607 \quad 0.0239$ & -117.22 & 6.787 \\
\hline TA & $-0.0291(0.0233)$ & -119.81 & 1.5945 \\
\hline FLA & $0.00165(0.000414)$ & -111.98 & 1.726 \\
\hline PRK & $0.0001788 \quad(0.0000593)$ & -115.90 & 9.415 \\
\hline TOT & $0.0145(0.00413)$ & -114.28 & 12.664 \\
\hline DAL & $0.0278(0.0372)$ & -120.33 & 0.547 \\
\hline FLA & $0.00164(0.000418)$ & -111.97 & 17.28 \\
\hline DAL & $0.00538 \quad(0.0410)$ & & \\
\hline FLA & $0.00152(0.000418)$ & -110.66 & 19.89 \\
\hline AP3 & $-0.628(0.408)$ & & \\
\hline TL & $-0.0686(0.0241)$ & -111.58 & 18.055 \\
\hline PRK & $0.000199(0.0000606)$ & & \\
\hline TL & $-0.0614(0.0235)$ & -114.26 & 12.70 \\
\hline AP3 & $-0.872(0.391)$ & & \\
\hline TA & $-0.0393(0.0239)$ & $-114 \cdot 51$ & 12.20 \\
\hline PRK & $0.000192(0.0000604)$ & & \\
\hline $\mathrm{TA}$ & $-0.0381(0.0241)$ & -112.99 & 15.23 \\
\hline TOT & $0.0152(0.00417)$ & & \\
\hline $\mathrm{TA}$ & $-0.03207(0.023)$ & -116.86 & 7.492 \\
\hline AP3 & $-0.872(0.392)$ & & \\
\hline
\end{tabular}

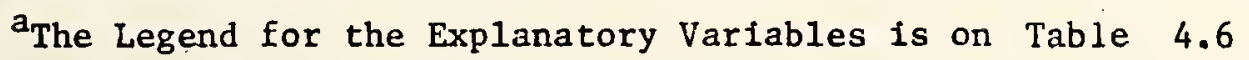

${ }^{b}$ Standard Deviation of Parameter in Parenthesis 
Table 4.8, Cont.

Explanatory

Variables ${ }^{a} \quad$ Parameter Estimate ${ }^{b}$

\begin{tabular}{llll}
\hline PRK & $0.000176(0.0000598)$ & -120.61 & 9.537 \\
DAL & $0.0139(0.0397)$ & & \\
\hline TOT & $0.0146(0.00415)$ & -114.02 & 13.168 \\
DAL & $0.0285(0.0397)$ & -111.51 & 18.185 \\
TOT & $0.0146(0.00417)$ & & 13.149 \\
AP3 & $-0.875(0.403)$ & -114.03 & \\
\hline PRK & $0.000158(0.0000585)$ & & \\
AP3 & $-0.726(0.401)$ & -105.79 & 31.168 \\
TL & $-0.0844(0.0251)$ & & \\
FLA & $0.00197(0.000437)$ & & \\
\hline FLA & $0.00182(0.000449)$ & & \\
TL & $-0.0798(0.0249)$ & & \\
AP3 & $-0.489(0.410)$ & & \\
\hline
\end{tabular}

$-2 \times$ Log LikeIthood
Likelihood Ratio

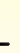


Models that contain three or more variables from the set available did not make any difference, as expected, for reasons given above.

It has been argued [16] that since actual human shopping behaviour may be random one would expect one out of four correct predictions to be made on the average, considering an average of four alternatives for each household. For all the models discussed in this chapter, the percentage correct prediction is more than $25 \%$ but less than $50 \%$. In a previous use of the multinomial logit model by Charles River Associates [16] on zonal shopping destinations in a mode choice-flavored context, a $40 \%$ correct prediction of actual destinations was achieved. It is difficult to come up with predictions that can be effectively aggregated if there is no provision to account for $50 \%$ of the sample in the choice of actual destinations. If actual destination choice was really random it would be better to randomly assign destinations in the first place. Random choice is only possible if all alternatives are equally likely. It is known that shopping destination choice is often based on characteristics of the shopping areas which are not the same for all alternatives. This point is discussed in connection with the attitudinal work on shopping destination choice presented in Chapter 6 . The impracticality of defining destination choice sets of varying size and the lack of a provision for aggregation in the use of the conditional logit model have been discussed in Chapters 2 and 3 . An additional factor that lessens the usefulness of the logit model for directly predicting actual destination choices is its low predictive accuracy as discussed in this chapter. 
An alternative modelling procedure presented theoretically in Chapter 5 with example application in Chapter 7 predicts functional classes of destination alternatives. If further variables are available one can go to the stage of using a choice model to predict actual choices within functional alternatives. It is pointed out in Chapter 5 that at this second stage simulation is considered the most practical way of handling the problem given the present quality of data available on spatial choices and the expectation that alternatives within functional destination categories are more equally likely. The alternative procedure will use ranges of variables as categories and also account for some of the interactions, the presence of which forfeited improvements that could have been achieved in predictability.

Summary

The multinomial logit model, increasingly becoming a tool in disaggregate modelling of urban travel demand, was found to yield low correct prediction levels of actual shopping destination choices. A 38 to 49 percent range of correct predictions was found regardless of whether one key variable or a combination of variables is used as an explanatory set of variables. Some of the key variables usedwere Line Haul Travel Time, Retail Floor Area and the Parking Spaces available. Ordinarily, one would have expected the models with irdependently acting variables to do better. This was not the case mairly because some of the variables (eg. approachability) really had little cffect on destination choice by virtue of 
the background of the sample used. Significant correlation between variables was found to reduce the effectiveness of models.

It is emphasized out that low predictive accuracy is not the only serious problem with the generalized multinomial logit procedure discussed in Chapter 3. Other shortcomings include destination choice set definition and aggregation as discussed in Chapters 2 and 3. 


\author{
CHAPTER 5 \\ DESTINATION CHOICE MODELLING WITH PRIOR \\ CONSIDERATION OF A SAMPLING FRAMEWORK FOR \\ AGGREGATE PREDICTION
}

The formulation and estimation of parameters for the multinomial response relation model are first introulced in this chapter. The adaption of the multinomial response approach to the analysis of the responses of market segments to functional travel behavior alternatives, after the definition and the statistical implications of the classification involved have been discussed, is provided. It is maintained that such a use of the multinomial response approach can foster aggregate prediction since market segmentation according to socio-economic and population characteristics from readily available sources can be tied to the sample survey for an operational transportation study. The use of the multinomial response procedure to provide estimates of the proportions of market segments that respond to functional travel alternatives for use in separate sampling logistic discrimination for disaggregate analysis is discussed. The recently developed logistic dịscrimination procedure has an advantage over classical procedures since it allows the handling of a combination of categorical and continuous variables. It is argued that separate sampling at activity centermarket segment interfaces be adopted for more efficient sampling for disaggregate analysis. 
Large samples (efficiently collected not to be excessive) are recommended in operational studies so that proper statistical inferences can be made on goodness of fit measures and on the parameters of probability distribution functions. General maximum likelihood estimation procedures, the assumptions involved and the associated asymptotic distributions of parameter estimators are extensively discussed to support the call for large sample surveys. [Multivariate statistical testing procedures relevant to parameters estimated for probability models of travel behavior are presented in Chapter 7]

Most importantly the presentation shows how recently developed statistical tools can allow the modelling of travel behavior without very sophisticated data collection and measurement scales. There is more reliance in survey design and systematic structuring of statistical models.

Multinomial Response Law and its Estimation

Suppose we have subjects under different experimental conditions reacting to categories of some response classification. We let the number of categories in the response classification be $m \geq 2$. The number of subjects under condition or market segment $j(j=1,2, \ldots, n)$ who fall in category $h$ of the classification is $r_{j h}$ where

$$
\sum_{h=1}^{m} r_{j h}=N_{j}
$$

Assuming a random selection of subjects, the probability of response frequencies $r_{j h}$ is given by:

$$
\sum_{j=1}^{n} \frac{N_{j} !}{r_{j 1} ! r_{j 2} ! \ldots r_{j m} !} P_{j 1}^{r_{j 1}} P_{j 2}^{r_{j 2}} \ldots P_{j m}^{r_{j m}}
$$


Suppose we have experimental variables that can be used to develop functions defining the response probabilities. A generalization of the binomial logit implicit in the work of Luce [39] and Mantel [94] can express the response probabilities in terms of multivariate logits $z_{j 1}, z_{j 2}, \ldots, z_{j m}$ as follows:

$$
P_{j h}=e^{Z} j h / D_{j} \quad h=1, \ldots, m
$$

where $P_{j h}$ is the probability that a member of market segment $j$ responds to the hth response category

$$
D_{j}=\sum_{h=1}^{m} e^{z j h}
$$

and

$$
z_{j h}=\sum_{\ell=1}^{t} \sum_{k=1}^{q} x_{j k} \xi_{k \ell} a_{\ell h}
$$

$x_{j k}$, the $j k t h$ element of an nxq matrix $\chi$ defined below, represents the $k$ th effect for the market segment $j \cdot a_{i h}$ is the ihth element of a $9 \times m$ A, discussed below, that corresponds to the eth effect of the hth response category. $\beta_{k \ell}$ is the parameter depicting the effect corresponding to the kth market segmentation effect and the lth response categorization effect.

A linear model expressing the logits in terms of the physical variables must provide for a structure of the categories in the response classification. This structure may be a result of a crossing or nesting of mutually exclusive classifications of the same subjects. We define a model that is sufficiently general to include both a structured response classification and multiple experimental variables as: 


$$
\begin{aligned}
& {\left[\begin{array}{llll}
z_{11} & z_{12} & \ldots & z_{1 m} \\
z_{21} & z_{22} & \ldots & z_{2 m} \\
\vdots & & & \\
z_{n 1} & z_{n 2} & \ldots & z_{n m}
\end{array}\right]=\left[\begin{array}{cccc}
x_{11} & x_{12} & \ldots & x_{1 q} \\
x_{21} & x_{22} & \ldots & x_{2 q} \\
\vdots & & & \\
x_{n 1} & x_{n 2} & \ldots & x_{n q}
\end{array}\right]} \\
& {\left[\begin{array}{llll}
\beta_{11} & \beta_{12} & \cdots & \beta_{1 t} \\
\beta_{21} & \beta_{22} & \cdots & \beta_{2 t} \\
\vdots & & & \\
\beta_{q 1} & \beta_{q 2} & \cdots & \beta_{q t}
\end{array}\right] \cdot\left[\begin{array}{cccc}
a_{11} & a_{12} & \cdots & a_{1 m} \\
a_{21} & a_{22} & \cdots & a_{2 m} \\
\vdots & & & \\
a_{1} & a_{2} & \cdots & a_{t m}
\end{array}\right]}
\end{aligned}
$$

which is equivalent in matrix notation to

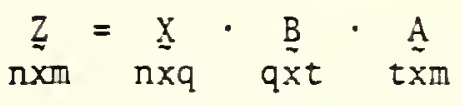

Matrix $\underset{\sim}{X}$ accounts for variation in the response-probabilities across the experimental conditions: $X$ is usually not of full column rank. If the rank of $X$ is $r \leq q$ it is necessary to reparameterize the model as

$$
\underset{n}{x}=\underset{\tilde{x} r}{K} \cdot \underset{r \times q}{L}
$$

where the rows of $L$ are coefficients of linearly estimable functions of

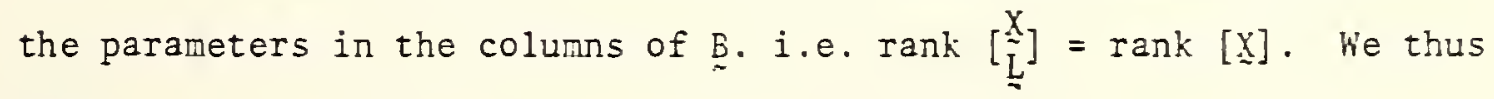
have

$$
\underline{K}=\underline{X} \underline{L}^{\prime}\left(\underline{L}_{\sim}^{\prime}\right)^{-1}
$$

Examples of the construction of $\mathrm{K}$ are discussed in Bock [86]. $\mathrm{X}$ can be referred to as the physical part of the model. $\underset{\sim}{\mathrm{K}}$ is a column basis of $\underline{X}$ 
Matrix $A$ in 5.2 accounts for the variation of response probabilities over response categories, $\underset{\sim}{A}$ is also usually of deficient rank. If rank (A) is $s \leq t$ then a reparameterization similar to 5.3 is

$$
\stackrel{A}{A}=\underset{t x s}{S} \cdot \underset{s \tilde{x m}}{T}
$$

where rank $\underset{\sim}{S}=s$ and the columns of $\underset{S}{S}$ are linearly dependent on those of $A$, we have

$$
\operatorname{rank}[\underset{\sim}{A}]=\operatorname{rank}[\underset{\sim}{A}, \underbrace{}_{]}] .
$$

Again we have

$$
\underline{T}=\left(\underline{S}^{\prime} \underline{S}\right)^{-1} \underline{S}^{\prime} \underline{\mathrm{A}}
$$

A can be called the response part of the model, for which $\underset{\sim}{ }$ is a row basis.

When $\underset{\sim}{X}$ and $\underset{\sim}{A}$ are of deficient rank, reparameterization of the model as discussed is necessary to make the matrix of second derivitives of the $\log$ of the likelihood function non-singular if maximum likelihood estimation via a suitable gradient technique is used.

The reparameterized full rank model is

where

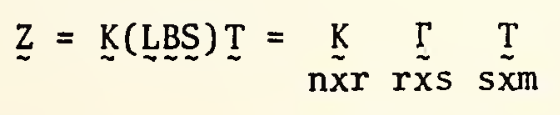

$$
\underline{\Gamma}=\underset{\sim}{\mathrm{LBS}}
$$

It is then the rxs matrix of parameters, $\Gamma$, that is estimated. The elements of $\underset{\sim}{\Gamma}$ in statistical terms will be called effects. 
I will be estimated using a maximum likelihood estimation procedure with the Newton-Raphson gradient technique. The log of the likelihood function given in 5.1 will be denoted by $L_{q}$.

The following are defined

$$
\stackrel{r}{r}_{j}=\left[\begin{array}{l}
r_{j 1} \\
r_{j 2} \\
\vdots \\
r_{j m}
\end{array}\right] \quad \text { and } \stackrel{P}{j}_{j}=\left[\begin{array}{c}
P_{j 1} \\
P_{j 2} \\
\vdots \\
P_{j m}
\end{array}\right]
$$

We denote the elements of $\underset{\sim}{\Gamma}$ as $\gamma_{k h}$. The $r s x l$ vector of first derivatives of $\mathrm{L}_{\mathrm{q}}$ with respect to the elements of $\underset{\sim}{\Gamma}$ considered as elements of an rsxl vector in which the column subscript varies first is given by [86]

$$
(\Gamma)=\sum_{j=1}^{n} \underset{s \times m}{T}\left(\underset{\sim j}{\underline{r}}-\underset{m \times 1}{N_{j}} \stackrel{P}{j}_{j}\right) \otimes \underset{r \times 1}{\underset{j}{K}}
$$

where $\otimes$ denotes a Kronecker product and $\underline{\sim}_{j}$ is the $j$ th row of $\underline{K}$ written as a column. (A Kronecker product is defined in a later section) Defining the following mxm matrix:

$$
{\underset{\sim}{j}}_{j}=\left[\begin{array}{cccc}
P_{j 1}\left(1-P_{j 1}\right) & -P_{j 1} P_{j 2} & \cdots \cdots & P_{j 1} P_{j m} \\
-P_{j 2} P_{j 1} & P_{j 2}\left(1-P_{j 2}\right) & \ldots & -P_{j 2} P_{j m} \\
\vdots & \vdots & & \vdots \\
-P_{j m} P_{j 1} & -P_{j m} P_{j 2} & \cdots & P_{j m}{ }^{\left(1-P_{j m}\right)}
\end{array}\right] \quad 5.10
$$

$\left[\underline{W}_{j}\right.$ is the variance-covariance matrix of the estimators of $\left.P_{j h}\right]$ The rsxrs matrix of second derivatives of $\mathrm{L}_{\mathrm{q}}$ is then: 


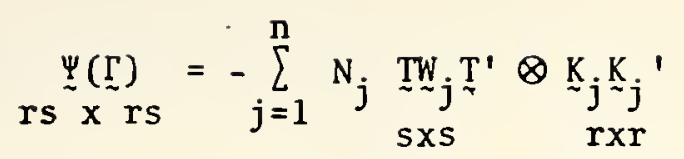

For the likelihood function to be maximized the first derivative of $\mathrm{L}_{\mathrm{q}}$ with respect to $\gamma_{k h}$ must be zero, i.e.

$$
\underset{\sim}{\operatorname{rsxl}} \underset{\sim}{(\Gamma)}=\underset{\tilde{r} s \times 1}{0}
$$

For solutions of equation (5.12) to be unique the matrix of second derivatives of $\underset{\sim q}{\mathrm{~L}}$ must be negative definite. Since $\underset{\sim j}{\mathbb{W}}$ is the variancecovariance matrix of the multinomial probabilities, it is positive semi definite with only one zero root. The characteristic vector, $\underset{\sim}{a}$, corresponding to the zero root has each component as unity. The matrix $\mathbb{T W}_{\mathbf{j}} \sim^{\prime}$ is therefore positive-definite so long as $s<m, \underline{T}$ is of full rank and $\mathrm{T}$ does not have a vector $\underset{\sim}{\mathrm{a}}$ as a row.

The matrix $\underset{\sim j}{K} \sim_{j}^{\prime}$ is positive-semidefinite and of rank one. The Kronecker product of $\operatorname{TW}_{\sim j} \sim^{\prime}$ and $\underset{\sim j}{K_{j}} K_{j}{ }^{\prime}$ can be established to be of rank $s$ [95]. For $n \geq r$ and $\underset{\sim}{K}$ of full rank, the sum over $j$ of these Kroneckerproducts will be positive definite. The matrix $\underset{\sim}{\Psi}(\underset{\sim}{\Gamma})$, being the negative of a positive definite matrix, is therefore negative definite for all finite $\underset{\sim}{.}$ A Newton-Raphson solution of the likelihood equations (5.12) should therefore converge to the maximum likelihood estimates from any finite initial values.

Let $\Gamma_{i}$ be the trial value at the ith iteration. From 5.7 the trial logits are

$$
\left[\hat{Z}_{j n}^{(i)}\right]=\underset{n \times n}{z_{i}}=\underset{\sim}{K} \Gamma_{i} \frac{T}{\sim}
$$


and the trial probabilities are

$$
\underset{n \times m}{P_{j}^{*}}=\underset{n \times n}{D_{i}^{-1}}\left[\underset{n \times m}{e^{Z^{(i)}}}\right]
$$

where $D_{i}$ is a diagonal matrix whose elements are the sum of elements in the rows of $\left[e^{\hat{z}}{ }^{(i)}\right]$. The elements in the rows of $\stackrel{p}{*}_{i}^{*}$ are the components of the vector ${\underset{\sim}{\mathrm{P}}}_{j}$ defined for equation (5.9) and used for equation (5.10). The adjustment vector is

$$
\stackrel{\delta}{i}_{i}=-\underline{\Psi}^{-1}\left(\hat{\Gamma}_{i}\right) \varphi\left(\hat{\Gamma}_{i}\right)
$$

where $\delta_{i}$ is an rsx 1 vector whose elements constitute ${\underset{\sim}{k h}}_{(i)}^{(i)}$ (adjustments to $\Gamma_{\sim \mathrm{kh}}^{(\mathrm{i})}$ ) where the subscript $\mathrm{h}$ varies first).

The adjustments are added to corresponding elements of $\underset{\sim}{\hat{\Gamma}}$ to get improved estimates up to a specified tolerance level.

A convenient goodness-of-fit test for the overall model is given by the likelihood ratio statistic $[49,89]$

$$
\chi^{2}=-2 \sum_{j=1}^{n} \sum_{k=1}^{m} r_{j k} \log _{e} N_{j} \hat{p}_{j k} / r_{j k}
$$

$\hat{\mathrm{P}}_{\mathrm{jk}}$ are as computed in equation (5.14).

The associated number of degrees of freedom is $n(m-1)$ - rs.

- More extensive discussion on inferences on the parameters estimated will be provided in the context of large sample maximum likelihood estimators in a later section. Hypothesis testing with the multinomial response model will be discussed during its application in Chapter 7 . The following section relates the multinomial response model to destination choice modelling for different market segments, for which the empirical analysis in Chapter 7 will be carried out. 


\section{A Specific Applied Discussion of the Multinomial Response Relation}

\section{Procedure}

In the discussion following equation 5.1 some multivariate logits, $z_{j h}$, were introduced whose elements form the matrix $z$ given in equation 5.2 as

$$
\underset{n \times m}{Z}=\underset{n \times g}{x} \cdot \underset{g x t}{B} \cdot \underset{t \tilde{x m}}{A}
$$

For expediency in the ensuing theoretical development matrices $\underset{\sim}{X}, \underset{\sim}{B}$, and $\underset{\sim}{A}$ were discussed in briefly general terms. Starting from equation 5.2, a presentation is given of the application of the multinomial response relation technique to the special kind of problems that will be of interest in this research.

A simple case where all the matrices involved in equation 5.2 are $2 \times 2$ matrices is considered for which

$$
\left[\begin{array}{ll}
z_{11} & z_{12} \\
z_{21} & z_{22}
\end{array}\right]=\left[\begin{array}{ll}
x_{11} & x_{12} \\
x_{21} & x_{22}
\end{array}\right]\left[\begin{array}{ll}
\beta_{11} & \beta_{12} \\
\beta_{21} & \beta_{22}
\end{array}\right] \quad\left[\begin{array}{ll}
a_{11} & a_{12} \\
a_{21} & a_{22}
\end{array}\right]
$$

The above expression implies:

$$
\begin{aligned}
& z_{11}=x_{11} \beta_{11} a_{11}+x_{12} \beta_{21} a_{11}+x_{11} \beta_{12} a_{21}+x_{12} \beta_{22} a_{21} \\
& z_{12}=x_{11} \beta_{11} a_{12}+x_{12} \beta_{21} a_{12}+x_{11} \beta_{12} a_{22}+x_{12} \beta_{22} a_{22} \\
& z_{21}=x_{21} \beta_{11} a_{11}+x_{22} \beta_{21} a_{11}+x_{21} \beta_{12} a_{21}+x_{22} \beta_{22} a_{21} \\
& z_{22}=x_{21} \beta_{11} a_{12}+x_{22} \beta_{21} a_{22}+x_{21} \beta_{12} a_{22}+x_{22} \beta_{22} a_{22}
\end{aligned}
$$

We can therefore deduce the expression for the multivariate logit $z_{j h}$ 


$$
z_{j h}=\sum_{=1}^{t} \sum_{k=1}^{g} x_{j k} \beta_{k \ell} a_{\ell h} \quad \begin{aligned}
h & =1,2, \ldots, m \\
j & =1,2, \ldots, n
\end{aligned}
$$

$Z_{j h}$ can also be expressed as

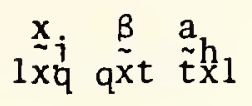

i.e. each multivariate $\operatorname{logit} z_{j i}$ corresponding to the $j$ th market segment and ith response category can be written as the product of row j of $\underset{\sim}{X}(\underset{\sim j}{x})$, the parameter matrix $\underset{\sim}{\beta}$ and column $h$ of $\underset{\sim}{A}(\underset{\sim}{a})$. Each . element $\beta_{k l}$ of is the parameter corresponding to the kth column of $x$ and the $\ell$ th row of $\underset{\sim}{A}$ which are described below.

Each column of $\underset{\sim}{X}$ represents an effect for the design model that it depicts and the same applies for each row of $\underset{\sim}{A}$. An element of the row vector $\underset{\sim}{x}$ is 0 or 1 according as the effect corresponding to its column position is absent or present. the eth row element of the column vector $\underset{\sim}{a}$ is 0 or 1 according as the effect associated with the th row is absent or present.

The matrices $\underset{\sim}{\mathrm{X}}$ and $\underset{\sim}{\mathrm{A}}$ can each represent a crossed or nested design. In the problems discussed in this study we consider our market segments separately in which case we need not be concerned with representing any design with $\underset{\sim}{x}$. The $\underset{\sim}{A}$ matrices in the applications in this research are all for crossed designs. We shall, however, discuss a hypothetical example in which each of the $\underset{\sim}{\mathrm{X}}$ and $\underset{\sim}{\mathrm{A}}$ matrices represents a crossed design.

The matrix $\underset{\sim}{X}$ depicts the experimental design configuration for a market segmentation process whilst the matrix $\underset{\sim}{A}$ represents the 
corresponding configuration for the response classification. An example of factors $W$ and $S$ corresponding to attitudinal descriptors "Wide selection of Goods" and "Shortest Travel Time" respectively. Suppose there are 2 categories for $W\left(W_{1}, W_{2}\right)$ and 3 classes for $S$ $\left(s_{1}, s_{2}, s_{3}\right)$ where the higher the category the more important the descriptor is to a respondent in an attitudinal survey. A basic $2 \times 3$ classification for the definition of $\underset{\sim}{X}$ is:

\begin{tabular}{llll} 
& $s_{1}$ & $s_{2}$ & $s_{3}$ \\
\cline { 2 - 4 }$w_{1}$ & 1 & 2 & 3 \\
$w_{2}$ & 4 & 5 & 6 \\
\hline
\end{tabular}

If the factors $W$ and $S$ act independently, an entry in cell $j$ $(j=1, \ldots, 6)$ of the above table is depicted by the main effects corresponding to its row and column coordinates. With each row of $\underline{x}$ corresponding to a cell in the classification table, it is formed as follows:

Main Effects

Cell No.

\begin{tabular}{|c|c|c|c|c|c|c|}
\hline & $\mu$ & $w_{1}$ & $w_{2}$ & $s_{1}$ & $\mathrm{~s}_{2}$ & $\mathrm{~S}_{3}$ \\
\hline \multirow{6}{*}{$\underset{\sim}{X}=$} & $\Gamma$ & 1 & 0 & 1 & 0 & 07 \\
\hline & 1 & 1 & 0 & $\theta$ & 1 & 0 \\
\hline & 1 & 1 & 0 & 0 & 0 & 1 \\
\hline & 1 & $a$ & 1 & 1 & 0 & 0 \\
\hline & 1 & 0 & 1 & 0 & 1 & 0 \\
\hline & 1 & 0 & 1 & 0 & 0 & 11 \\
\hline
\end{tabular}

Cell 5 is affected by the general mean and the main effects $W_{2}$ and $S_{2}$ so entries in $\underset{\sim}{X}$ for cell 5 are 1 for these effects, all others being 0 . 
It is noticed, as was indicated previously, that each column of $\underset{\sim}{X}$ represents an effect and each row of $\underset{\sim}{X}$ corresponds to a market segment or classification cell.

What is meant by the column rank of $\underset{\sim}{x}$ in terms of the problem under discussion is the number of independent effects we can identify. If we have a sample and observe a portion of it as responding to the category $W_{1}$ we know that the remainder of the sample respond to category $W_{2}$. Similarly, if we know the number of responses to any two of $S_{1}, S_{2}$, $S_{3}$, we can obtain the number of responses to the third category of factor $\mathrm{S}$ by simple subtraction. Since we can only estimate $1 \mathrm{~W}$ category effect relative to the other and 2 category effects of factor $S$ relative to a third, we say that the column rank of $\underset{\sim}{X}$ is 3 . The practice adopted in this study is to consider the effects relative to the first or last category of each classification.

If there is an interaction effect between one $W$ category and another of the $S$ factor, this effect is reflected in the row of $x$ corresponding to the cell defined by the categories in question. $A W_{1}, S_{1}$ interaction, therefore, will have an entry of 1 corresponding to cell 1 . We then have

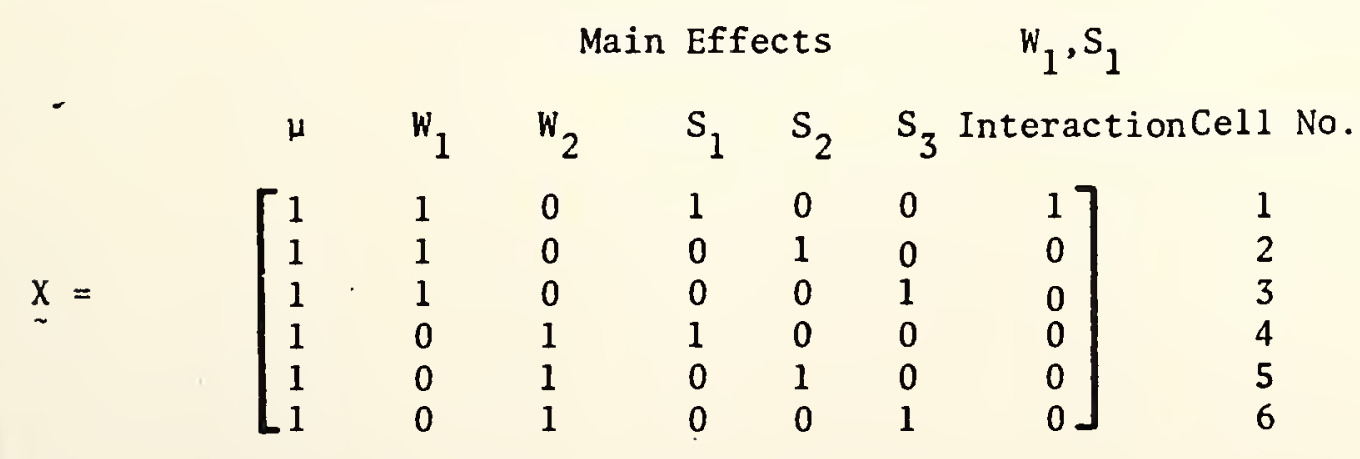

$\mu$ denotes a general mean effect 
The column rank of $x$ becomes 4 with the addition of the interaction effect.

Since it has been discussed why one can only estimate, say, $W_{1}$ relative to $w_{2}$ and $S_{1}$ and $s_{2}$ relative to $S_{3}$, in the modified or reparameterized problem, the 1,1 interaction corresponds to a $\left(W_{1}-W_{2}\right)$ by $\left(S_{1}-S_{3}\right)$ interaction.

All the discussion on the design matrix $\underset{\sim}{X}$ so far and subsequent developments regarding it can be easily adapted for the matrix A if the roles of rows and columns are interchanged:

(i) We speak of the rows of $\underset{\sim}{A}$ as representing the main effects of the categories of classification.

- (ii) Each column of A corresponds to a cell of the classification it defines.

(iii) The row rank of $A$ is the sum of the independent effects of the categories of classification that can be defined and the number of estimable interactions.

A hypothetical example is considered where the response classification categories are defined by the crossing of 2 classes of Retail Floor Area, $F_{1}$ and 3 categories of Airline Distance, $D$ where we have the following table:

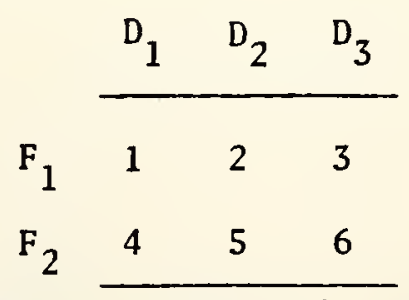

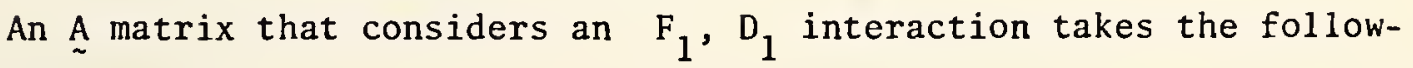
ing form: 


\begin{tabular}{|c|c|c|c|c|c|c|c|c|}
\hline $\mathrm{Cel}$ & No, & 1 & 2 & 3 & 4 & 5 & 6 & \\
\hline & $\mu$ & 1 & 1 & 1 & 1 & 1 & 1 & \\
\hline \multirow{5}{*}{$\begin{array}{l}\text { Main } \\
\text { Effects }\end{array}$} & $\mathrm{F}_{1}$ & 1 & 1 & 1 & 0 & 0 & 0 & \\
\hline & $\mathrm{F}_{2}$ & 0 & 0 & 0 & 1 & 1 & 1 & \\
\hline & $\mathrm{D}_{1}$ & 1 & 0 & 0 & 1 & 0 & 0 & $=\stackrel{A}{ }$ \\
\hline & $\mathrm{D}_{2}$ & 0 & 1 & 0 & 0 & 1 & 0 & \\
\hline & $\mathrm{D}_{3}$ & 0 & 0 & 1 & 0 & 0 & 1 & \\
\hline Interaction & $F_{1}, D_{1}$ & 1 & 0 & 0 & 0 & 0 & 0 & \\
\hline
\end{tabular}

$\mu$ denotes a general mean effect

In a reparameterized problem in which we estimate effects relative to the last category we shall estimate $\left(F_{1}-F_{2}\right),\left(D_{1}-D_{3}\right)$ and $\left(D_{2}-D_{3}\right)$ main effects and an $\left(F_{1}-F_{2}\right)$ by $\left(D_{1}-D_{3}\right)$ interaction. The row rank

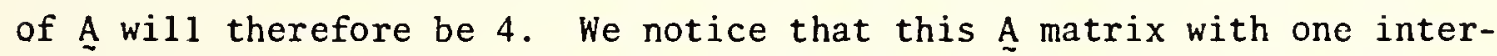
action is the transpose of the $\underset{\sim}{X}$ matrix with similar effects previously discussed.

Discussions in connection with equations (5.1) to (5.6) led to the reparameterized model that expresses the matrix of multivariate logits, ? as:

$$
\underline{Z}=\underset{n \tilde{x} r}{\stackrel{K}{r x}} \underset{\sim}{\Gamma} \underset{s \tilde{x m}}{T} \quad \text { as given in equation } 5.7
$$

The multivariate logits $z_{j h}$ form the elements of $z$. The probability that a member of market segment $j$ responds to category $h$ in the response classification is given by

$$
P_{j h}=\frac{e^{z_{j h}}}{e^{z_{j 1}}+e^{Z_{j 2}}+\ldots+e^{z m}} \quad \begin{array}{ll}
j=1, \ldots, n \\
h=1, \ldots, m
\end{array}
$$


$\mathbf{n}=$ number of cells in the classification defining $\underset{\sim}{X}$

$\mathrm{r}=$ column rank of $\underset{\sim}{\mathrm{X}}$ as previously defined

$\mathrm{m}=$ number of cells in the classification defining $\mathrm{A}$

$\mathrm{s}=$ row rank of $\underset{\sim}{\mathrm{A}}$ as previously defined

$\underline{K}=$ column of basis of $\underset{\sim}{X}$

$\mathrm{T}^{\prime}=$ row basis of $\stackrel{\mathrm{A}}{\mathrm{A}}$

$I=$ the rxs matrix whose elements are linear functions of the original model parameters

The linear functions defining the elements of $\underset{\sim}{\Gamma}$ in terms of the original parameters in $\beta$ (See equation 5.2) are not of immediate importance for the estimation process since we can consider the problem as that of estimating $\underset{\sim}{\Gamma}$. Once this has been accomplished, one can relate the elements of $\underset{\sim}{\Gamma}$ to those of $\underset{\beta}{\beta}$. A simple example of this procedure will be given later. In terms of the previous examples in defining $\underset{\mathrm{X}}{\mathrm{a}}$ and $\stackrel{\mathrm{A}}{ }$

$$
\mathrm{n}=6 \quad \mathrm{r}=4 \quad \mathrm{~m}=6 \quad \mathrm{~s}=4
$$

Since $\quad \underset{\sim}{X}=$ Transpose (A) we also have the relationship $\underline{\sim}=$ Transpose $(\underset{\sim}{T})$ for the examples discussed.

The basis construction for crossed designs will now be discussed in terms of $T$.

$h$ categories are supposed in a way of classification in a crossed design. In the crossed design corresponding to the above A matrix, $h=2$ for Retail Floor Area and $h=3$ for Airline Distance.

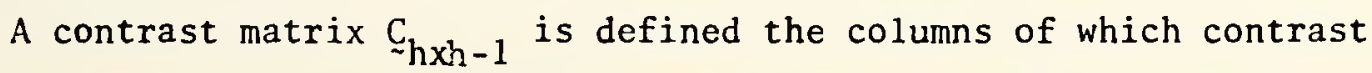
the main effect of the last class with each of the remaining classes: 


$$
\mathrm{C}_{h \times h-1}=\left[\begin{array}{cccc}
1-1 / h & -1 / h & \ldots & -1 / h \\
-1 / h & 1-1 / h & \ldots & -1 / h \\
\vdots & & & \vdots \\
-1 / h & -1 / h & \ldots & 1-1 / h \\
-1 / h & -1 / h & \ldots & -1 / h
\end{array}\right]
$$

The interpretation of $\subseteq$ is given below with the Airline Distance classifications $D_{1}, D_{2}, D_{3}$. With $h=3$ and the contrasts being relative to the last category, we have

$$
\stackrel{\mathrm{C}}{3 \times 2}_{3}=\left[\begin{array}{cc}
2 / 3 & -1 / 3 \\
-1 / 2 & 2 / 3 \\
-1 / 3 & -1 / 3
\end{array}\right]
$$

Defining a row vector $R=\left[D_{1} D_{2} D_{3}\right]$ whose elements are airline distance classification effects,

$$
\underset{\sim}{\mathrm{R}}=\left[\mathrm{D}_{1}-\frac{\left(\mathrm{D}_{1}+\mathrm{D}_{2}+\mathrm{D}_{3}\right)}{3}, \mathrm{D}_{2}-\frac{\left(\mathrm{D}_{1}+\mathrm{D}_{2}+\mathrm{D}_{3}\right)}{3}\right]
$$

The first element of $\underset{\sim}{\mathrm{R}} \underset{\sim}{\mathrm{c}}$ can also be expressed as:

$$
\left(D_{1}-D_{3}\right)-\frac{1}{3}\left[\left(D_{1}-D_{3}\right)+\left(D_{2}-D_{3}\right)+\left(D_{3}-D_{3}\right)\right]
$$

which is a contrast of the effect $D_{1}$ relative to $D_{3}$ and the average of all the category effects relative to $D_{3}$. Similar remarks can be made about the second element of $\underset{\sim}{\mathrm{RC}}$.

For the hypothetical example in connection with the $\underset{\sim}{\text { A matrix }}$ definition, a $\underset{\sim}{C}$ matrix for Retail Floor Area Classification is

$$
C_{2 \times 1}=\left[\begin{array}{c}
1 / 2 \\
-1 / 2
\end{array}\right]
$$


A detailed discussion of basis construction has been given by Bock [105]. The simplified discussion in this section is adequate for the work in this study.

The basis $\mathrm{T}$ for a crossed design is obtained from the Kronecker product of columns of matrices of the form []$\left._{h}, C\right]$ where

$$
1_{h}=\left[\begin{array}{c}
1 \\
1 \\
\vdots \\
1
\end{array}\right] \quad Q_{h x h}=\left[1_{h}, C\right] \text { is defined. }
$$

The Kronecker product of matrices $U_{\operatorname{mxn}}$ and $V_{p x_{q}}$ is defined as

$$
\underline{U} \otimes \underline{V}=\left[\begin{array}{cccc}
u_{11} V & u_{12} V & \ldots & u_{1 n} V \\
u_{21} V & u_{22} V & \ldots & u_{2 n} V \\
\vdots & & & \\
u_{m 1} V & u_{m 2} V & \ldots & u_{m n} V
\end{array}\right]
$$

For the $2 \times 5$ classification with Retail Floor Area and Airline Distance presented above, the basis $T$ is formed as the kronecker products of appropriate columns of the following matrices

$$
S_{1}=\left[\begin{array}{cc}
0 & 1 \\
1 & -1 / 2
\end{array}\right] \text { and } \quad Q_{2}=\left[\begin{array}{ccc}
0 & 1 & 2 \\
1 & 2 / 3 & -1 / 3 \\
1 & -1 / 3 & 2 / 3 \\
1 & -1 / 3 & -1 / 3
\end{array}\right]
$$

where $Q_{1}$ and $\underline{Q}_{2}$ correspond to Retail Floor Area and Airline Distance classifications, respectively. he denote $i, j$ as the kronecker product of Column $i(i=0,1)$ of $\underline{Q}_{1}$ and Colum $j(j=0,1,2)$ of $Q_{2}$. 
Examples of what effects such Kronecker products correspond to when the basis $T$ is formed are:

Kronecker Product

Indices

$$
\begin{array}{lll}
1,0 & - & F_{1}-F_{2} \text { Main effect } \\
0,1 & - & D_{1}-D_{3} \text { Main effect } \\
0,2 & - & D_{2}-D_{3} \text { Main effect } \\
1,1 & -\left(F_{1}-F_{2}\right) \times\left(D_{1}-D_{3}\right) \text { Interaction }
\end{array}
$$

The $4 \times 6$ basis $I$ corresponding to the above effects, of row rank=4, whereby the Kronecker products form rows of $\mathrm{T}$, is:

$$
I_{4 \times 6}=\left[\begin{array}{rrrrrr}
1 / 2 & 1 / 2 & 1 / 2 & -1 / 2 & -1 / 2 & -1 / 2 \\
2 / 3 & -1 / 3 & -1 / 3 & 2 / 3 & -1 / 3 & -1 / 3 \\
-1 / 3 & 2 / 3 & -1 / 3 & -1 / 3 & 2 / 3 & -1 / 3 \\
1 / 3 & -1 / 6 & -1 / 6 & -1 / 3 & 1 / 6 & 1 / 6
\end{array}\right]
$$

In all the applications of the multinomial response relation technique in this research, different market segments are analyzed separately instead of constructing a basis $K$ whose column rank is equal to the number of market segments. The problems considered thereby are those of contingency tables formed by classifications defined for the response eategories. Another reason for the separate analysis is the ehance allowed for certain multivariate tests to be performed on the parameter vectors estimated and their associated covariance matrices.

The computer program written for estimating multinomial response relation model parameters has provision for constructing bases $\underset{\sim}{\mathrm{K}}$ and $\underset{\sim}{\mathrm{T}}$ 
for up to 4 ways of classification for crossed designs. The estimation procedure provides parameters which constitute the elements of $\underset{\sim}{\Gamma}$ in equation 5.7 through an iterative procedure discussed between equations 5.13 and 5.15 . The initial elements of $\underset{\sim}{\Gamma}$ are assumed to be all zero and convergence of estimates is usually achieved within six iterations. A detailed discussion of the parameter estimation procedure is given in Appendix $\underset{\sim}{\mathrm{A}}$ with an example problem.

\section{Multinomial Response Relation Model and Destination Choice Modelling}

For destination choice modelling for shopping travel, for example, the $\underset{\sim}{X}$ matrix in equation 5.2 can be defined from a cross classification scheme that defines market segments according to factors that affect the choice of functional shopping destinations as discussed in the previous section. The functional classification of shopping areas can be on the basis of a measure of attraction, parking availability and the relative location of the shopping area. Figure 5.1 illustrates boxes $P$ and $Q$ respectively that illustrate classifications that define matrices $\underset{\sim}{\mathrm{X}}$ and $\underset{\sim}{\mathrm{A}}$ in equation 5.2 .

In the general case $\underset{\sim}{X}$ will have as many rows as there are nonempty cells in box $P$ and as many columns of the main effects and interactions that account for the classification in box P. For each cell of $P$ that defines a row $j$ of $\underset{\sim}{X}$ the column element is 1 or 0 depending on whether it impinges on the cell or not. Further examples of the construction of design matrices like $\underset{\sim}{x}$ can be found in texts on linear models, [92, 96]. The construction of matrix A can be discussed in terms of box $Q$ as has been done for matrix $\underset{\sim}{X}$. One can consider cell 


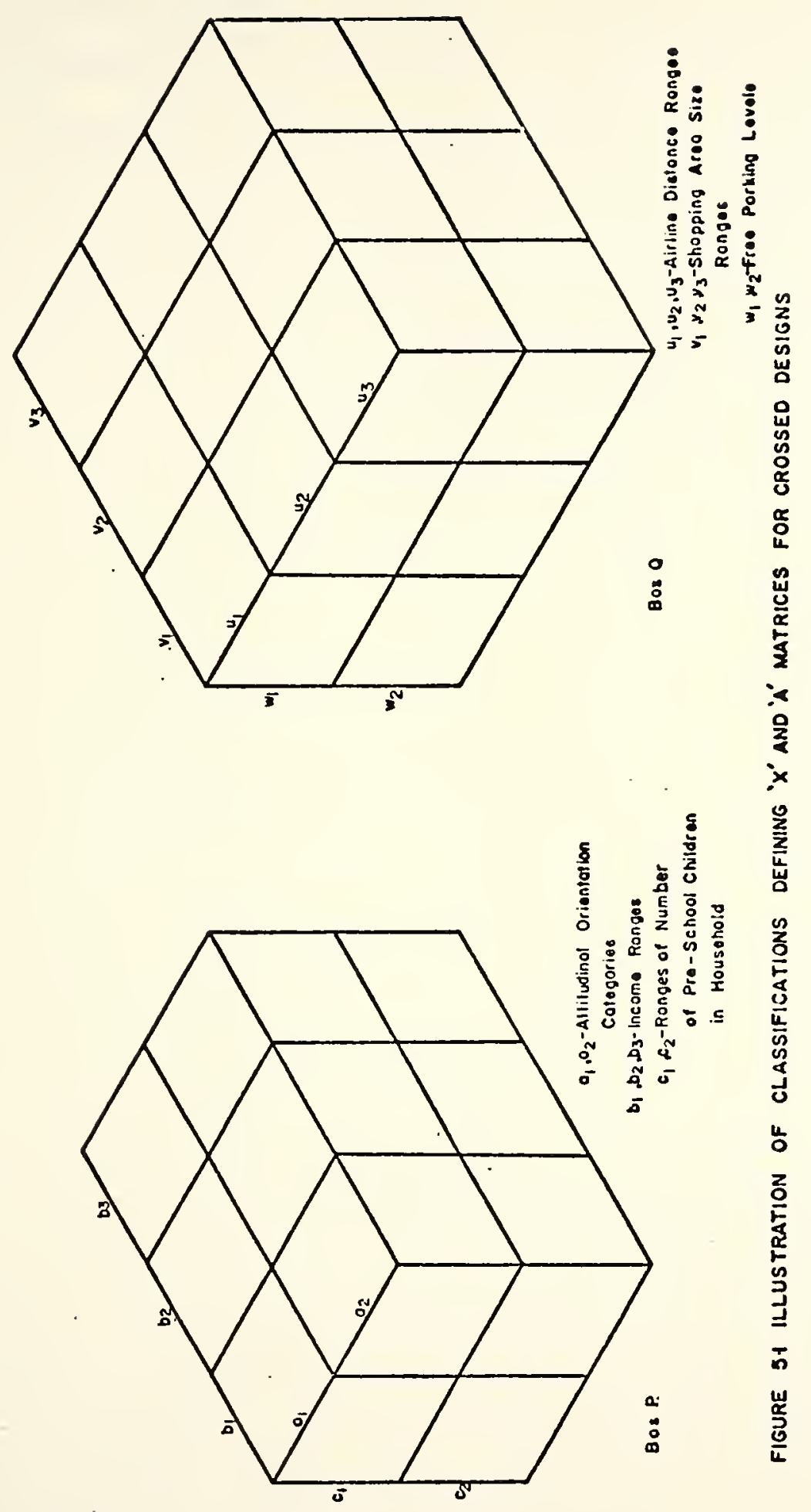


$j$ of box $P$ as market segment $j$ and cell $h$ of box $Q$ as the functional shopping destination $h . M_{j}$ in equation 5.1 is the number of individuals or households that belong to market segment $j$. The term $r_{j h}$ is the number of the members of market segment $j$ that choose functional shopping destination $h$. The term $P_{j h}$ is the probability with which a member of market segment $j$ chooses a functional destination $h$. Once matrices $\underset{\sim}{X}$ and $\underset{\sim}{A}$ and $r_{j h}$ and $N_{j}$ have been defined, the rest of the development in the previous section is independent of the context in which the multinomial response model is being applied.

The major requirements for applying the approach discussed in this section are the specification of the geographical distribution of characteristics on which the travel market segmentation is based, the geographical distribution of destination opportunities and factors with which they can be classified and a suitably designed sampling scheme for data collection. It is then possible to estimate $\hat{r}_{j h}$, the number of people in market segment $j$ that select functional travel category $h$. The number of people in the whole population belonging to market segment $j$ who choose travel category $h$ is estimated by $\hat{R}_{j h}=f_{j} \hat{r}_{j h}$ where $f_{j}$ is an appropriate sampling ratio for market segment $j$. A simulation technique can then be employed to assign say, specific destinations. One criterion is to choose the closest physical destination that falls within a chosen functional destination from the point of view of the location of a housenolds or cluster of households. The frequency distribution of individual characteristics that will be used in the simulation will be obtained from the observed distribution of those characteristics for the $\mathrm{N}_{\mathrm{j}}$ individuals in the sample belonging to market segment $\mathbf{j}$. 
To design a sampling scheme census records can be used to determine the geographical distribution of socio-economic and population attributes that contribute to the market segmentation process. The city block geographical coordinate system being developed for some metropolitan areas will provide the needed geographical framework [97]. A similar treatment will be given to the geographical distribution of shopping areas. A random mail or telephone survey or a small-sample home interview can be taken, say, of auto travellers after randomiy selecting cells [representing subzones or a finer division] in the scheme in Fig. 5.1. For shopping travel, a suitable diary [61] can be solicited or a straightforward interview can be conducted. The important requirement is that one be able to collect sufficient information to adequately cover all market segments. It is possible to make the sampling efficient with a prior identification of market segments from census data. The trade-off between taking a reasonably large sample that covers a majority of the market segments and using an excessive sample to cover all the market segments can be better appreciated this way. Under the assumption that the pattern of travel of market segments does not change drastically with respect to a given trip purpose, such a survey can be conducted at 15 to 20 year interva?s.

The above has discussed how aggregate predictions of functional travel behaviour can be accomplished, supplemented with simulation to assign people to spocific shopping areas that are impinged upon by primary urban travel. In situations like subarea studies, the opening up of new activity centers or new residential areas, etc., a transportation planner would like to predict the travel patterns of 
individuals in an isolated context. A logistic discrimination approach, later discussed in this chapter, can be used to classify individuals into classes of functional travel behaviour. The random sample discussed earlier in this section can be used to develop such a discrimination model for each market segment or for the whole population in which case the market segmentation factors will contribute to the discrimination function. To accomodate the possibility of the failure of such a discrimination model to adequately represent relatively uncommon categories of travel behavior, a separate sampling logistic discrimination procedure will be outlined. In small urban areas where the underrepresentation of some travel behavioural categories is less likely, the discrimination model can be developed directly to estimate $\mathbf{r}_{j h}$ frequencies that can be expanded to obtain aggregate predictions $R_{j h}$.

The multinomial response model provides estimates of the proportion of market segment $j$ that falls into functional travel category $h_{:-} \Pi_{j h}$; or the proportion of the total population that falls into functional travel category $h:-\quad \Pi_{h}$. It also allows the testing of interaction effects that may affect the development of the discrimination model if only main effects are considered. The logistic discrimination approach can be particularly useful in a small urban area where the simulation previously discussed could deal with predicting the probability of individuals being associated with functional travel alternatives.

It must be noted that in the context of clearly identified nonspatial choices the problem discussed in this section is considerably simplified since the alternatives are specific and aggregate predictions 
can be made more directly. The incorporation of attitudinal orientation in the market segmentation can be operational if it is possible to relate attitudes to some socio-economic or population characteristics. Not much success has been realized in this respect. The utility of attitudinal data, meanwhile, will be in short term studies.

It is possible to extend the travel functional classification in Fig. 5.1 for a given purpose to travel frequency, time of day and route functional type as further ways of classification. Level of service attributes developed from prevailing traffic conditions will go into the definition of route functional types. Though such an extensive functional classification is theoretically feasible the number of travel behavior categories can easily get unwieldy. It is then necessary to conduct tests of independence in the resulting contingency table so that the block (See Fig. 5.1) of classification can be partitioned into manageable subregions for separate conditional analyses. The associated extensive data requirements for such an exercise should not be a deterrent since it would in the long run throw more light into the analysis of travel behavior.

The objection may be raised against the use of categorical variables in this section and the implied reduction of "continuous" variables like airline distance and travel time. The present level of data availability in many aspects of travel behaviour and scale of measurement is such that one cannot help conceding that most of the variables on hand are qualitative. There is evidence in perceived data on travel distance and travel time that these variables are usually reported in pulses in a frequency distribution chart [see Fig. 5.2, for 


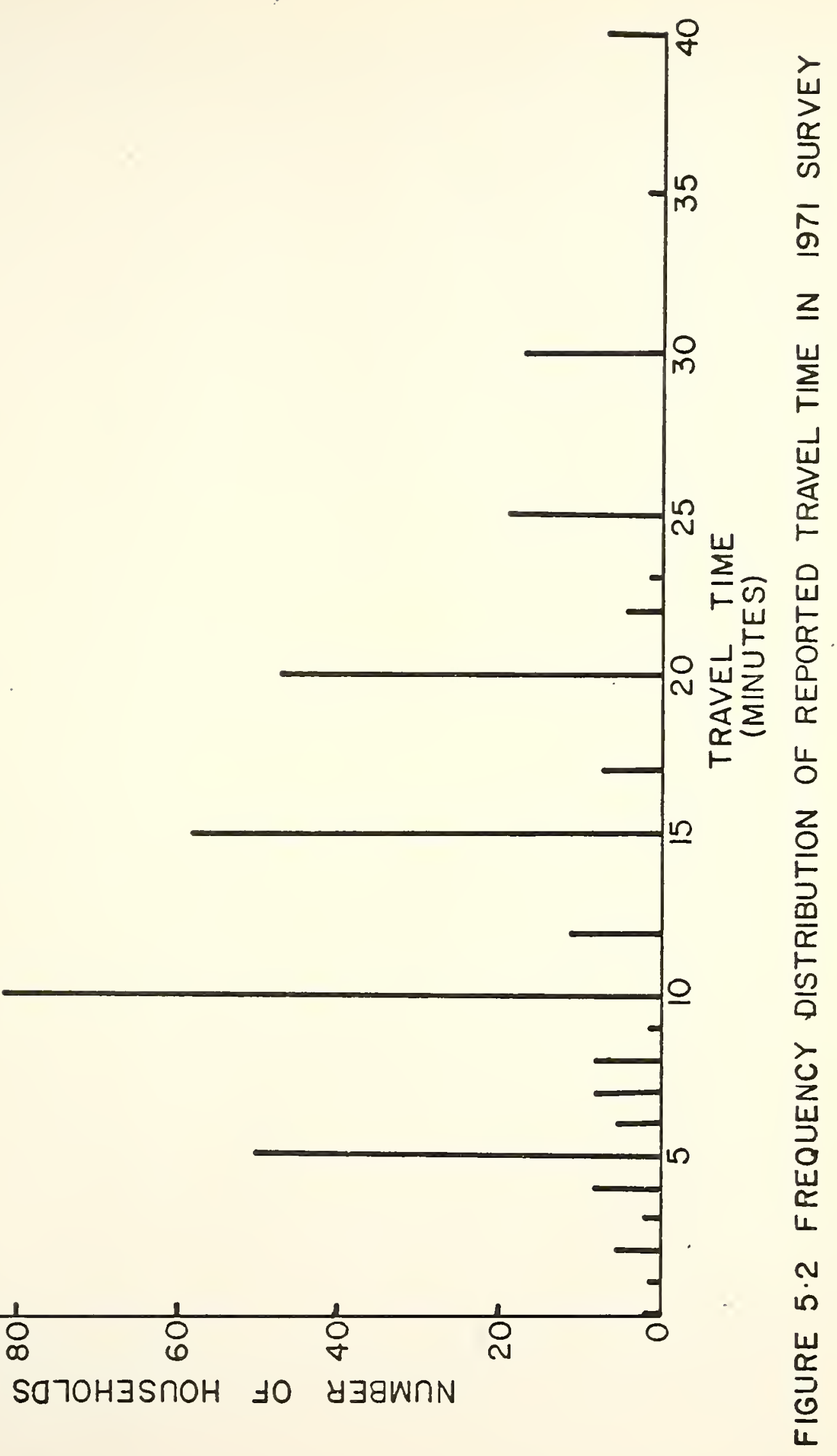


example]. The logistic discrimination approach is capable of mixing continuous and categorical variables, however, using a similar transformation of continuous distributions into discrete ones. The discussion in this section can be summarized in the form of Fig. 5.3 where the use of separate analytical tools on attitudes, level of service on routes, functional destination classification and market segmentation can be brought into a single perspective for the purpose of predicting aggregate travel behavioral demand. There is provision for iteration within a simulation context. The advantage in such usage of the multinomial response approach is that it does not attempt to develop a single model with all the detailed factors and variables that go into the functional classification of spatial choices, market segmentations and attitudinal categorization.

\section{Logistic Discrimination}

Many problems often crop up where there is interest in discriminating between two or more populations using discrete, categorical and/or continuous variables. In urban travel behavior analysis, we may want to discriminate between auto users and transit users or discriminate among different populations that are associated with different functional travel alternatives. The greater amount of previous statistical work in discrimination has been with multivariate normal distributions or with techniques based on Fisher's linear discriminant function [89] which are optimal only for normal distributions.

Some earlier attempts at discrimination with qualitative variables $[98,99,100]$ have been restricted in the number of variables permitted. 


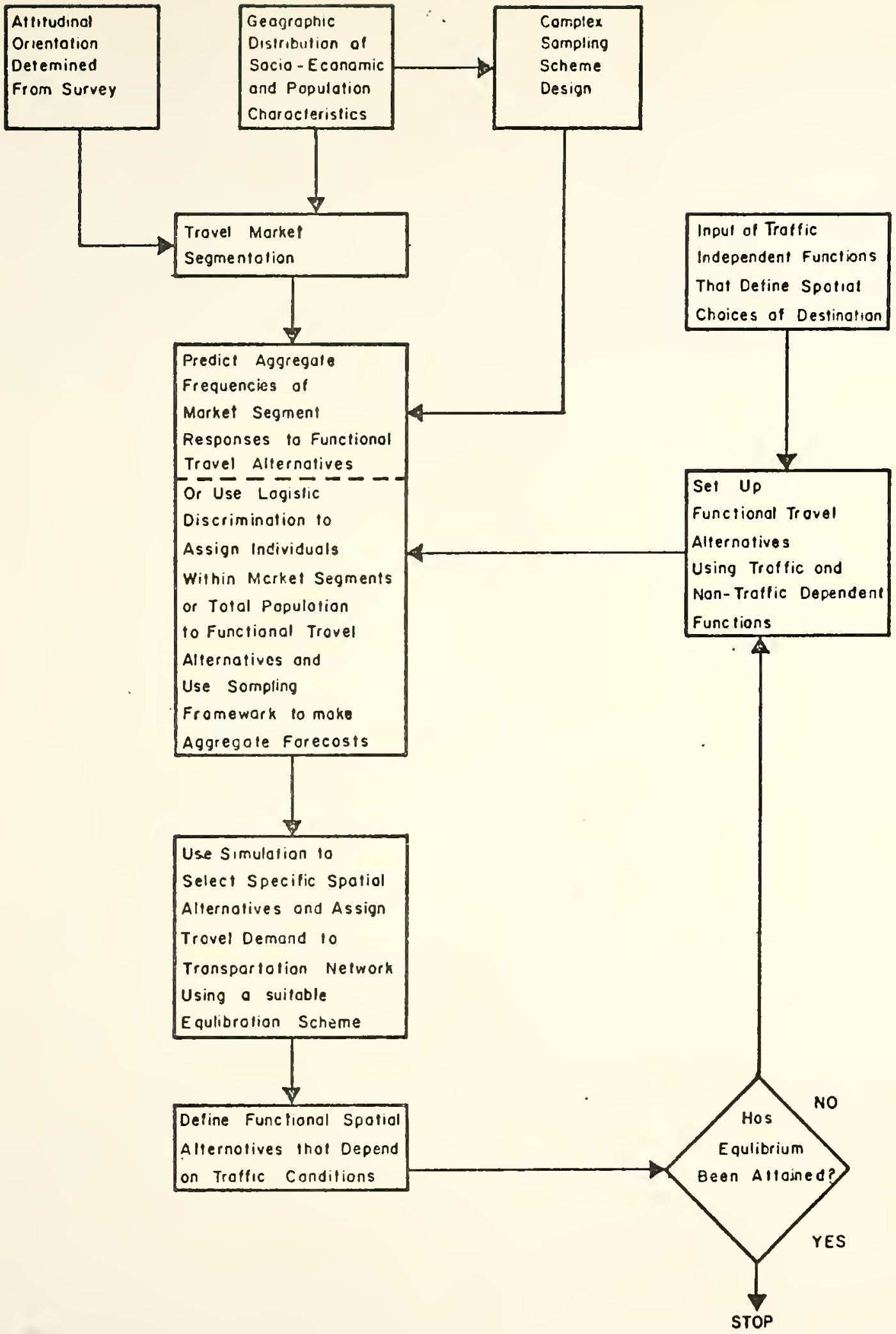

FIGURE 5.3 PERSPECTIVE OF AGGREGATE TRAVEL DEMAND

PREDICTION CONSIDERING A EHOAD RANGE OF FACTORS 
A recent method by Martin and Bradley [101] is only restricted to discrete variables. A very useful approach is that of logistic discrimination introduced by Cox [102] and Day and Kerridge [103] and further developed by Anderson [90]. Quoting Anderson [91], "With this technique, continuous and discrete variables, jointly or separately, can be handled with equal facility. There is no restriction on the number of variables that can be used other than those imposed by sample size and computer time. To date, 20 variables have been used and there is no doubt that larger problems could be handled--they have just not arisen."

The problem of interest is to discriminate among $\mathrm{k}$ populations $\mathrm{H}_{1}$, $\mathrm{H}_{2}, \ldots, \mathrm{H}_{\mathrm{k}}$ based on the vector of observations ${\underset{\sim}{x}}^{\prime}=\left(x_{0}, x_{1}, \ldots, x_{p}\right)$ where the prime indicates a transpose. $x_{0} \equiv 1$ to account for a constant term. The components of $\underset{\sim}{x}$ are real discrete or continuous variables. Sample points or observations are available from each population $s(s=1,2, \ldots, k)$ and the discrimination problem is to develop a means of allocating further sample points $\underset{\sim}{x}$ to populations. If the likelihood of $\underset{\sim}{x}$, given $H_{S}$ is $f_{S}(\underset{\sim}{x})$ and the further sample points to be allocated are from a mixture of distributions $\underset{k}{\operatorname{mon}} \mathrm{H}_{1}, \mathrm{H}_{2}, \ldots, \mathrm{H}_{k}$ in the proportions $\underset{\sim}{\prod^{\prime}}=\left(\Pi_{1}, \Pi_{2}, \ldots, \Pi_{k}\right)$, where $\sum_{s=1} \Pi_{s}=1$, a simple way of optimizing the method of discrimination is to maximize the probability of correct allocation or classification.

The sample point $\underset{\sim}{x}$ is therefore allocated to $H_{s}$ if $\pi_{s} f_{s}(x) \geq$ $\Pi_{t} f_{t}(x)(t=1, \ldots, k ; t \neq s)$

or

$$
P_{r}\left(H_{S} \mid \underset{\sim}{x}\right) \geq P_{t}\left(H_{t} \mid \underset{\sim}{x}\right) \quad(t=1, \ldots, k ; t \neq s)
$$

where $\mathrm{P}_{\mathrm{r}}(\mathrm{a}) \equiv$ probability of ' $\mathrm{a}$ '. 
A discussion of the above allocation criteria can be found in Rao [89]. It is noted here that the multinomial logit model for travel choices with a common set of alternatives has the same allocation rule. In this case the pooling of variance-covariance estimates discussed in Chapter 3 comes from the different common alternatives.

Cox [102] and Day and Kerridge [103] proposed the logistic form for posterior probabilities as a basis for discrimination between two populations :

$$
\mathrm{P}_{\mathrm{r}}\left(\mathrm{H}_{1} \mid \underset{\sim}{\mathrm{x}}\right)=\mathrm{e}^{\underline{x^{\prime}} \underline{\alpha}} \cdot \mathrm{P}_{\mathrm{r}}\left(\mathrm{H}_{2} \mid \underset{\sim}{\mathrm{x}}\right)
$$

where $\underline{\alpha}^{\prime}=\left(\alpha_{0}, \alpha_{1}, \ldots, \alpha_{p}\right)$ is the transpose of a column of coefficients and

$$
\operatorname{Pr}\left(\mathrm{H}_{2} \mid \underline{x}\right)=1 /\left(1+\mathrm{e}^{\underline{x}} \stackrel{\alpha}{\alpha}^{\prime}\right)
$$

$\underset{\sim}{\alpha}$ is estimated directly compared with the standard discrimination approach with multivariate normal distributions which essentially estimates $\underset{\sim}{\alpha}$ as a function of the distribution means and covariances.

An extension of equations 5.18 and 5.19 to $k$ populations [90] is given by

$$
\begin{aligned}
& \operatorname{Pr}\left(\mathrm{H}_{\mathrm{s}} \mid \underset{\sim}{\mathrm{x}}\right)=\mathrm{e}^{\underset{\sim}{\mathrm{x}} \stackrel{\alpha}{\alpha} \mathrm{s}} \cdot \operatorname{Pr}\left(\mathrm{H}_{\mathrm{k}} \mid \underset{\sim}{\mathrm{x}}\right) \quad(\mathrm{s}=1, \ldots, \mathrm{k}-1) \quad 5.20 \\
& \operatorname{Pr}\left(\mathrm{H}_{\mathrm{k}} \mid \underset{\sim}{x}\right)=1 /\left\{1+\sum_{\mathrm{s}=1}^{\mathrm{k}-1} \mathrm{e}^{\tilde{x}^{\prime} \alpha} \mathrm{s}\right\}
\end{aligned}
$$

where $\underset{\alpha_{s}}{\alpha}=\left(\alpha_{s_{0}}, \alpha_{r_{1}}, \ldots, \alpha_{s_{p}}\right)$.

This represents an extension of an asymmetrical binary logistic distribution, compared to Bock's [86] extension of a symmetrical form as 
a result of which the estimation of a mean term in the symmetrical case is sacrificed. Bock's multinomial response model and the multinomial logit model used in many urban travel behavior analyses involve the extension of the symmetrical binary logistic model. Only the parameters, $\underset{\sim}{q}$ required for discrimination are estimated, the method being the same for all $\mathrm{f}_{\mathrm{s}}(\underset{\sim}{\mathrm{x}})$ satisfying equations $(5.20)$ and $(5.21)$. Classical approaches, however, derive the allocation rule from estimates of all the parameters postulated in each distribution with the result that many more parameters have to be estimated and different methods are necessary for different assumed families of distributions $\left\{f_{S}(x)\right\}$. The important advantages of the Cox-Day-Kerridge approach are realized in the fact that equations $(5.20$ and (5.21) are satisfied by many of the families of distributions commonly postulated in discrimination. Examples are:

(i) multivariate nornal with equal dispersion matrices

(ii) multivariate independent dichotomous $(0,1)$ variables

(iii) multivariate dichotomous variates following the log linear model [104] with second and higher order effects the same in each population.

(iv) a combination of (i) and (iii).

Equations (5.20) and $(5.21)$ hold exactly or approximately in many other cases and will hold over a wider class of distributions if second order terms are included. The inclusion of second order terms compounds the number of parameters to be estimated, however. 


\section{Estimation when Sampling From a Mixture of Distributions}

The Cox-Day-Keridge formulation assumed that sample points $\underset{\sim}{x}$ were available from the mixture of two populations in unknown proportions. Generalizing this to $k$ populations it is supposed that $\mathrm{n}_{\mathrm{k}} \mathrm{sx}$ sample points are observed from $H_{s}$ at the point $\underset{\sim}{x}$. Defining $\sum_{s=1} n_{s \underset{\sim}{x}}=n_{\underset{x}{x}}, n_{\underset{\sim}{x}}$ of a sample size $n$ are observed at $\underset{\sim}{x}$. Usually most of the $\pi_{s \underset{\sim}{x}}$ will be zero and the rest unity. If $\underset{\underset{\sim}{x}}{n_{s \underset{\sim}{x}}}=n_{s}$, then the $\left\{n_{s}\right\}$ are random variables.

Defining $\phi_{\underset{\sim}{x}}$ as the $\tilde{l}_{i k e l i h o o d}$ of the mixture distribution at $\underset{x}{x}$

$$
\phi_{\underset{\sim}{x}}=\sum_{s=1}^{k} \pi_{s} f_{s}(\underset{\sim}{x}) \text { where the }\left\{\pi_{s}\right\} \text { are the unknown mixing }
$$

proportions.

The log-likelihood of the sample can be written as

$$
\log L=\text { Constant }+\sum_{\underset{\sim}{x}} \sum_{s} n_{s \underset{\sim}{x}} \log \left(P_{s_{x}^{x}} \phi_{\sim}^{x}\right)
$$

where $P_{S \underset{\sim}{x}}$ is the probability of sample point $\underset{\sim}{x}$ being allocated to population $s$.

It can be shown [90] that the maximum likelihood equations for $\left\{\alpha_{s}\right\}$ are

$$
\begin{array}{r}
\frac{\partial \log L}{\partial \alpha_{s j}}=\sum_{\underset{\sim}{x}}\left(n_{s \underset{\sim}{x}}-n_{\sim} \underset{\sim}{p_{\sim}}\right)_{j}=0 \quad(s=1, \ldots, k-1) \\
(j=0,1, \ldots, p)
\end{array}
$$

The solution of (5.22) is discussed later.

Estimation Under Separate Sampling of Populations.

In many situations samples are taken from each population separately, in which case the $\left\{n_{s}\right\}$ are fixed. The mixture of distributions from which the sample points to be allocated are drawn must be defined. The 
mixing proportions, ${\underset{\sim}{\prime}}^{\prime}=\left(\Pi_{1}, \Pi_{2}, \ldots, \Pi_{k}\right)$ corresponding to populations $\mathrm{H}_{1}, \mathrm{H}_{2}, \ldots, \mathrm{H}_{\mathrm{k}}$ are specified where $\sum_{\mathrm{s}=1} \Pi_{\mathrm{s}}=1$. Where possible, these mixing proportions are given or estimated from other data. The estimation of these proportions from a multinomial response relation analysis has been previously discussed. Where the mixing proportions cannot be estimated, likelihood ratios can be used as later discussed.

The joint likelihood of the samples from populations $\mathrm{H}_{1}, \mathrm{H}_{2}, \ldots, \mathrm{H}_{k}$ is given by

$$
\log L=\text { constant }+\sum_{s=1}^{k} \sum_{\underset{\sim}{x}} n_{s x}\left\{\log L\left(\underline{\sim}_{\underline{x}}^{x} \mid \mathrm{H}_{s}\right)\right\}
$$

Temporarily supposing $x_{j}$ is dichotomous with values 0 or $1(j=1, \ldots, p)$ then

$$
L\left(\underset{\sim}{x} \mid H_{S}\right)=\operatorname{pr}\left(\underset{\sim}{x} \mid H_{S}\right)=\operatorname{Pr}\left(H_{S} \mid \underset{\sim}{x}\right) \operatorname{Pr}(\underset{\sim}{x}) / \operatorname{Pr}\left(H_{S}\right)
$$

Letting $\phi_{\underline{X}}=\operatorname{Pr}(\underset{\sim}{x})$

$$
L\left(\underset{\sim}{x} \mid H_{s}\right)=P_{s \underset{\sim}{x}} \phi_{x} / \Pi_{s}
$$

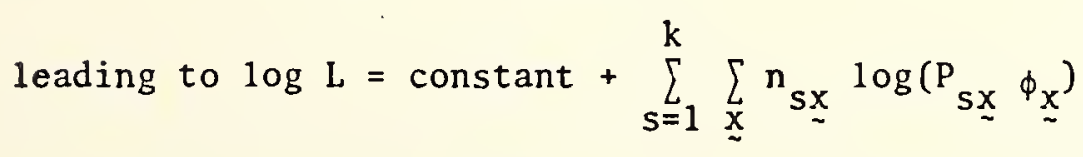

where the constant includes terms independent of the $\left\{\alpha_{s}\right\}$ and the $\left\{\phi_{\underline{x}}\right\}$

The likelihood in equation (5.24) is identical to the one given by the Cox-Day-Keridge formulation. However, the unknown parameters here are related to the following functionally independent conditions.

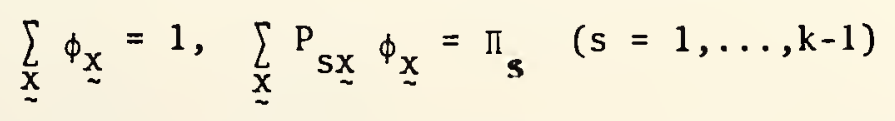

The estimation problems in the two cases are therefore not the same. 
With the method of constrained maximum likelihood estimation of Aitchison and Silvey [73] the parameters in equation (5.25) can be estimated subject to the constraints in equation (5.26). The algebra in this procedure is very heavy while the asymptotic dispersion matrix is unwieldy. A less direct approach used by Anderson [90] greatly simplifies the problem.

We note that the proportions $\underset{\sim}{\pi}$ can be fixed at arbitrary levels subject to the usual conditions on probabilities. Considering a set of proportions, $\underset{\sim}{\Pi}$, to which all the preceeding equations in this section apply, and a second set of proportions, $\prod_{\sim}^{\prime}$, for which

$$
\operatorname{Pr}^{\prime}\left(H_{s} \mid \underset{\sim}{x}\right)=P_{S \underset{\sim}{x}}^{\prime}=e^{\underbrace{T}_{\underline{T}} \underline{\alpha}^{\prime}} \cdot \operatorname{Pr}^{\prime}\left(H_{k} \mid x\right) \quad(s=1, \ldots, k-1) \quad 5.27
$$

where $\underset{\sim}{\mathrm{T}}=\underset{\sim}{x}$-transpose

$$
\operatorname{Pr}\left(H_{k} \mid \underset{\sim}{x}\right)=P_{k x}^{\prime}=1 /\left\{1+\sum_{s=1}^{k-1} e^{x^{\mathrm{T}} \underline{\alpha}^{\prime}} s\right\}
$$

and

$$
\operatorname{Pr}^{\prime}(\underset{\sim}{x})=\phi_{\underline{\sim}}^{\prime} \text { for all } \underset{\sim}{x}
$$

Since the samples from $L\left(\underset{\sim}{x} \mid H_{S}\right)$ do not depend on the choice of $\underset{\sim}{\pi}$

$$
L\left(\underset{\sim}{x} \mid H_{s}\right)=P_{s \underset{\sim}{x}} \phi_{\underset{x}{x} / \Pi_{s}}=P_{s \underset{\sim}{x}}^{\prime} \phi^{\prime} \underline{\sim}^{/ \pi_{s}^{\prime}} \quad(s=1, \ldots, k)
$$

Dividing the sth equation of 5.29 by the kth

$$
\begin{aligned}
& P_{S \underline{\sim}}^{\prime}=e^{\left(\beta_{S}+\underline{x}^{T}{\underset{\alpha}{\alpha}}_{S}\right)} P_{k}^{\prime} \underset{\sim}{(x)} \\
& \mathrm{P}_{\mathrm{kx}}=1 /\left\{1+\sum_{s=1}^{\mathrm{k}-1} \mathrm{e}^{\left(\beta_{\mathrm{s}}+\dot{x}_{\sim}^{\mathrm{T}} \underset{\sim}{\alpha}\right)}\right\}
\end{aligned}
$$


where

$$
\beta_{s}=\log \left\{\Pi_{k} \Pi \cdot s /{ }^{\prime}{ }_{k} \Pi_{s}\right\}
$$

It is noticed that

$$
\begin{aligned}
& \alpha_{s 0}^{\prime}=\alpha_{s o}+\beta_{s} \\
& \alpha_{s j}^{\prime}=\alpha_{s j} \\
& (s=1, \ldots, k-1) \quad(j=1, \ldots, p)
\end{aligned}
$$

The above implies that only the $\left\{\alpha_{\text {so }}\right\}$ are changed when $\underset{\sim}{\Pi}$ is varied, all other coefficients $\left\{\alpha_{s j}, j \neq 0\right\}$ being the same. The maximum likelihood estimates of the $\{\underset{\sim}{\alpha} s\}$ for one $\underset{\sim}{\pi}$ can be derived, therefore, from those of another, say, ${\underset{\sim}{\prime}}^{\prime}$. The choice of $\underset{\sim}{\mathbb{I}}={\underset{\sim}{*}}^{*}=\mathrm{n}_{\mathrm{s}} / \mathrm{n}$ considerably simplifies the constrained maximization problem [90]. For this reason the most appropriate procedure is to carry out the estimation with ${\underset{\sim}{*}}^{*}$ and then adjust the $\left\{\alpha_{\text {so }}\right\}$ for the defined $\mathbb{I}$.

Anderson [90] has shown that the estimates of the $\{\underset{\sim}{\alpha}\}$ with $\underset{\sim}{\mathbb{I}}={\underset{\sim}{*}}^{*}$ given by maximizing the likelihood in equation (5.25) subject to the constraints in equation $(5.26)$ is given by:

$$
\sum_{\underline{x}}\left(n_{s \underset{\sim}{x}}-n_{\underset{\sim}{x}}{ }^{p}{\underset{\sim}{x}}^{x}\right) x_{j}=0 \quad(s=1, \ldots, k-1 ; j=0,1, \ldots, p)
$$

This result is obtained after a considerable amount of algebraic reduction using Lagrange multipliers.

It is noted that equations (5.22) and (5.33) are identical. The same procedure can therefore be used to estimate the $\left\{\alpha_{s}\right\}$ in both situations--mixture and separate sampling discrimination. Anderson [90] has used Aitchison and Silvey's [73] result on asymptotic dispersion 
matrices with constrained maximum likelihood to show that the asymptotic dispersion matrices of the estimates of $\left\{\alpha_{s}\right\}$ for separate and mixture sampling differ only in the variance and covariances associated with the $\left\{\alpha_{\text {so }}\right\}$.

Though the above discussion has considered only dichotomous variables, Anderson [90] has shown that the methods can be extended to continuous and polychotomous variables. This is outlined below:

If the observations are continuous the log likelihood in equation (5.25) is unchanged but the constraints in equation $(5.26)$ become:

$$
\int \phi_{\underline{x}}{ }_{x}^{d}=1, \quad \int P_{s \underset{x}{x}} \phi_{\underset{x}{x}} \underset{\sim}{d x}=\pi_{s} \quad(s=1, \ldots, k-1) \quad 5.34
$$

The maximization of $\log \mathrm{L}$ in equation (5.25) subject to constraints in equation (5.34) requires assumptions about the functional form of $\phi_{\underset{\sim}{x}}$. This can entail extra parameters $\underset{\sim}{\theta}$ for $\phi_{\underset{\sim}{x}}$ and the resulting maximum likelihood equations will not reduce to two sets for $A=\left[\alpha_{1}, \ldots, \alpha_{k-1}\right]$ and $\underset{\sim}{\theta}$ separately. Such a problem is similar to the classical approaches with all their shortcomings. However, it is possible to get around such a problem by making the continuous distribution discrete and estimate $\phi_{\underset{x}{x}} \Delta_{\underline{x}}$ in which case the solution of equations (5.33) can be used.

$$
\text { If we put } \underset{\sim}{\underset{X}{X}}=\phi_{\underset{\sim}{x}} \Delta_{\underline{X}} \text { (for a } 11 \underset{\sim}{x} \text { ) }
$$

then the conditions in equation (5.34) become, approximately

or

$$
\sum_{\sim} \phi_{\underset{\sim}{x}} \Delta_{\underset{x}{x}}=1, \quad \sum_{\sim}^{x} \phi_{\underset{\sim}{x}} \mathrm{P}_{s \underset{\sim}{x}} \Delta_{\underset{\sim}{x}}=\pi_{s}
$$




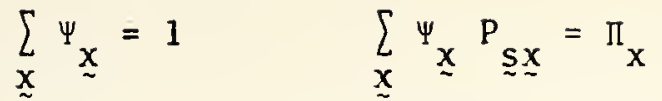

$$
\begin{aligned}
& \text {. }(s=1, \ldots, k-1)
\end{aligned}
$$

The likelihood then becomes

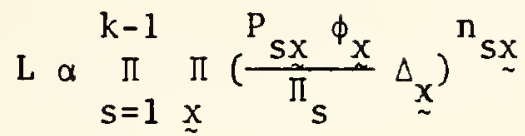

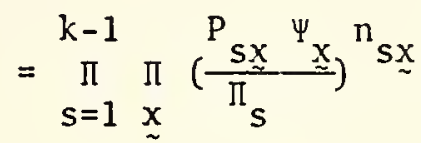

The maximization of the expression in equation (5.37) subject to the constraints in equation (5.36) is then similar to that discussed leading to equations (5.23) to (5.33). It is demonstrated in Anderson [90] with some simulation that the above approach gives good estimates of the discriminant function when $k=2$ and the underlying distributions are multivariate normal.

When the mixing proportions, $\underset{\sim}{\pi}$, are unknown or cannot be estimated, the allocation rule of equation $(5.16)$ cannot be used. The obvious criterion to use in this case is the likelihood ratio for which estimation equations (5.22) and (5.33) can still be used. .

Defining the likelihood ratio for $H_{s}$ and $H_{t}$ as $R_{s t}$, and assuming hypothetical proportions $\underset{\sim}{\pi}$

$$
R_{s t}=\frac{L\left(\underset{\sim}{x} \mid H_{s}\right)}{L\left(\underset{\sim}{x} \mid H_{i}\right)}=\frac{P_{s x} \Pi_{t}}{P_{t \underset{\sim}{x}} \Pi_{s}}
$$

from which 


$$
\begin{aligned}
& \log R_{s t}={\underset{\sim}{x}}^{\mathrm{T}}\left({\underset{\sim}{s}}_{s}-{\underset{\sim}{\alpha}}_{t}\right)-\mathrm{r}_{s t} \quad(s, t,=1, \ldots, k-1) \\
& \log \mathrm{R}_{s k}={\underset{\sim}{x}}^{\mathrm{T}}\left(\stackrel{\alpha}{s}_{s}-\mathrm{r}_{s k}\right) \quad(s=1, \ldots, k-1)
\end{aligned}
$$

where

$$
r_{s t}=\log \left(\pi_{s} / \pi_{t}\right), \quad(s, t=1, \ldots, k)
$$

If the $\{\underset{\sim}{\alpha}\}$ are estimated with $\prod_{\sim}^{*}$ defining a hypothetical mixture, estimates of the likelihood ratios can be obtained from equation (5.38).

The Newton-Raphson iterative procedure has been used by Cox, Day and Kerridge and Anderson $[90,103]$ for estimating $\left\{{\underset{\sim}{S}}_{S}\right\}$ in equations (5.22) and (5.33). This procedure has already been discussed in con-. nection with the multinomial response model earlier in this chapter.

The likelihood equations $(5.22)$ and $(5.33)$ can be written as

$$
\begin{aligned}
& \frac{\partial \log L}{\partial \alpha_{s j}}=f_{s j}=\sum_{\underset{\sim}{x}}(n_{s \underset{\sim}{x}}-\underbrace{n_{x}}_{\sim}{\underset{\sim}{x}}_{\sim}) x_{j}=0 \\
& (s=1, \ldots, k-1 ; j=0, \ldots, \ldots, p) \\
& \frac{\partial f_{s j}}{\partial \alpha_{t 1}}=\sum_{\sim}{\underset{\sim}{x}}_{\sim} P_{s \underset{\sim}{x}} P_{t \underset{\sim}{x}} x_{j} x_{1} \quad(s \neq t) \\
& \frac{\partial \underset{s j}{f}}{\partial \alpha_{s 1}}=-\sum_{\sim}^{x} \underline{\sim}_{\underline{x}} P_{s \underset{\sim}{x}}\left(1-P_{s \underset{\sim}{x}}\right) x_{j} x_{1}
\end{aligned}
$$

The $(k-1)(p+l)$ square matrix $\underset{\sim}{F}$ with elements $F_{s j, t l}=\partial f_{s j} / \partial \alpha_{t l}$ is equivalent to the matrix $\Psi$ defined in connection with the multinomiai response model in equation (5.11).

\section{Choosing Between Mixture and Separate Sampling}

Though there is little difference in the asymptotic properties of the dispersion matrices for the maximum likelihood estimates for mixture and separate sampling logistic discrimination, Anderson [90] recommends separate sampling provided the $n_{s}$ can be preselected to be 
approximately equal, $\mathrm{n}_{\mathrm{s}}$ being the fixed sample size for population $\mathrm{s}$ in separate sampling. This provides a balance among the $\mathrm{n}_{\mathrm{s}}$. In mixture sampling the $n_{s}$ are random variables and there is a strong possibility that travel behavioral responses of low incidence (e.g. transit users, senior citizens and other captives, in auto-oriented cities) can be missed. In spite of the intractability of the smallsample properties of maximum likelihood estimation Anderson expects that for a given total sample size $n$, samples with balanced $n_{s}$ give better estimates on the average than those with imbalance, particularly where some of the populations have a relatively higher incidence than the others. The advantage of separate sampling over mixed sampling will definitely be better realized in large-sampling estimation with some relaxation in balancing $\mathrm{n}_{\mathrm{s}}$. For stable parameter estimates that can be used for forecasting and computation of quantities like the value of travel time and elasticities, large samples made efficient through an appropriate partitioning of the sample size among the $n_{s}$ in order not to over-represent or under-represent any travel population, is recommended for transportation studies. Examples of the separate populations include auto users and transit users in mode choice analysis, auto travelers identified with a given functional category of shopping travel destination in shopping trip destination choice analysis, people associated with a given trip frequency for a given purpose in "trip generation", and people engaged in some non-work trip at a given time of day, in analyzing the effects of time of day. Car license plates, credit card addresses, and direct interviews of transit riders on board are all methods that can be investigated for 
planning such separate sampling. With the high $k$ value that is bound to prevail in most transportation studies one cannot expect to leave to chance the likelihood of covering all the $k$ travel "behavioral populations" in mixture sampling. Suppose there are three functional travel destinations $D_{1}, D_{2}, D_{3}$ with relative patronage proportions $10 \%$, $15 \%$, and $75 \%$, a sample size of 500 would be needed to cover $50 D_{1}$, $75 \mathrm{D}_{2}$ and $375 \mathrm{D}_{3}$ in random mixture sampling. In separate sampling a sample size of only 225 would be required to cover $75 D_{1}, 75 D_{2}$ and $75 \mathrm{D}_{3}$ with an estimate of the populations obtained from a different data source.

\section{Methodology for Data for This Research}

With the Multinomial Response Relation model [MRR] as illustrated in Figure 5.1. each cell of box $P$ is equivalent to a submarket segment which is defined at a finer level than a sampling scheme can achieve. A sampling framework can stratify a population according to variables like income and age but further variables and factors like attitude, "accessibility", the number of pre-school children, and an intervening opportunity field relative to a household location are more difficult to specify prior to data collection. It is supposed that the ways of classification that contribute to the matrix $\underset{\sim}{X}$ in the discussion of the MRR model are A, B, C, D. What logistic discrimination essentially does is to use for example, A (or A and B) for market segmentation that can be developed prior to major data collection (e.g. segmentation according to income or structure type). The logistic discrimination approach then develops a model for each market segment 
provided observations are available for such a purpose. For each market segment $B, C, D($ or $C$ and $D$ ) are used as the basis of discrimination among $\mathrm{k}$ populations. The MRR approach estimates a probability distribution function for choosing among the cells of box $Q$ in Figure 5.1 for each cell $j$ in box $P$ in Figure 5.1. The MRR procedure thus uses the factors characterizing the attraction measures of destination and their relative location to develop probability distribution functions for the different market segments. In the case of the logistic discrimination method, however, the characteristics of the destinations that define the cells of box $Q$ of Figure 5.1 are not used any further since the cells are thought of as mutually exclusive populations. If the number of ways of classification that goes into $Q$ is high there can be a large number of populations for which extensive data collection will be needed. In addition, there can be several cases of low frequencies within some cells. The separate sampling logistic discrimination approach alleviates the difficulty with low cell frequencies provided the relative population proportions can be estimated from more cheaply available data. Though the likelihood ratio can be used as the criterion for classification in the event the proportions cannot be estimated, the procedure can be computationally tedious in operational transportation planning.

There is evidence that spatial choices of destinations are more influenced by the characteristics of the alternatives than by individual socio-economic or the transportation network configuration relative to individuals [10]. What this means is that after a functional classification has been achieved the only essential factors that remain may be on attitudes, relative accessibility and intervening opprotunity fields. 
With the nature of available data on destination choice in general, the way in which Kannel's data was collected, and the limited sample size for the latter, empirical testing of the separate sampling logistic discrimination procedure could not be accomplished in this research. This does not mean that logistic discrimination is not a feasible approach. If one can define sufficient variables that influence the choice of functional shopping classifications, models for discriminating among functional destination categories can be achieved. One may at this stage question the need for using functional destination alternatives but this takes one back to the problem of choice set definition in which we have concluded that any approach using physical alternatives for destinations on a large scale is impractical. Where there is a common physical choice set as in mode choice or a conceptual choice set as in time of day choice, one does not only have few populations to discriminate among, but there is not the possibility of exhausting traditional variables in the definition of a functional choice set.

In the opinion of the writer, the logistic discrimination method, particularly when efficiently used with separate sampling, could be an excellent tool in such situations.

To summarize the above discussion, the MRR approach using a random sample was the more reasonable procedure to use to estimate a destination choice model using the data available for this research. The cells in box $\mathrm{P}$ of Figure 5.1 can be appropriately aggregated prior to a suitable factoring for aggregate prediction. The contribution of the discussion on logistic discrimination relates to how it can be tied to efficient sampling for an operationa1ly economical data collection shceme, an 
area that further research with suitably collected data can be addressed to. The conclusion therefore, is that, with the available data on destination choices, one is compelled to use the MRR approach which may be inefficient in its sampling scheme. With the availability of further variables that are identified through attitudinal work or the definition of better level of service variables and socio-economic factors, one can consider using logistic discrimination with more efficient sampling. Only the MRR approach is estimated and discussed in succeeding chapters. The provision for aggregation with the MRR method is only a natural consequence since the indicators and foundations for aggregation are derived from the level to which the cells of box $P$ in Figure 5.1 can be put together to a stage where a data sampling scheme based on secondary data can define an appropriate expansion factor for aggregate predictions.

\section{Large Sample Maximum Likelihood Estimators and Their Statistical}

\section{Properties.}

The procedures of multinomial logit analysis with a common set of alternatives [See Chapter 3], and the multinomial response relation and logistic discrimination analyses can also be viewed essentially as specifying cell (physical or functional alternative) probabilities as functions $\Pi_{1}(\underset{\sim}{\theta}), \ldots, \Pi_{k}(\underset{\sim}{\theta})$ involving q unknown parameters $\left(\theta_{1}, \ldots, \theta_{q}\right)=\underline{\theta}^{\prime}$. Such a specification is for a given market segment. The $\Pi_{i}$ as discussed here are cumulative distribution functions of the logit or logistic distributions for the situations cited. 
A form of asymptotic efficiency as given by Rao [89] is now defined:

Let $P(\cdot, \ldots, \mid \theta)$ be the probability density of the random variables $x_{1}, \ldots, x_{n}$ and define the random variable

$$
z_{n}=\frac{1}{n} \frac{d \log P\left(x_{1}, \ldots, x_{n} \mid \theta\right)}{d \theta}
$$

A consistent estimator $T_{n}$ of $\theta$ is said to be efficient if $\sqrt{n}\left|T_{n}-\dot{\theta}-\beta(\theta) Z_{n}\right| \rightarrow 0$ in probability or with a probability of 1 where $\beta$ does not involve the observations.

In the multiparameter case where the parameter vector is $\underline{\theta}^{\prime}=\left(\theta_{1} ; \theta_{2}, \ldots, \theta_{q}\right)$, a vector of derivatives is defined as

$$
\sim_{n}=\left(z_{n}^{1}, \ldots, z_{n}^{q}\right)
$$

where

$$
z_{n}^{i}=\frac{1}{n} \frac{\partial \log P}{\partial{ }_{i}}, \quad i=1, \ldots, q
$$

and a vector of deviations of the estimators from the true values as

$$
\begin{aligned}
\underset{\sim}{D_{n}^{\prime}} & =\left({\underset{\sim}{n}}_{n}-\theta\right) \\
& =\left(T_{n}^{1}-\theta_{1}, \ldots, T_{n}^{q}-\theta_{q}\right) .
\end{aligned}
$$

$\mathrm{T}_{\mathrm{n}}$ is said to be efficient if

$$
\sqrt{\mathrm{n}}|\underset{\sim \mathrm{n}}{\mathrm{D}}-\underset{\sim}{\mathrm{Bz}}{\underset{\mathrm{n}}{\mathrm{n}}}| \rightarrow 0
$$

in probability or with probability 1 , where $\underset{\sim}{\beta}$ is a matrix of constants that may depend on $\underset{\sim}{\theta}$.

Getting back to the original problem introduced in the first paragraph, $\underset{\sim}{\hat{\theta}}$ is assumed to be an efficient estimator of $\underset{\sim}{\theta}$ in the sense 
of (5.41), and that each $\Pi_{i}(\underset{\sim}{)})$ admits continuous partial derivatives of the first order (only) with respect to $\theta_{j}, j=1, \ldots, q$. Alternatively, it is assumed each $\pi_{i}(\theta)$ is a totally differentiable function of $\theta_{1}$, $\theta_{2}, \ldots, \theta_{q}$. The matrix $\underset{\sim}{M}$ is defined such that:

$M=\left(\pi_{r}^{-1 / 2} \partial \pi_{r} / \partial \theta_{s}\right)$ of order $(k x q)$ computed at the true values of $\underset{\sim}{\theta}$ with rank $q$.

The asymptotic distribution of

$$
x^{2}=\left[\frac{\left(n_{i}-n \hat{\pi}_{i}\right)^{2}}{n \hat{\pi}_{i}}\right.
$$

is $x^{2}(k-1-q)$ where $\hat{\pi}_{i}=\pi_{i}(\hat{\theta})$ and $n_{i}$ and $n$ are the observed frequency in cell $i$ and total number of observations, respectively. Rao [89] has discussed that maximum likelihood estimators of $\underset{\sim}{\theta}$ for the multinomial distribution are consistent, provided they exist. Previous discussions in Chapter 3 and in the present chapter have given conditions for the existence of the maximum likelihood estimators.

The goodness of fit testing of equation (5.42) would be adequate if one was interested only in the overall performance of the postulated model without any inference on specific or groups of elements of the parameter estimator $\underset{\sim}{\hat{\theta}}$. However, in urban transportation planning one may be interested in functions of the elements of $\underset{\sim}{\hat{\theta}}$ in the computation of elasticities and values of travel time for different situations. To make proper inference about the components of $\underset{\sim}{\epsilon}$ the joint distribution $\underset{\sim}{\theta}$, which is tractable only in large samples, is needed.

It is assumed that $x_{1}, \ldots, x_{n}$ are identically, independently distributed random variables that may be multidimensional. $P(x, \theta)$ is defined 
as the probability density depending on a q-dimensional parameter $\stackrel{\theta}{ }^{\prime}=\left(\theta_{1}, \theta_{2}, \ldots, \theta_{q}\right) \cdot \underset{\sim}{\theta}$ is assumed to be admissible in that it belongs to a nondegenerate interval of the q-dimensional Euclidean space. The log likelihood of $\mathrm{n}$ independent observations is

$$
1(\underset{\theta}{)})=\log p(x, \underset{\sim}{\theta})+\log p\left(x_{2}, \underset{\sim}{\theta}\right)+\ldots+\ldots \log p\left(x_{n}, \underset{\sim}{\theta}\right)
$$

The first derivative of the $\log$ likelihood function evaluated at $\stackrel{\theta}{ }$ with respect to $\underset{\sim}{\theta}$ is

$$
\frac{\partial 1}{\partial \theta_{i}}=\int_{\bar{P}\left(x_{1}, \theta\right)} \frac{\partial P\left(x_{1}, \theta\right)}{\partial \theta_{i}}+\ldots+\frac{1}{P\left(x_{n}, \theta\right)} \frac{\partial P\left(x_{n}, \theta\right)}{\partial \theta_{i}}
$$

After Rao [89] the following efficient score is defined.

$$
\phi_{i}=\frac{1}{\sqrt{n}} \frac{\partial L}{\partial \theta_{i}}
$$

The information matrix on $\underset{\sim}{\theta}$ in a single observation $x$, is defined as

$$
\mathscr{L}=\left(\mathscr{L}_{\mathrm{rS}}\right)=E\left\{\frac{1}{\mathrm{P}(\mathrm{x}, \underset{\sim}{\theta})} \frac{\partial \mathrm{P}}{\partial \theta_{\mathrm{r}}} \cdot \frac{1}{\mathrm{P}(\mathrm{x}, \underset{\sim}{\theta})} \frac{\partial \mathrm{P}}{\partial \theta_{\mathrm{S}}}\right\}
$$

where E denotes "expectation". Defining the vector $\underset{\sim}{V}$ ' $\left.=\left(\phi_{1} \underset{\sim}{\theta}\right), \ldots, \phi_{q}(\underset{\sim}{\theta})\right)$, it can be proved [89] that the asymptotic distribution of $\underset{v}{\mathrm{~V}}$ is qvariate normal with mean zero and dispersion matrix $\frac{1}{n} \mathscr{L}^{-1}$.

Under some regularity conditions [89] for $P\left(x_{1}, \theta\right)$ and denoting consistent roots of the equations of the likelihood equation based on $n$ observations by $\bar{\theta}$, the following asymptotic equivalencies can be established. 


$$
\begin{aligned}
& \underline{v}=\underline{D} \text { and } 2[1(\underset{\sim}{\bar{\theta}})-1(\underset{\sim}{\theta})]=\mathrm{D}_{\sim}^{\prime} \mathscr{L} \mathrm{D} \text {, where } \\
& \underline{\sim}^{\prime}=\left[\sqrt{n}\left(\bar{\theta}_{1}-\theta_{1}\right), \ldots, \sqrt{n}\left(\bar{\theta}_{q}-\theta_{q}\right)\right]
\end{aligned}
$$

The equivalence between these asymptotic equivalences and the NewtonRaphson procedure for maximizing the log likelihood function is clear.

It is recalled here that $\Pi_{i}$ is a function of $\underset{\sim}{\theta}=\left(\theta_{1}, \ldots, \theta_{q}\right)$ where the vector $\underset{\sim}{\theta}$ belongs to an admissible set $\theta$. It is supposed that the true value $\underline{\theta}^{\circ}$ is an interior point of $\theta$. Before the asymptotic distribution of the maximum likelihood estimators of $\underline{\theta}$ is introduced it is necessary to make some assumptions [89]. Some of these assumptions have been previously stated but the whole set is given here for completeness.

Assumption 1.1: Given a $\delta>0$, it is possible to find $\varepsilon$ such that

$$
\inf _{\underset{\sim}{\theta}-\underline{\sim}^{\circ} \mid>\delta} \sum \pi_{i}\left(\underline{\sim}^{\circ}\right) \log \frac{\pi_{i}\left(\underline{\theta}^{\circ}\right)}{\pi_{i}(\theta)} \geq \varepsilon
$$

where $\left|\underset{\sim}{\theta}-\underline{\sim}^{\circ}\right|$ is the distance between $\underset{\sim}{\theta}$ and ${\underset{\sim}{\theta}}^{\circ}$. This assumption may be referred to as a strong identifiability condition, implying that outside the sphere $\left|\underline{\theta}-\stackrel{\theta}{0}^{0}\right| \leq \delta$, there is no sequence of points ${\underset{\sim}{r}}_{\mathrm{r}}$ such that $\Pi(\underset{\sim}{\theta}) \rightarrow \Pi\left(\stackrel{\theta}{\theta}^{\circ}\right)$ as $\mathrm{r} \rightarrow \infty$, i.e. there are no values of $\underset{\sim}{\theta}$ remote from ${\underset{\sim}{\theta}}^{\circ}$ but yielding nearly the same set of probabilities $\pi_{\mathbf{i}}\left(\stackrel{\theta}{ }^{\circ}\right)$.

Assumption 1.2: $\Pi_{i}\left(\underset{\sim}{\theta} \neq \Pi_{i}(\underline{\beta})\right.$ for at least one $i$ when $\underline{\theta} \neq \neq \underline{\beta}$, which is a weaker identifiability condition.

Assumption 2.1: The functions $\Pi_{\mathbf{i}}(\underset{\sim}{\theta}), i=1, \ldots, k$ are continuous in $\underset{\sim}{\theta}$. Assumption 2.2: The functions $\pi_{i} \underset{\sim}{(\theta)}$ admit first-order partial derivatives. 
Assumption 2.3: The functions $\Pi_{i}(\underset{\sim}{\theta})$ admit first-order partial derivatives that are continuous at $\underline{\sim}^{\circ}$.

Assumption 2.4: The functions $\pi_{i}(\underset{\sim}{\theta})$ are totally differentiable at $\underline{\theta}^{\circ}$.

Assumption 3: Let the information matrix $\mathscr{L}_{\sim}$ be non-singular at $\stackrel{\theta}{ }^{\circ}$ where

$$
\begin{aligned}
\mathscr{L} & =E\left\{\frac{1}{P(x, \underset{\sim}{\theta})} \frac{\partial P}{\partial \theta_{r}} \cdot \frac{1}{P(x, \theta)} \frac{\partial P}{\partial \theta_{j}}\right\} \\
& =\sum_{j=1}^{g} \frac{1}{\pi_{j}} \frac{\partial \pi_{j}}{\partial \theta_{r}} \frac{\partial \pi_{j}}{\partial \theta_{s}}
\end{aligned}
$$

$\underline{\theta}^{*}$ is defined as an approximate maximum likelihood estimator if

$$
L\left[\Pi\left(\underline{\sim}^{*}\right)\right] \geq c \operatorname{Sup}_{\underline{\theta} \varepsilon \theta} L[\Pi(\underline{\theta})]
$$

That assumption 1.1 implies $\underline{\theta}^{*} \rightarrow \underline{\theta}^{\circ}$ with probability 1 as $n+\infty$ is shown as follows:

It can be proved that [89]

$$
\sum P_{i} \log \frac{\pi_{i}\left(\theta^{*}\right)}{P_{i}} \rightarrow 0 \text { over the admissible set } \theta \text {. Since }
$$

$\log \pi_{i}\left(\underline{\theta}^{*}\right)$ are bounded as $\underset{P}{\mathrm{P}} \rightarrow \underline{\pi}^{0}$,

$$
\begin{aligned}
& \left(\underset{\sim}{\dot{P}}=\left(P_{1}, \ldots, P_{k}\right),{\underset{\sim}{\Pi}}^{\circ}=\left(\Pi_{1}\left(\underline{\theta}^{\circ}\right), \ldots, \Pi_{k}\left(\underline{\theta}^{\circ}\right)\right)\right. \\
& \sum \pi_{i}\left(\underline{\theta}^{\circ}\right) \log \frac{\pi_{i}\left(\stackrel{\theta}{*}^{*}\right)}{\pi_{i}\left(\underline{\sim}^{\circ}\right)} \rightarrow 0 \text { over the admissible set } \theta \text {. }
\end{aligned}
$$

From assumption $1.1\left|{\underset{\sim}{*}}^{*}-{\underset{\sim}{ }}^{0}\right| \leq \delta$ with probability 1 in which case $\underline{\theta}^{*} \rightarrow \underline{\sim}^{\circ}$ with probability 1 as $\delta$ is arbitrarily chosen close to zero. Assumptions 1.1 and 2.1 imply that the maximum likelihood estimator, 
$\underset{\theta}{\hat{\theta}}$ of $\underset{\sim}{\theta}$ exists and converges to $\underline{\sim}^{\circ}$ with probability 1 [89]. Assumptions 1.1 and 2.2 imply that the maximum likelihood estimator is the root of the equations

$$
\frac{\partial 1}{\partial \theta_{i}}=0, \quad i=1, \ldots, k
$$

with a probability of 1 .

By choosing $\delta$ in such a way that the sphere $\left|\underset{\sim}{\theta}-{\underset{\sim}{\theta}}^{\circ}\right| \leq \delta$ in the interior of $\theta$, the supremum of $L[\Pi(\theta)]$ is attained in an open interval

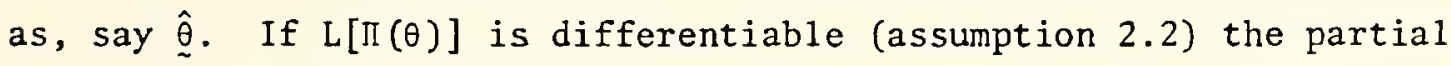
derivatives must vanish at $\hat{\theta}$.

Under assumptions $1.2,2.3$, and 3 , and denoting the (rs)th element of the inverse of $\mathscr{L}_{\sim}$ by $i^{\text {rs }}$ and

$$
z_{r}=\sum_{i=1}^{k} \frac{P_{i}}{\pi_{i}(\underbrace{\circ}_{\sim})} \frac{\partial \pi_{i}}{\partial \theta_{r}^{\circ}},
$$

there exists a consistent root $\hat{\theta}_{\sim}^{-}$of the likelihood equation (5.46) which may not be a maximum likelihood estimator and

$$
\sqrt{n}\left|\bar{\theta}_{r}-\theta_{r}^{0}-i^{r l} z_{1}-\ldots-i^{r q} z_{q}\right| \rightarrow 0 \quad r=1, \ldots, q .
$$

with a probability of 1 .

This implies that the maximum likelihood estimators are efficient in the sense of equation (5.41) and that their asymptotic distribution is q-variate normal [89].

i.e. $\quad \underset{n \rightarrow \infty}{\hat{\theta}} \sim N_{\mathrm{q}}\left(\stackrel{\theta}{\sim}^{\circ}, \frac{1}{\mathrm{n}} \mathscr{L}_{\sim}^{-1}\right)$

where $\mathrm{N}_{\mathrm{q}}$ denotes a $\mathrm{q}$-variate normai distribution. 
All the discussion so far on maximum likelihood estimators applies to the estimators for a multinomial logit model for a common alternative set, multinomial response relation and logistic discrimination estimation problems. That all the assumptions are satisfied by the symmetric and asymmetric logistic distributions defining $\pi_{i}(\underset{\sim}{\theta})$ in the discussion is clear.

\section{Summary.}

The theoretical development of the multinomial response relation procedure and its parameter estimation are discussed, with a detailed presentation on its specific application to problems of interest in this research. The advantage in the ability of the method to include interaction effects in developing predictive models is emphasized. In order to consider both categorical and continuous variables, the latter are partitioned into appropriate classes. This is particularly important in destination choice modelling where most of the factors are qualitative. The application of the multinomial response relation approach to functional destination choice modelling is discussed in terms of cross-classification tables both for market segmentation and functional destination definition. The logical provision for making aggregate forecasts of functional destination choice implied in the use of the multinomial response relation approach is discussed as well as its possible extension to other travel decisions.

The theory behind a recently developed logistic discrimination technique is presented and the technique recommended as the eventual operational statistical to be used, given standardized functional 
destinations. It is pointed out that this discrimination technique can be readily applied to travel decisions like mode and time of day choices. The extension of the mixed (or mixed population) logistic discrimination technique to the separate sampling situation is also discussed, the latter being especially recommended for travel behaviour modelling. This is to ensure that one captures all essential travel market segments without excessive data collection at unnecessary expense.

Large sample statistical properties of maximum likelihood estimators are discussed. It is pointed out that it is only under large sample estimation that one can take advantage of asymptotic statistical distributions of parameters to make proper statistical inferences and develop stabler and more representative models. Separate sampling model development strikes a suitable compromise between the statistical large sample requirement and the need to cover all market segments on the one hand and the parsimony in minimizing on manpower and fiscal resource expenditure in data collection on the other. 
CHAPTER 6

ATTITUDINAL CONSIDERATIONS IN
DESTINATION CHOICE MODELLING

This chapter discusses the statistical preparation of successive categorical data in which ratings were assigned to different factors that may influence the selection of a general shopping area destination. Such preparation is necessary to minimize multicollinearity or interaction among the factors prior to their use in market segmentation in predicting the choice of functional destination alternatives. Similar considerations with respect to successive category data in mode choice analysis have been discussed in recent transportation planning literature $[78,79]$. The normality assumptions in the use of the raw attitudinal data for some multivariate analyses and classical approaches with roots in Thurstone's Law of Categorical Judgement $[85,86]$ do not appear to hold very well for the attitudinal data available for this research. Since there is no guarantee that further data collection would provide a better data base to fit classical approaches, and considering the immense data collection cost and the time lag between successive data collection efforts in transportation planning, it is necessary that other statistical approaches be used to derive the best information from available data. With the qualitative nature of the variables there is heavy reliance on contingency table techniques in this chapter. 
Description of Available Successive Category Data

The preception by individuals of factors that could affect the choice of shopping destinations was solicited by Kannel [10] through a 7-point successive category rating scale [Figure 6.1]. The higher the rating for a factor the higher its level of importance to a given individual. Table 6.1 shows a listing of the factors and their mean ratings for the total sample used in Kannel's work [10]. The ratings give the impression that the choice of shopping destinations is more influenced by the characteristics of the shopping areas than by the characteristics of the transportation system. Factors related to shop characteristics that received high ratings were "a wide selection of goods", and "appearance of the store and surroundings". Out of 15 factors, the descriptors referring to distance, travel time and travel cost were ranked in positions 11,12 , and 13 respectively. Since most shopping area developments are tied up with parking the factors relating to the ease of parking and the cost of parking were considered as part of the shopping area characteristics. These two factors were rated second and tenth, respectively. The ability to quickly find a parking spot was ranked fifth.

As is indicated later in this chapter, the factors in Table 6.1 are not all independent. The average rating is of no use in predicting shop destination choice behavior unless one has a very large sample for which the rating scales for different subsamples would differ substantially in which case the effect of the different scales can be considered in model development. The sample size available to this research was limited and it was unlikely to find much difference 
When you select a place to go shopping how important is it:

Not

At All

of

Important

Greatest

Importance

A. to go in an area of town you are familiar with?

$\begin{array}{lllllll}1 & 2 & 3 & 4 & 5 & 6 & 7\end{array}$

B. to go where you can walk around and shop at several stores?

C. to go where there are many employees to help you?

D. to go where there is a wide selection of items to choose from?

E. to go where you can make the trip in the shortest time?

F. to go where it costs less to park?

G. to go where many other people do their shopping?

$\begin{array}{lllllll}1 & 2 & 3 & 4 & 5 & 6 & 7\end{array}$

$\begin{array}{lllllll}1 & 2 & 3 & 4 & 5 & 6 & 7\end{array}$

$\begin{array}{lllllll}1 & 2 & 3 & 4 & 5 & 6 & 7\end{array}$

$\begin{array}{lllllll}1 & 2 & 3 & 4 & 5 & 6 & 7\end{array}$

$\begin{array}{lllllll}1 & 2 & 3 & 4 & 5 & 6 & 7\end{array}$

$\mathrm{H}$. to go to places where the roads are not congested?

I. to go where you don't have to walk far after you get off the bus or out of the car?

$\begin{array}{lllllll}1 & 2 & 3 & 4 & 5 & 6 & 7\end{array}$

J. to go where you can easily return home?

1. $\begin{array}{llllll}2 & 3 & 4 & 5 & 6 & 7\end{array}$

K. to go where you can ride to several other stores at different locations?

$\begin{array}{lllllll}1 & 2 & 3 & 4 & 5 & 6 & 7\end{array}$

L. To go where you can quickly find a place to park?

$\begin{array}{lllllll}1 & 2 & 3 & 4 & 5 & 6 & 7\end{array}$

M. to go where the cost of travel is less?

$\begin{array}{lllllll}1 & 2 & 3 & 4 & 5 & 6 & 7\end{array}$

N. to shop as close to home as possible?

$\begin{array}{lllllll}1 & 2 & 3 & 4 & 5 & 6 & 7\end{array}$

0 . to go where the stores and surroundings have a pleasant appearance?

$\begin{array}{lllllll}1 & 2 & 3 & 4 & 5 & 6 & 7\end{array}$

FIGURE 6.1. SUCCESSIVE CATEGORY QUESTIONNAIRE ON SHOPPING DESTINATION CHOICE. (After Kannel [10]) 
Table 6.1. Attitudinal Ratings of Factors Important in Selection of a Shopping Trip Destination.

(After Kannel [10])

\begin{tabular}{|c|c|c|c|}
\hline Generalized Descriptor & $\begin{array}{l}\text { Average } \\
\text { Rating* }\end{array}$ & & $\begin{array}{l}\text { Rank } \\
\text { Order }\end{array}$ \\
\hline Familiar area & 5.07 & & 8 \\
\hline Shop at several stores & 5.61 & & $51 / 2$ \\
\hline Employees to help you & 5.01 & & 9 \\
\hline Wide selection & 6.25 & & 1 \\
\hline Shortest trip time & 4.74 & & 13 \\
\hline Parking cost & 4.81 & & 10 \\
\hline Go where others shop & 3.31 & - & 15 \\
\hline Roads not congested & 5.30 & & 7 \\
\hline Walking distance from vehicle & 5.72 & & 2 \\
\hline Easy to return home & 5.67 & & 4 \\
\hline Ride to several stores & 4.36 & & 14 \\
\hline Quickly find place to park & 5.61 & & $51 / 2$ \\
\hline Travel cost & 4.74 & & 12 \\
\hline Distance & 4.79 & & 11 \\
\hline Pleasant appearance & 5.71 & & 3 \\
\hline
\end{tabular}

*Maximum rating $=7.0$ 
in rating scales for sub groups within this small sample for the specially selected group of relatively stable households. The results of a Kolmogorov-Smirnov test for differences in shopping destination choice influencing factor perceptions by subgroups as determined by Kannel gave support to this. A way to use the attitudinal data is to classify individuals (not groups) according to their response patterns on the successive category rating form, With a substantial sample size a 3-or 4-way classification could be accomplished. It is, however, impractical to consider anything beyond a 2-way classification, considering the limited sample size available and the fact that the factors are not independent. Seven factors were therefore selected, considering the average rankings in Table 6.1, their predominance in previous traditional destination choice models and the possibility that two or more factors semantically could be reduced to one descriptor. The factors selected for later detailed work are listed in Table 6.2.

Table 6.2. Shopping Destination Choice Factors Considered in this Research

1. Many Employees in Shopping Establishment

2. Wide Selection of Goods

3. Shopping Destination Requiring Shortest Travel Time

4. Uncongested Approach Roads to Shopping Destination

5. Desire to Visit Several Stores at Different Locations

6. The Ability to Quickly Find a Parking Space

7. A Destination Closest to Home 
Some Approaches for Successive Category Data

The discriminal process (not directly observable but playing a central role in judgemental models) associated with a stimulus $x_{j}$ will be represented as a random variable $v_{j}[86]$. A value of $v_{j t}$ for $a$ randomly sampled subject, $t$, is considered to be composed of a fixed component $\mu_{j}$, specific to $x_{j}$, but common to all subjects, and $\varepsilon_{j t}$, a random component, i.e. $v_{j t}=\mu_{j}+\varepsilon_{j t}$. For successive categories a second discriminal process is postulated which pertains to the perception of a given point on the rating form:

$$
v_{k t}=\tau_{k}+\pi_{t}+\varepsilon_{k t}
$$

$\tau_{k}$ is a fixed component associated with point $k$ on the continum represented by the rating form. $\pi_{t}$ is an individual difference component that depends on the interpretation of the rating form for a particular subject t. $\varepsilon_{k t}$ is a random component allowing for variability of interpretations over subject, $t$, of point $k$ on the rating form.

The joint distribution of $\varepsilon_{j t}$ and $\pi_{t}+\varepsilon_{k t}$ is assumed to be bivariate normal with means zero and variances $\delta_{j}^{2}$ and $\gamma_{k}^{2}$ and intercorrelation zero. It is further assumed [86] that $\gamma_{k}^{2}=\gamma^{2}$ for all values of $k$.

Subject $i$ will rate stimulus $j$ at or below point $k$ if

$$
v_{j k i}=v_{j i}-v_{k i}=\mu_{j}-\tau_{k}+\varepsilon_{j i}-\varepsilon_{k i} \leq 0
$$

$v_{j k}$ is normally distributed with means $\mu_{j}-\tau_{k}$ and variance

$$
\delta_{j}^{2}+\gamma_{k}^{2}=\sigma_{j}^{2}
$$


With the normality assumption, the probability that a randomly selected subject $i$ will judge stimulus $x_{j}$ at or below point $k$ on the rating form is given by

$$
P_{j k i}=\frac{1}{\sigma_{j} \sqrt{2 \pi}} \int_{-\infty}^{0} \exp \left(-\frac{1}{2} \frac{\left[y-\left(\mu_{j}-\tau_{k}\right)\right]^{2}}{\sigma_{j}^{2}}\right) d y
$$

where $y$ is the normal deviate corresponding to a unit normal distribution.

Bock and Jones [86] have discussed graphical and minimum Normit $x^{2}$ procedures for estimating $\gamma_{k}, b_{j}$ and $\mu_{j}$ in equation 6.1. To simplify the normit $x^{2}$ procedure for successive-category data, it is necessary to assume that the responses to different objects or stimuli for the sample in question are independently distributed. Such independence is not strictly true since the same individuals are responding to all the objects. An extreme case is when objects are presented to all subjects in the same order and two similar objects follow each other. In such a case the distributions of the response frequencies will be similar. If the order in which the objects are presented to the individuals is randomized the dependency in response distributions will be minimized. If the correlation of the error term is roughly constant and is within some plausible bounds the expressions for the expected sums of squares and sampling variance of parameter estimators can be generalized in the correlation case. The analysis can easily get unwieldy in such a situation. One could also investigate the need to use the procedure that always considers such 
correlation as a routine measure in cases where the correlation may be statistically different from zero but judged to be of a low order.

The correlation matrix for the response frequencies to the factors in Table 6.2 is shown in Table 6.3. Though most of the correlations are significantly different from zero at the 1-percent level very few of them have an absolute value that exceeds 0.4 in which case the lack of independence may not completely vitiate the analysis. Besides, the independence assumption, the normality assumption implied in the above discussion must be verified for the available data. Figure 6.2 shows the frequency distributions for the response categories for the seven factors under consideration. The Kolmogorov-Smirnov normality tests for the response frequencies reject the normality assumption for all cases. In view of the nature of the frequency distributions in pigure 6.2 , some of the rating categories were combined after which tests of pairwise independence in contingency tables were conducted for two different sets of $3 \times 3$ and a set of $2 \times 2$ contingency tables as shown in Tables $6,4 a$ to 6.6. The test of independence is based on the goodness-of-fit $x^{2}$ value for main effects models. Except for a couple of cases, the assumption of pairwise independence is rejected at the 1-percent level in all cases for the $3 \times 3$ tables. In the $2 \times 2$ tables the assumption of independence is rejected in all but two cases. The effect of the lack of independence will be investigated in a later section assuming a logistic distribution for the response categories for selected combinations of factors. The importance of this analysis lies in the fact that one is interested in selecting 
Table 6.3 Correlotion Matrix For 7 Shopping Destination Choice Factors.

\begin{tabular}{|c|c|c|c|c|c|c|c|}
\hline & 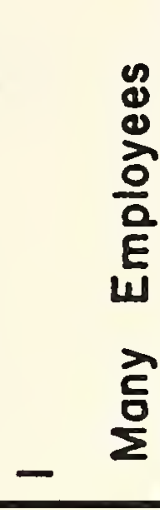 & 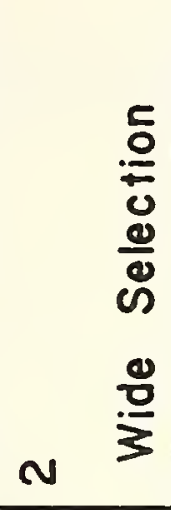 & 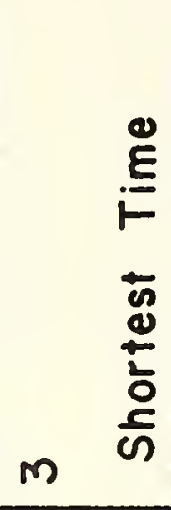 & 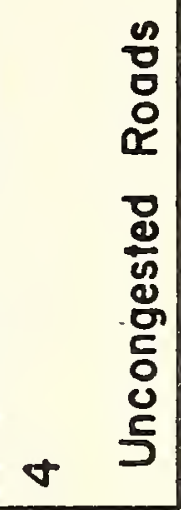 & के & 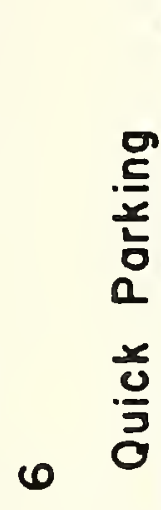 & 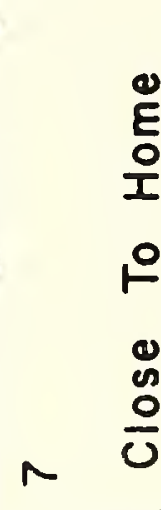 \\
\hline 1 & - & .216 & .127 & .205 & .260 & .108 & .188 \\
\hline 2 & & - & .201 & .244 & .182 & .262 & .173 \\
\hline 3 & & & - & .262 & .176 & .235 & .405 \\
\hline 4 & & & & - & .310 & .432 & .304 \\
\hline 5 & & & & & - & .314 & .296 \\
\hline 6 & & & & & & - & .266 \\
\hline 7 & & & & & & & - \\
\hline
\end{tabular}


"Many Employees"

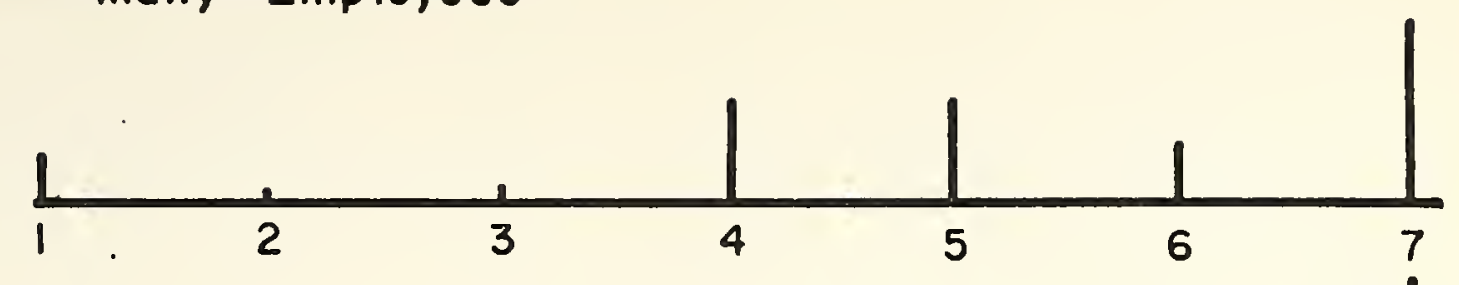

"Wide Selection"

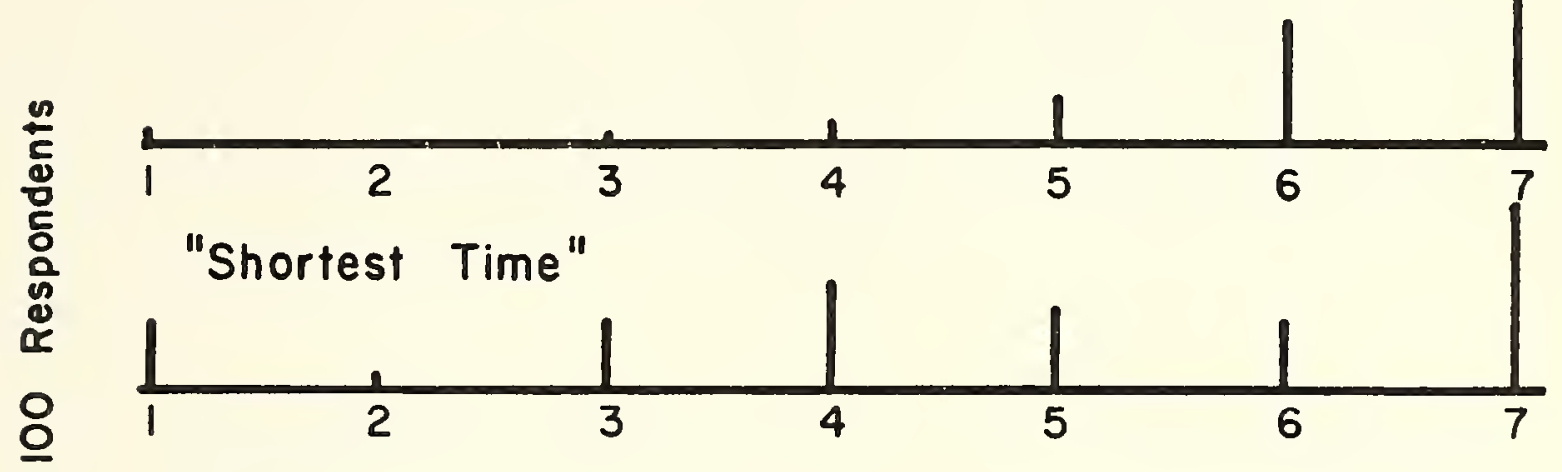

z- "Uncongested Roods"

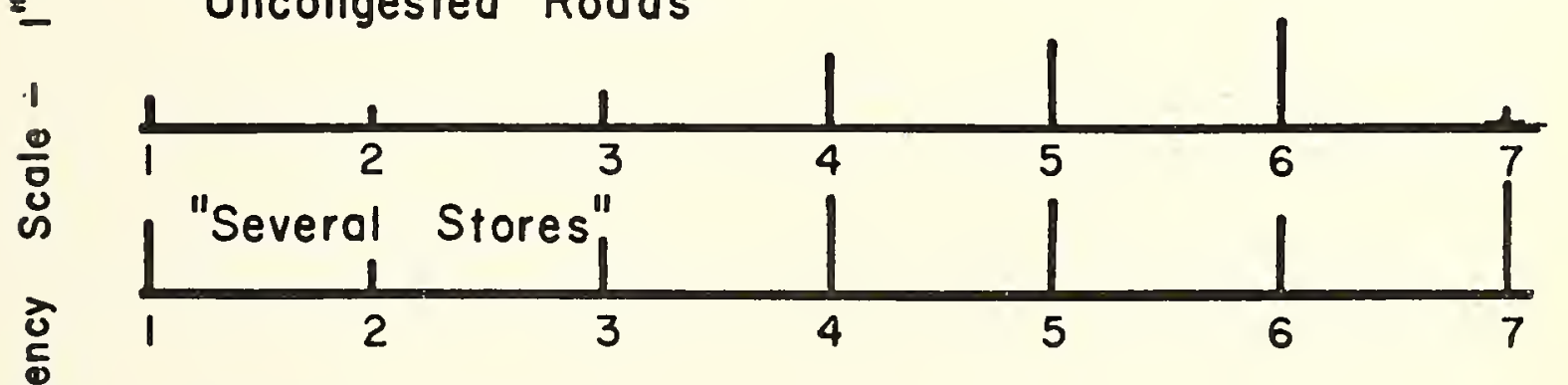

"Quick Parking"

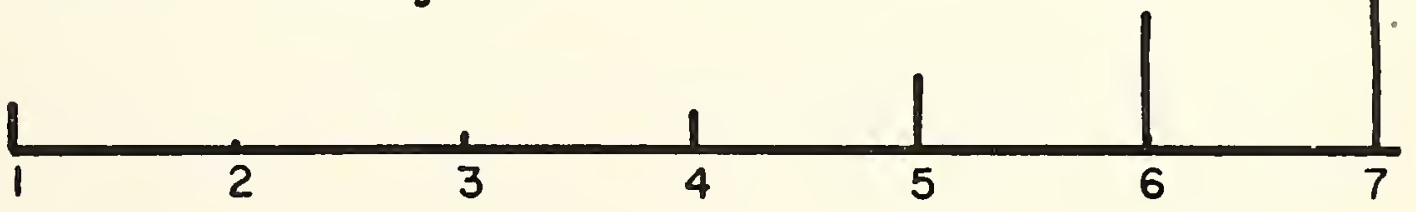

"Close to Home"

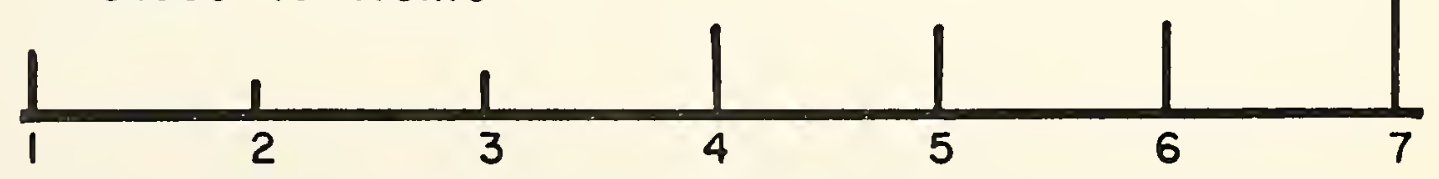

FIGURE 6.2 FREQUENCY DISTRIBUTIONS FOR THE RESPONSE CATEGORIES OF SEVEN DESTINATION CHOICE FACTORS 
the most effective shopping destination choice influencing factors for model development in Chapter 7 and finding out if interactions among the attitudinal factors need to be considered. The method of analysis to be used will be a special case of the multinomial response relation model that can be used for a factorial experiment or a crossclassification problem. Since a linear model for the effects of cross-classification of subjects according to their response categories to objects is the same as that for a factorial design on the objects, the theoretical presentation given by Bock and Jones [86] for a factorial experiment, as briefly discussed below, is pertinent.

The incorporation of the linear model of a factorial design into the measurement model for the method of successive intervals, assumes equal discriminal dispersions (i.e. $\delta_{j}=\delta$ for all $j$ ).

A factorial experiment is assumed in which the response to the treatment combinations consists of independent judgements obtained from a rating form. Assuming the distribution of judgement into $n+1$ categories follows Thurstone's law of categorical judgement, the probability that a response to the $h^{\text {th }}$ treatment combination (or "cell") will fall in or below the $k^{\text {th }}$ successive category is:

$$
\mathrm{P}_{\mathrm{hk}}=\underbrace{y_{h k}=\left(\tau_{k}-\mu_{h}\right) / \delta_{h}}_{-\infty} \mathrm{g}(\mathrm{z}) \mathrm{d} z
$$

$\tau_{k}$ is a parameter specifying the upper boundary of an interval associated with the $k^{\text {th }}$ category of the rating scale. $\mu_{h}$ is a parameter that indicates the effect of the $h^{\text {th }}$ treatment. $\delta_{h}$ is a scale 
parameter for the $h^{\text {th }}$ treatment combination and $g(z)$ is a probability density function. We assume the logistic form for $g(z)$ as follows:

$$
g(z)=\frac{1}{4} \operatorname{sech}^{2} \frac{z}{2}
$$

from which $P_{h k}=1 /\left(1+e^{-Y h k}\right)$

where $\quad Y_{h k}=\log \left[P_{h k} /\left(1-P_{h k}\right)\right]$

It is assumed that $\delta_{h}$ is sufficiently homogeneous in which case $\delta_{h}=\delta$ for all h. Without loss of generality $\delta$, can be taken to be 1 by a suitable choice of scaling unit. The linear model for a treatment combinations is then expressed as:

$$
\underset{n \times 1}{\mu}=\underset{n \tilde{x} m}{A} \underset{m \tilde{x} 1}{\xi}
$$

If $A$ is singular of rank $r<m, r \leq n$ a reparameterization of the model in terms of $\mathrm{r}$ linear estimable functions of the parameters in the form of $\underline{\theta}=\underline{L} \underline{\xi}$. becomes necessary. This has been previously rixm

discussed in Chapter 5 in connection with the multinomial response relation mode1. It follows that

$$
\underline{\mu}=\underset{n \tilde{x} r}{\stackrel{\theta}{K}} \underset{r \tilde{x} l}{\theta}
$$

where $\underline{y}_{h}=\underline{k}_{n}^{\prime} \theta-h=1,2, \ldots, n$

where $\underset{\sim}{\mathrm{k}} \mathrm{h}$ is the row of $\underset{\sim}{\mathrm{K}}$ corresponding to treatment combination $h$. The response model in equation 6.2 becomes:

$$
P_{h k}=\frac{1}{2} f_{-\infty}^{Y_{h k}}=\tau_{k}-k_{h}^{\prime} \theta_{r} \underset{\operatorname{sech}^{2} z / 2 \mathrm{~d} z}{.}
$$


The problem then becomes that of estimating $\tau$ and $\underset{\sim}{\theta}$ from independent judgements randomly sampled from populations defined by equation 6.3. Bock and Jones [86] have discussed a logit $x^{2}$ solution for the parameter estimation involved. The procedure that was used in subsequent work in this chapterwas maximum likelihood estimation based on the multinomial response relation model, using a symmetrical logistic distribution. Bock [66] has discussed the connection between the asymmetrical and symmetrical distribution situations for binary choice and the extension of the symmetrical case for a multiple-choice problem as discussed in Chapter 5.

\section{The Reproduction of Attitudinal Orientation Patterns}

In order to make attitudinal information obtained from a survey useful for present day or short-term forecasting, one has to be able to reproduce the pattern of attitudinal orientation obtained from the survey through some independent variables or factors or with a suitable alternative technique. Though it may not yet be possible to use attitudinal information for long-range forecasting, the consistent good performance of some attitudinal factors that are directly associated with some objectively measurable variables or factors puts the transportation planner in a position to improve future data collection. The need for such improved future data collection in destination choice modelling is becoming increasingly clearer since the currently available zonal retail floor area and retail employment attraction measures are unable to reveal all the intricacies in destination choice behaviour. Whatever the technique used for reproducing attitudinal orientation patterns, one has to know 
how the factors act jointly or in statistical terms, one would be interested in the joint distribution of the factors. In the case of two-way associations among the factors, the correlation coefficient is often used to determine the degree the two factors concerned might confound each other in the same model. Quite often there can be some 2-way or 3-way interactions among some of the factors that are more conveniently measured. Since such factors are not easily dispeñsed with, the interaction effects must be included in model building. Assuming the availability of independent destination choice attitudinal factors, the question of what further independent variables or factors can be used to predict the observed attitudinal orientation patterns still prevails. Little success has been experienced with the use of scio-economic variables for this purpose. Extensive research is needed, with greater demands for data collection and complicated analysis in order to approach the threshold of the problem. The likely danger is that the problem can become complicated, making the analyst lose sight of the nature of the original transportation planning problem--the prediction of aggregate flows of primary traffic on a transportation network. Considering the problem in the context of an experimental design, as has been previously argued, the reproduction of attitudinal orientation can be accomplished at a level quite adequate for the current level of data availability, allowing for interactions among the attitudinal factors. This is a direct way of incorporating attitudinal factors in travel demand modelling rather than going through independent predictive factors that are extremely difficult to identify. 
The procedure used in this research to reproduce attitudinal orientation patterns uses cross-classifications with respect to categories of successive category rating ranges. It must be pointed out that a crossed design is not the only one that can be used. Nesting or other designs can also be used provided that they are planned for in the original data collection.

The multinomial response relation technique, the theory of which was presented in Chapter 5 , is sufficiently general to handle al1 the design situations. Attempts at reproducing attitudinal patterns using two different sets of $3 \times 3$ and one set of $2 \times 2$ cross-classification tables will be discussed. The patterns for those tables are shown in Figure 63. Since a more detailed discussion of the empirical application of the multinomial response relation procedure has been discussed in Chapter 5 (with detailed examples in Appendix A) only the essential points for the interpretation of models fitting the observed attitudinal patterns for 348 households will be presented in the remainder of this chapter. Main effect parameters are all relative to the last category of classification. In the $3 \times 3$ tables, parameter estimates for each way of classification are for category 1 relative to category 3 and for category 2 relative to category 3 . In the $2 \times 2$ tables, the category 1 effect is estimated relative to category 2 for each way of classification. An I,J interaction in a $3 \times 3$ table is, therefore, the interaction of level I relative to level 3 with level $\mathrm{J}$ relative to level 3 . When all interactions are negligible, the model fits the data well and the two factors can be considered to be independent. 


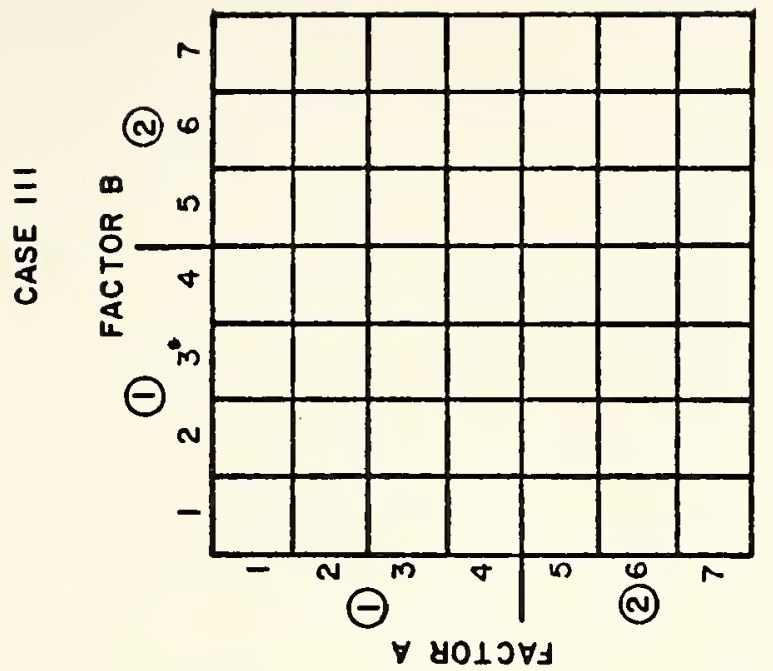

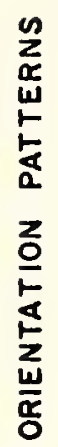

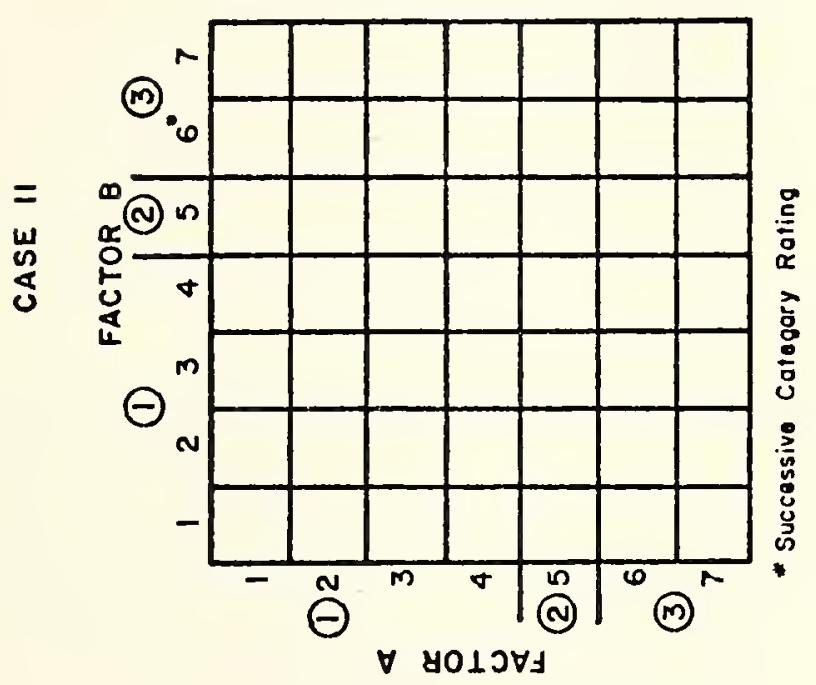

$\frac{1}{2}$
$\frac{1}{2}$
$\frac{2}{5}$

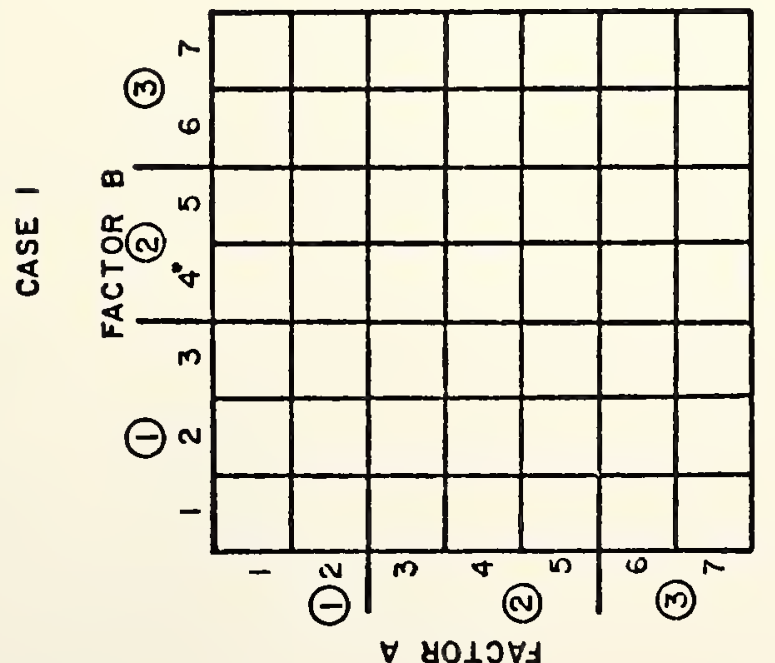

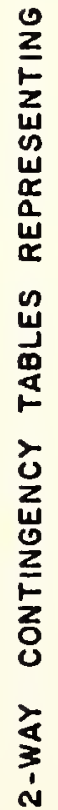

$\ddot{0}$

峁 
A main effects model, therefore, is expected to reproduce the attitudinal orientation pattern well. A significant goodness-of-fit $x^{2}$ value for a given model indicates bad reproducibility of the observed attitudinal orientation pattern. Each interaction is associated with 1 degree of freedom and each interaction fitted, if significant, must reduce the goodness-of-fit $\mathrm{x}^{2}$ by at least an amount corresponding to the $x^{2}$ value for 1 degree of freedom at a given significance level. For the purposes of the work being done in this research, if the goodness-of-fit $x^{2}$ is significant for a model for reproducing the attitudinal orientation pattern due to two factors, the factors concerned cannot be considered simultaneously in any model of travel behavior. In such a situation there usually is a systematic way of association between the two factors.

Introduction of Tables that Present Models for Predicting Attitudinal Orientation Patterns

The presentation of the tables discussed in the remaining sections of this chapter is to enable the reader to get the essential objectives of the tables before they are discussed in detail. Several of the tables refer to Case I, Case II or Case III models which are models based on cross-classification designs presented in Figure 6.3 .

Tables $6.4 a$ to 6.8 give goodness-of-fit $x^{2}$ values associated with models for predicting response patterns for pairings of attitudinal factors in 2-way contingency tables. Cases I and II models are for $3 \times 3$ contingency tables. Case III models refer to $2 \times 2$ contingency tables. For Case I models both tables $6.4 \mathrm{a}$ and 
6.4b show four layers of goodness-of-fit $x^{2}$ values. In Table 6.4a the layers, starting from the top, represent models with the following effects:

1. Main Effects (Pearsonian $x^{2}$ value computed)

2. Main Effects (Likelihood Ratio $X^{2}$ value computed)

3. Main Effect $+1,1$ Interaction

4. Main Effects $+1,2$ Interaction

The four layers of Likelihood Ratio $x^{2}$ values in Table $6.4 \mathrm{~b}$, from the top, represent models with the following effects:

1. Main Effects

2. Main Effects $+2,1$ Interaction

3. Main Effects $+2,2$ Interaction

4. Main Effects $+1,1+2,2$ Interactions

The above description of the layers of goodness-of-fit $x^{2}$ values for Case I models in Tables $6.4 \mathrm{a}$ and $6.4 \mathrm{~b}$ apply to the corresponding $x^{2}$ values for Case II models displayed in Tables $6.5 \mathrm{a}$ and $6.5 \mathrm{~b}$ respectively.

The two layers of goodness-of-fit $x^{2}$ values for Case III models, given in Table 6.6 represent Pearsonian and Likelihood Ratio $x^{2}$ values respectively.

Tables 6.7 and 6.8 show reductions in goodness-of-fit $x^{2}$ values achieved, compared to the main effects model, by considering 1,1 and 2,2 interaction effects separately in Case I and Case.II model development. The entries in Tables 6.7 and 6.8 were obtained from appropriate subtractions in Tables $6.4 \mathrm{a}$ and $6.5 \mathrm{a}$. for reductions caused by the 1,1 interaction and in Tables $6.4 \mathrm{~b}$ and $6.5 \mathrm{~b}$ for 
reductions caused by the 2,2 interaction. Each $X^{2}$ value in Tables 6.7 and 6.8 has one degree of freedom.

Tables 6.9 a to $6.9 \mathrm{c}$ present Case III attitudinal orientation pattern prediction models that displayed an insignificant lack of fit. Tables 6.10 and 6.11 are corresponding tables for main effects Case I and Case II models, respectively.

Tables $6.12 \mathrm{a}$ to $6.12 \mathrm{e}$ present five attitudinal orientation pattern prediction models that achieved an improved goodness-of-fit $\mathrm{X}^{2}$ value as a result of the inclusion of a 1,1 interaction in Case $I$ prediction models. Tables $6.13 \mathrm{a}$ to $6.13 \mathrm{~d}$ present corresponding Case II models that included the 1,1 interaction effect.

Tables $6.14 \mathrm{a}$ and $6.14 \mathrm{~b}$ show two Case II models that obtained a significant improved goodness-of-fit with the inclusion of main effects and 2,2 interactions in the predictive models developed.

Tables $6.15 \mathrm{a}$ to $6.15 \mathrm{e}$ present results for six Case I models that consider main effects $+1,1$ and 2,2 interactions in the development of models to predict the attitudinal orientation patterns in $3 \times 3$ contingency tables. Tables $6.16 \mathrm{a}$ to $6.16 \mathrm{j}$ summarize the results for eight corresponding predictive models that consider similar effects for Case II $3 \times 3$ contingency tables. It is noticed that the models with main effects $+1,1$ and 2,2 interactions have very low goodnessof-fit $X^{2}$ values compared to their equivalent main effects models. In all the attitudinal orientation patterns prediction models discussed above, row parameters refer to the effects of the row way of classification. The column parameters correspond to the effects of the column way of classification. The ways of classification in 
the above models refer to the attitudinal factors that define corresponding contingency tables.

Main Effects Models

Tables $6.4 \mathrm{a}$ and $6.5 \mathrm{a}$ show that no pair of factors produce an attitudinal orientation pattern that can be reproduced effectively with a main effects model. The combination of "Many Employees" and "Shorter Time" barely misses being a good model for Case I in Table 6.4a and produces a good model for Case II in Table 6.5a. The Pearsonian $x^{2}$ and Likelihood Ratio (L.R.) $x^{2}$ values are expected to be close. The presence of both is a checking device. The Case III $2 \times 2$ model in Table 6.6 gives a good fit for "Many Employees" by "Wide Selection," "Wide Selection by "Shorter Time" and "Wide Selection" by "Uncongested Roads." With Case III the categories have been combined so much that the effectiveness of the joint distribution between a pair of factors is likely to have been reduced in the process of combining categories in the various ways of classification. Not much weight need be attached to the results for Case III except for the fact that the independent classifications provide a $2 \times 2$ representation of the data which is useful for illustrating the need for a 2-way classification for the small sample size available. Cases $I$ and II in Tables $6.4 \mathrm{a}$ and $6.5 \mathrm{a}$ respectively show that except for the pairing of "Many Employees" with "Shorter Time," no pair of attitudinal factors can be considered as acting independently. The observed and predicted frequency distributions for the classification tables discussed in this Section are indicated in Tables 6.9a to $6.9 \mathrm{c}$ and Tables 6.10 and 6.11 . 
Table 6.4a $\chi^{2}$ Values in 2-Way Tables - Case I

\begin{tabular}{|c|c|c|c|c|c|c|c|}
\hline & 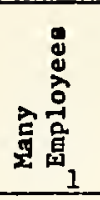 & 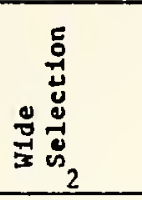 & 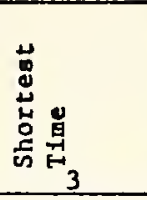 & 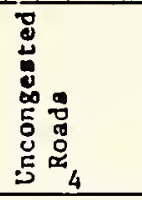 & 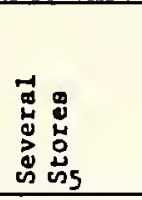 & 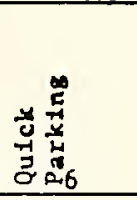 & $\begin{array}{l}0 \\
4 \\
8 \\
0 \\
0 \\
0 \\
0 \\
0\end{array}$ \\
\hline $\begin{array}{l}\text { Many }^{1} \\
\text { Employees }\end{array}$ & - & $\begin{array}{l}31.19^{\star \star} \\
33.95^{\star \star} \\
29.40^{\star \star} \\
27.53^{\star \star}\end{array}$ & $\begin{array}{c}10.01^{\star \star} \\
9.59^{\star} \\
3.38 \\
9.07^{\star}\end{array}$ & $\begin{array}{c}29.00^{\star \star} \\
26.02^{\star \star} \\
9.30^{\star} \\
20.44^{\star \star}\end{array}$ & $\begin{array}{l}58.08^{\star \star} \\
55.88^{\star \star} \\
35.70 \\
55.15^{\star \star}\end{array}$ & $\begin{array}{l}24.61_{\star \star}^{\star \star} \\
25.36^{\star \star} \\
16.42^{\star \star} \\
13.49^{\star \star}\end{array}$ & $\begin{array}{c}24.37^{\star \star} \\
22.71^{\star \star} \\
9.71^{\star} \\
20.95^{\star \star}\end{array}$ \\
\hline \begin{tabular}{l}
\multicolumn{2}{c}{${ }^{2}$} \\
Weldection
\end{tabular} & & - & $\begin{array}{l}14.90^{\star \star} \\
13.55^{\star \star} \\
4.00^{\star \star} \\
12.81^{\star \star}\end{array}$ & $\begin{array}{l}31.83^{\star \star} \\
25.73^{\star \star} \\
12.40^{\star} \\
24.83^{\star \star}\end{array}$ & $\begin{array}{l}17.98^{\star \star} \\
20.00^{\star \star} \\
17.80^{\star \star} \\
14.07^{\star \star}\end{array}$ & $\begin{array}{l}51.24^{\star \star} \\
36.11^{\star \star} \\
14.29^{\star \star} \\
35.57^{\star \star}\end{array}$ & $\begin{array}{c}12.21^{\star \star} \\
12.20^{\star \star} \\
8.41^{\star} \\
10.04^{\star}\end{array}$ \\
\hline \begin{tabular}{l}
\multicolumn{1}{c}{3} \\
Shortent \\
TIme
\end{tabular} & & & - & $\begin{array}{l}34.88^{\star \star} \\
35.73^{\star \star} \\
25.86^{\star \star} \\
34.34^{\star \star}\end{array}$ & $\begin{array}{l}25.92^{\star \star} \\
24.83^{\star \star} \\
15.46^{\star \star} \\
22.61^{\star \pi}\end{array}$ & $\begin{array}{l}21.11^{\star \star} \\
21.43^{\star \star} \\
15.95^{\star \star} \\
20.65^{\star \star}\end{array}$ & $\begin{array}{l}77.41^{\star \star} \\
72.26^{\star \star} \\
32.59^{\star \star} \\
69.71^{\star \star}\end{array}$ \\
\hline $\begin{array}{l}4 \\
\text { Uncongested } \\
\text { Roads }\end{array}$ & & & & - & $\begin{array}{l}49.52^{\star \star} \\
47.33^{\star \star} \\
17.93^{\star \star} \\
47.32^{\star \star}\end{array}$ & $\begin{array}{l}66.21^{\star \star} \\
63.06^{\star \star} \\
40.66^{\star \star} \\
62.70^{\star \star}\end{array}$ & $\begin{array}{l}43.23^{\star \star} \\
40.91^{\star \star} \\
19.48^{\star \star} \\
40.66^{\star \star}\end{array}$ \\
\hline \begin{tabular}{l}
\multicolumn{1}{c}{5} \\
Several \\
Storea
\end{tabular} & & & & & - & $\begin{array}{l}40.06^{\star \star} \\
41.79^{\star \star} \\
27.68^{\star \star} \\
38.52^{\star \star}\end{array}$ & $\begin{array}{l}46.55^{\star \star} \\
45.09^{\star \star} \\
24.83^{\star \star} \\
43.81^{\star \star}\end{array}$ \\
\hline $\begin{array}{l}6 \\
\text { Quick } \\
\text { Parking }\end{array}$ & & & & & & - & $\begin{array}{l}28.38^{\star \star} \\
26.92^{\star \star} \\
11.07^{\star \star} \\
25.70^{\star \star}\end{array}$ \\
\hline \begin{tabular}{l}
\multicolumn{1}{c}{7} \\
Close to \\
Home
\end{tabular} & & & & & & & - \\
\hline
\end{tabular}

* * Significance Level $\leq .01$

*. . $01<$ Significance Level $\leq .05$ d.f.is as indicated below unless otherwise shown in parenthesis

Layers from top

1. Pearsonian $\chi^{2}$ - Main Effects (4 dif.)

2. $L \cdot R \cdot x_{2}^{2}-$ Main Effects ( 4 d.f.)

3. $L \cdot R \cdot{ }^{2}$ - Main Effects $+1,1$ Interaction ( 3 d. E.)

4. $L \cdot R \cdot{ }^{2}$ - Maĺ Effects $+1,2$ Inzeraction ( 3 d.f.) 
Table 6.4b $\chi^{2}$-Values in 2-Way Tables ${ }^{a}$ - Case I

\begin{tabular}{|c|c|c|c|c|c|c|c|}
\hline & 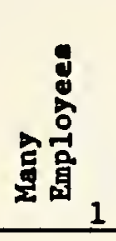 & 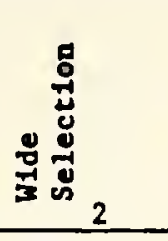 & 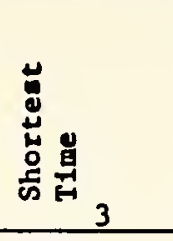 & $\begin{array}{l}8 \\
8 \\
8 \\
0 \\
8 \\
8 \\
0 \\
0 \\
0 \\
0\end{array}$ & 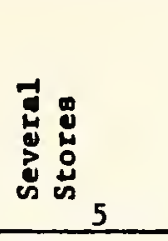 & 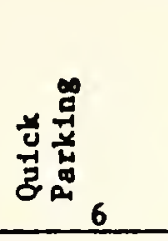 & 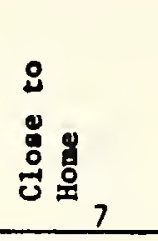 \\
\hline $\begin{array}{l}1 \\
\text { Many } \\
\text { Employees }\end{array}$ & - & $\begin{array}{l}33.95^{\star \star} \\
28.66^{\star \star} \\
25.16^{\star \star} \\
21.03^{\star \star}\end{array}$ & $\begin{array}{l}9.59^{\star} \\
9.40^{\star} \\
7.32 \\
2.07\end{array}$ & $\begin{array}{c}26.02^{\star *} \\
25.34^{\star \star} \\
16.40^{\star \star} \\
2.06\end{array}$ & $\begin{array}{l}55.88^{\star \star} \\
54.20^{\star \star} \\
32.66^{\star \star} \\
18.93^{\star \star}\end{array}$ & $\begin{array}{l}25.36^{\star \star} \\
23.64^{\star \star} \\
21.35^{\star \star} \\
13.21^{\star \star}\end{array}$ & $\begin{array}{c}22.71^{\star \star} \\
20.44^{\star \star} \\
12.15^{\star \star} \\
2.00\end{array}$ \\
\hline $\begin{array}{l}2 \\
\text { Wide } \\
\text { Selection }\end{array}$ & & - & $\begin{array}{c}13.55^{\star \star} \\
12.59^{\star \star} \\
12.75^{\star \star} \\
3.41\end{array}$ & $\begin{array}{c}25.73^{\star \star} \\
21.49^{\star \star} \\
13.28^{\star \star} \\
0.75\end{array}$ & $\begin{array}{l}20.00^{\star \star} \\
19.77^{\star \star} \\
18.38^{\star \star} \\
16.34^{\star \star}\end{array}$ & $\begin{array}{c}36.11^{\star \star} \\
35.77^{\star \star} \\
22.53^{\star \star} \\
1.44\end{array}$ & $\begin{array}{c}12.20^{\star \star} \\
12.20^{\star \star} \\
10.59^{\star} \\
6.96^{\star}\end{array}$ \\
\hline \begin{tabular}{l}
\multicolumn{1}{c}{3} \\
Shortest \\
Tine
\end{tabular} & & & - & $\begin{array}{l}35.73^{\star \star} \\
35.47^{\star \star} \\
26.90^{\star \star} \\
19.01^{\star \star}\end{array}$ & $\begin{array}{c}24.83^{\star \star} \\
23.74^{\star \star} \\
11.55^{\star \star} \\
5.96\end{array}$ & $\begin{array}{l}21.43^{\star \star} \\
17.21^{\star \star} \\
18.72^{\star \star} \\
13.83^{\star \star}\end{array}$ & $\begin{array}{l}72.26^{\star} \\
68.41^{\star \star} \\
46.31^{\star \star} \\
15.49^{\star \star}\end{array}$ \\
\hline \begin{tabular}{l}
\multicolumn{1}{c}{} \\
Uncongested \\
Roads
\end{tabular} & & & & - & $\begin{array}{l}47.33^{\star \star} \\
42.39^{\star \star} \\
37.82^{\star \star} \\
12.38^{\star \star}\end{array}$ & $\begin{array}{l}63.05^{\star \star} \\
53.52^{\star \star} \\
54.98^{\star \star} \\
34.08^{\star \star}\end{array}$ & $\begin{array}{l}40.91^{\star \star} \\
39.19^{\star \star} \\
31.48^{\star \star} \\
12.84^{\star \star}\end{array}$ \\
\hline \begin{tabular}{l}
\multicolumn{1}{c}{5} \\
Several \\
Stores
\end{tabular} & & & & & - & $\begin{array}{l}41.79^{\star \star} \\
39.71^{\star \star} \\
32.79^{\star \star} \\
20.67^{\star \star}\end{array}$ & $\begin{array}{l}45.09^{\star} \\
44.92^{\star \star} \\
32.99^{\star \star} \\
17.67^{\star \star}\end{array}$ \\
\hline \begin{tabular}{l}
\multicolumn{1}{c}{6} \\
Quick \\
ParkIng
\end{tabular} & & & & & & - & $\begin{array}{l}26.92^{\star \star} \\
22.27^{\star \star} \\
23.20^{\star \star} \\
8.42^{\star \star}\end{array}$ \\
\hline $\begin{array}{l}7 \\
\text { Close to } \\
\text { Hone }\end{array}$ & & & & & & & - \\
\hline
\end{tabular}

\footnotetext{
**. SIgnificance Level $\leq .01$

$.01<$ Stgnificance Level $\leq .05$
}

d. $\mathrm{f}$ is as Indicated below unless otherwise shown in parenthesis

Layers from top

1. $L \cdot R \cdot X^{2}-$ Main Effects (4 d.f.)

2. $L \cdot R \cdot \chi^{2}$ - Main Effects + 2,I Inter$\operatorname{act1on}(3 \mathrm{~d} . \mathrm{f}$.

3. $L \cdot R \cdot X^{2}-$ Main Effects $+2,2$ Interaction (3d.f.)

4. $L \cdot R \cdot X^{2}$ - Main F.ffects $+1,1+2,2$ Interactions (2 d.f.) 
Table 6.5a $\chi^{2}$ - Values 1n 2-Way Tablesa- Case II, Maln Effecta

\begin{tabular}{|c|c|c|c|c|c|c|c|}
\hline & 욜 & 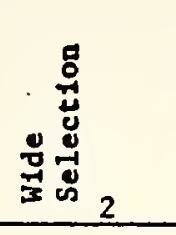 & 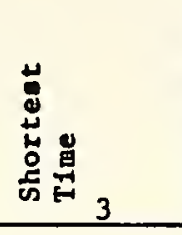 & 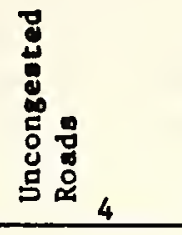 & 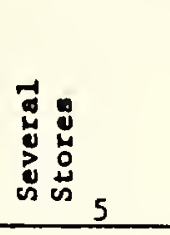 & 苞菩 & $\begin{array}{l}0 \\
\vdots \\
0 \\
0 \\
0 \\
0 \\
\end{array}$ \\
\hline $\begin{array}{l}1 \\
\text { Many } \\
\text { Enployeeo }\end{array}$ & - & $\begin{array}{l}24.16^{\star \star} \\
25.12^{\star \star} \\
23.28^{\star \star} \\
25.11^{\star \star}\end{array}$ & $\begin{array}{l}8.61 \\
8.26 \\
3.19 \\
7.82\end{array}$ & $\begin{array}{l}14.93^{\star \star} \\
14.33^{\star \star} \\
5.04^{\star \star} \\
14.10^{\star \star}\end{array}$ & $\begin{array}{l}46.68^{\star \star} \\
48.36^{\star \star} \\
21.15^{\star \star} \\
48.30^{\star \star}\end{array}$ & $\begin{array}{c}10.82^{\star} \\
10.44^{\star} \\
5.79 \\
8.17^{\star}\end{array}$ & $\begin{array}{c}14.69^{\star \star} \\
14.24^{\star \star} \\
7.86^{\star} \\
14.14^{\star \star}\end{array}$ \\
\hline $\begin{array}{l}\text { W1de }^{2} \\
\text { Select1on }\end{array}$ & & - & $\begin{array}{l}16.53^{\star \star} \\
14.68^{\star \star} \\
10.89^{\star \star} \\
14.64^{\star \star}\end{array}$ & $\begin{array}{l}18.23^{\star \star} \\
17.56^{\star \star} \\
13.85^{\star \star} \\
15.96^{\star \star}\end{array}$ & $\begin{array}{l}26.71^{\star \star} \\
32.76^{\star \star} \\
17.60^{\star \star} \\
27.21^{\star \star}\end{array}$ & $\begin{array}{l}35.84^{\star \star \star} \\
\text { (3) } 29.06^{\star \star} \\
\text { (2) } 12.74^{\star \star} \\
\text { (2) } 28.97^{\star \star}\end{array}$ & $\begin{array}{l}19.32^{\star \star} \\
19.58^{\star \star} \\
13.78^{\star \star} \\
18.54^{\star \star}\end{array}$ \\
\hline \begin{tabular}{l}
\multicolumn{1}{c}{3} \\
Shortest \\
Time
\end{tabular} & & & - & $\begin{array}{l}37.64^{\star \star} \\
35.47^{\star \star} \\
22.57^{\star \star} \\
28.95^{\star \star}\end{array}$ & $\begin{array}{c}20.62^{\star \star} \\
20.62^{\star \star} \\
5.62^{\star \star} \\
19.63^{\star \star}\end{array}$ & $\begin{array}{l}21.56^{\star \star} \\
23.11^{\star \star} \\
18.38^{\star \star} \\
21.94^{\star \star}\end{array}$ & $\begin{array}{l}51.97^{\star \star} \\
52.08^{\star \star} \\
20.88^{\star \star} \\
51.99^{\star \star}\end{array}$ \\
\hline $\begin{array}{l}4 \\
\text { Uncongested } \\
\text { Roads }\end{array}$ & & & & - & $\begin{array}{l}31.61^{\star \star} \\
32.85^{\star \star} \\
13.16^{\star \star} \\
32.57^{\star \star}\end{array}$ & $\begin{array}{l}56.95^{\star \star} \\
54.67^{\star \star} \\
27.75^{\star \star} \\
54.16^{\star \star}\end{array}$ & $\begin{array}{c}37.86^{\star \star} \\
37.77^{\star \star} \\
9.35^{\star} \\
37.75^{\star \star}\end{array}$ \\
\hline \begin{tabular}{l}
\multicolumn{1}{c}{5} \\
Several \\
Stores
\end{tabular} & & & & & - & $\begin{array}{l}32.58^{\star \star} \\
35.87^{\star \star} \\
14.55^{\star \star} \\
34.46^{\star \star}\end{array}$ & $\begin{array}{l}42.14^{\star \star} \\
41.54^{\star \star} \\
26.32^{\star \star} \\
41.10^{\star \star}\end{array}$ \\
\hline \begin{tabular}{l}
\multicolumn{1}{c}{6} \\
Quick \\
Parking
\end{tabular} & & & & & & - & $\begin{array}{l}23.74^{\star \star} \\
22.40^{\star \star} \\
10.24^{\star} \\
22.36^{\star \star}\end{array}$ \\
\hline $\begin{array}{l}7 \\
\text { Close to } \\
\text { Bome }\end{array}$ & & & & & & & - \\
\hline
\end{tabular}

$d \cdot f$ is as 1ndicated below unless otherwise shown in parenthesis

a Layers from top

1. Fearsonian $\chi^{2}$ - Main Effects (4 d.f.)

2. $L \cdot R \cdot X^{2}-$ Main Effects ( $4 \cdot$ d.f.)

3. $L \cdot R X^{2}$ - Main Effects $+1,1$ Inter action (3 d.f.)

4. $L \cdot R \chi^{2}$ - Main Effects $+1,2$ Interaction ( 3 d.f.) 
Table 6.5b $x^{2}$ - Values in 2-Way Tableg - Case II

\begin{tabular}{|c|c|c|c|c|c|c|}
\hline 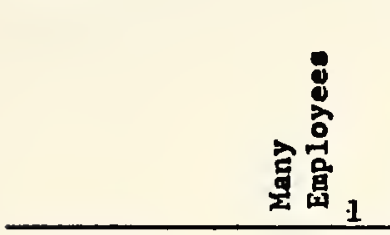 & 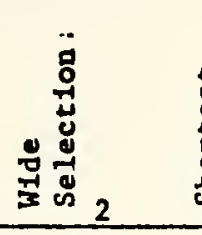 & 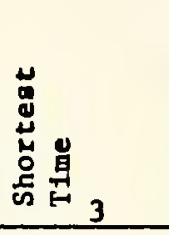 & 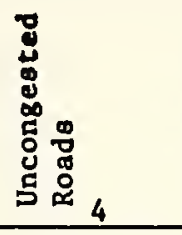 & 站怘 & 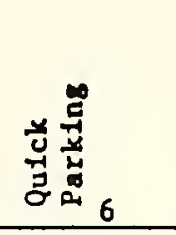 & $\begin{array}{l}8 \\
0 \\
: 0 \\
0 \\
0 \\
0 \\
\end{array}$ \\
\hline $\begin{array}{l}1 \\
\text { Kany } \\
\text { Employees }\end{array}$ & $\begin{array}{l}25.12^{\star \star} \\
22.56^{\star \star} \\
15.27^{\star \star} \\
13.76^{\star \star}\end{array}$ & $\begin{array}{l}8.26 \\
7.90 \\
5.35 \\
1.16\end{array}$ & $\begin{array}{l}14.33^{\star \star} \\
13.93^{\star \star} \\
10.43^{\star} \\
2.22\end{array}$ & $\begin{array}{l}48.36^{\star \star} \\
48.23^{\star \star} \\
47.12^{\star \star} \\
21.04^{\star \star}\end{array}$ & $\begin{array}{c}10.44^{\star \star} \\
10.40^{\star} \\
6.32 \\
2.25\end{array}$ & $\begin{array}{l}14.24^{\star \star} \\
13.72^{\star \star} \\
10.25^{\star} \\
4.97\end{array}$ \\
\hline $\begin{array}{l}{ }^{2} \\
\text { Wide } \\
\text { Selection: }\end{array}$ & - & $\begin{array}{l}14.68^{\star \star} \\
13.09^{\star \star} \\
5.39 \\
2.07\end{array}$ & $\begin{array}{c}17.56^{\star \star} \\
15.29^{\star \star} \\
10.36^{\star} \\
6.97^{\star}\end{array}$ & \multicolumn{2}{|c|}{$\begin{array}{l}32.76^{\star \star}(3) 29.06^{\star \star} \\
\text { N.C. } 27.87^{\star \star} \\
31.98^{\star \star} \text { (2) } 18.10^{\star \star} \\
17.10^{\star \star} \text { (1) } 2.42\end{array}$} & $\begin{array}{c}19.58^{\star \star} \\
15.47^{\star \star} \\
12.99^{\star \star} \\
7.55^{\star}\end{array}$ \\
\hline \begin{tabular}{l}
\multicolumn{1}{c}{3} \\
Shortest \\
Time
\end{tabular} & & - & $\begin{array}{l}35.47^{\star \star} \\
33.14^{\star \star} \\
26.76^{\star \star} \\
12.31^{\star \star}\end{array}$ & $\begin{array}{c}20.62^{\star \star} \\
20.59^{\star \star} \\
19.19^{\star \star} \\
5.28\end{array}$ & $\begin{array}{l}23.11^{\star \star} \\
16.81^{\star \star} \\
20.58^{\star \star} \\
16.32^{\star \star}\end{array}$ & $\begin{array}{l}52.08^{\star \star} \\
51.85^{\star \star} \\
47.90^{\star \star} \\
19.04^{\star \star}\end{array}$ \\
\hline $\begin{array}{l}4 \\
\text { Uncongested } \\
\text { Roads }\end{array}$ & & & - & $\begin{array}{l}32.85^{\star \star} \\
32.84^{\star \star} \\
31.53^{\star \star} \\
12.77^{\star \star}\end{array}$ & $\begin{array}{l}54.67^{\star *} \\
51.63^{\star \star} \\
44.67^{\star \star} \\
19.54^{\star \star}\end{array}$ & $\begin{array}{c}37.77^{\star \star} \\
37.12^{\star \star} \\
35.10^{\star \star} \\
8.07^{\star}\end{array}$ \\
\hline $\begin{array}{c}5 \\
\text { Several } \\
\text { Stores }\end{array}$ & & & & - & $\begin{array}{l}35.87^{\star \hbar} \\
28.95^{\star \star} \\
21.83^{\star \star} \\
2.44\end{array}$ & $\begin{array}{l}41.54^{\star \star} \\
41.06^{\star \star} \\
32.61^{\star \star} \\
20.48^{\star \star}\end{array}$ \\
\hline \begin{tabular}{l}
\multicolumn{1}{c}{6} \\
Quick \\
Parking
\end{tabular} & & & & & - & $\begin{array}{l}22.40^{\star \star} \\
19.91^{\star \star} \\
14.94^{\star \star} \\
4.02\end{array}$ \\
\hline $\begin{array}{l}7 \\
\text { Close to } \\
\text { Home }\end{array}$ & & & & & & - \\
\hline $\begin{array}{l}\text { ** Signiflicance Level } \\
\text { * .01 < Significance } \\
\text { N.C. - No Convergence }\end{array}$ & $\begin{array}{l}\leq .01 \\
\text { Level } \leq .05\end{array}$ & & 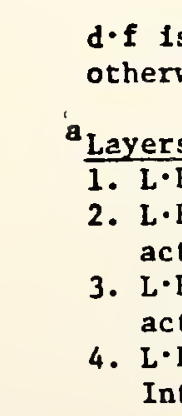 & $\begin{array}{l}s \text { as Indic } \\
\text { wise showr } \\
\text { s from tor } \\
R \cdot \chi^{2}-\mathrm{Ma} \\
\mathrm{R} \cdot \chi^{2}-\mathrm{Ma} \\
t \text { ion }(3 \mathrm{~d} \\
\mathrm{R} \cdot \chi^{2}-\mathrm{Ma} \\
\text { tion }(3 \mathrm{~d} \\
\mathrm{R} \cdot \chi^{2}-\mathrm{Ma} \\
\text { teraction }\end{array}$ & $\begin{array}{l}\text { in pared below } \\
\text { in Effects } \\
\text { in Effects } \\
\text { f.) } \\
\text { in Effects } \\
\text { f.) } \\
\text { in Effects } \\
(2 \text { d.i.) }\end{array}$ & $\begin{array}{l}\text { unless } \\
\text { hesis } \\
(4 \text { d.f.) } \\
+2,1 \text { Inter- } \\
+2,2 \text { Inter- } \\
+1,1+2,2\end{array}$ \\
\hline
\end{tabular}


Table $6.6 x^{2}$ - Values in 2-Way Tables, Maln Effects Only ${ }^{a}$ Case III - 2 × Cross-Classification, E. F. = 1 in all Cases.

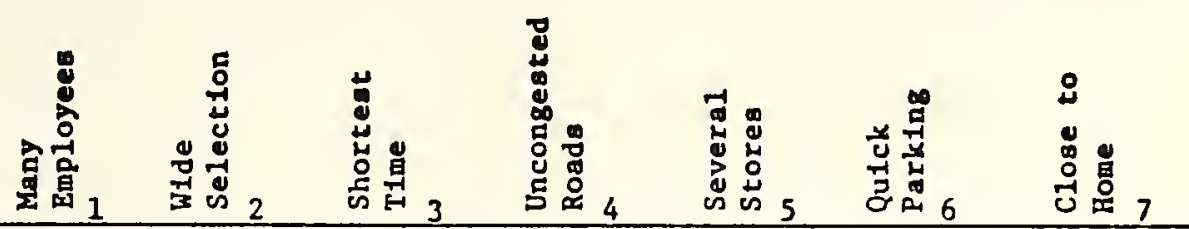

\begin{tabular}{|c|c|c|c|c|c|c|}
\hline $\begin{array}{c}1 \\
\text { Many } \\
\text { Employeeg }\end{array}$ & $\begin{array}{l}1.38 \\
1.84\end{array}$ & $\begin{array}{l}4.59^{\star} \\
5.08^{\star}\end{array}$ & $\begin{array}{l}8.72^{\star \star} \\
9.29^{\star}\end{array}$ & $\begin{array}{l}25.62^{\star \star} \\
27.21^{\star}\end{array}$ & $\begin{array}{l}4.18^{\star} \\
4.65^{\star}\end{array}$ & $\begin{array}{l}5.85^{\star} \\
6.38^{\star}\end{array}$ \\
\hline $\begin{array}{l}{ }^{2} \\
\text { Hide } \\
\text { Selection }\end{array}$ & - & $\begin{array}{l}3.08 \\
3.79\end{array}$ & $\begin{array}{l}3.19 \\
3.71\end{array}$ & $\begin{array}{l}12.64^{\text {k }} \\
15.16^{\star \star}\end{array}$ & $\begin{array}{l}18.12^{\star \star} \\
16.32^{\star \star}\end{array}$ & $\begin{array}{l}5.00^{\star} \\
5.81^{\star}\end{array}$ \\
\hline
\end{tabular}

\begin{tabular}{|c|c|c|c|c|}
\hline $\begin{array}{l}3 \\
\text { Shortest } \\
\text { Tlme }\end{array}$ & $\begin{array}{l}12.21^{\star \star} \\
13.05^{\star \star}\end{array}$ & $\begin{array}{l}14.07^{\star \star} \\
14.99^{\star \star}\end{array}$ & $\begin{array}{l}4.19^{\star} \\
4.74^{\star}\end{array}$ & $\begin{array}{l}29.69^{\star \star} \\
31.20^{\star \star}\end{array}$ \\
\hline
\end{tabular}

\begin{tabular}{|c|c|c|c|c|}
\hline $\begin{array}{l}4 \\
\text { Uncongested } \\
\text { Roads }\end{array}$ & - & $\begin{array}{l}18.34^{\star \star} \\
19.69^{\star \star}\end{array}$ & $\begin{array}{l}27.56^{\star \star} \\
26.92^{\star \star}\end{array}$ & $\begin{array}{l}27.34^{\star \star} \\
28.42^{\star \star}\end{array}$ \\
\hline
\end{tabular}

\begin{tabular}{|c|c|c|c|}
\hline \begin{tabular}{l}
\multicolumn{1}{c}{5} \\
Several \\
Stores
\end{tabular} & - & $\begin{array}{l}12.98^{\star \star} \\
14.26^{\star \star}\end{array}$ & $\begin{array}{l}14.27^{\star \star} \\
15.22^{\star \star}\end{array}$ \\
\hline
\end{tabular}

\begin{tabular}{lr}
\hline 6 & $11.40^{\star \star}$ \\
Qulck & $12.16^{\star \star}$ \\
Parking & --
\end{tabular}

Close to
Home

\begin{tabular}{|c|c|c|}
\hline$\star^{*}$ & $\begin{array}{l}\text { Significance Level } \leq .01 \\
.01<\text { Significance Level } \leq .05\end{array}$ & 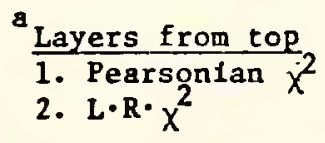 \\
\hline
\end{tabular}


Models With Main Effects and 1,1 Interactions

For Case $I$ in Table 6.4a combinations of "Many Employees" with "Shorter Time" and "Wide Selection" with "Shorter Time" give reasonably good fits. Pairings that come close to a fair reproducibility of observed attitudinal orientation patterns are "Many Employees" with "Uncongested Roads" "Many Employees" with "Close to Home" and "Wide Selection" with "Close to Home." For Case II in Table 6.5a an improved fit for "Many Employees" paired with "Shorter Time" is provided and the fits are good for "Many Employees" with "Uncongested Roads," "Many Employees" with "Quick Parking" and "Shorter Time" with "Several Stores." The fitting for an interaction indicates that the model allows for a systematic change in the relationship between two factors at the combination of factor levels corresponding to the interaction. A 1,1 interaction between "Many Employees" and "Shortest Time" indicates that those to whom the presence of many employees is not important do not also place a high value on getting to their shopping destination as early as possible. A similar interpretation can be given to other models that fitted this interaction well as pointed out above. The observed and predicted frequency distributions of attitudinal orientation patterns for the models discussed in this paragraph are shown in Tables $6.12 \mathrm{a}$ to $6.12 \mathrm{e}$ and Tables $6.13 \mathrm{a}$ to $6.13 \mathrm{~d}$. The $x^{2}$ reductions due to the 1,1 interactions are given in Tables 6.7 and 6.8 .

Mode1s With Main Effects and 1,2 or 2,1 Interactions

Tables $6.4 \mathrm{a}, 6.4 \mathrm{~b}, 6.5 \mathrm{a}$ and $6.5 \mathrm{~b}$ indicate that the introduction of 1,2 or 2,1 interactions in addition to main effects does not 
Table $6.7 \chi^{2}$ - Values in 2-Way Tables - Case I, Interact1ons

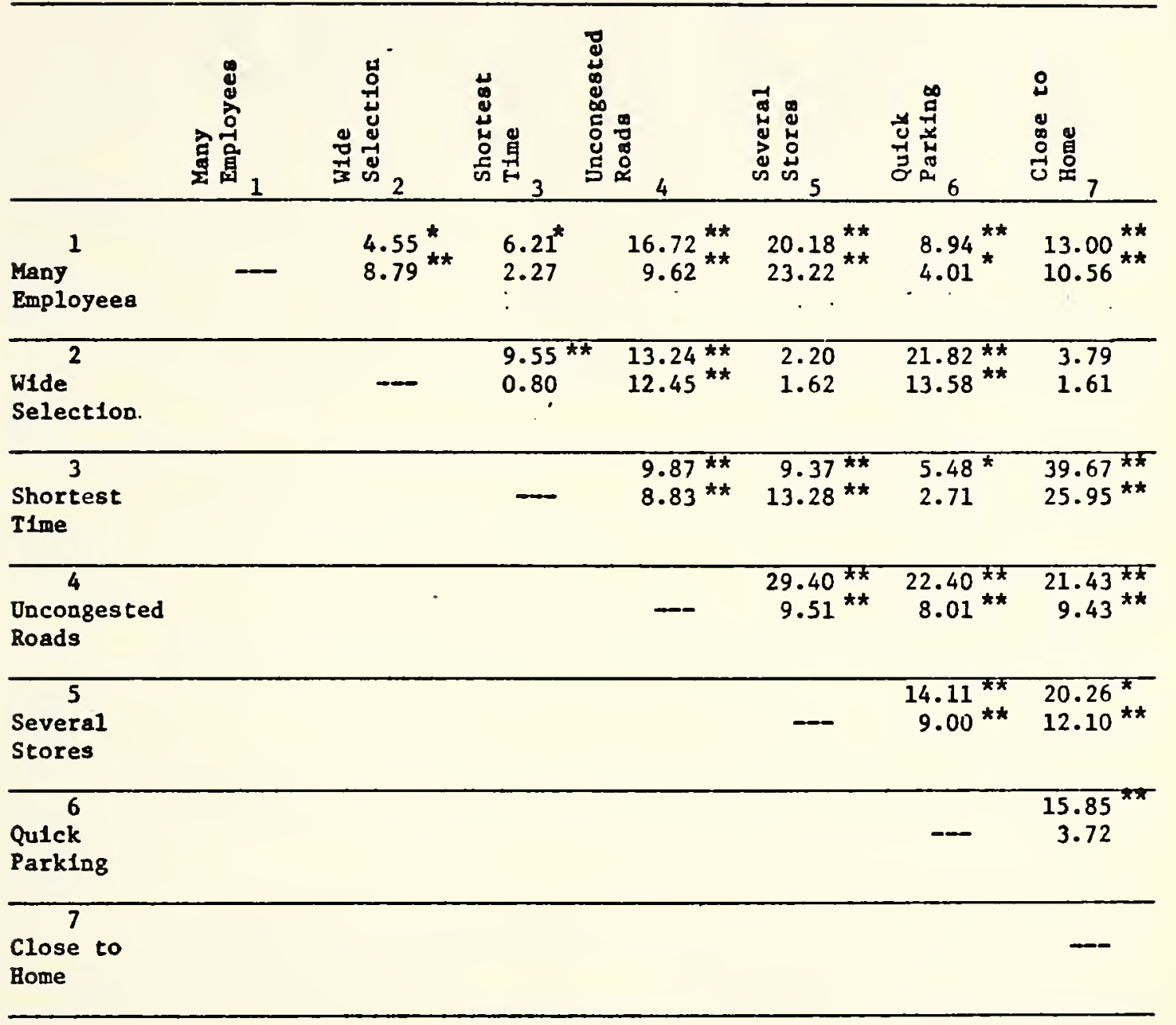

\begin{tabular}{|c|c|}
\hline $\begin{array}{l}\text { ** S1gnificance level } \leq .01 \\
.01<\text { Significance level } \leq .05\end{array}$ & $\begin{array}{l}\text { Layers from top } \\
\begin{array}{l}1 \cdot L \cdot R \cdot X^{2} \text { due to } 1,1 \text { Interaction } \\
2 . L \cdot R \cdot X^{2} \text { due to } 2,2 \text { Interaction }\end{array}\end{array}$ \\
\hline
\end{tabular}


Table $6.8 \chi^{2}$ - Values in 2-Way Tables - Case II, Interactione

\begin{tabular}{|c|c|c|c|c|c|c|c|}
\hline & 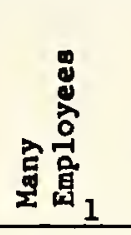 & 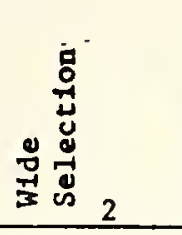 & 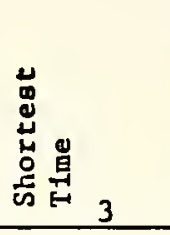 & 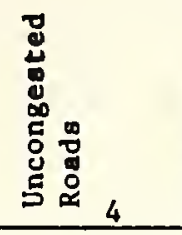 & 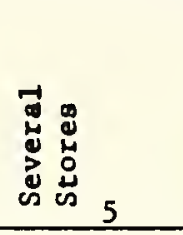 & 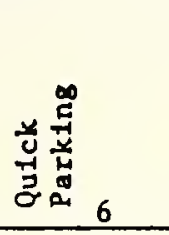 & 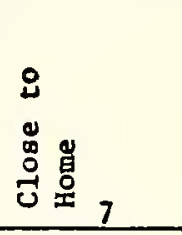 \\
\hline $\begin{array}{l}1 \\
\text { Kany } \\
\text { Employees }\end{array}$ & - & $\begin{array}{l}1.84 \\
9.85^{\star \star}\end{array}$ & $\begin{array}{l}5.07^{\star} \\
3.91^{\star}\end{array}$ & $\begin{array}{l}9.29^{\star \star} \\
3.90^{\star}\end{array}$ & $\begin{array}{l}27.21^{\star \star} \\
1.24\end{array}$ & $\begin{array}{l}4.65^{\star} \\
4.12^{\star}\end{array}$ & $\begin{array}{l}6.38^{\star \star} \\
3.99^{\star}\end{array}$ \\
\hline $\begin{array}{l}{ }^{2} \\
\text { Wide } \\
\text { Selection. }\end{array}$ & & - & $\begin{array}{l}3.79 \\
9.29^{\star \star}\end{array}$ & $\begin{array}{l}3.71 \\
7.20^{\star \star}\end{array}$ & $\begin{array}{c}15.16^{\hbar \hbar} \\
0.80\end{array}$ & $\begin{array}{l}16.32^{\star \star} \\
10.96^{\star \star}\end{array}$ & $\begin{array}{l}5.80^{k} \\
6.59^{\star}\end{array}$ \\
\hline \begin{tabular}{l}
\multicolumn{1}{c}{3} \\
Shortest \\
TIme
\end{tabular} & & & - & $\begin{array}{l}12.90^{\text {*x }} \\
8.71^{\text {* }}\end{array}$ & $\begin{array}{c}15.00^{x x} \\
1.43\end{array}$ & $\begin{array}{l}4.73^{\star} \\
2.53\end{array}$ & $\begin{array}{c}31.20^{\star \star} \\
4.18^{\star}\end{array}$ \\
\hline $\begin{array}{l}4 \\
\text { Uncongested } \\
\text { Rosdo }\end{array}$ & & & & - & $\begin{array}{c}19.69^{\star \star} \\
1.32\end{array}$ & $\begin{array}{l}26.92^{\star \star} \\
10.00^{\star \star}\end{array}$ & $\begin{array}{c}28.42^{\star \star} \\
2.67\end{array}$ \\
\hline \begin{tabular}{l}
\multicolumn{1}{c}{5} \\
Several \\
Stores
\end{tabular} & & & & & - & $\begin{array}{l}21.32^{\star \star} \\
14.04^{\star \star}\end{array}$ & $\begin{array}{c}15.22^{\star \star \star} \\
8.94^{\star \star}\end{array}$ \\
\hline \begin{tabular}{l}
\multicolumn{1}{c}{6} \\
Qu1ck \\
Park1ng
\end{tabular} & & & & & & $\ldots$ & $\begin{array}{c}12.16^{x *} \\
7.46^{* \star}\end{array}$ \\
\hline \begin{tabular}{l}
\multicolumn{1}{c}{} \\
Close to \\
Home
\end{tabular} & & & & & & & - \\
\hline
\end{tabular}

** Significance level $\leq .01$

* $.01<$ Significance leve $1 \leq .05$ a Layers from top

1. $L \cdot R \cdot X^{2}$ due to 1,1 Interaction

2. L.R. $\chi^{2}$ due to 2,2 Interaction 
Tables 6.9a-6.9c Attitudinal Orientation Pattern Prediction Tables ${ }^{a, b}$ Case III, Main Effects Models

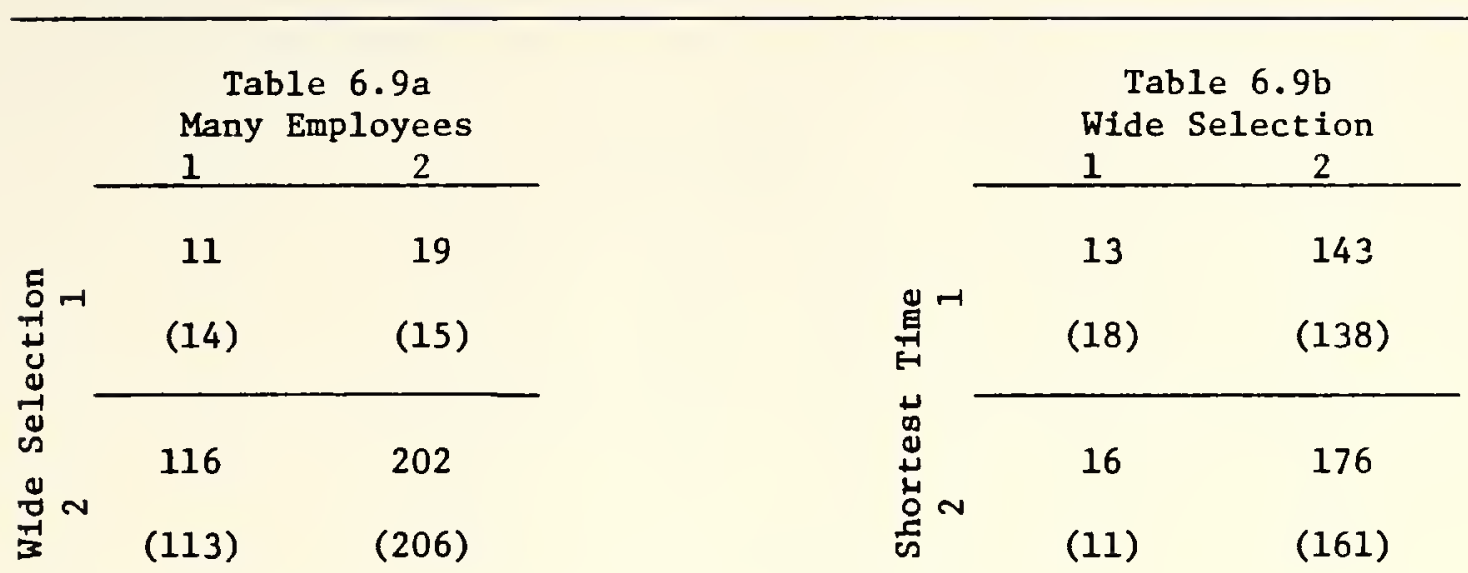

Row Parameter -2.3978

(0.193)

Col. Parameter -0.5540

(0.111)

Goodness-of-fit $\chi^{2}: 1.84$

Row Parameter -0.2076

$(0.127)$

Col. Parameter -2.3978

(0.193)

Goodness-of-fit $x^{2}: 3.79$

Table $6.9 \mathrm{c}$

Wide Selection

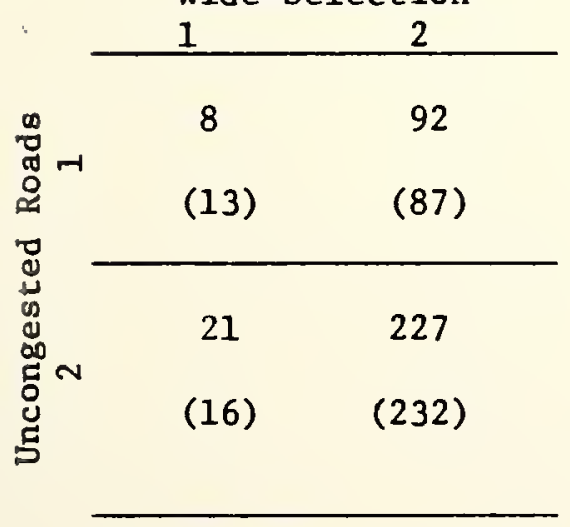

${ }^{a}$ Cell numbers are predicted frequencies with observed frequencies in parenthesis

$\mathrm{b}_{\text {The standard deviation of }}$ each parameter is in parenthesis

$c_{\text {Each }} \chi^{2}$ value has 1 d.f.

Row Parameter -0.9083

(0.118)

Col. Parameter -2.3978

(0.193)

Goodness-of-fit $\chi^{2}: 3.71$ 
Table 6.10 Attitudinal Orfentation Pattern Prediction Table ${ }^{z, b}$ - Case I, Main Effects Models

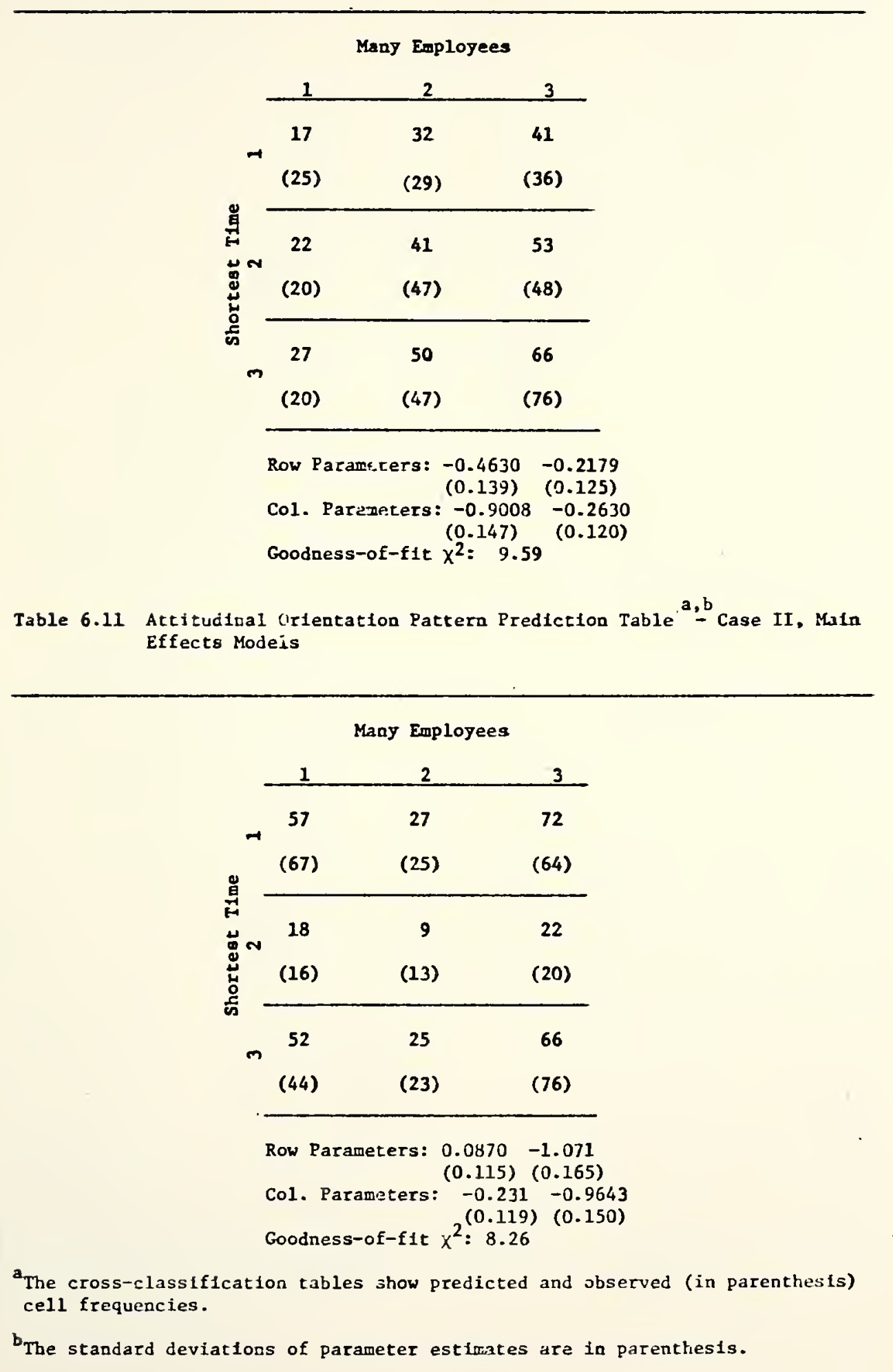


Tables 6.12a - 6.12d Attitudinal Orientation Pattern Prediction Tables ${ }^{a, b}-$ Maln Effects $+1,1$ Interaction Models

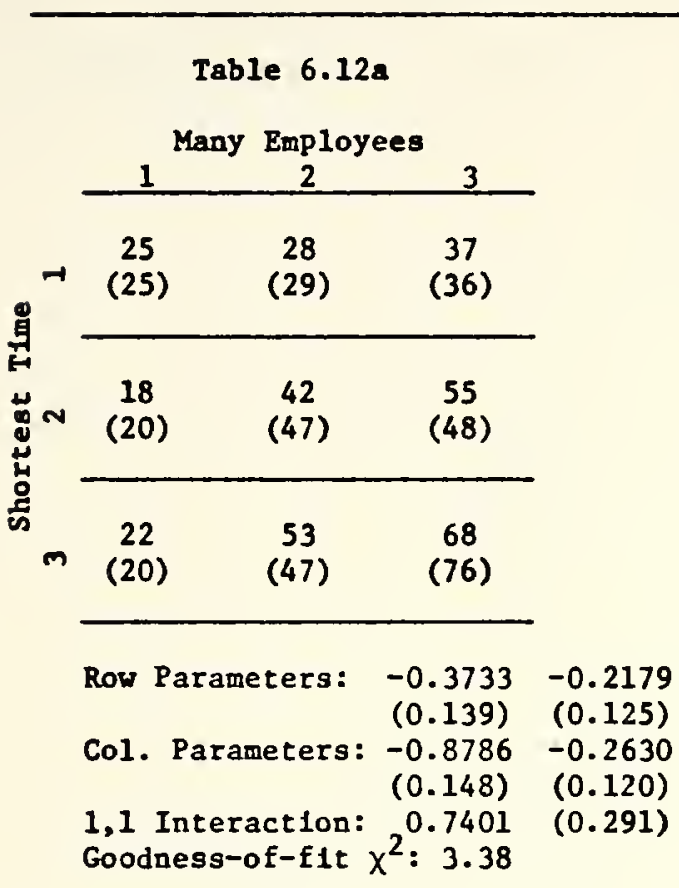

Table 6.12c

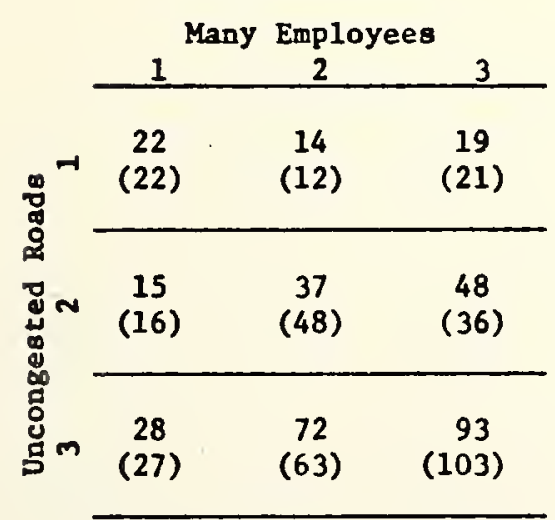

$\begin{array}{lrr}\text { Row Parameters: } & -1.1559 & -0.6575 \\ & (0.157) & (0.123) \\ \text { Col. Parameters: } & -0.7384 & -0.2630 \\ & (0.149) & (0.120) \\ & 1.3548 & (0.320) \\ \text { 1,1 Interaction: } & 1.350 \text { - } \chi^{2}: 9.30 & \end{array}$
Case I

Table $6.12 b$

\begin{tabular}{|c|c|c|c|}
\hline & \multicolumn{3}{|c|}{ Wide Selection } \\
\hline & 1 & 2 & 3 \\
\hline & $\begin{array}{c}9 \\
\text { (9) }\end{array}$ & $\begin{array}{c}13 \\
(16)\end{array}$ & $\begin{array}{c}68 \\
(65)\end{array}$ \\
\hline & $\begin{array}{c}2 \\
(3)\end{array}$ & $\begin{array}{c}18 \\
(20)\end{array}$ & $\begin{array}{c}95 \\
(92)\end{array}$ \\
\hline$m$ & $\begin{array}{c}3 \\
(2)\end{array}$ & $\begin{array}{c}22 \\
(16)\end{array}$ & $\begin{array}{c}118 \\
(125)\end{array}$ \\
\hline
\end{tabular}

Row Parameters: $\quad 0.0267-0.2179$

$(0.212) \quad(0.125)$

Col. Parameters: $-3.1791-1.6907$

$(0.324)(0.151)$

1,1 Interaction: $1.7267 \quad(0.571)$

Goodness-of-fit $x^{2}: 4.00$

Table 6.12d

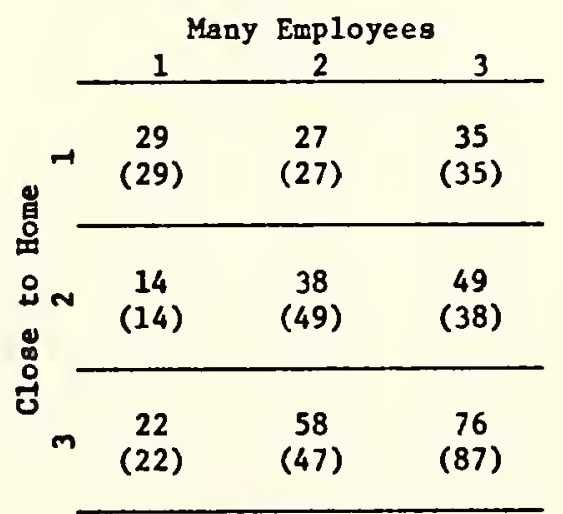

$\begin{array}{lcc}\text { Row Parameters: } & -0.4202 & -0.4347 \\ & (0.1 .92) & (0.127) \\ \text { Col. Parameters: } & -0.8928 & -0.2630 \\ & (0.150) & (0.119) \\ & 1.0548 & (0.287) \\ \text { 1,1 Interaction: } & 1.048 & \\ \text { Goodness-of-fit } x^{2}: 9.71 & \end{array}$

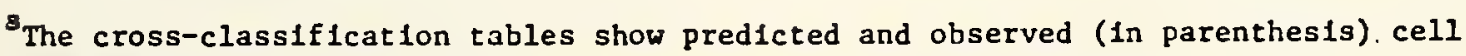
frequencles.

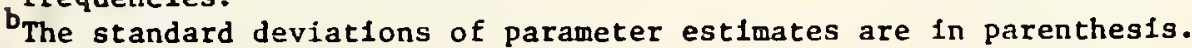


Tables 6.12e - 6.13b Attitudinal Orientation Pattern Prediction Tables ${ }^{\mathbf{a}, b}-$ Main Effects $+1,1$ Interaction Models

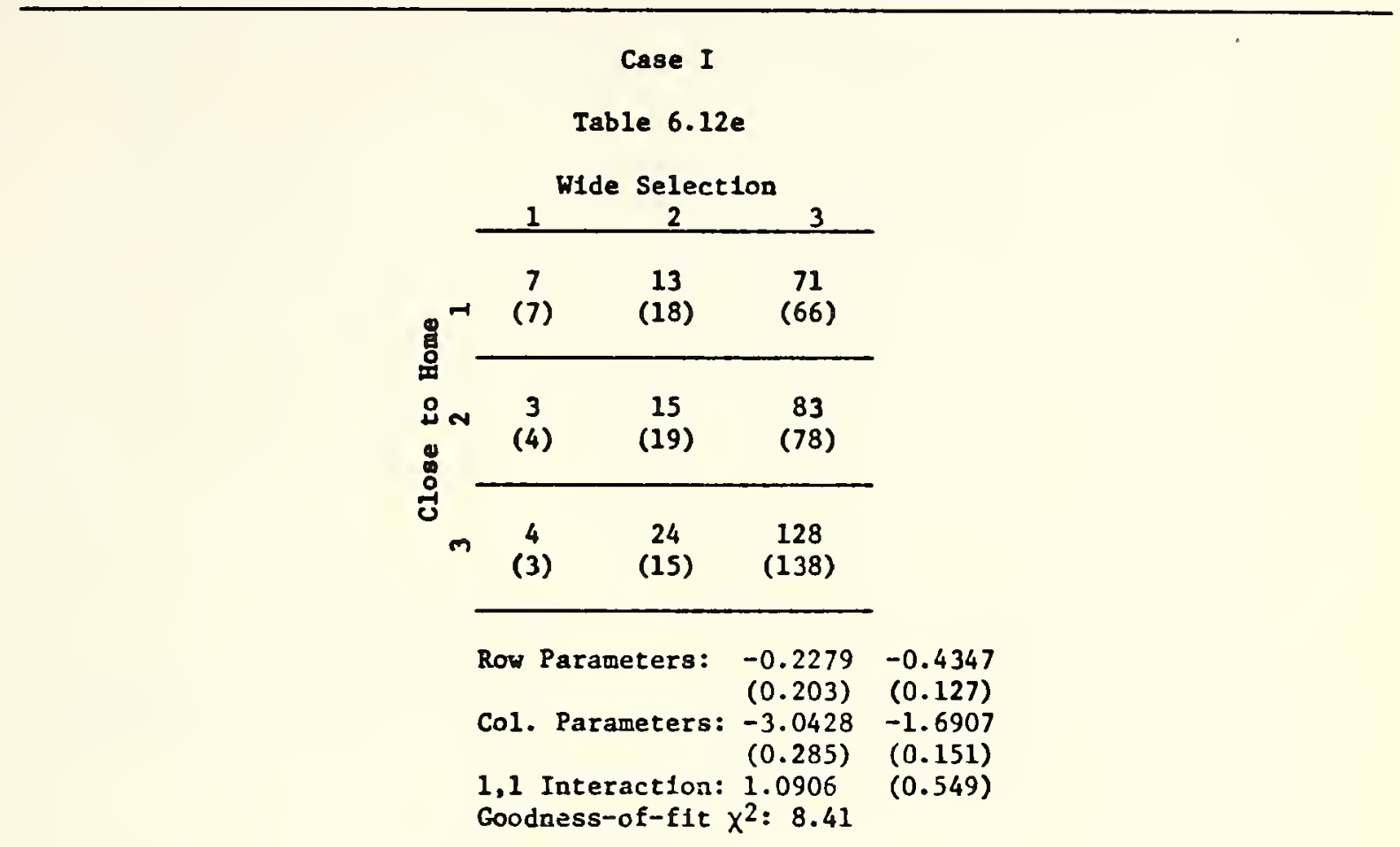

Table $6.13 a$

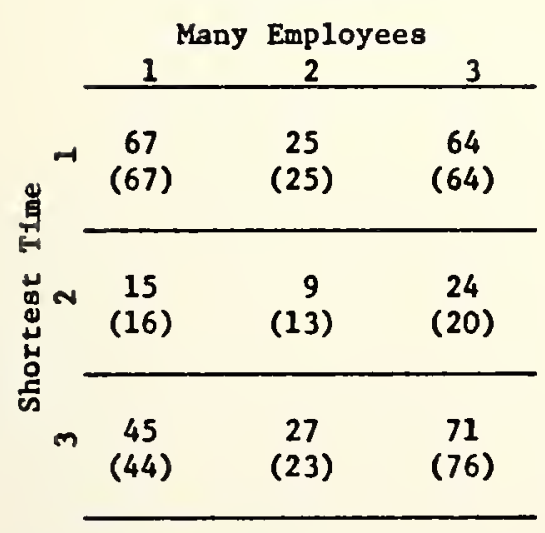

Row Parameters: $0.0687-1.0709$

(0.117) (0.165)

Col. Parameters: $-0.2973-0.9643$

(0.126) $(0.150)$

1,1 Interaction: $0.5045 \quad(0.224)$

Goodness-of-fit $\chi^{2}: 3.19$

\section{Case II}

Table $6.13 \mathrm{~b}$

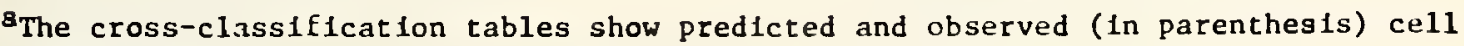
frequencies.

the standard deviations of parameter estimates are in parenthesis. 
Tablea 6.13c - 6.13d Attftudinal Orientation Pattern Prediction Tables a,b - Main Effects $+1,1$ Interaction Modela

\section{Case II}

Table $6.13 \mathrm{c}$

\begin{tabular}{|c|c|c|c|}
\hline & 1 & $\begin{array}{c}\text { Emp } 1 \\
2 \\
\end{array}$ & 3 \\
\hline & $\begin{array}{c}33 \\
(33)\end{array}$ & $\begin{array}{l}10 \\
(8)\end{array}$ & $\begin{array}{c}26 \\
(28)\end{array}$ \\
\hline 車 & $\begin{array}{c}15 \\
(17)\end{array}$ & $\begin{array}{c}8 \\
(13)\end{array}$ & $\begin{array}{c}22 \\
(15)\end{array}$ \\
\hline$m$ & $\begin{array}{c}79 \\
(77)\end{array}$ & $\begin{array}{c}43 \\
(40)\end{array}$ & $\begin{array}{c}112 \\
(117)\end{array}$ \\
\hline
\end{tabular}

$\begin{array}{lrr}\text { Row Parameter : } & -1.2643 & -1.6487 \\ & (0.141) & (0.162) \\ \text { Col. Parameters: }-0.1574 & -0.9643 \\ & (0.124) & (0.150) \\ & 0.5901 & (0.272) \\ \text { 1,1 Interaction: } & 0.79 & \\ \text { Goodneas-of-fit } x^{2}: 5.79 & \end{array}$

Table $6.13 \mathrm{~d}$

\begin{tabular}{|c|c|c|c|}
\hline & 1 & $\begin{array}{c}c t e s t \\
2 \\
\end{array}$ & 3 \\
\hline & $\begin{array}{c}95 \\
(95)\end{array}$ & $\begin{array}{c}20 \\
(21)\end{array}$ & $\begin{array}{c}57 \\
(56)\end{array}$ \\
\hline & $\begin{array}{c}20 \\
(25)\end{array}$ & $\begin{array}{c}10 \\
\text { (11) }\end{array}$ & $\begin{array}{c}28 \\
(21)\end{array}$ \\
\hline$m$ & $\begin{array}{c}41 \\
(36)\end{array}$ & $\begin{array}{c}20 \\
(17)\end{array}$ & $\begin{array}{c}58 \\
(66)\end{array}$ \\
\hline
\end{tabular}

$\begin{array}{lrr}\text { Row Parameters: } & 0.2716 & -0.7361 \\ & (0.124) & (0.161) \\ \text { Col. Parameters: } & -0.0580 & -1.0710 \\ (0.124) & (0.165) \\ & 0.8441 & (0.220) \\ \text { 1.1 Interaction: } & 0.84 & \\ \text { Goodness-of-fit } \mathrm{X}^{2}: 5.62 & \end{array}$

Tables 6.14a - 6.14b Attitudinal Orfentation Pattern Prediction Tables ${ }^{a, b}$ - Main Effects $+2,2$ Interaction Models

\section{Case II}

Table 6.14a

\begin{tabular}{|c|c|c|c|}
\hline \multirow{2}{*}{$g_{-1}^{-1}$} & 1 & $\begin{array}{c}\text { Emp } 1 \\
2 \\
\end{array}$ & 3 \\
\hline & $\begin{array}{c}58 \\
(67)\end{array}$ & $\begin{array}{c}25 \\
(25)\end{array}$ & $\begin{array}{c}73 \\
(64)\end{array}$ \\
\hline N & $\begin{array}{c}16 \\
(16)\end{array}$ & $\begin{array}{c}13 \\
\text { (13) }\end{array}$ & $\begin{array}{c}20 \\
(20)\end{array}$ \\
\hline n & $\begin{array}{c}53 \\
(44)\end{array}$ & $\begin{array}{c}23 \\
(23)\end{array}$ & $\begin{array}{c}67 \\
(76)\end{array}$ \\
\hline
\end{tabular}

$\begin{array}{lrr}\text { Bow Parameters: } & 0.0870 & -0.9924 \\ & (0.116) & (0.169) \\ \text { Co1. Parameters: } & -0.2310 & -0.8580 \\ (0.119) & (0.135) \\ & 0.6357 & (0.358)\end{array}$

Table 6.14b

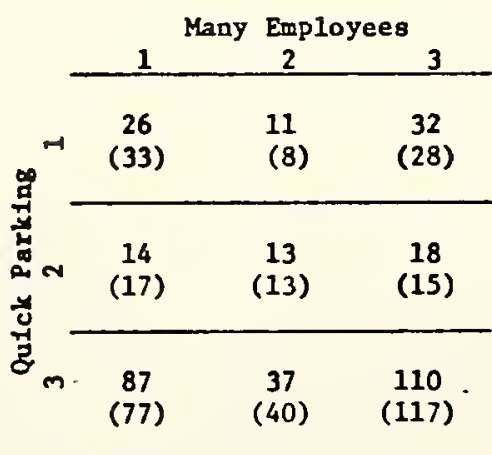

\begin{tabular}{|c|c|c|}
\hline Row Paramezers: & -1.2212 & -1.5607 \\
\hline CoI. Pa & $\begin{array}{l}-0.2310 \\
(0.119)\end{array}$ & $\begin{array}{l}-0.8293 \\
(0.140)\end{array}$ \\
\hline $\begin{array}{l}2,2 \text { Interaction: } \\
\text { Goodness-of-fit }\end{array}$ & $\begin{array}{r}0.7693 \\
\times^{2}: 6.32\end{array}$ & $(0.364)$ \\
\hline
\end{tabular}

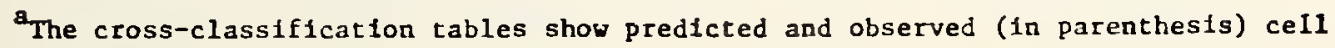
frequencles.

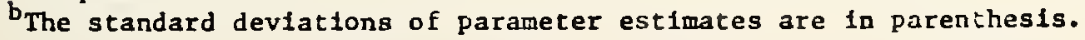


bring any improvement in attitudinal pattern prediction above that provided by the Main Effects models.

Models With Main Effects and 2,2 Interactions

With the addition of a 2,2 interaction the significant reductions in $x^{2}$ values due to this interaction were not enough to appreciably improve the accuracy of reproducibility of observed attitudinal orientation patterns between pairs of factors for Case I, shown in Table 6.4b. For Case II in Table $6.5 \mathrm{~b}$ only the pairings of "Many Employees" with "Shortest Time" and "Many Employees" with "Quick Parking" yield reasonable models.

The significant $x^{2}$ reductions due to the 2,2 interactions are indicated in Tables 6.7 and 6.8. Observed and predicted frequency distributions for models described above are shown in Tables 6.14a and $6.14 \mathrm{~b}$.

Mode1s With Main Effects, 1,1 and 2,2 Interactions

The models fitted using main effects as well as 1,1 and 2,2 interactions give good predictions when the factor "Many Employees" is paired with "Shortest Time," "Uncongested Roads" and "Close to Home" as shown in Table 6.4b for Case I. The same applies in this table to the pairings of "Wide Selection" with "Shorter Time," "Wide Selection" with "Quick Parking" and "Shorter Time" with "Several Stores." Case II essentially gives similar results in Table 6.5b and in addition shows good predictions for "Many Employees" paired with "Quick Parking," "Several Stores" with "Quick Parking" and "Quick Parking" with "Close to Home." The predicted 
and observed frequency distributions for the models mentioned are shown in Tables $6.15 \mathrm{a}$ to $6.15 \mathrm{f}$ and Tables $6.16 \mathrm{a}$ to $6.16 \mathrm{j}$.

In the few situations in which Case I differs from Case II, such a difference can be attributed to the way the categories were defined. Case II appears preferable since it provides good predictions for more pairings of factors than Case I. If the sample size was large enough, or the categories were no more thanfive, it would not be necessary to have to try different combinations of extreme categories on the successive category rating scale to obtain a useful classification table. The main effect with 1,1 and 2,2 interaction model is the one recommended as best fitting the survey data for Cases I and II. This is on the basis of the good predictions that this model achieves, demonstrated by the associated low goodness-of-fit $x^{2}$ values.

\section{Deductions From the Models}

The important deduction that can be made in evaluating the models is that the following pairs of factors may be considered in modelling shopping destination choice for the sample investigated on the basis of Case II models.

1. "Many Employees" and "Shortest Time"

2. "Many Employees" and "Uncongested Roads"

3. "Many Employees" and "Quick Parking"

4. "Many Employees" and Close to Home"

5. "Wide Selection" and "Shortest Time"

6. "Wide Selection" and "Quick Parking"

7. "Shorter Time" and "Several Stores" 
Tables 6.15a - 6.15d Attitudinal Orientation Pattern Prediction Tablea,b - Maln Effects $+1,1$ Interaction $+2,2$ Interaction Modele

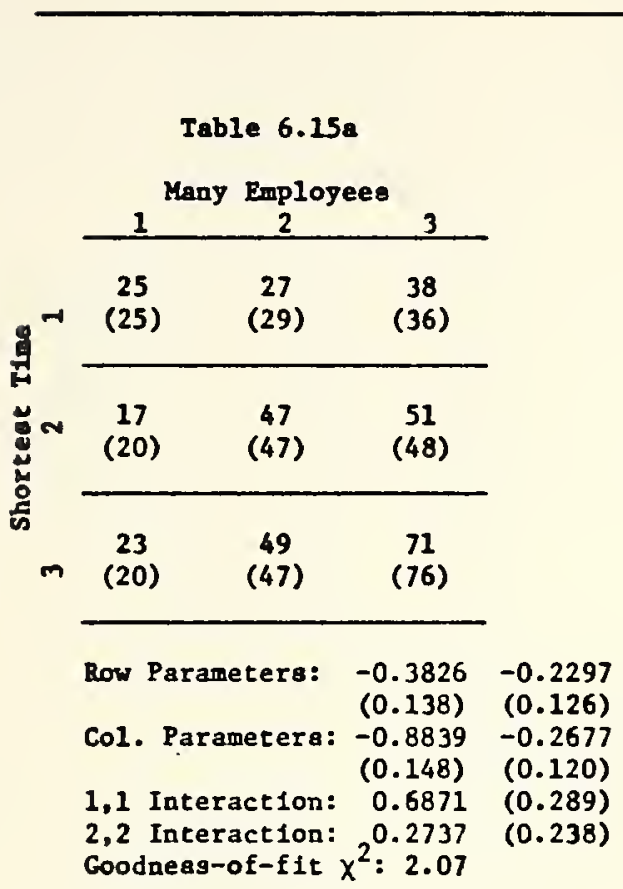

Case I

\begin{tabular}{|c|c|c|c|}
\hline \multirow{2}{*}{$\stackrel{0}{g}^{-1}$} & $1^{\mathrm{Ma}}$ & Boployees & es \\
\hline & $\begin{array}{c}22 \\
(22)\end{array}$ & $\begin{array}{c}13 \\
(12)\end{array}$ & $\begin{array}{r}20 \\
(21)\end{array}$ \\
\hline$\underset{\mathbb{g}}{\mathbb{g}} N$ & $\begin{array}{c}12 \\
(16)\end{array}$ & $\begin{array}{c}48 \\
(48)\end{array}$ & $\begin{array}{c}40 \\
(36)\end{array}$ \\
\hline${ }_{\mathrm{E}} \mathrm{m}$ & $\begin{array}{c}31 \\
(27)\end{array}$ & $\begin{array}{c}62 \\
(63)\end{array}$ & $\begin{array}{c}100 \\
(103)\end{array}$ \\
\hline
\end{tabular}

$\begin{array}{lrr}\text { Row Parameters: } & -1.1734 & -0.7014 \\ & (0.157) & (0.126) \\ \text { Col. Parameters: } & -0.2519 & 1.2574 \\ & (0.152) & (0.121) \\ & 1.2574 & (0.323) \\ \text { 1,1 Interact Ion: } & 0.6603 & (0.345) \\ 2,2 \text { Interaction: } & 0.660 \\ \text { Goodness-of-f1t } \chi^{2}: 2.06 & \end{array}$

Table 6.15d

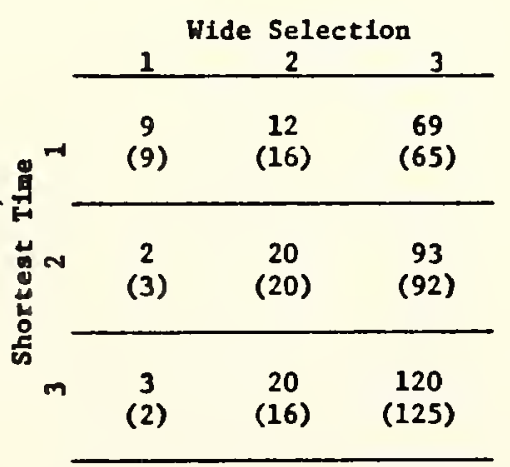

Row Parameters: $0.0214-0.1753$

$(0.212) \quad(0.136)$

Co1. Parameters: $-3.1807 .-1.6963$

$\begin{array}{ll}(0.324) \quad(0.151) & 0\end{array}$

1,1 Interaction: $1.7096 \quad(0.181)$

2,2 Interaction: $0.2421 \quad(0.311)$

Goodness-of-f1t $\chi^{2}: 3.41$

The cross-classification tables show predicted and observed (In parenthesis) cell Erequencies.

${ }^{b}$ The standard deviations of parameter estimatea are in parenthesis. 
Tables 6.15e,f and 6.16a,b Attjtudinal Orlentation Pattern Prediction Tables ${ }^{a, b}$ MaIn Effects + 1,1 Interaction + 2,2 Interaction Models

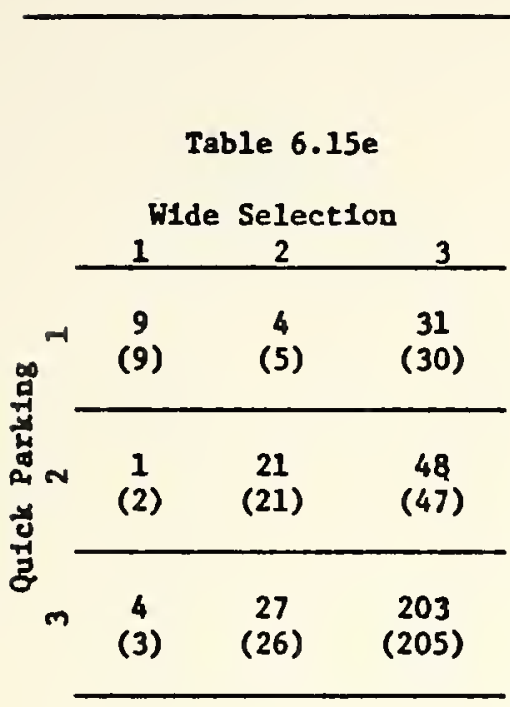

$\begin{array}{rrr}\text { Row Parameters: } & -0.9883 & -1.0435 \\ (0.222) & (0.143) \\ \text { Col. Parameters:-3.0222 } & -1.6233 \\ (0.326) & (0.154) \\ \text { 1,1 Interaction: } 2.6827 & (0.585) \\ \text { 2,2 Interaction: } 1.1936 & (0.323) \\ \text { Goodness-of-f1t } \chi^{2}: 1.44 & \end{array}$

Table 6.16a

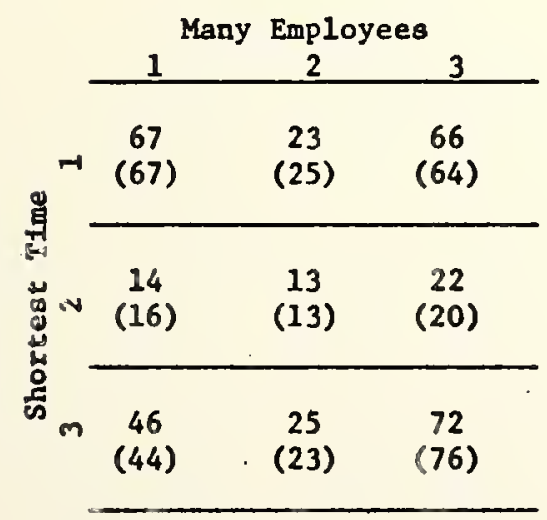

Row Parameters: $0.0680-1.0097$

$(0.116)(0.169)$

Col. Parameters: $-0.2942-0.8791$

$(0.124) \quad(0.159)$

1,1 Interaction: $0.463 i \quad(0.226)$

2,2 Interaction: $0.5315 \quad(0.363)$
Case I

\begin{tabular}{|c|c|c|c|}
\hline \multirow{3}{*}{ 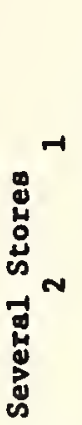 } & \multicolumn{3}{|c|}{ Shortest Time } \\
\hline & $\begin{array}{c}40 \\
(40)\end{array}$ & $\begin{array}{c}26 \\
(30)\end{array}$ & $\begin{array}{c}43 \\
(39)\end{array}$ \\
\hline & $\begin{array}{c}22 \\
.(27)\end{array}$ & $\begin{array}{c}55 \\
(55)\end{array}$ & $\begin{array}{c}43 \\
\text { (38) }\end{array}$ \\
\hline & $\begin{array}{c}28 \\
(23)\end{array}$ & $\begin{array}{c}34 \\
(30)\end{array}$ & $\begin{array}{c}56 \\
(66)\end{array}$ \\
\hline
\end{tabular}

$\begin{array}{lrr}\text { Row Parameters: } & -0.0671 & -0.0187 \\ & (0.134) & (0.131) \\ \text { Col. Parsmeters: } & -0.4863 & -0.2588 \\ & (0.136) & (0.128) \\ 1,1 \text { Interaction: } & 0.6184 & (0.260) \\ \text { 2,2 Interaction: } 0.7462 & (0.242) \\ \text { Goodness-of-fit } \chi^{2}: 5.96 & \end{array}$

Case II

Table 6.16b

\begin{tabular}{|c|c|c|c|}
\hline \multirow{2}{*}{$\begin{array}{l}\mathbb{D}^{-1} \\
\text { D }^{\circ}\end{array}$} & \multicolumn{3}{|c|}{$\begin{array}{c}\text { Many Employees } \\
2\end{array} 3$} \\
\hline & $\begin{array}{c}49 \\
(49)\end{array}$ & $\begin{array}{l}13 \\
(16)\end{array}$ & $\begin{array}{c}38 \\
(35)\end{array}$ \\
\hline 总 $N$ & $\begin{array}{l}16 \\
(18)\end{array}$ & $\begin{array}{l}15 \\
(15)\end{array}$ & $\begin{array}{r}24 \\
(22)\end{array}$ \\
\hline 㖞 & $\begin{array}{c}62 \\
(60)\end{array}$ & $\begin{array}{c}33 \\
(30)\end{array}$ & $\begin{array}{c}98 \\
(103)\end{array}$ \\
\hline
\end{tabular}

$\begin{array}{lrr}\text { Row Parameters: } & -0.7075 & -1.1875 \\ & (0.127) & (0.156) \\ \text { Co1. Parameters: } & -0.2137 & -0.8825 \\ & (0.120) & (0.156) \\ & 0.6987 & (0.244) \\ \text { 1,1 Interacticn: } & 0.5948 & (0.344) \\ 2,2 \text { Interaction: } & 0.5948 & \\ \text { Goodness-of-f1t } \chi^{2}: 2.22 & \end{array}$

${ }^{a}$ The cross-classification tables show predicted and observed (In parenthesis) cell frequencies

${ }^{b}$ The standard deviations of parameter estimates are in parenthesis 
Tables 6.16c - 6.16f Att1tudinal Orientation Pattern Prediction Tables a,b - Main Effects $+1,1$ Interaction $+2,2$ Interaction Modela

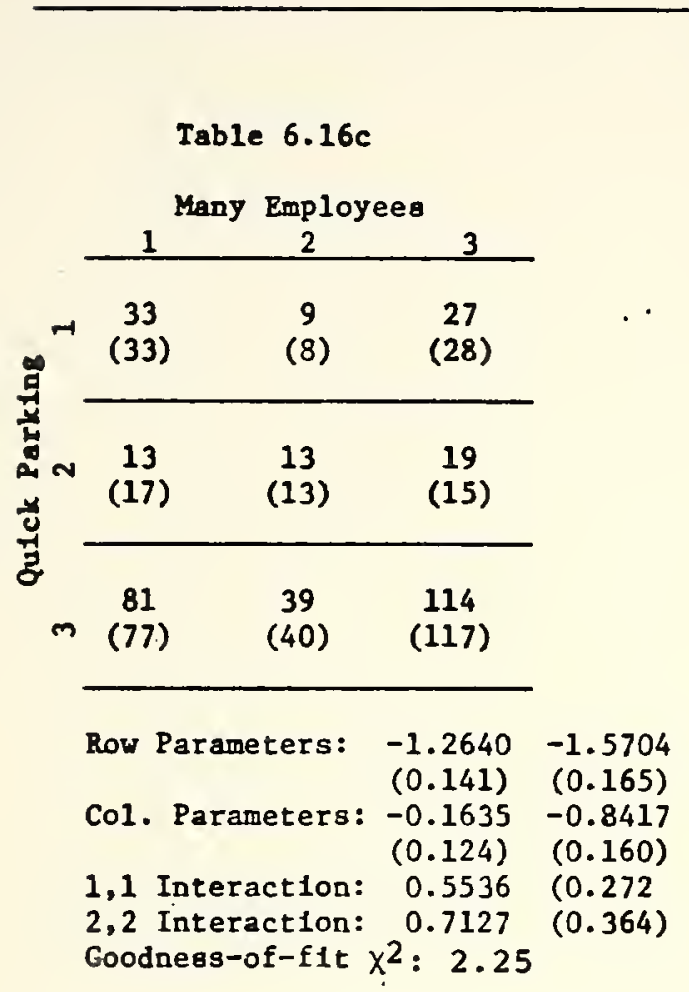

Table $6.16 \mathrm{e}$

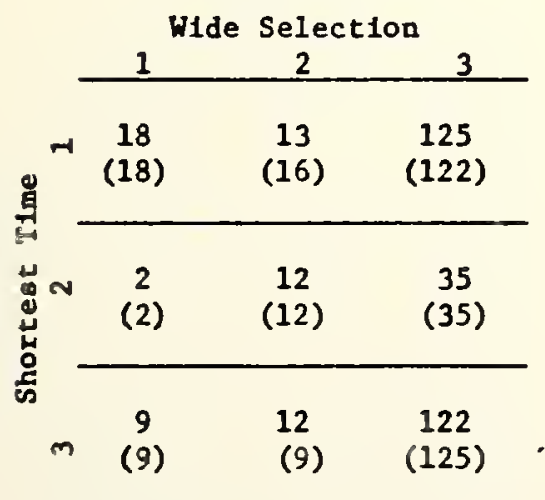

\begin{tabular}{lcc}
\hline Row Parameters: & 0.2648 & -0.8503 \\
& $(0.153)$ & $(0.175)$ \\
Col. Parameters: & -2.4177 & -1.8809 \\
& $(0.224)$ & $(0.179)$ \\
1,1 Interaction: & 0.7156 & $(0.399)$ \\
2,2 Interaction: & 1.2341 & $(0.398)$
\end{tabular}

\section{Case II}

Table $6.16 \mathrm{~d}$

\begin{tabular}{|c|c|c|c|}
\hline & 1 & $\begin{array}{c}\mathrm{Emp} 1 \\
2 \\
\end{array}$ & 3 \\
\hline$g^{-1}$ & $\begin{array}{c}63 \\
(63)\end{array}$ & $\begin{array}{c}20 \\
(26)\end{array}$ & $\begin{array}{c}59 \\
(53)\end{array}$ \\
\hline \& & $\begin{array}{c}14 \\
(16)\end{array}$ & $\begin{array}{c}14 \\
(14)\end{array}$ & $\begin{array}{c}22 \\
(20)\end{array}$ \\
\hline$m$ & $\begin{array}{c}50 \\
(48)\end{array}$ & $\begin{array}{c}27 \\
(21)\end{array}$ & $\begin{array}{c}79 \\
(87)\end{array}$ \\
\hline
\end{tabular}

Row Parameters: $\quad-0.1190-1.0692$

$(0.117) \quad(0.165)$

Col. Parameters: $-0.2824-0.8692$

$(0.122) \quad(0.157)$

1,1 Interaction: $0.5238 \quad(0.228)$

2,2 Interaction: 0.6229 (0.355)

Goodness-of-fit $x^{2}: 4.97$

Table $6.16 \mathrm{f}$

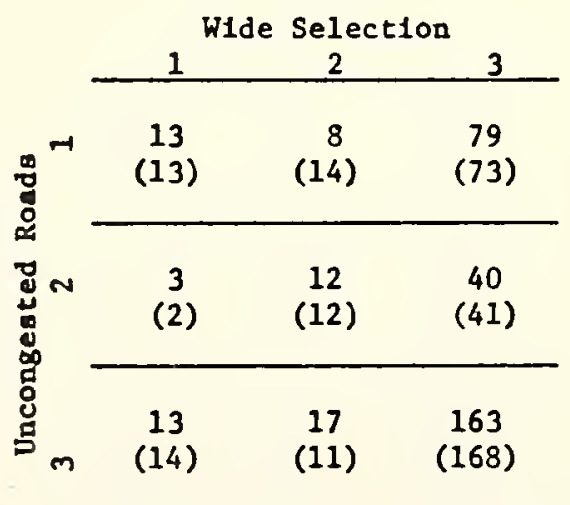

Row Parameters: $\quad-0.4816-1.0534$

$(0.154) \cdot(0.165)$

Col. Parameters: $-2.2951-1.9139$

$(0.200) \quad(0.178)$

1,1 Interaction: $0.7386 \quad(0.394)$

2,2 Interaction: $1.0702 \quad(0.388)$

Goodness-of-f1t $x^{2}: 6.97$

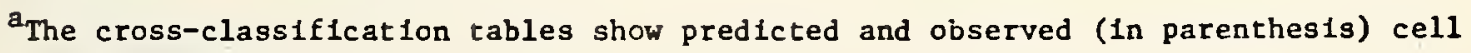
frequencles.

The standard devlations of parameter estimates are in parenthesis. 
Tables 6.168 - 6.16j Attitudinal Orientation Pattern Prediction Tables ${ }^{a, b}$ - Main Effects $+1,1$ Interaction $+2,2$ Interaction Models

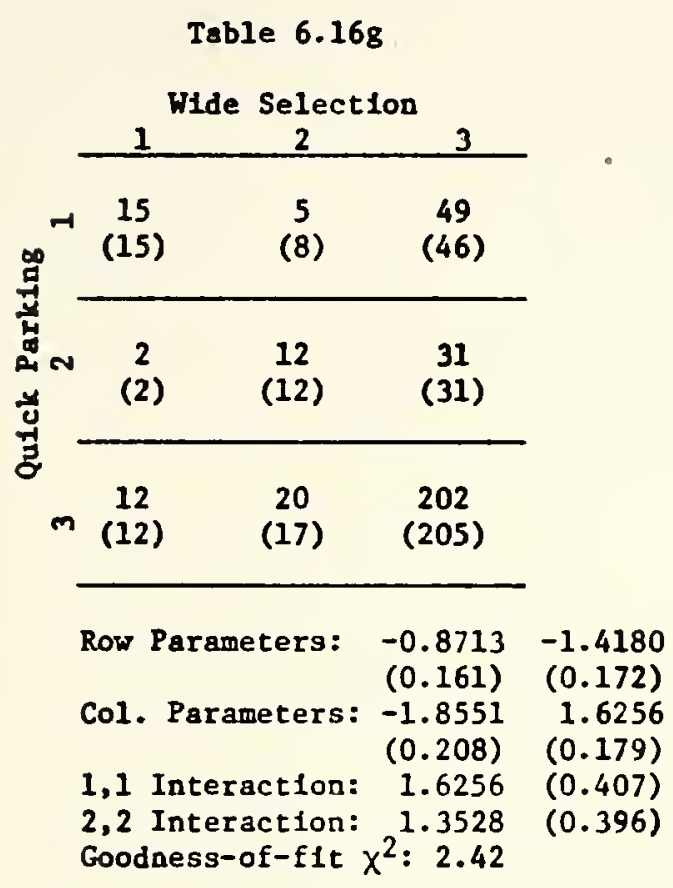

Table 6.161

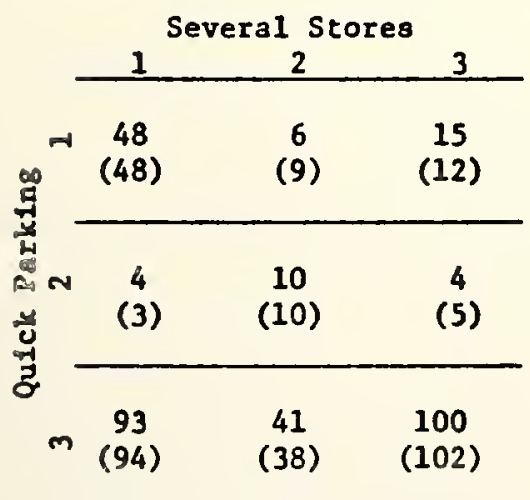

Table $6.16 \mathrm{~h}$

Shortest Time

\begin{tabular}{|c|c|c|c|}
\hline & 1 & 2 & 3 \\
\hline & $\begin{array}{c}95 \\
(95)\end{array}$ & $\begin{array}{c}19 \\
(21)\end{array}$ & $\begin{array}{c}58 \\
(56)\end{array}$ \\
\hline & $\begin{array}{c}19 \\
(25)\end{array}$ & $\begin{array}{c}11 \\
(11)\end{array}$ & $\begin{array}{c}27 \\
(21)\end{array}$ \\
\hline$m$ & $\begin{array}{c}42 \\
(36)\end{array}$ & $\begin{array}{c}19 \\
(17)\end{array}$ & $\begin{array}{c}58 \\
(66)\end{array}$ \\
\hline
\end{tabular}

Row Parameters: $\quad 0.2719-0.7002$

$(0.124) \quad(0.171)$

Col. Parameters: $-0.0566-1.0418$

$(0.124) \quad(0.171)$

1,1 Interaction: $0.8244 \quad(0.223)$

2,2 Interaction: $0.2283 \quad(0.382)$

Goodness-of-fit $x^{2}: 5.28$

Table 6.16j

\begin{tabular}{|c|c|c|c|}
\hline & \multicolumn{3}{|c|}{ Quick Parking } \\
\hline & 1 & 2 & 3 \\
\hline$\rightarrow$ & $\begin{array}{c}41 \\
(41)\end{array}$ & $\begin{array}{c}14 \\
(19)\end{array}$ & $\begin{array}{c}87 \\
(82)\end{array}$ \\
\hline${ }_{0}^{8}$ & $\begin{array}{c}6 \\
(6)\end{array}$ & $\begin{array}{c}13 \\
(13)\end{array}$ & $\begin{array}{c}31 \\
(31)\end{array}$ \\
\hline$m$ & $\begin{array}{c}22 \\
(22)\end{array}$ & $\begin{array}{c}18 \\
(13)\end{array}$ & $\begin{array}{c}116 \\
(122)\end{array}$ \\
\hline
\end{tabular}

$$
\begin{aligned}
& \text { Row Parameters: } 0.0183-0.9893 \\
& \text { (0.123) (0.169) } \\
& \text { Col. Parameters: }-1.3561-1.5219 \\
& \text { (0.170) (0.167) } \\
& 1,1 \text { Interaction: } 0.9015 \quad(0.275) \\
& \text { 2,2 Interaction: } 0.9758 \quad(0.373) \\
& \text { Goodness-of-fit } \chi^{2}: 4.02
\end{aligned}
$$

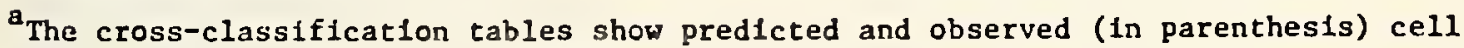
frequencies.

b The standard deviations of parameter estlnates are in parenthesis. 
8. "Several Stores" and "Quick Parking"

9. "Quick Parking" and "Close to Home"

It is noticed that some of the pairings of factors are essentially indicating the same thing. An example is that with pairs 1 and 5 since where there is a wide selection of goods there are usually more employees and congested roads usually.require more travel time. The results cannot be taken as conclusive but it must be noted that generally no three of the factors can be considered jointly in a model since two of them are likely to have a significant interaction that can distort the predictive power of a model using all three factors. This is a welcome finding especially if it can be verified in further research since it is likely to indicate that model development should be with just two or three attitudinal factors that can be associated with some measurable variables. An example of a good pair would be "Wide Selection" and "Shortest Time."

Summary

It was established that therewas significant correlation between many pairs of the destination choice successive category factors available for this research. The frequency distributions of the ratings for the factors did not display normality necessary for classical successive category data analysis approaches. This necessitated the use of contingency tables with a smaller number of categories in the ways of classification because of the small sample size, for reproducing observed attitudinal orientation patterns. Such predictability is argued to be necessary in short range 
forecasting or the expansion of attitudinal orientation patterns for the total population using data for a sample.

It was found that essentially only two of the factors need be present in a single modelling framework since most of them have a similar effect. A combination of three factors cannot occur without significant interaction between two of them distorting the modelling results. With the inclusion of certain interaction effects in 2-way classifications, good predictability of the attitudinal orientation patterns was possible for many pairs of factors. The essential factors are related to measures of the wide range of goods or services at a shopping area or the convenience in reaching a destination in terms of travel time and distance. 


\section{CHAPTER 7 \\ ESTIMATION WITH PROPOSED FUNCTIONAL DESTINATION CHOICE MODELLING FRAMEWORK}

The objective of this chapter is to illustrate the multinomial response relation framework for modelling the choice of functional destinations. This modelling framework has a logical provision for aggregate forecasts and hence can be used in an operational set of models. It is clear that the sample size used in this research was limited by its smallness. Also the data were not collected with the analytical procedures discussed in this research in mind. The examples of the application of the multinomial response relation approach are, therefore, given the best way the data allowed. The fundamental theoretical arguments for adopting the approach illustrated in this chapter were presented in Chapter 5. It is strongly maintained by the writer that if encouraging results occur they should serve as a basis for the collection, in the future, of a more appropriate data set to better appreciate the usefulness of the multinomial response relation approach.

Not more than three market segments were considered at a time in the empirical analyses discussed in this chapter mainly because of the small sample size of households. It would have been desirable not only to have considered 2-way classification categories for market segmentation with respect to the attitudinal variables but to 
combine the attitudinal factors and the approachability measures for segmentation for the same model. Though the small sample size did not permit this, the effect of the combination of attitudinal and approachability factors was examined by testing their independence and the reproducibility of their classifications.

The functional classification of destinations was also limited to 2-way classifications because of the small sample size of the available data. 2-way classifications involving Retail Floor Area with each of Line Haul Travel Time and Airline Distance kere used in model development to define functional destination alternatives, as illustrated in Figures 7.1 and 7.2. Based on the fact that not more than three market segments were involved in any single application of the multinomial response relation approach, a separate contingency table for each market segment was analyzed. A comparison of the parameters estimated for models predicting the contingency table cell frequencies established the effectiveness or need for a given variable or factor to be used as a basis for such a one-way market segmentation. Some mutivariate statistical tests were employed for testing the equality of model parameter vectors and their covaiance matrices.

The data that were used for the empirical analysis in this chapter were derived from data originally collected by Kannel [10] in Indianapolis in 1971, supplemented with further data collection and preparation by the writer. The data base has been described in Chapters 4 and 6. A discussion of some assumptions implied in functional destination choice modelling, with the aid of some empirical analysis presented in Appendix B, is also presented. 


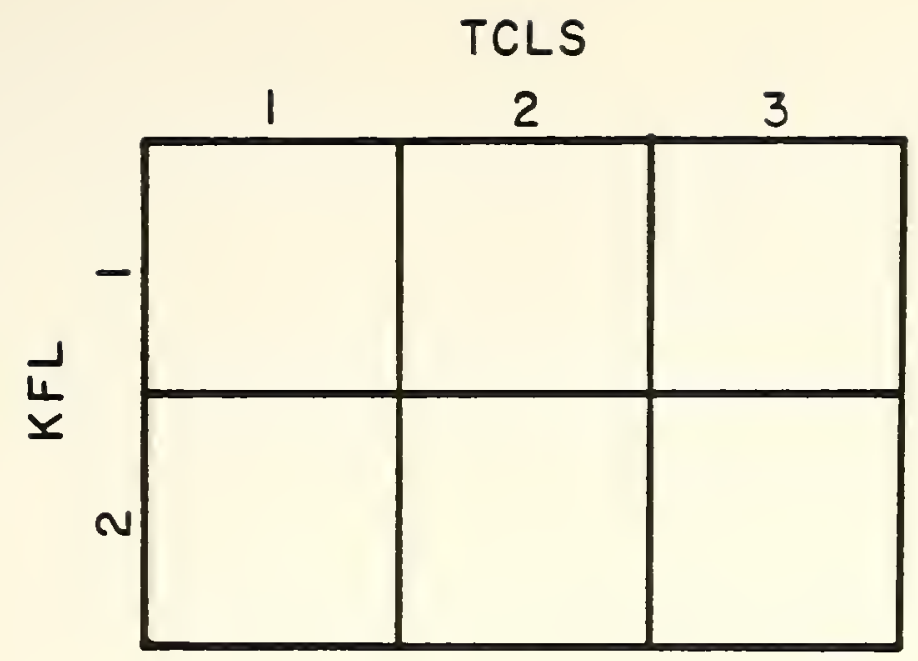

KFL

1 Retail Floor Area $\geqslant 300,000$ sq. $\mathrm{ft}$.

2 Retoil Floor Areo $<300,000$ sq. ft.

TCLS

I

Line Houl Travel Time $\geqslant 10$ mins.

25 mins. $\leqslant$ Line Houl Travel Time $<10$ mins.

3

Line Houl Travel Time $<5$ mins.

FIGURE 7.1 FUNCTIONAL SHOPPING DESTINATION CATEGORIES DEFINED BY RETAIL FLOOR AREA AND LINE HAUL TRAVEL TIME 


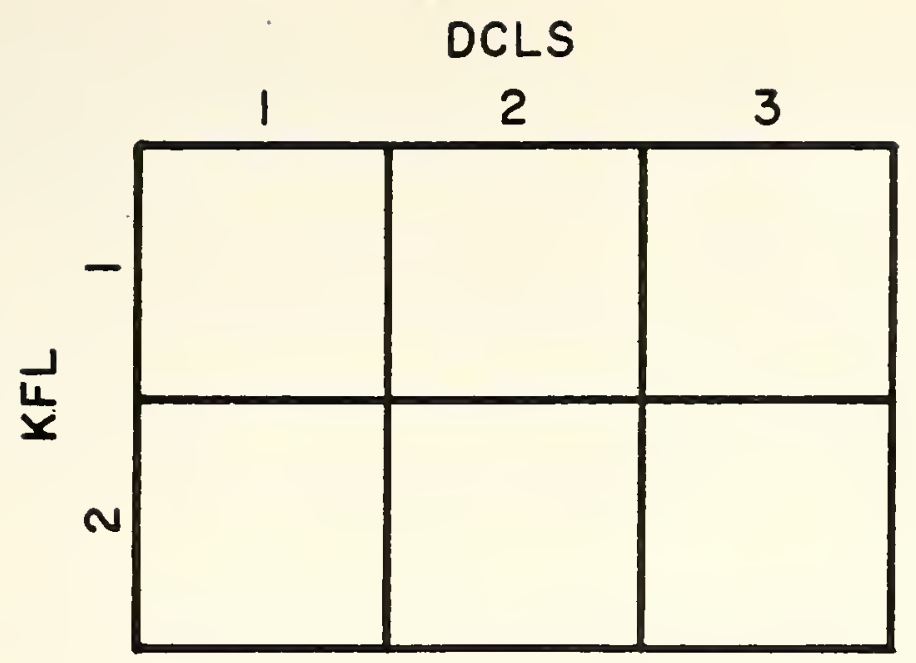

KFL

I Retail Floor Area $\geqslant 300,000$ sq. $f t$.

2 Retail Floor Area $<300,000$ sq. ft.

DCLS

I

Airline Distance $\geqslant 8$ units

24 units $\leqslant$ Airline Distance $<8$ units

3

Airline Distance $<4$ units

Each unit of Distance is equivalent to 0.833 miles

FIGURE 7.2 FUNCTIONAL SHOPPING DESTINATION CATEGORIES DEFINED BY RETAIL FLOOR AREA AND AIRLINE DISTANCE 
The theory and application of the multinomial response relation (MRR) approach have been presented in Chapter 5. Detailed example calculations are given in Appendix A. The bases used for empirical investigation in this chapter are derived in the manner discussed for the basis construction example in Chapter 5 since all the applications in this chapter are for $2 \times 3$ crossed designs.

Prediction of Functional Shopping Destinations Defined With Respect to

Retail Floor Area and Line Haul Travel Time by Attitudinal Factor Market Segments

Table 7.1 summarizes the result of an experimental model to reproduce the cell frequencies in the contingency table with respect to Retail Floor Area and Line haul Travel Time that defines functional shopping destinations. The predictive accuracy of the model summarized in Table 7.1 is very good and reflects on the reliability of destination choice models in terms of functional destinations. The question that is addressed in this section is whether the attitudinal orientation of groups of people causes them to select functional shopping destinations differently. With respect to each destination choice attitudinal factor, an individual belongs to market segment 1 if the rating for that factor on the successive category scale is less than or equal to 4 and to segment 2 if the rating is greater than 4 . Less than 10 percent of the sample fell into market segment 1 for the attitudinal factor relating to "Shortest Travel Time" so.it was not possible to develop a predictive model for segment 1 for this factor for which reason it was excluded from the analysis. 
Table 7.1 Prediction of Functional Destination Choice Frequencies for the Total Sample With Respect to Retail Floor Area and Line Haul Travel Time a,b

\begin{tabular}{ccc}
\hline & TCLS \\
& 2 & 3 \\
\hline 58 & 68 & 76 \\
$(61)$ & $(68)$ & $(73)$ \\
\hline \multirow{2}{*}{$\begin{array}{c}1 \\
(6)\end{array}$} & $(10)$ & 12 \\
\hline
\end{tabular}

Std.

Parameters Deviation

$a_{\mathrm{KFL}}$ and TCLS are retail floor area and line haul travel time categories defined in Figure 7.1

${ }^{b}$ Numbers in cells are predicted frequencies with observed frequencies in parenthesis

Table 7.2 Prediction of Functional Destination Choice Frequencies for the Total Sample With Respect to Retail Floor Area and Airline Distance $a, b$

\begin{tabular}{|c|c|c|c|c|c|c|}
\hline \multirow{4}{*}{ 至. } & 1 & $\begin{array}{c}\text { DCLS } \\
2\end{array}$ & 3 & \multirow{4}{*}{\multicolumn{2}{|c|}{$\begin{array}{l}\quad \text { Row: } 1.874 \\
\text { Co1. (1): }-1.304 \\
\text { Col. (2): }-0.626 \\
\text { Goodness-of-fit } \chi^{2}:\end{array}$}} & \multirow{2}{*}{$\begin{array}{l}\text { Std. } \\
\text { Deviation } \\
(0.193) \\
(0.190) \\
(0.149) \\
7 \quad(2 \text { d.f. })\end{array}$} \\
\hline & $\begin{array}{r}30 \\
(31)\end{array}$ & $\begin{array}{c}60 \\
(62)\end{array}$ & $\begin{array}{r}112 \\
(109)\end{array}$ & & & \\
\hline & 5 & 9 & 17 & & & \\
\hline & (4) & (7) & (20) & & & \\
\hline
\end{tabular}

${ }^{a} \mathrm{KFL}$ and DCLS are retail floor area and airline distance categories defined in Figure 7.2

$b_{\text {Numbers }}$ in cells are predicted frequencies with observed frequencies in parenthesis 
The goodness-of-fit $x^{2}$ values for models fitted with main effects with respect to attitudinal market segments in predicting functional destinations are shown in Table 7.3. In three cases the $x^{2}$ value was significant, at most, at the 5-percent level of significance. After fitting the 1,1 interaction effect in addition to main effects, as shown in Table 7.3, the goodness-of-fit $x^{2}$ value is reduced in all cases. The reduction in $x^{2}$ value accounted for by the 1,1 interaction is significant at the 5 percent level in all cases where there was a need to fit this interaction to reduce the goodness-of-fit $x^{2}$ value. That the contribution of the 1,2 interaction is small is seen from the reduction in goodness-of-fit it brings about as shown in Table 7.3. The observed and predicted cell frequencies and model parameter estimates are presented in Tables $7.4 \mathrm{a}$ to $7.9 \mathrm{~b}$ for the main effects models and Tables $7.10 \mathrm{a}$ to $7.15 \mathrm{~b}$ for the main effects plus 1,1 interaction models. Considering the fact that the relatively higher percentage errors of prediction occur with the cells of low observed frequencies, many of the main effects models perform quite well. The models fitted with main effects and 1,1 interaction give almost perfect prediction. This should only serve as a strong indication of the usefulness in fitting for certain key interactions where the number of degrees of freedom for the goodness-of-fit $x^{2}$ is large enough. In the present context, since the 1,2 interaction effects are negligible, fitting for the 1,1 interaction may amount to a self-fulfilling prophecy.

Interpretation of Modelling

In Tables $7.4 \mathrm{a}$ to $7.9 \mathrm{~b}$ the following interpretation is given to the parameter estimated. The row parameter is denoted by $F$ and the 
Table 7.3 Likelihood Ratio Goodness-of-Fit $\chi^{2}$ Values for Fitting KFL $x$ TCLS ${ }^{1}$ Contingency Tables

Effects Fitted in Model

\begin{tabular}{lcccccc}
$\begin{array}{lccc}\text { Destination Choice } \\
\text { Attitudinal Factor }\end{array}$ & Main Effects & Main Effects & \multicolumn{2}{c}{ Main Effects } \\
Used for Market & Market Segment & Market Segment & Market Segment \\
Segmentation & 1 & 2 & 1 & 2 & 1 & 2 \\
\hline Many Employees & 0.62 & $9.19^{*}$ & 0.48 & 0.53 & 0.02 & $8.70^{* *}$ \\
Wide Selection & 5.35 & 2.85 & 0.28 & 0.15 & 5.30 & 1.49 \\
Uncongested Roads & $6.24^{*}$ & 2.96 & 0.42 & 0.32 & $6.06^{*}$ & 1.47 \\
Several Stores & 1.97 & $6.66^{* *}$ & 0.05 & 0.02 & 1.85 & 5.67 \\
Quick Parking & 5.84 & 3.78 & 0.23 & 0.83 & 3.75 & 3.77 \\
Close to Home & 3.67 & 5.65 & 0.02 & 0.34 & 2.59 & 5.54
\end{tabular}

${ }^{1} \mathrm{KFL}$ and TCLS refer to Retail Floor Area and Line Haul Travel Time Categories defined in Figure 7.1 .

${ }^{2}$ Each Likelihood Ratio Goodness of Fit $x^{2}$ Value has 2 d.f.

${ }^{3}$ Each Likelihood Ratio Goodness of Fit $\chi^{2}$ Value has 1 d.f.

*Significant at the 0.05 level.

** Significant at the 0.01 level. 
Table 7.4a Many Employees

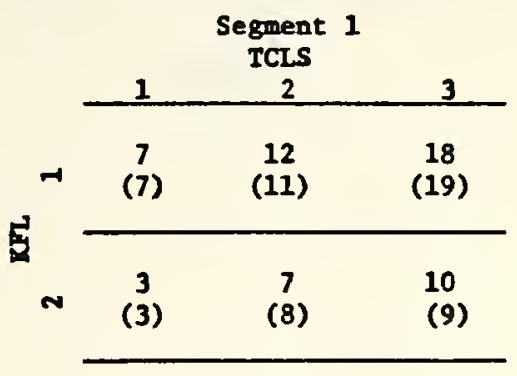

Std.

Parameterg Dev1stion

$\begin{array}{lll}\text { Row: } 0.6152 & (0.278) \\ \text { Co1. (1): }-1.030 & (0.367) \\ \text { Co1. (2): }-0.388 & (0.296)\end{array}$

Goodness-of-f1t $x^{2}: 0.62$

Table 7.4b Many Moployees

\begin{tabular}{|c|c|c|c|}
\hline & & $\begin{array}{l}\text { egment } \\
\text { ICLS }\end{array}$ & \\
\hline & 1 & 2 & 3 \\
\hline-1 & $\begin{array}{c}39 \\
(46)\end{array}$ & $\begin{array}{c}44 \\
(42)\end{array}$ & $\begin{array}{c}42 \\
(37)\end{array}$ \\
\hline $\boldsymbol{N}$ & $\begin{array}{l}13 \\
(6)\end{array}$ & $\begin{array}{c}15 \\
(17)\end{array}$ & $\begin{array}{l}15 \\
(20)\end{array}$ \\
\hline
\end{tabular}

$\begin{array}{lrr}\text { Row: } 1.067 & (0.176) \\ \text { Co1. (1): }-0.092 & (0.191) \\ \text { Col. (2): } 0.034 & (0.185) \\ & \\ \text { Coodness-of-f1t } \chi^{2}: 9.19^{\star}\end{array}$

Table 7.58 Wide Selection

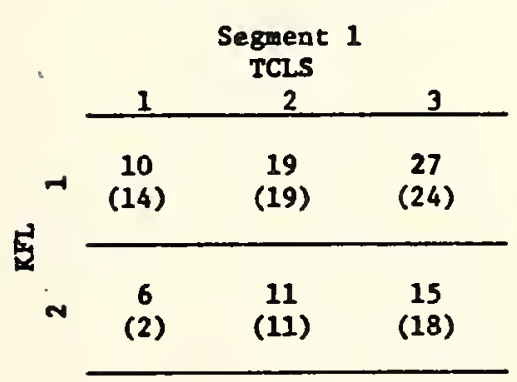

Table $7.5 b$ wide Selection

\begin{tabular}{|c|c|c|c|}
\hline & 1 & $\begin{array}{c}\text { genent } \\
\text { TCLS } \\
2\end{array}$ & 3 \\
\hline$-r$ & $\begin{array}{c}35 \\
(39)\end{array}$ & $\begin{array}{c}37 \\
(34)\end{array}$ & $\begin{array}{c}33 \\
(32)\end{array}$ \\
\hline $\boldsymbol{N}$ & $\begin{array}{l}11 \\
(7)\end{array}$ & $\begin{array}{c}11 \\
(14)\end{array}$ & $\begin{array}{l}10 \\
\text { (11) }\end{array}$ \\
\hline
\end{tabular}

$\begin{array}{rr}\text { Ros: } 0.609 & (0.222) \\ \text { Co1. (1): }-0.965 & (0.294) \\ \text { Col. (2): }-0.365 & (0.238)\end{array}$

Goodness-of-f1t $x^{2}: 5.35$

$$
\begin{aligned}
& \text { Rov: } 1.1882 \quad(0.202) \\
& \begin{array}{lll} 
& \\
\text { col. (2): } 0.1100, & (0.210)
\end{array}
\end{aligned}
$$

Goodness-of-f1t $x^{2}: 2.85$

$a_{\mathrm{KF}}$ and TCLS are retall floor srea and line haul travel time categorles defined In F1gure 7.1

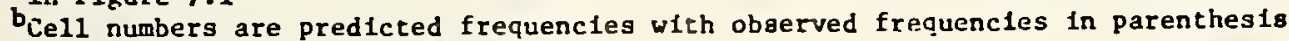
${ }^{\star}{ }^{2}$ value significant at $5 \%$ level 
Tables 7.6a - 7.7b Functional Destination Cholce Predictions by Market Segments $a, b$

Table $7.6 \mathrm{a}$ Uncongested Roads $\mathrm{s}^{\mathrm{a}, \mathrm{b}}$

\begin{tabular}{|c|c|c|c|}
\hline & 1 & $\begin{array}{c}\text { Segmen } \\
\text { TCLS } \\
2 \\
\end{array}$ & 3 \\
\hline-1 & $\begin{array}{c}30 \\
(36)\end{array}$ & $\begin{array}{c}43 \\
(42)\end{array}$ & $\begin{array}{c}45 \\
(40)\end{array}$ \\
\hline$\sim$ & $\begin{array}{l}12 \\
(6)\end{array}$ & $\begin{array}{c}17 \\
(18)\end{array}$ & $\begin{array}{c}17 \\
(22)\end{array}$ \\
\hline
\end{tabular}

Std.

Parameters Deviation

$\begin{array}{lrr}\text { Row: } 0.942 & (0.174) \\ \text { Col. (1): }-0.890 & (0.199) \\ \text { Col. (2): }-0.033 & (0.180)\end{array}$

Goodness-of-fit $x^{2}: 6.24^{*}$

Table $7.6 \mathrm{~b}$ Uncongested Roads

\begin{tabular}{|c|c|c|c|}
\hline & 1 & $\begin{array}{c}\text { Segmer } \\
\text { TCLS } \\
2 \\
\end{array}$ & 3 \\
\hline $\boldsymbol{H}$ & $\begin{array}{c}14 \\
(17)\end{array}$ & $\begin{array}{c}13 \\
\text { (11) }\end{array}$ & $\begin{array}{c}17 \\
(16)\end{array}$ \\
\hline$N$ & $\begin{array}{c}6 \\
(3)\end{array}$ & $\begin{array}{c}5 \\
(7)\end{array}$ & $\begin{array}{c}6 \\
(7)\end{array}$ \\
\hline
\end{tabular}

$\begin{array}{rrr}\text { Row: } & 0.951 & (0.285) \\ \text { Co1. (1): } & -0.140 & (0.306) \\ \text { Col. (2): } & -0.245 & (0.314)\end{array}$

Table 7.78 Several Storea

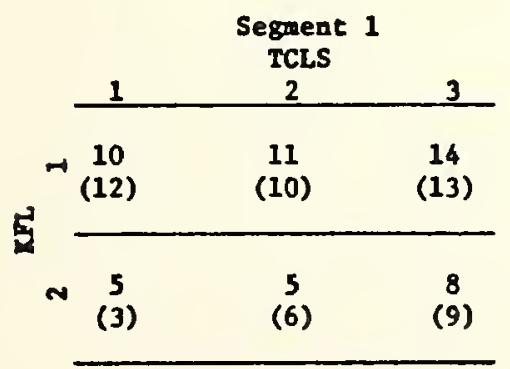

Goodness-of-fit $x^{2}: 2.96$

\author{
Row: $0.665 \quad(0.290)$ \\ Col. (1): $-0.383 \quad(0.334)$ \\ Col. (2): $-0.318 \quad(0.328)$ \\ Goodness-of-fit $x^{2}: 1.97$
}

Table $7.7 b$ Several Stores

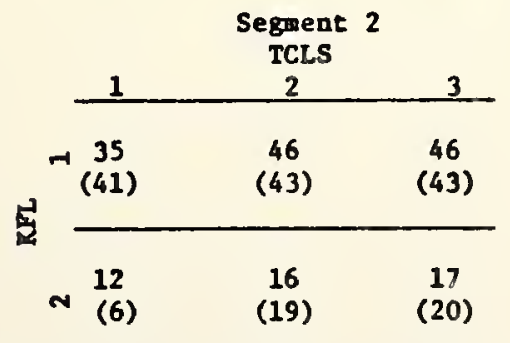

$\begin{array}{ll}\text { Row: } 1.038 & (0.173) \\ \text { Col. (1): }-0.293 & (0.192) \\ \text { Col. (2): }-0.016 & (0.179) \\ \text { Goodness-of-f1t } \chi^{2}: 6.66^{\star}\end{array}$

$a_{K F L}$ and TCLS are retall floor area and line haul travel time categories defined In F1gure 7.1

${ }^{b} \mathrm{Cell}$ numbers are predicted frequencies witb observed frequenctes in psrenthesis ${ }^{\star} X^{2}$ value significance at $5 \%$ level 
Table 7.8s Quick Parking

\begin{tabular}{|c|c|c|c|}
\hline & \multicolumn{3}{|c|}{$\begin{array}{l}\text { Segment } 1 \\
\text { TCLS }\end{array}$} \\
\hline & 1 & 2 & 3 \\
\hline-1 & $\begin{array}{c}25 \\
(30)\end{array}$ & $\begin{array}{c}28 \\
(25)\end{array}$ & $\begin{array}{c}32 \\
(31)\end{array}$ \\
\hline$N$ & $\begin{array}{l}10 \\
(5)\end{array}$ & $\begin{array}{c}12 \\
(10)\end{array}$ & $\begin{array}{l}13 \\
(14)\end{array}$ \\
\hline
\end{tabular}

\author{
Std. \\ Parameters Devistion \\ Rour: $0.899 \quad(0.200)$ \\ Col. (1): -0.273 \\ $(0.224)$ \\ Col. (2): -0.140 \\ $(0.216)$ \\ Goodness-of-f1t $x^{2}: 5.84$
}

Table 7.8b Quick Parking

\begin{tabular}{|c|c|c|c|}
\hline & & gent & \\
\hline & 1 & 2 & 3 \\
\hline-1 & $\begin{array}{c}20 \\
(23)\end{array}$ & $\begin{array}{c}28 \\
(28)\end{array}$ & $\begin{array}{c}28 \\
(25)\end{array}$ \\
\hline $\mathbf{N}$ & $\begin{array}{c}7 \\
(4)\end{array}$ & $\begin{array}{c}10 \\
(10)\end{array}$ & $\begin{array}{c}11 \\
(14)\end{array}$ \\
\hline
\end{tabular}

$\begin{array}{lrr}\text { Roy: }: 0.998 & (0.221) \\ \text { Co1. (1): }-0.368 & (0.250) \\ \text { Col. (2): }-0.026 & (0.226)\end{array}$

Table 7.9 a Close to Howe

\begin{tabular}{|c|c|c|c|}
\hline & \multicolumn{3}{|c|}{$\begin{array}{l}\text { Segment } 1 \\
\text { ICLS }\end{array}$} \\
\hline & 1 & 2 & 3 \\
\hline 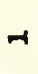 & $\begin{array}{c}24 \\
(28)\end{array}$ & $\begin{array}{c}27 \\
(25)\end{array}$ & $\begin{array}{c}27 \\
(25)\end{array}$ \\
\hline$N$ & $\begin{array}{l}10 \\
(6)\end{array}$ & $\begin{array}{c}12 \\
(14)\end{array}$ & $\begin{array}{c}11 \\
\text { (13) }\end{array}$ \\
\hline
\end{tabular}

coodness-of-fit $x^{2}: 3.78$

Tsble 7.9b Close to Bowe

\begin{tabular}{|c|c|c|c|}
\hline & & $\begin{array}{l}\text { gment } \\
\text { TCLS }\end{array}$ & \\
\hline & 1 & 2 & 3 \\
\hline$\rightarrow$ & $\begin{array}{c}21 \\
(25)\end{array}$ & $\begin{array}{c}29 \\
(28)\end{array}$ & $\begin{array}{c}35 \\
(31)\end{array}$ \\
\hline N & $\begin{array}{c}7 \\
(3)\end{array}$ & $\begin{array}{c}10 \\
\text { (11) }\end{array}$ & $\begin{array}{c}12 \\
(16)\end{array}$ \\
\hline
\end{tabular}
Row: $0.860 \quad(0.208)$
Col. (1): $-0.111 \quad(0.238)$
Col. (2): $0.026 \quad(0.228)$
Goodness-of-fit $x^{2}: 3.67$
Row: $1.080 \cdot(0.212)$
Col. (1): $-0.518 \quad(0.238)$
Col. (2): $-0.187 \quad(0.216)$
Goodness-of-fit $x^{2}: 5.65$

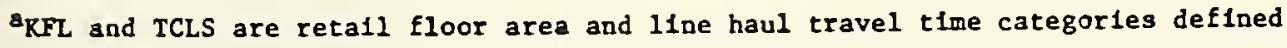
In Figure 7.1

bCell numbers are predicted frequencles with observed frequencies in parenthesis ${ }^{*} \chi^{2}$ value significance st $5 \%$ level 
Tables 7.10a - 7.11b Functional Destination Cholce Predictlons by Market Segments 1,1 Interaction Included $a, b$

\begin{tabular}{|c|c|c|c|}
\hline & Tables & 7.10. Many & Employees \\
\hline & \multicolumn{3}{|c|}{$\begin{array}{l}\text { Segment } 1 \\
\text { TCLS }\end{array}$} \\
\hline & 1 & 2 & 3 \\
\hline-1 & $\begin{array}{c}7 \\
(7)\end{array}$ & $\begin{array}{c}12 \\
\text { (11) }\end{array}$ & $\begin{array}{l}18 \\
(19)\end{array}$ \\
\hline $\boldsymbol{N}$ & $\begin{array}{c}3 \\
(3)\end{array}$ & $\begin{array}{c}7 \\
(8)\end{array}$ & $\begin{array}{l}10 \\
(9)\end{array}$ \\
\hline
\end{tabular}

Table 7.10b Many Employeea

\begin{tabular}{|c|c|c|c|}
\hline & 1 & $\begin{array}{r}\text { retsent } \\
2 \\
\end{array}$ & 3 \\
\hline-1 & $\begin{array}{c}46 \\
(46)\end{array}$ & $\begin{array}{c}40 \\
(42)\end{array}$ & $\begin{array}{c}39 \\
(37)\end{array}$ \\
\hline$v$ & $\begin{array}{c}6 \\
(6)\end{array}$ & $\begin{array}{l}19 \\
\text { (17) }\end{array}$ & $\begin{array}{c}18 \\
(20)\end{array}$ \\
\hline
\end{tabular}

Std.

Parametera Dev1ation

$\begin{array}{rrr}\text { Row: } 0.661 & (0.306) \\ \text { Col. (1): }-1.077 & (0.396) \\ \text { Co1. (2): }-0.388 & (0.296) \\ 1,1 \text { Inter- } 0.279 & (0.751)\end{array}$
action

Goodness-of-fit $\chi^{2}: 0.42$

\author{
Row: 1.185 \\ Col. (1): -0.469 \\ Col. (2): 0.034 \\ 1,1 Inter- 1.278 \\ action \\ (0.196) \\ $(0.266)$ \\ $(0.186)$ \\ $(0.477)$ \\ Goodness-of-fit $\chi^{2}: 0.53$
}

Table 7.11a W1de Selection

\begin{tabular}{|c|c|c|c|}
\hline & \multicolumn{3}{|c|}{$\begin{array}{l}\text { Segment } 1 \\
\text { TCLS }\end{array}$} \\
\hline & 1 & 2 & 3 \\
\hline-1 & $\begin{array}{l}14 \\
(14)\end{array}$ & $\begin{array}{c}18 \\
(19)\end{array}$ & $\begin{array}{c}25 \\
(24)\end{array}$ \\
\hline N & $\begin{array}{c}2 \\
(2)\end{array}$ & $\begin{array}{c}12 \\
(11)\end{array}$ & $\begin{array}{c}17 \\
(18)\end{array}$ \\
\hline
\end{tabular}

$\begin{array}{ll}\text { Row: } 0.911 & (0.298) \\ \text { Col. (1): }-1.359 & (0.408) \\ \text { Col. (2): }-0.336 & (0.239) \\ 1,1 \text { Inter- } 1.552 & (0.791) \\ \text { action } & \\ \text { Goodness-of-fit } x^{2}: 0.28\end{array}$

Table 7.11b Wide Selection

\begin{tabular}{|c|c|c|c|}
\hline & & $\begin{array}{l}\text { gment } \\
\text { ICLSS }\end{array}$ & \\
\hline & 1 & 2 & 3 \\
\hline-1 & $\begin{array}{c}39 \\
(39)\end{array}$ & $\begin{array}{c}35 \\
(34)\end{array}$ & $\begin{array}{c}31 \\
(32)\end{array}$ \\
\hline N & $\begin{array}{c}7 \\
(7)\end{array}$ & $\begin{array}{c}13 \\
(14)\end{array}$ & $\begin{array}{c}12 \\
(11)\end{array}$ \\
\hline
\end{tabular}

$$
\begin{aligned}
& \text { Row: } 1.220 \\
& \text { Col. (1): }-0.150 \\
& \text { Col. (2): } 0.110 \\
& 1,1 \text { Inter- } 0.747 \\
& \text { action } \\
& \text { Goodnere-of-fit } \chi^{2}: 0.15
\end{aligned}
$$

a KFL and TCLS are retafl floor area and line haul travel time categories defined In Figure 7.1

bCell numbers are predicted frequencles with observed frequencies in parenthesia ${ }^{\star} X^{2}$ value signiflcance at $5 z$ level 
Tables 7.12a - 7.13b Functional Destination Cholce Predictions by Market Segmente 1,1 Interaction Included $\mathbf{a , b}$

Table 7.12a, Uncongested Roado

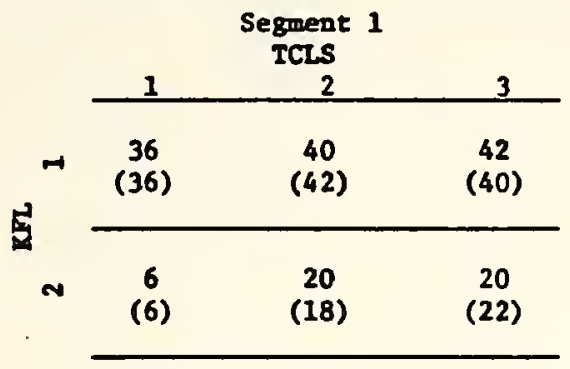

$\begin{array}{rll} & \text { Psrameters } & \begin{array}{l}\text { Std. } \\ \text { Deviation }\end{array} \\ \text { Row: } 1.076 & (0.195) \\ \text { Co1. (1): }-0.683 & (0.256) \\ \text { Col. (2): }-0.033 & (0.181) \\ 1,1 \text { Inter- } 1.074 & (0.430) \\ \text { action } & \\ \text { Goodness-of-E1t } \chi^{2}: & 0.42\end{array}$

Table 7.12b Uncongested Roads

\begin{tabular}{|c|c|c|c|}
\hline & & $\begin{array}{l}\text { zment } \\
\text { rCLS }\end{array}$ & \\
\hline & 1 & 2 & 3 \\
\hline-4 & $\begin{array}{c}17 \\
\text { (17) }\end{array}$ & $\begin{array}{c}12 \\
\text { (11) }\end{array}$ & $\begin{array}{c}15 \\
\text { (16) }\end{array}$ \\
\hline$N$ & $\begin{array}{c}3 \\
(3)\end{array}$ & $\begin{array}{c}6 \\
(7)\end{array}$ & $\begin{array}{c}8 \\
(7)\end{array}$ \\
\hline
\end{tabular}

$\begin{array}{ll}\text { Row: } 1.016 & (0.302) \\ \text { Col. (1): }-0.424 & (0.379) \\ \text { Col. (2): }-0.245 & (0.314) \\ \text { 1,1 Inter- } 1.078 & (0.706) \\ \text { action } & \\ \text { Goodness-of-f1t } \chi^{2}: 0.32\end{array}$

Table 7.13a Several Stores

\begin{tabular}{|c|c|c|c|}
\hline & \multicolumn{3}{|c|}{$\begin{array}{l}\text { Segment } 1 \\
\text { TCLS }\end{array}$} \\
\hline & 1 & 2 & 3 \\
\hline-1 & $\begin{array}{c}12 \\
(12)\end{array}$ & $\begin{array}{l}10 \\
(10)\end{array}$ & $\begin{array}{l}13 \\
(13)\end{array}$ \\
\hline$N$ & $\begin{array}{c}3 \\
(3)\end{array}$ & $\begin{array}{c}6 \\
(6)\end{array}$ & $\begin{array}{c}9 \\
(9)\end{array}$ \\
\hline
\end{tabular}

$\begin{array}{ll}\text { Row: } 0.747 & (0.308) \\ \text { Col. (1): }-0.584 & (0.389) \\ \text { Col. (2): }-0.318 & (0.328) \\ \text { 1.1 Inter- } 0.959 & (0.724) \\ \text { actIon } & \\ \text { Goodness-of-fit } \chi^{2}: 0.05\end{array}$

Table $7.13 b$ Several Storea

\begin{tabular}{|c|c|c|c|}
\hline & \multicolumn{3}{|c|}{ Segment 2} \\
\hline & 1 & 2 & 3 \\
\hline-1 & $\begin{array}{c}41 \\
(41)\end{array}$ & $\begin{array}{c}43 \\
(43)\end{array}$ & $\begin{array}{c}43 \\
(43)\end{array}$ \\
\hline N & $\begin{array}{c}6 \\
(6)\end{array}$ & $\begin{array}{c}19 \\
(19)\end{array}$ & $\begin{array}{c}20 \\
(20)\end{array}$ \\
\hline
\end{tabular}
- Row: 1.168
Col. (1): -0.621
Col. (2): -0.016
1,1 Inter- 1.131
action
Goodness-of-fit $\chi^{2}: 0.02$
$(0.194)$
$(0.254)$
$(0.179)$
$(0.477)$

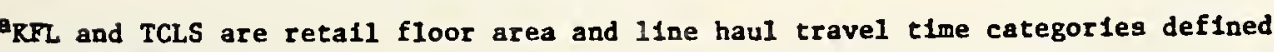
In Figure $7.1^{\circ}$

bCell numbers are predicted frequencles with observed frequencies in parenthesis ${ }^{\star} x^{2}$ value algniflcance at $5 \%$ level 
Tables 7.14a - 7.15b Functional Destination Cholce Predict1ons by Market Segments 1,1 Interaction Iocluded $a, b$

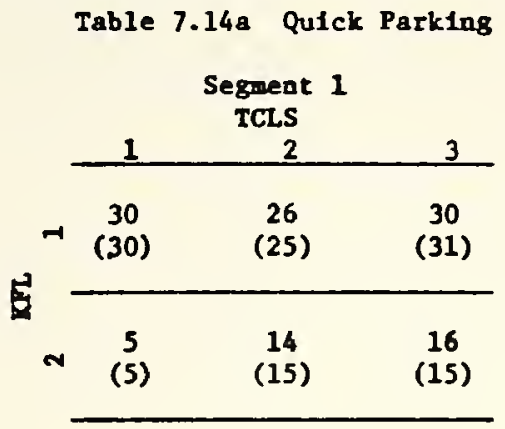

\begin{tabular}{rll} 
& Parameters & \multicolumn{1}{l}{$\begin{array}{l}\text { Std. } \\
\text { Deviation }\end{array}$} \\
Row: 1.013 & & $(0.220)$ \\
Co1. (1): -0.582 & $(0.284)$ \\
Col. (2): -0.140 & $(0.216)$ \\
1,1 Inter- & $(0.168)$ \\
action 1.168 & \\
Goodneas-of-f1t $x^{2}: 0.23$
\end{tabular}

Table 7.14b Qu1ck Parking

Segment 2 TCLS

\begin{tabular}{rrr}
1 & 2 & 3 \\
\hline
\end{tabular}

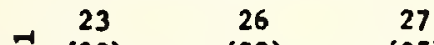

(23) (28) (25)

뇨

N

$\begin{array}{ccc}4 & 12 & 12 \\ (4) & (10) & (14)\end{array}$

Table 7.15a Close to Home

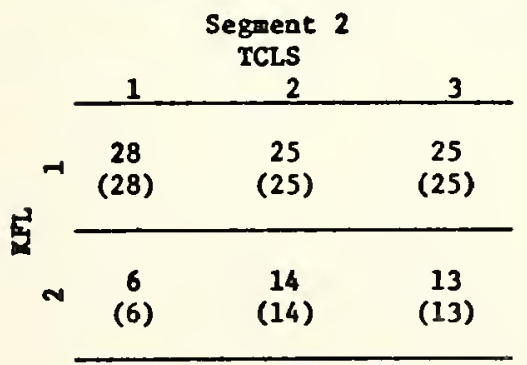

Table 7.15b Close to Home

\begin{tabular}{|c|c|c|c|}
\hline & & CLLS & \\
\hline & 1 & 2 & 3 \\
\hline-1 & $\begin{array}{c}25 \\
(25)\end{array}$ & $\begin{array}{c}27 \\
(28)\end{array}$ & $\begin{array}{c}32 \\
(31)\end{array}$ \\
\hline$N$ & $\begin{array}{c}3 \\
(3)\end{array}$ & $\begin{array}{c}12 \\
(11)\end{array}$ & $\begin{array}{c}15 \\
(16)\end{array}$ \\
\hline
\end{tabular}

\author{
Row: 1.111 \\ Co1. (1): -0.633 \\ Col. (2): -0.026 \\ 1,1 Inter- \\ action 0.957 \\ $(0.244)$ \\ (0.319) \\ (0.228) \\ (0.594) \\ Goodness-of-f1c $\chi^{2}: 0.83$
}

$\begin{array}{ll}\text { Row: } 1.228 & (0.256) \\ \text { Col. (1): }-0.924 & (0.340) \\ \text { Co1. (2): }-0.187 & (0.216) \\ \text { 1,1 Inter- } & (0.652) \\ \text { act1on } 1.339 & \\ \text { Goodness-of-f1t } x^{2}: 0.24\end{array}$

$a_{\mathrm{KFL}}$ and TCLS are retall floor area and line haul travel time categories defined 1n Figure 7.1

${ }^{b}$ Cell numbers are predicted frequencles with observed frequencles in parentheala ${ }^{*} \chi^{2}$ value significance at $5 \%$ level 
column parameters by $\mathrm{T} 1$ and $\mathrm{T} 2$. Each parameter for a way of classification is examined relative to the last category. KFL categories 1 and 2 represent high and low to medium retail floor area respectively. TCLS categories 1,2 and 3 represent high, medium and low line haul travel time ranges respectively. The parameter $F$ corresponds to the effect of the high floor area category relative to the low floor area class. $\mathrm{T} 1$ and $\mathrm{T} 2$ represent the effects of high and medium line haul travel time ranges compared with the low time category.

A positive $F$ parameter implies that the probability of a functional destination choice increases with increasing retail floor area. A negative value for either of the parameters T1 and T2 means that the probability of a functional destination choice decreases with increasing travel time. It is noticed that the parameters $F$ and $T_{1}$ and $T_{2}$ have the appropriate signs in all the models estimated in Tables $7.4 \mathrm{a}$ - 7.9b for the main effects models. The same observation applies to the models that include a 1,1 interaction effect as shown in Tables $7.10 a-7.15 b$.

The Effectiveness of Attitudinal Orientation for Market Segmentation

One of the questions addressed was whether the attitudinal orientation of groups of individuals causes them to behave differently in their choice of functional shopping destinations. In Tables $7.4 \mathrm{a}$ - 7.9b and Tables 7.10a - 7.15b segment 1 for an attitudinal factor indicates insignificance of the attitudinal descriptor to the group of individuals and segment 2 indicates strong importance of the descriptor. Assuming that each multinomial response relation model fits the observed response pattern well for each attitudinal market 
segment, a statistical test of whether the parameter vectors for the two market segments are different can establish whether the market segment responses to functional destinations are different. Such tests for attitudinal factors "Wide Selection," "Quick Parking" and "Close to Home" in Tables $7.5,7.8$ and 7.9 are discussed in detail at the end of this chapter. All of them except"Quick Parking" indicate a significant difference in the response patterns for the market segments in each case. For attitudinal factors "Many Employees," "Uncongested Roads" and "Several Stores," in Tables 7.4, 7.6 and 7.7 respectively, a main effects model adequately fits the observed response pattern for one market segment while an interaction model is needed for good prediction for the other market segment. This basic difference in the models for the two attitudinal market segments is sufficient basis for their response patterns to differ. A comparison of the parameters estimated conveys this message clearly.

That there is statistical difference in the response patterns for two attitudinal market segments is not sufficient reason to consider the attitudinal segmentation worthwhile. One would also like to know if the direction of change of the parameters for the two market segments is as expected for each attitudinal descriptor. In Tables $7.4 \mathrm{a}$ and 7.4b for "Many Employees" it is noticed that the F parameter for segment 2 is about sixty percent greater than that for segment 1 which indicates that those who like to shop where there are many employees also like to shop where the retail floor area is greater or where the retail activity is more intensive. It is also noticed that the parameters $\mathrm{T} 1$ and $\mathrm{T} 2$ are of a greater magnitude for segment 1 
than for segment 2. This implies that those who consider having many employees at their shopping areas do not consider travel time as important in satisfying their need.

The remarks made above for "Many Employees" apply equally well to the attitudinal description "Wide Selection" as can be observed in Tables $7.5 \mathrm{a}$ and $7.5 \mathrm{~b}$. It is noticed that the tro attitudinal factors essentially have the same effect in market segmentation for predicting functional destination choice.

Considering the attitudinal factors "Uncongested Roads", for which model results are summarized in Tables $7.6 \mathrm{a}$ and $7.6 \mathrm{~b}$, it is noticed that the effect of shopping area size does not differ significantly for the two market segments. The interpretation given to "Uncongested Roads" by the respondents is not clear. Assuming a strong preference for uncongested roads implies a greater affinity to freeways or expressways, one can explain the difference in the $\mathrm{T} 1$ and T2 parameters for the two market segments. Since individuals in segment 1 travel more on local roads they are more sensitive to the distance travelled and hence travel time, since the travel speed is usually less on lower type facilities. The lower magnitude of the T1 and T2 parameters for segment 2 indicates that with a higher travel speed on higher type facilities like freeways, travel time does not become as important any longer.

The remarks made above for the attitudinal factor "Many Employees" apply in principle to "Several Stores", the results for which are in Tables $7.7 \mathrm{a}$ and $7.7 \mathrm{~b}$. It is noticed that the $\mathrm{Tl}$ parameter is not much smaller in magnitude for segment 2 compared with segment 1 . 
A likely reason is that those who prefer several stores consider travel time (or indirectly distance) as a controlling factor. It is possible that several clusters or small units of retail outlets develop around downtown or central areas. The travel time towards the central area of a city is a formidable consideration even for those who expect to satisfy their need for several retail outlets.

Tables $7.8 \mathrm{a}$ and $7.8 \mathrm{~b}$ show that there is no essential difference between the response patterns for market segments 1 and 2 for attitudinal factor "Quick Parking." This is mainly for the reason that only shopping trips to major shopping areas were considered for which parking was not a real problem for any of them.

The difference between individuals who do and those who do not feel strongly about shopping close to home is clearly borne out in Tables $7.9 \mathrm{a}$ and $7.9 \mathrm{~b}$. It is clear that the line haul travel time parameters $\mathrm{T} 1$ and $\mathrm{T} 2$ are of a much greater magnitude for segment 2 that feels strongly about the description "Close to Home," just as expected.

The above discussion on whether the functional destination response patterns implied for different attitudinal market segments conform with what one would normally expect in practice is essentially applicable to the models that include a 1,1 interaction summarized in Tables $7.10 \mathrm{a}-7.15 \mathrm{~b}$. The interaction models only help bring out expected patterns that the main effects mode1s could not adequately portray because of the poor model fit without the interaction consideration. 
Prediction of Functional Shopping Destination Choices Defined With

Respect to Retail Floor Area and Airline Distance by Attitudinal

Factor Market Segments

The results of a predictive model for the total sample that predicts frequencies of choice of functional shopping destinations defined with respect to Retail Floor Area and Airline Distance are given in Table 7.2. It is noticed that the predictive accuracy of the model is very good. To determine whether market segmentation according to attitudinal factors produces different patterns of functional shopping destination choice, models were fitted for such market segment. The goodness-of-fit $x^{2}$ values are presented in Table 7.16 for these main effects models. Tables $7.17 \mathrm{a}$ to $7.22 \mathrm{~b}$ present the observed and predicted cell frequencies as well as the model parameters.

Except for the cells of low observed cell frequencies, the percentage of correct cell frequency prediction is very good for all the models. It was not necessary to fit any interaction effect since the goodness-of-fit $x^{2}$ values are not significant at the 5 percent level. Differences exist between sets of parameters estimated for the total sample model in Table 7.2 and for the models for market segments summarized in Tables $7.17 \mathrm{a}$ to $7.22 \mathrm{~b}$. There is reason to believe that the market segmentation is necessary at an operational level. It is clear that functional shopping destinations defined by Retail Floor Area and Airline Distance are predicted with greater stability and accuracy for both the total sample and attitudinal market segments than functional shopping 
Table 7.16 Likelihood Ratio Goodness-of-Fit $\chi^{2}$ Values for Fitting KFL $\mathrm{x}$ DCLS $^{1}$ Contingency Tables.

Destination Choice Attitudinal

Factor Osed for Market Segmentation
Main Effects 2,3

Model

Market Segment

1

$0.40 \quad 4.46$

Many Employees

$0.60 \quad 2.87$

Wide Selection

$4.65 \quad 0.28$

Uncongested Roads

$0.77 \quad 3.00$

Several Stores

$1.56 \quad 2.13$

Close to Home

3.08

3.29

$1_{\mathrm{KFL}}$ and DCLS refer to Retail Floor Area and Airline Distance Categories defined in Figure 7.2.

2 Each Likelihood Ratio Goodness of fit $\chi^{2}$ value has $2 \mathrm{~d} . \mathrm{f}$.

${ }^{3}$ None of the $\chi^{2}$ values is significant at the 0.05 significance level. 
Tables 7.17a - 7.18b Punctions1 Destination Cholce Predictions by Market Segments ${ }^{a, b}$

Table 7.17a Many Employeea

\begin{tabular}{|c|c|c|c|}
\hline & & $\begin{array}{l}\text { nent } \\
\text { cLS }\end{array}$ & \\
\hline & 1 & 2 & 3 \\
\hline $\boldsymbol{H}$ & $\begin{array}{c}4 \\
\text { (4) }\end{array}$ & $\begin{array}{c}6 \\
(5)\end{array}$ & $\begin{array}{c}27 \\
(28)\end{array}$ \\
\hline $\boldsymbol{N}$ & $\begin{array}{c}2 \\
(2)\end{array}$ & $\begin{array}{c}3 \\
(4)\end{array}$ & $\begin{array}{c}15 \\
(14)\end{array}$ \\
\hline
\end{tabular}

Std.

Parameters Deviation

$\begin{array}{lll}\text { Row: } 0.615 & (0.278) \\ \text { Col. (1): }-1.946 & (0.436) \\ \text { Col. (2): }-1.540 & (0.367)\end{array}$

Goodness-of-fit $x^{2}: 0.40$

Table 7.17b Many Employees

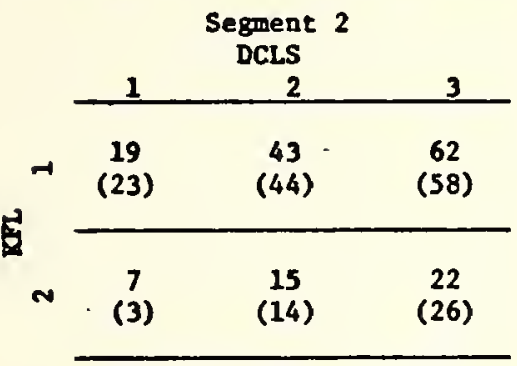

$\begin{array}{lll}\text { Row: } 1.067 & (0.177) \\ \text { Col. (1): }-1.173 & (0.224) \\ \text { Col. (2): }-0.370 & (0.170)\end{array}$

Table $7.18 \mathrm{a}$ W1de Selection

\begin{tabular}{|c|c|c|c|}
\hline & & $\begin{array}{l}\text { Sment } \\
\text { CLLS }\end{array}$ & \\
\hline & 1 & 2 & 3 \\
\hline-1 & (4) & $\begin{array}{c}18 \\
(19)\end{array}$ & $\begin{array}{c}36 \\
(34)\end{array}$ \\
\hline$N$ & $\begin{array}{c}2 \\
(2)\end{array}$ & $\begin{array}{c}9 \\
(8)\end{array}$ & $\begin{array}{c}19 \\
(21)\end{array}$ \\
\hline
\end{tabular}

Goodness-of-fit $x^{2}: 4.46$

Row: 0.609

Col. (1): -2.216

Col. (2): -0.712

$(0.222)$

(0.427)

Goodness-of-fit $x^{2}: 0.60$

$(0.235)$

Table $7.18 b$ W1de Selection

\begin{tabular}{|c|c|c|c|}
\hline & & $\begin{array}{l}\text { zment } \\
\text { CLSS }\end{array}$ & \\
\hline & 1 & 2 & 3 \\
\hline-1 & $\begin{array}{c}20 \\
(23)\end{array}$ & $\begin{array}{c}31 \\
(30)\end{array}$ & $\begin{array}{c}54 \\
(52)\end{array}$ \\
\hline N & $\begin{array}{c}6 \\
(3)\end{array}$ & $\begin{array}{c}9 \\
(10)\end{array}$ & $\begin{array}{c}17 \\
\text { (19) }\end{array}$ \\
\hline
\end{tabular}

$\begin{array}{lll}\text { Row: } 1.188 & (0.202) \\ \text { Col. (1): }-1.005 & (0.228) \\ \text { Co1. (2): }-0.574 & (0.198)\end{array}$

Goodness-of-ftt $X^{2}: 2.87$

aFL and DCLS are retall floor ares and airline distance categories defined in f1gure 7:2

bcell numbers are predicted frequenc1es with observed frequencies in parentbesis

${ }^{*} X^{2}$ value significant at $5 \%$ level

${ }^{\star} x^{2}$ value significant at $1 \%$ level 
Tables 7.19s - 7.20b Functional Dea:Ination Cholce Predictions by Market Segmentga,b

Table 7.19a Uncongested Roads

\begin{tabular}{|c|c|c|c|}
\hline & 1 & $\begin{array}{l}\text { gment } \\
\text { DCLS } \\
2\end{array}$ & 3 \\
\hline-1 & $\begin{array}{c}14 \\
(18)\end{array}$ & $\begin{array}{c}34 \\
(34)\end{array}$ & $\begin{array}{c}70 \\
(66)\end{array}$ \\
\hline $\boldsymbol{N}$ & $\begin{array}{c}6 \\
(2)\end{array}$ & $\begin{array}{c}13 \\
(13)\end{array}$ & $\begin{array}{c}27 \\
\text { (31) }\end{array}$ \\
\hline
\end{tabular}

Std.

Parameters Deviation

Row: $0.942 \quad(0.296)$

Col. (1): $-1.579 \quad(0.246)$

Col. (2): $-0.725 \quad(0.178)$

Goodness-of-f1t $\chi^{2}: 4.65$

Table $7.19 \mathrm{~b}$ Uncongested Roada

\begin{tabular}{|c|c|c|c|}
\hline & & $\begin{array}{l}\text { ment } \\
\text { CLS }\end{array}$ & \\
\hline & 1 & 2 & 3 \\
\hline-1 & $\begin{array}{c}9 \\
(9)\end{array}$ & $\begin{array}{c}14 \\
\text { (15) }\end{array}$ & $\begin{array}{c}21 \\
(20)\end{array}$ \\
\hline$\sim$ & $\begin{array}{c}3 \\
(3)\end{array}$ & $\begin{array}{c}6 \\
(5)\end{array}$ & $\begin{array}{c}8 \\
(9)\end{array}$ \\
\hline
\end{tabular}

$\begin{array}{lll}\text { Row: } 0.951 & (0.286) \\ \text { Col. (1): }-0.882 & (0.342) \\ \text { Col. (2): }-0.372 & (0.290)\end{array}$

Coodness-of-f1t $\chi^{2}: 0.28$

Table 7.20a Several Stores

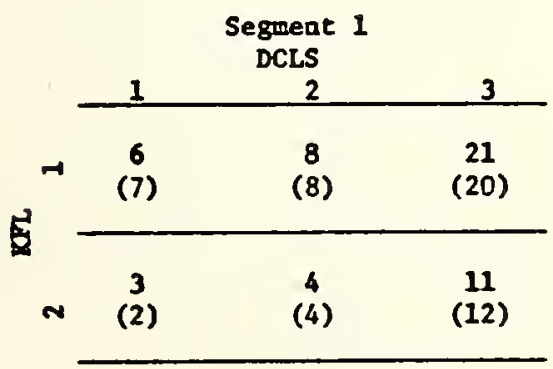

$\begin{array}{rr}\text { Row: } 0.665 & (0.290) \\ \text { Col. (1): }-1.268 & (0.376) \\ \text { Co1. (2): }-0.981 & (0.338)\end{array}$

Table 7.20b Several Stores

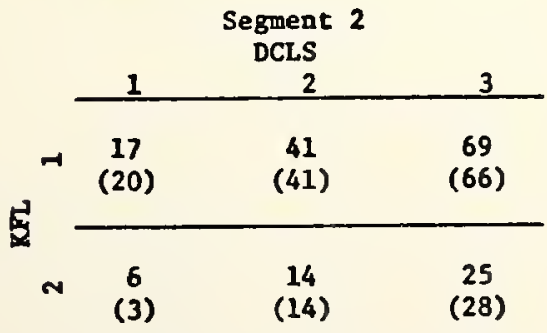

coodness-of-fit $x^{2}: 0.77$

$\begin{array}{lll}\text { Row: } 1.038 & (0.173) \\ \text { Col. (1): }-1.408 & (0.233) \\ \text { Col. (2): }-0.536 & (0.169)\end{array}$

Goodness-of-f1t $x^{2}: 3.00$

KFL and DCLS are retall floor area and alrline distance categories defined in Figure 7.2

bcell numbers are predicted frequencles with observed frequencles in parentbesis ${ }^{\star} x^{2}$ value signiflcant at $5 \%$ level

${ }^{\star} X^{2}$ value significant at $1 \%$ level 
Tables 7.21a - 7.22b Functional Destination Cholce Predictions by Market Segmeatsa,b

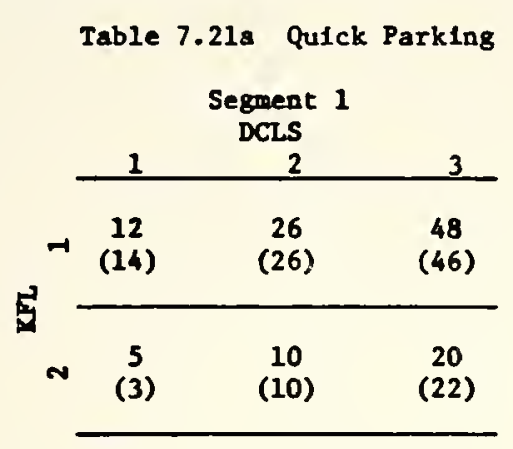

Table 7.21b Quick Parking

\begin{tabular}{|c|c|c|c|}
\hline & \multicolumn{3}{|c|}{$\begin{array}{l}\text { Segment } 2 \\
\text { DCLS }\end{array}$} \\
\hline & 1 & 2 & 3 \\
\hline-1 & $\begin{array}{c}11 \\
(13)\end{array}$ & $\begin{array}{c}23 \\
(23)\end{array}$ & $\begin{array}{c}42 \\
(40)\end{array}$ \\
\hline$\sim$ & (2) & $\begin{array}{c}8 \\
(8)\end{array}$ & $\begin{array}{l}16 \\
(18)\end{array}$ \\
\hline
\end{tabular}

Table 7.22a Close to Hone

\begin{tabular}{|c|c|c|c|}
\hline & 1 & $\begin{array}{l}\text { gment } \\
\text { DCLS } \\
2\end{array}$ & 3 \\
\hline-1 & $\begin{array}{c}14 \\
(17)\end{array}$ & $\begin{array}{c}23 \\
(21)\end{array}$ & $\begin{array}{c}41 \\
(40)\end{array}$ \\
\hline$N$ & $\begin{array}{c}6 \\
(3)\end{array}$ & $\begin{array}{c}10 \\
(12)\end{array}$ & $\begin{array}{c}17 \\
(18)\end{array}$ \\
\hline
\end{tabular}

Table 7.22b close to Home

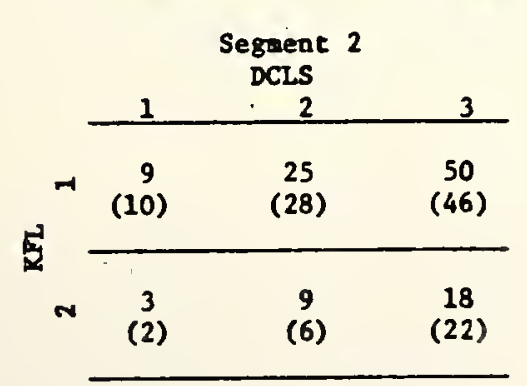

Std.

Parametera Deviation

$\begin{array}{rrr}\text { Row: } & 0.899 & (0.200) \\ \text { Col. (1): }-1.386 & (0.270) \\ \text { Col. (2): }-0.636 & (0.206)\end{array}$

Goodness-of-fit $\chi^{2}: 1.56$

\author{
Row: 0.998 \\ Co1. (1): -1.352 \\ Col. (2): -0.626 \\ $(0.221)$ \\ $(0.290)$ \\ $(0.222)$
}

\author{
Row: 0.860 \\ Co1. (1): -1.065 \\ Col. (2): -0.564 \\ (0.208) \\ $(0.259)$ \\ $(0.218)$
}

$\begin{array}{ll}\text { Row: } 1.030 & (0.212) \\ \text { Co1. (1): }-1.735 & (0.296) \\ \text { Col. (2): }-0.693 & (0.210) \\ \text { Goodness-of-f1t } x^{2}: 3.29\end{array}$

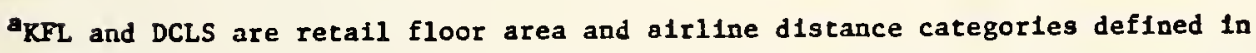

Figure 7.2
${ }^{C}$ Cell numbers are predicted frequencies with observad frequencles in parenthesis $\chi^{2}$ value significant at $5 \%$ level.

${ }^{*}{ }^{2}$ value significant at 17 level 
destinations defined by Retail Floor Area and Line Haul Travel Time. This is a welcome trend that must be further investigated since it could make the application of the methodology of multinomial response relations to predicting functional shopping destinations much more practical. The reason is that airline distances are easier to compute than travel times.

The definition of airline distance range categories is equivalent to that for line haul travel time in that an increasing category class number implies a decreasing airline distance. The effects for the Retail Floor Area by Airline Distance models fitted in Tables $7.17 \mathrm{a}$ to $7.23 \mathrm{~b}$ are also relative to the last category. All the remarks in connection with model interpretation, the need for attitudinal market segmentation and the consistency in the response patterns implied by the models in connection with the Retail Floor Area by Line Haul Travel Time functional destination models in Tables $7.4 \mathrm{a}$ to $7.15 \mathrm{~b}$ apply essentially to the models for Retail Floor Area by Airline Distance functional destinations summarized in Tables 7.17 a to $7.23 \mathrm{~b}$. That the Airline Distance models show good promise has been discussed above. Statistical tests to establish the need for the market segmentation are discussed in detail at the end of this chapter.

Prediction of Functional Shopping Destination Choices Defined for Approachability Market Segments

Approachability market segments $1,2,3$ refer to poor, medium and good approachability to a shopping destination from a given direction, as defined in Chapter 4. The cell frequencies of some of the 
functional classification tables are so low that the results being discussed can only be for illustration. The prediction cell frequencies and main effects model parameters are shown in Tables $7.23 \mathrm{a}$ to 7.23c for Retail Floor Area by Line Haul Travel Time functional shopping destinations and in Tables $7.24 \mathrm{a}$ to $7.24 \mathrm{c}$ for Retail Floor Area by Airline Distance functional shopping destination categories. It is not surprising that most of the models are not good enough since the approachability measure was found not to have any effect on destination choices in Chapter 4. In response to direct questions on why they chose certain destinations in Kannel's survey [10], the respondents rarely stated directly a reason that indicated a factor related to the quality of the transportation system or traffic flow. This situation arises because of the special nature of the sample selected or the nature of the transportation network in the Indianapolis area relative to shopping area locations.

The Feasibility of Having Attitudinal and Approachability Factors in the Same Model for Functional Shopping Destination Prediction

The small sample size available did not permit any partioning into four subsamples. It was therefore not possible to consider any market segmentation derived from a 2-way classification using an attitudinal factor and approachability. It is still instructive to determine if attitudinal factors and approachability act independently, in which case attitudinal and transportation network level-of-service considerations can be incorporated in the same model. With attitudinal factors in two categories defined and approachability in three categories, Tables 7.25 to 7.31 show results of attempts to 
Tables 7.23a - 7.23c Functional Destinstion Cholce Predictions by Market Segmeatsa,b

Table 7.23a Approachab111ty

\begin{tabular}{|c|c|c|c|}
\hline & \multicolumn{3}{|c|}{$\begin{array}{l}\text { Segment } 1 \\
\text { TCLS }\end{array}$} \\
\hline & 1 & 2 & 3 \\
\hline-1 & $\begin{array}{l}17 \\
(18)\end{array}$ & $\begin{array}{c}14 \\
(15)\end{array}$ & $\begin{array}{c}24 \\
(22)\end{array}$ \\
\hline$\sim$ & $\begin{array}{c}2 \\
(1)\end{array}$ & $\begin{array}{c}1 \\
(0)\end{array}$ & $\begin{array}{c}2 \\
(4)\end{array}$ \\
\hline
\end{tabular}

Std.

\section{Parameterg Deviation}

Row: 2.398

Col. (1): -0.314

Co1. (2): -0.550

$(0.464)$

$(0.302)$

Goodnes9-of-f1t $\chi^{2}: 4.26^{*}$ (1 d.f.)

Table 7.23b Approachab1l1ty

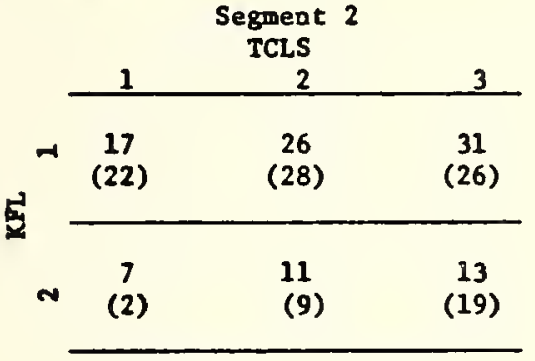

Row: 0.916

Col. (1): -0.606

$(0.216)$

Col. (2): $-0.173 \quad(0.223)$

$(0.253)$

Table 7.23c Approachab111ty

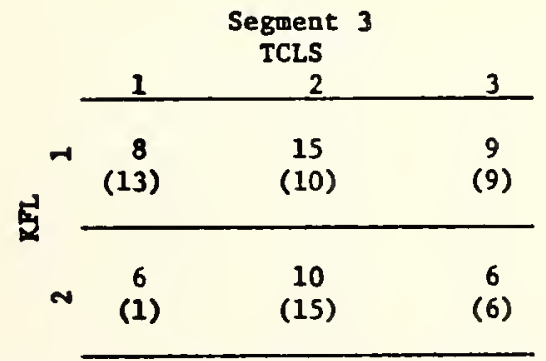

Goodoess-of-f1t $X^{2}: 10.64^{* *}$ (2 d.f.)

Row: 0.374

Col. (1): -0.069

Col. (2): 0.511

$(0.276)$

$(0.370)$

Goodnesg-of-fit $x^{2}: 11.95^{\star \star}(2$ d.f.)

akF and TCLS are retall floor are and line haul travel time categorles defined in Figure 7.1

bCell numbers are predicted frequencles with observed frequencles io parenthesis * $x^{2}$ value signtficant at $5 \%$ level

${ }^{*}{ }^{2}$ value sigalflcant at $1 \%$ level 
Tablea 7.24a - 7.24c Functional Destination Cholce Predictions by Market Segmentsa,b

Table 7.24a Approachability

\begin{tabular}{|c|c|c|c|}
\hline & 1 & $\begin{array}{l}\text { CLS } \\
\text { CLS }\end{array}$ & 3 \\
\hline-1 & $\begin{array}{c}28 \\
(30)\end{array}$ & $\begin{array}{c}23 \\
(21)\end{array}$ & $\begin{array}{c}5 \\
(4)\end{array}$ \\
\hline$\sim$ & $\stackrel{2}{(0)}$ & $\begin{array}{c}2 \\
(4)\end{array}$ & $\begin{array}{l}1 \\
(1)\end{array}$ \\
\hline
\end{tabular}

Std.

Parameters Deviation

Row: $2.400 \quad(0.465)$

col. (2): $1.609 \quad(0.488)$

Goodnes8-of-f1t $x^{2}: 7.43^{*}$ (1 d.f.)

Table 7.24b Approachabll1ty

\begin{tabular}{|c|c|c|c|}
\hline & & $\begin{array}{l}\text { gment } \\
\text { DCLS }\end{array}$ & \\
\hline & 1 & 2 & 3 \\
\hline-1 & $\begin{array}{c}29 \\
(35)\end{array}$ & $\begin{array}{c}36 \\
(31)\end{array}$ & $\begin{array}{c}9 \\
(9)\end{array}$ \\
\hline$N$ & $\begin{array}{l}12 \\
(6)\end{array}$ & $\begin{array}{c}15 \\
(20)\end{array}$ & $\begin{array}{c}4 \\
(4)\end{array}$ \\
\hline
\end{tabular}

$\begin{array}{lll}\text { Row: } & 0.916 & (0.216) \\ \text { Col. (1): } & 1.149 & (0.320) \\ \text { Col. (2): } & 1.367 & (0.311)\end{array}$

Table 7.24c Approachabilfty

Segment 3

DCLS

\begin{tabular}{|c|c|c|c|}
\hline & 1 & 2 & 3 \\
\hline-1 & $\begin{array}{c}15 \\
(19)\end{array}$ & $\begin{array}{c}15 \\
(12)\end{array}$ & $\begin{array}{c}1 \\
(1)\end{array}$ \\
\hline$N$ & $\begin{array}{l}11 \\
(7)\end{array}$ & $\begin{array}{c}11 \\
(14)\end{array}$ & $\begin{array}{c}1 \\
(1)\end{array}$ \\
\hline
\end{tabular}

Goodness-of-fit $x^{2}: 7.14^{\star}(2$ d.f.)

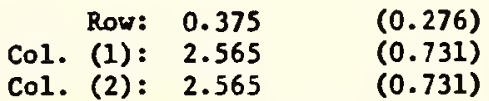

Goodness-of-fit $\chi^{2}: 4.05(2$ d.f.)

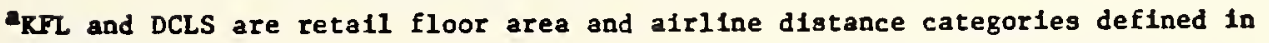
P1gure $7 \cdot 2$

${ }^{b}$ Cell numbers are predicted frequencies with observed frequencles in parenthesis ${ }^{\star} x^{2}$ value significant at $5 \%$ level

${ }^{*} x^{2}$ value significant at $1 \%$ level 
Table 7.25 Prediction of the Joint Relationship Between "Many Employees" (SC1) and Approachabllity $(\mathrm{AP})^{\mathrm{a}}$

\begin{tabular}{|c|c|c|c|}
\hline & \multicolumn{3}{|c|}{$\mathbf{A P}$} \\
\hline & 1 & 2 & 3 \\
\hline 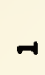 & $\begin{array}{c}15 \\
(12)\end{array}$ & $\begin{array}{c}26 \\
(35)\end{array}$ & $\begin{array}{l}13 \\
(7)\end{array}$ \\
\hline$N$ & $\begin{array}{c}45 \\
(48)\end{array}$ & $\begin{array}{c}79 \\
(70)\end{array}$ & $\begin{array}{c}41 \\
(47)\end{array}$ \\
\hline
\end{tabular}

Std.

Parameters Deviacion

$\begin{array}{lrr}\text { Row: } & -1.117 & (0.156) \\ \text { Co1. (1): } 0.105 & (0.188) \\ \text { Co1. (2): } 0.665 & (0.167)\end{array}$

Goodness-of-fit $\chi^{2}: 9.27^{\star \star}$

Tab!e 7.26 Pred1ction of Jolnt Relatlonsh1p Between "Wide Select1on" (SD1) and Approachability $(A P)^{a}$

\begin{tabular}{|c|c|c|c|}
\hline & \multicolumn{3}{|c|}{$\mathbf{A} \mathbf{P}$} \\
\hline & 1 & 2 & 3 \\
\hline-1 & $\begin{array}{c}23 \\
(25)\end{array}$ & $\begin{array}{c}41 \\
(44)\end{array}$ & $\begin{array}{c}21 \\
(16)\end{array}$ \\
\hline$N$ & $\begin{array}{c}37 \\
(35)\end{array}$ & $\begin{array}{c}64 \\
(61)\end{array}$ & $\begin{array}{c}33 \\
(38)\end{array}$ \\
\hline
\end{tabular}

$\begin{array}{lrr}\text { Row: } & -0.455 & (0.139) \\ \text { Col. (1): } & 0.105 & (0.187) \\ \text { Col. (2): } & 0.665 & (0.167)\end{array}$

Goodness-of-fit $x^{2}: 2.61$

Table 7.27 Prediction of the Joint Relationsh1p Between "Shortest T1me" (SE1) and Approachability (AP) ${ }^{a}$

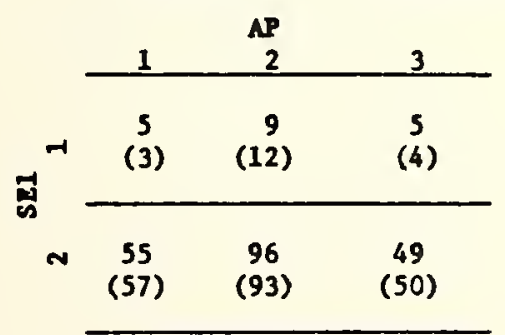

$\begin{array}{lrr}\text { Row: } & -2.354 & (0.239) \\ \text { Co1. (1): } 0.105 & (0.187) \\ \text { Col. (2): } 0.665 & (0.167)\end{array}$

Goodness-of-fit $\chi^{2}: 2.23$

Table 7.28 Prediction of the Joint Relationship Between "Uncongested Roads" (SHI) and Approachability (AP) ${ }^{a}$

\begin{tabular}{|c|c|c|c|}
\hline & & $\Delta \mathbf{P}$ & \\
\hline & 1 & 2 & 3 \\
\hline$\rightarrow$ & $\begin{array}{c}44 \\
(45)\end{array}$ & $\begin{array}{c}77 \\
(80)\end{array}$ & $\begin{array}{c}39 \\
(35)\end{array}$ \\
\hline$N$ & $\begin{array}{c}16 \\
(15)\end{array}$ & $\begin{array}{c}28 \\
(25)\end{array}$ & $\begin{array}{c}15 \\
(19)\end{array}$ \\
\hline
\end{tabular}

$\begin{array}{lll}\text { Row: } 0.998 & (0.152) \\ \text { Co1. (1): } 0.105 & (0.188) \\ \text { Co1. (2): } 0.665 & (0.167) \\ \text { Goodness-of-f1t } \chi^{2}: & 2.42\end{array}$

acell numbers are predicted frequencles with observed frequeacies in parenthesis * $\chi^{2}$ value significant at $5 \%$ level

${ }^{\star} x^{2}$ value significant at $1 \%$ level 
Table 7.29 Pred1ction of the Jo1nt Relationsh1p Between "Several Stores" (SKL) and Approachability (AP) a

\begin{tabular}{|c|c|c|c|}
\hline & 1 & $\begin{array}{r}A P \\
2 \\
\end{array}$ & 3 \\
\hline$\pi$ & $\begin{array}{c}14 \\
\text { (13) }\end{array}$ & $\begin{array}{c}25 \\
(31)\end{array}$ & $\begin{array}{l}13 \\
\text { (7) }\end{array}$ \\
\hline $\mathbf{N}$ & $\begin{array}{c}46 \\
(47)\end{array}$ & $\begin{array}{c}81 \\
(74)\end{array}$ & $\begin{array}{c}41 \\
(47)\end{array}$ \\
\hline
\end{tabular}

Std.

Parametera Deviation

Col. $\begin{array}{rr}\text { Row: } & -1.192:(0.160) \\ 0.105 & (0.187)\end{array}$

Col. (2): $0.665 \quad(0.167)$

Goodness-of-fit $\chi^{2}: 5.92$

Table 7.30 Prediction of the Jo1nt Relat1onahip Between "Qu1ck Parking" (SLI) and Approachab1lity (AP) ${ }^{a}$

\begin{tabular}{|c|c|c|c|}
\hline & 1 & $\begin{array}{r}A P \\
2\end{array}$ & 3 \\
\hline-1 & $\begin{array}{c}32 \\
(26)\end{array}$ & $\begin{array}{c}56 \\
(63)\end{array}$ & $\begin{array}{c}29 \\
(27)\end{array}$ \\
\hline N & $\begin{array}{c}28 \\
(34)\end{array}$ & $\begin{array}{c}49 \\
(42)\end{array}$ & $\begin{array}{c}25 \\
(27)\end{array}$ \\
\hline
\end{tabular}

$\begin{array}{rll}\text { Row: } & 0.119 & (0.135) \\ \text { Col. (1): } & 0.105 & (0.187) \\ \text { Co1. (2): } & 0.665 & (0.167)\end{array}$

Goodness-of-fit $x^{2}: 4.53$

Table 7.31 Prediction of the Jolnt Relationahip Between "Close to Home" (SNI) and Appronchability (AP) ${ }^{a}$

\begin{tabular}{|c|c|c|c|}
\hline \multirow{2}{*}{ 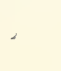 } & \multicolumn{3}{|c|}{$\mathbf{A P}$} \\
\hline & 1 & 2 & 3 \\
\hline$-r$ & $\begin{array}{c}30 \\
(28)\end{array}$ & $\begin{array}{c}52 \\
(53)\end{array}$ & $\begin{array}{c}27 \\
(27)\end{array}$ \\
\hline$N$ & $\begin{array}{c}30 \\
(32)\end{array}$ & $\begin{array}{c}53 \\
(52)\end{array}$ & $\begin{array}{c}27 \\
(27)\end{array}$ \\
\hline
\end{tabular}

$\begin{array}{lrr}\text { Row: } & -0.027 & (0.135) \\ \text { Col. (1): } 0.105 & (0.187) \\ \text { Col. (2): } 0.665 & (0.167)\end{array}$

Goodness-of-fit $x^{2}: 0.24$

acell numbers are predicted frequencles with observed frequenclea in parenthesis $x^{2}$ value significant at $5 \%$ level

${ }^{*}{ }^{2}$ value significant at $1 \%$ level 
reproduce 2 -way contingency table cell frequencies defined by the two types of factors. Except for the factor of "Many Employees" all the attitudinal factors relative to shopping destination choice act independently of the approachability measure and the level of accuracy of cell frequency prediction is good. It has been pointed out that approachability is not a significant factor in shopping destination choice for the sample used in this research. The two-category attitudinal factors are also too gross. No indication is given, however, that the attitudinal factors act in conflict with the approachability measure. This expectation of independence can be extended to direct measures that the attitudinal factors are related to.

Testing the Hypothesis That the Attitudinal Market Segments Used in Functional Destination Choice Prediction Represent Different

Behavioral Populations

It was discussed in Chapter 5 that under maximum likelihood estimation with a large enough sample size, the joint distribution of the parameters estimated is multivariate normal. To test the equality of two parameter vectors one must first test the equality of their covariance matrices.

Testing the Equality of Two Covariance Matrices

Three multivariate statistical testing criteria were used to test the equality of parameter covariance matrices for the attitudinal market segments. These are: 1. Hotelling's Trace Criterion

2. Pillai's Trace Criterion

3. Roy's Largest Root Criterion 
The three tests and associated tables are discussed in Pillai [62].

The hypothesis that $\mathrm{p} \times \mathrm{p}$ covariance matrices $\sum_{1}$ and $\Sigma_{2}$ are equal is equivalent to

$$
H_{0}: \quad r_{i}=1 \quad i=1, \ldots p
$$

where the $\gamma_{i}$ 's are the characteristic roots of $\Sigma_{1} \Sigma_{2}^{-1}$; ie. the roots of

$$
\left|\sum_{1} \sum_{2}^{-1}-\gamma I\right|=0
$$

The alternate hypothesis is

$$
H_{1}: r_{i} \geq 1, \sum_{i=1}^{p} r_{i}>p
$$

Sample estimates of $\Sigma_{1}$ and $\Sigma_{2}$ are defined as $S_{1}$ and $S_{2}$ respectively. If the sample sizes involved in the estimation of $\Sigma_{1}$ and $\Sigma_{2}$ are $N_{1}$ and $N_{2}$ respectively, the quantities $M$ and $N$, used for the three tests, are defined as follows:

$$
M=\frac{N_{1}-p-2}{2} \text { and } N=\frac{N_{2}-p-2}{2}
$$

The $p$ characteristic roots of $S_{-1} S_{2}^{-1}$ are $\lambda_{i} i=1, \ldots p$.

The roots of $s_{1}\left(s_{1}+s_{2}\right)^{-1}$ are $\theta_{i}, i=1=1 \ldots p$ where

$$
\theta_{i}=\frac{\lambda_{i}}{1+\lambda_{i}} \quad i=1, \ldots p
$$


Hotelling's Trace Criterion uses the trace of the matrix $s_{1} s_{2}{ }^{-1}$ which is given by

$$
U(p)=\sum_{i=1}^{p} \lambda_{i}
$$

The hypothesis that $\Sigma_{1}=\Sigma_{2}$ is rejected at a given significance level if $U^{(p)}$ exceeds the tabular value [62] for $p, M$ and $N$.

Pillai's Trace Criterion performs the test of the equality of $\underline{\Sigma}_{1}$ and $\underline{\Sigma}_{2}$ using the trace of the matrix $s_{1}\left(s_{1}+s_{2}\right)^{-1}$ which is

$$
v^{(p)}=\sum_{i=1}^{p} \theta
$$

$V(P)$ is compared with the tabular value [62] for $p, M$ and $N$ at a given significance level and the null hypothesis rejected if $v(p)$ exceeds the tabulated value.

Roy's Largest Root Criterion uses the largest characteristic root of the matrix $S_{1}\left(S_{1}+S_{2}\right)^{-1}, \theta(\max )$ and compares it with a tabular value [62] for $p, M$ and $N$ at a given signifance level. The null hypothesis is rejected if $\theta(\max )$ is greater than the tabular value.

The development of the above test criteria was based on covariance matrice estimates estimated directly from sample observations. When the covariance matrices are estimated from maximum likelihood estimation, a correction must be made for the degrees of freedom lost in parameter estimation in the use of $N_{1}$ and $N_{2}$ in the computation of $M$ and N. By the implication of the orthogonality of sets of effects corresponding to ways of calssification in the models used, the covariance terms between orthogonal effects are necessarily zero. On the average, for the range of parameter vector sizes involved in 
the tests performed in this study, one parameter is estimated for each component of a covariance matrix. To correct for this loss of degree of freedom $N_{1}-1$ and $N_{2}-1$ are used in the place of $N_{1}$ and $N_{2}$ respectively in the computation of $M$ and $N$ required for performing the hypothesis testing. The sample sizes involved in the application of the tests in this research are so large that this correction makes an indiscernible difference.

Testing the Equality of Two Parameter Vectors

If the hypothesis that the covariance matrices of parameter vectors are equal, discussed above, is rejected then it is obvious that the two parameter vectors involved belong to two different normal populations. With regard to the problem at hand this implies the market segmentation by attitudinal orientation was necessary since the statistical distributions of the parameter vectors of the two market segments involved being different necessarily implies that the response patterns of the two market segments to functional destination choice are different.

A multivariate test will be discussed that assumes that the hypothesis of the equality of covariance matrices is not rejected. The statistic used is Hotelling's $\mathrm{T}^{2}$ [63]. Denoting the parameter vectors for the two market segments or populations by $x_{1}$ and $x_{2}$, Hotelling's statistic is given by

$$
T^{2}=\frac{N_{1} N_{2}}{N_{1}+N}\left(\underline{x}_{-1}-\underline{x}_{2}\right) \cdot \underline{s}^{-1}\left({\underset{x}{1}}_{1}-\underline{x}_{2}\right)
$$

where

$$
\underline{s}=\underline{S}_{1}+\underline{s}_{2}
$$


where $S_{-1}$ and $\underline{S}_{-2}$ are estimates of the covariance matrices of the two populations. The previous discussion on corrections applied to $N_{1}$ and $\mathrm{N}_{2}$ applies here as well.

The statistic $F_{T}=\frac{{ }_{N_{1}+N_{2}-p-1}}{p} \cdot \frac{T^{2}}{N_{1}+N_{2}-2}$

has an $F$ distribution with $p$ and $N_{1}+N_{2}-p-1$ degree of freedom. The test of the equality of parameter vectors is performed by comparing $\mathrm{F}_{\mathrm{T}}$ with the appropriate tabulated value in F-tables at a given significance level.

Testing the Hypothesis That two Attitudinal Market Segment Multinomial Response Relation Model Parameter Vectors Have the Same Multivariate Normal Distribution

It has been previously discussed that if the multinomial response relation functional destination choice model parameter vectors for two attitudinal market segments belong to the same multivariate normal population then there is no need for the market segmentation with the attitudinal factor in question. The preceeding sections presented appropriate multivariate statistical tests for determining such a need. for attitudinal market segmentation. The results are summarized in Table 7.32. It is noticed that the attitude of respondents to the need for quick parking does not affect their response patterns in their choice of functional destinations. The possible reason for this has been discussed in earlier sections. All other results in Table 7.32 justify the attitudinal market segmentation adopted. 


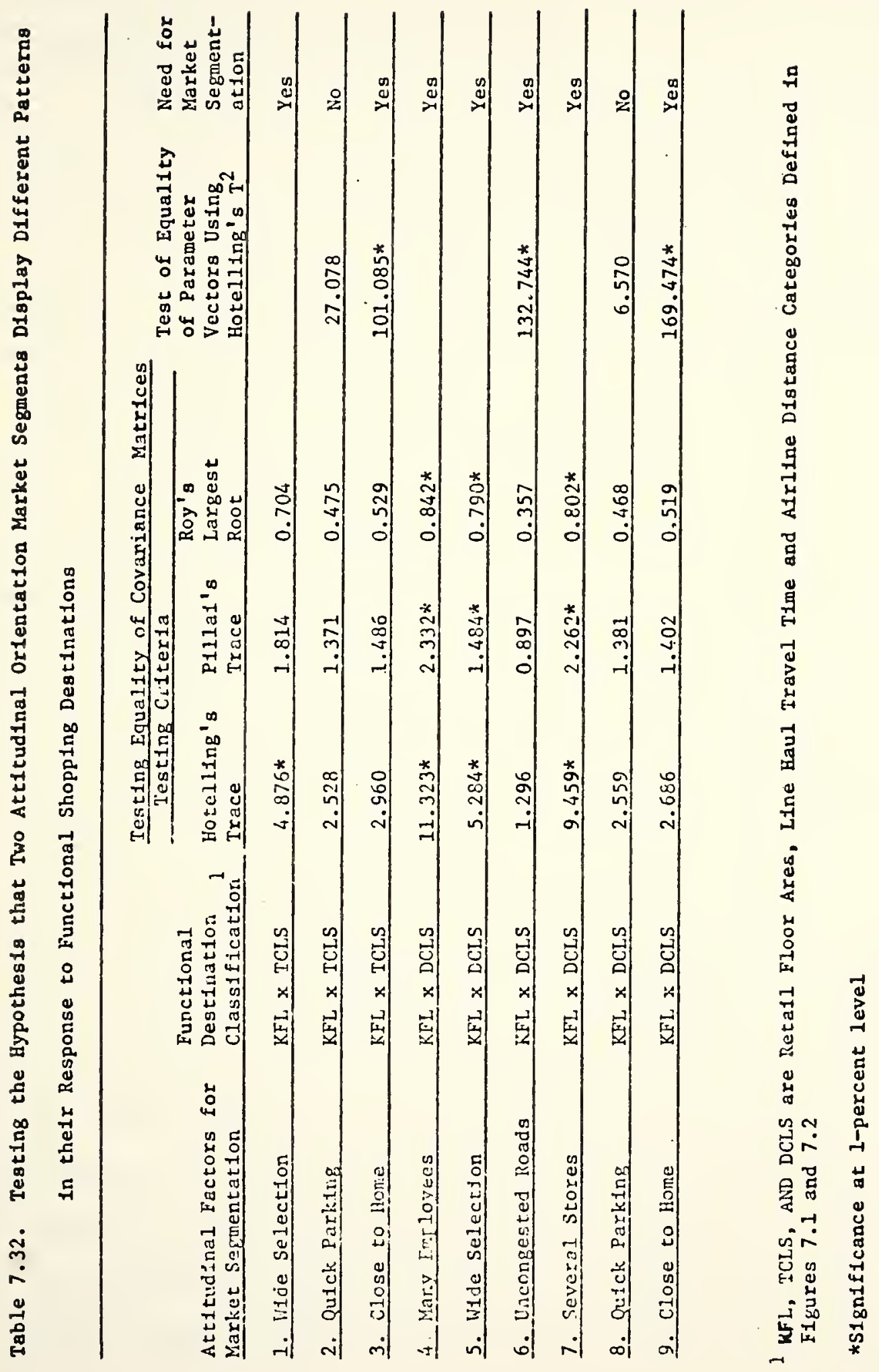


The Use of Travel Data on Zonal Shopping Destination Choice to

Provide an Approximate Verification of Some Assumptions Used in

Functional Destination Choice Modelling

Working on the assumption that shopping destinations defined along traffic zonal boundaries may suffice for functional destination choice models for groups of travellers, 1964 travel data on shopping trips to zonal destinations were used to roughly verify some basic assumptions that are implicit in the functional shopping destination choice modelling discussed in this chapter. Details of the empirical analysis carried out can be found in Appendix B.

That travel market segmentation is necessary to model the different response patterns to functional shopping destinations of different groups of people is clearly established. In spite of the definition of shopping areas along traffic zone boundaries being unrealistic in many cases the impression given by the models developed in Appendix $B$ is that Zonal Retail Floor Area or Zonal Retail Employment and Inter-zonal Distance are adequate for modelling the shopping patterns of higher income groups, with improved results if local travel is excluded from consideration. There was not sufficient information on 1964 retail land-use for the whole of Indianapolis to enable the identification of proper shopping area boundaries. Consistency in the response patterns for subsamples of different size for the high income market segments should establish the complete adequacy of using zonal destinations for these market segments. Statistical tests discussed in Appendix B do not indicate this consistency, clearly establishing the need to use actual shopping area boundaries 
in the definition of functional shopping destinations. The lack of further data on 1964 specific shopping areas did not enable the pursuance of the issue with the 1964 data. The encouraging results with models using actual shopping areas, as discussed in this chapter, strongly support the call to discontinue using zonal shopping destinations.

The empirical analysis discussed in Appendix B indicates that urban travellers consider few categories of each factor that defines functional shopping destinations. Three categories of Retail Floor Area, Retail Employment and interzonal Airline Distance ranges were found to be adequate for the modelling discussed in Appendix $B$. Greater numbers of classification categories did not display any statistically reproducible patterns of functional destination choice behavior or monotonicity or regularity of the effects of the factors of functional destination classification. The need for considering certain interactions in model development is also borne out in the analyses discussed in Appendix B.

\section{Summary}

The stability and accuracy of models that predict functional shopping destinations for both the total sample and market segments are demonstrated by the empirical analysis discussed in this research. The findings apply generally to functional shopping destinations defined by Retail Floor Area and Line Haul Travel Time and more specifically to those defined by Retail Floor Area and Airline Distance. The implication of this in operational destination choice modelling is invaluable since airline distances are easier to compute than travel times. It is established that in larger classification tables 
the fitting of certain key interactions in the predictive model development greatly improves the accuracy of the results. Approachability is not expected to play an important role in functional shopping destination choice modelling because of the background of the sample used, and this was found to be the case.

No reason was found why market segmentation according to attitudinal orientation should not be adopted or further investigated for operational model development. Multivariate statistical tests on mode1 parameters for different attitudinal market segments and the interpretation of the sense of the functional destination choice model parameters strongly support patterns of shopping behavior that one would expect in practice. The need for attitudinal market segmentation was established for all the factors considered except for that relating to the ability to find a parking space quickly, a plausible reason for that being given.

A discussion of empirical analyses on functional shopping destinations carried out in Appendix B strongly supports the major objections to the use of zones to define retail areas and the irregularity of the effects of shopping attraction variables like zonal retail floor area and zonal retail employment. The view that urban travellers usually consider a small number of categories of factors affecting their travel behavior is supported.

The limited sample size available could not allow the two-way classification of attitudinal factors in market segmentation or the combination of attitudinal orientation and approachability for the same purpose. An investigation of the joint relationship 
between attitudinal factors and approachability gave no indication why attitudinal and transportation level of service considerations would conflict in the same predictive model.

In spite of the limitations posed by the small sample size available, the results of the empirical analysis in this chapter strongly recommend the adoption of the multinomial response relation (MRR) approach to functional shopping destination choice modelling in further investigations, using a more appropriate data base and for subsequent adoption in operational modelling. 
CHAPTER 8

CONCLUSIONS AND RECOMMENDATIONS

Summary

This dissertation presents the development of a theoretical framework that allows for a practical modelling of destination choice. The spatial choice of destinations is selected in order to highlight the more immense problems posed by spatial choices in travel demand analysis and to demonstrate that more specific travel choices can be incorporated in the resulting modelling framework as special cases. Currently available techniques for disaggregate analysis of destination choice are over-generalized and do not achieve what they claim to accomplish, statistically. The present formulation of the current approaches also makes it virtually impossible for aggregate forecasts of destination choice behavior to be made.

The multinomial response relation methodology proposed in this research enables a straightforward computation of aggregate forecasts with regard to the choice of types of shopping destination choice behavior. This is because the approach is directly tied to the sampling design used in data collection. A major advantage of the multinomial response relation approach is that it is not demanding on detailed variables since the classification scheme used reduces continuous variables into intervals. This allows botin discrete and continuous variables in a single modelling framework. 
This is particularly useful where a detailed and sophisticated data base is not available and yet the best information must be extracted from currently available data in order to plan a more ambitious data collection effort. A further advantage of the multinomial response relation model is the ability to include interaction effects in the analysis.

To obtain a common choice set of shopping destination type alternatives, a functional destination concept is introduced. This is, basically, a classification of shopping areas with respect to their attraction measures and their geographic or time frame location relative to households or subzones of travel origin. The two-way classification used for functional shopping destination definition in this research is only a result of the limited sample size for the data available. The definition of travel market segments with respect to socio-economic characteristics or attitudinal orientation becomes necessary in order to identify the different patterns of travel behavior exhibited by different market segments. Attitudinal orientation is the means of market segmentation examined in detail in this research.

The number of people in a given travel market segment that are associated with a given functional shopping destination classification is predicted by the multinomial response relation model. Applying the expansion factor that relates the sampling of the market segment to the total population, a forecast of the aggregate responses to shopping behavior categories (or functional shopping destinations) is made. For a given traffic zone or subzone, one can use census or other secondary data to identify the number of households belonging to 
a particular travel market segment. The multinomial response relation model predicts the proportion of the market segment that chooses a given functional shopping destination category. An example of such

a functional destination category is the set of shopping areas falling within a specified retail floor area range and a distance interval. Since retail floor area and distance are used in defining functional shopping destinations, one needs further factors that condition the choice of specific shopping areas that fall within the functional shopping destination category in question. Such factors may include the frequency of sales of certain items in one locality or the dependability of products of certain stores in another. The measures of factors conditioning the selection of specific shopping destinations for a given commodity depend on the type of market segment and the particular stores that fall within the functional destination category in question. The measures also depend on the geographic location of the zone or subzone where the market segment originated from in "home to shop" travel. It is clear that an attempt to develop a uniform value system for defining factors affecting the choice of specific shopping areas introduces insurmountable complications. A finer classification of functional shopping destinations provides a large number of alternative categories. In such an event, the number of specific destinations is likely to be small enough for the assignment of specific destinations to be based on experience with the patronage of particular shopping areas. At this level, a simulation model can be used to assign specific destinations whereby the probabilities of specific destination choice are dependent on prevailing local 
conditions. A simple license plate survey at selected shopping areas can provide information on the origin of customers found at different shopping areas. This information gives an idea of the relative patronage of certain types of shopping areas.

The current belief that disaggregate models developed with traditional random sampling require smaller samples than aggregate models is not supported by the theoretical work in this research. Separate sampling in the context of stratified sampling at activity centermarket segment interfaces is recommended. It is also suggested sample sizes should be large enough in order to validate statistical proceedures associated with the model development that assume the availability of large samples. Random sampling leaves to chance the frequency of association observed for each category of functional shopping destination. In order to cover the infrequently chosen categories, a very large sample may be needed. Separate sampling considers each functional shopping destination category as a stratum and samples each stratum as in stratified sampling. With separate sampling there is no danger of over-representing certain categories of functional shopping destinations at the expense of others.

The multinomial response relation approach, with a standardized functional choice set, can be viewed as a discrimination procedure if further variables are available for such discrimination above the variables used for defining functional destinations. Travel decisions like mode and time of day choices have standardized alternatives. This enables a ready application of a recently developed logistic discrimination approach with separate sampling. The logistic 
discrimination procedure uses the logistic distribution as against classical techniques that use the multivariate normal distribution.

\section{Major Conclusions and Recommendations}

Choice Set Definition

Current disaggregate modelling of destination choices rejects the assumption that all individuals have the same set of physical destinations and goes to an extreme in specifying physical destination choice sets of varying size for different individuals. The result is that the methodology cannot be adopted on a large scale. The predictive accuracy of logit models using arbitrarily selected destination choice sets is not satisfactory. It is suggested that functional destinations defined with the attraction attributes of shopping areas and individuals' relative location to shopping destinations be used in order to define a common shopping destination behavioral choice set. The multinomial response relation methodology postulates a linear model that predicts the probability of association with each functional shopping destination for each travel market segment.

\section{Aggregation}

Current generalized probabilistic choice modelling of travel behavior does not have any provision for making aggregate forecasts tied to its theoretical formulation or data collection scheme. The multinomial response relation approach has a direct provision for aggregation. Only appropriate expansion factors, derived from the sampling framework used, need be applied to predicted frequency responses to functional destination categories to obtain aggregate forecasts. 


\section{Attitudinal Orientation}

Few attitudinal factors need be considered in a single model for shopping travel prediction. A suitable market segmentation by attitudinal orientation can use only two attitudinal factors - one relating to measures of the wide range of goods and services at a shopping area, the other to the ease of getting to the shopping area in terms of distance or travel time. Even with a two-way classification, good predictability of attitudinal orientation patterns requires the consideration of certain interaction effects.

Market segmentation by single attitudinal factors is statistically shown to be valid. A direct behavioral interpretation of the patterns of functional destination choice behavior for different market segments is possible in all cases.

Predictive Performance of the Conditional Logit Model and the Multinomial Relation Response Relation Model for Actual and Functional Shopping Destination Choices, Respectively

All the models developed using the conditional logit model for predicting specific destination choices achieved less than 50 percent predictive accuracy, notwithstanding other objections to the use of the methodology with regard to choice set definition and aggregation. An alternative modelling framework in terms of multinomial response relations is proposed, using functional shopping destinations. Except for a few categories of low frequency, the empirical investigation of the methodology gives very good forecasts of functional shopping destination choices. 
Reduction of Data Requirements and the Need for Statistically Sound

Modelling

The need to simplify data collection needs in model development often conflicts with the requirements for good statistical modelling. The finding that few attitudinal factors need be considered in one model is in a good direction as far as the simplification of data collection is concerned. To obtain more reliable and sounder models one has to take advantage of the asymptotic properties of the joint distribution of model parameter estimators, a realization of which can only be in terms of large, but not excessive, sample sizes. It is concluded that, in order to achieve a suitable compromise and yet cover as many travel market segments as possible, it is necessary to use separate sampling which is an efficient way of data collection that avoids redundant data collection. The extension of the multinomial response relation methodology into a separate sampling context is possible, but the discussion of the latter in terms of logistic discrimination is for the reason that, with the standardization of functional destination choice sets, the multinomial response relation procedure can be regarded as that of discrimination with a common functional choice set.

\section{Recommendations for Further Research}

The following are some areas in which further research is recommended.

1. The extension of the multinomial response relation approach to cover trip generation and time of day choices and the prediction of aggregate demand. 
2. Given that functional travel alternatives relative to spatial choices are standardized, research is needed to investigate the extent to which the multinomial response relation model can be extended as a separate sampling logistic discrimination problem.

3. A large scale investigation is recommended to illustrate the incorporation of the multinomial response relation model into a simulation model that brings the analysis to specific shopping destination and route choices.

4. Work is needed in defining appropriate shopping area attraction factors or variables that are related to destination choice attributes that are predominant in attitudinal surveys. 
LIST OF REFERENCES 


\section{LIST OF REFERENCES}

1. Oi, W., and Shuldiner, P., Analysis of Urban Travel Demand. Northwestern University, Press, 1962.

2. Report of the Panel, "Transportation Analysis: Past and Prospects" Highway Research Record 309, Washington, D.C., Highway Research Board, 1970.

3. Cherington, P. W., "Transportation Research," Transportation Research Forum Proceedings, Vol. XII, No, 1, 1971.

4. Stopher, P. R., and Lisco, T. E., "Modelling Travel Demand: A Disaggregate Behavioral Approach-Issues and Application" Transportation Research Forum Proceedings, 1970.

5. Manheim, M., "Practical Implications of Some Fundamental Properties of Travel Demand Mode1s," Paper presented at the Highway Research Board annual meeting, January 1972.

6. Bureau of Public Roads, Guidelines for Trip Generation Analysis, U. S, Government Printing Office, 1967.

7. Kassoff, H., and Deutschman, H., "Trip Generation: A Critical Appraisal," Highway Research Record 297, Highway Research Board, Washington, D. C., 1969.

8. McCarthy, G. M., "Multiple Regression Analysis of Household Trip Generation - A Ctitique," Highway Research Record 297, Highway Research Board, Washington, D. C., 1969.

9. Stowers, J. R., and Kanwit, E. L., "The Use of Behavioral Surveys in Forecasting Transportation Requirements," Highway Research Record 106, Highway Research Board, Washington, D. C., 1966.

10. Kannel, E. J., "A Disaggregate Analysis of Urban Trave1 Behavior," Ph. D. Thesis, Purdue University, 1972.

11. Warner, S. L., Stochastic Choice of Mode in Urban Trave1: A Study in Binary Choice, Evanston, Illinois, Northwestern University Press, 1962. 
12. Watson, P. L., "Predictions of Inter-City Mode Choice From Disaggregate, Behavioral, Stochastic Models," paper presented at the Highway Research Board annual meeting, January, 1973.

13. Rassam, P. R., Ellis, R. H., and Bennett, J. C., "The NDimensional Logit Model: Development and Application," Washington, D. C., Peak Marwick, Mitchell and Co., 1970.

14. McGillivray, R. G., "Demand and Choice Models of Modal Split," Journal of Transport Economics and Policy, Vol. 4, No. 2, 1970.

15. Quarmby, D. A., "Choice of Travel Mode for the Journey to Work: Some Findings," Journal of Transport Economics and Policy, Vol. 1, No. 3, 1967.

16. Charles River Associates, "A Disaggregated Behavioral Model of Urban Travel Demand," Federal Highway Administration, March 1972.

17. Ben-Akiva, M., "Structure of Passenger Travel Demands Models," $\mathrm{Ph}$. D. Thesis, Mass. Institute of Technology, 1973.

18. Nakkash, T. Z., "Activity-Accessibility Models of Trip Generation," Ph. D. Thesis, Purdue University, 1969.

19. Aldana, E., "Microanalysis of Urban Transportation Demand," paper presented at the Highway Research annual meeting, January 1973.

20. Stopher, P. R., and Lavender, J. O., "Disaggregate, Behavioral Travel Demand Models: Empirical Tests of Three Hypotheses," Transportation Research Forum, Vol. XIII, No. 1, 1972.

21. Hartgen, D. T., and Tanner, G. H., "Behavioral Model of Mode Choice," New York State Department of Transportation Albany, New York, 1970.

22. Wilson, A. G., "Advances and Problems in Distribution Modelling," Transportation Research Vol., No. 1, 1970.

23. Allen, W. S., and Isseman, A., "Behavioral Modal Split," High Speed Ground Transportation Journal, Vol. 6, No. 2, 1972.

24. Hyman, G. M., "Trip Distribution and Modal Split by Categories of Households," Transportation Research, Vol. 4, No. 1, 1970 . 
25. Wilkie, D. F., and Stefanek, R. G., "Precise Determination of Equilibrium in Travel Forecasting Problems Using Numerical Optimization Techniques," Highway Research Record 369, Hìghway Research Board, Washington, D. C., 1971.

26. Wilkie, D. F., "Applications of Some Control Theory Techniques to Transportation Systems Analysis," Ford Motor Company Report 69-3, Dearborn, Michigan, May 1969.

27. Manheim, M. L. and Ruiter, E. R., "DODOTRANS I: A DecisionOriented Computer Language for Analysis of Multi-Mode Transportation Systems," Highway Research Record 314, Highway Research Board, Washington, D. C., 1970.

28. Dial, R. B., "A Probabilistic Multipath Traffic Assignment Model Which Obviates Path Enumeration," Transportation Research Vo1. 5, No. 2, June 1971.

29. Blalock, H. M., Jr., Causal Inferences in Non-Experimental Research. University of North Carolina Press, 1964.

30. de Neufville, R. and Stafford, H. H., Systems Analysis for Engineers and Managers. McGraw-Hi11, New York, 1971.

31. Tukey, J. W., "Causation, Regression and Path Analysis," in Oscar Kempthorne et al., Statistics and Mathematics in Biology, Hafner Publishing Co., New York, 1964.

32. Duncan, O. D., "Path Analysis: Sociological Examples," American Journal of Sociology, Vol, 72, 1966.

33. Hyman, H., Survey Designs and Analysis. Chapter 7. Glencoe: The Free Press, 1955.

34. Kain, J. F., "A Multiple Equation Model of Household Locational and Trip Making Behavior," RAND Memorandum 3086, RAND Corporation, Santa Monica, California, 1962.

35. Kraft, G., and Woh1, M., "New Directions for Passenger Demand Analysis and Forecasting," Transportation Research, Vol. 1,. 1967.

36. McFadden, D., "The Revealed Preferences of a Government Bureaucracy," Technical Report W 17, Institute of International Studies, University of California, Berkeley, 1968.

37. Theil, H., "A Multinomial Extension of the Linear Logit Mode1," International Economic Review, 1969. 
38. Berkson, J., "Application of the Logistic Function to Bioassay," Journal of American Statistical Association, 1944.

39. Luce, R. D., Individual Choice Behavior, John Wiley and Sons, New York, 1959 .

40. Peat, Marwick, Mitchell and Co., "Implementation of the NDimensional Logit Model," Final Report, Comprehensive Planning Organization, San Diego County, California.

41. Wigner, Martha F., "Disaggregated Mode Choice Models of Downtown Trips in the Chicago Region," paper presented at the Highway Research Board Annual meeting, January 1973.

42. Inglis, P., "A Multimodal Logit Model of Modal Split for a Short Journey," paper presented at the Highway Research Board annual meeting, January 1973.

43. Paine, F. T., et al., "Consumer Conceived Attributes of Transportation: An Attitude Study," Maryland University, Department of Business Administration, 1967.

44. Brown, G. R., "Analysis of User Preferences for System Characteristics to Cause a Modal Shift," Highway Research Record 417, Highway Research Board, Washington, D. C., 1972.

45. Wachs, M., "Relationship Between Drivers' Attitudes Toward Alternative Routes and Driver and Route Choice Characteristics." Highway Research Record 197, Highway Research Board, Washington, D. C., 1967.

46. Michaels, R. M., "Attitudes of Drivers Determine Choice Between Alternative Highways," Public Roads, Vol. 33, No. 11, December, 1965.

47. Golob, T. F., and Beckman, M. J., "A Utility Model for Travel Forecasting," Publication GMR-1006, General Motors Corp. Research Lab., Warren, Michigan, 1970.

48. Lancaster, K. J., "A New Approach to Consumer Theory," Journal of Political Economy, Vol. 74, 1966.

49. Anderson, T. W., An Introduction to Multivariate Statistical Analysis, John Wiley, New York, 1958.

50. Hartgen, D. T., "A Note on the Ability of Socio-Economic Variables to Explain Attitudinal Bias Toward Alternative Travel Modes," High Speed Ground Transportation Journal, Vol. 6, No. 2, 1972. 
51. Burnett, K. P., "The Dimensions of Alternatives in Spatial Choice Processes," 1973, in press.

52. Burnett, K, P., "A Three-State Markov Model of Choice Behavior Within Spatial Structures," 1973, in press.

53. Golob, T. T. and R. Dobson, "The Assessment of Preferences and Perceptions Toward Attributes of Transportation Alternatives," Resource Paper for the Conference on Issues in Travel Demand Modelling and the Valuation of Travel Time, South Berwick, Maine, July 1973.

54. Shepard, R. M., Romney, A. K., Nerlove, S. B., eds., Multidimensional Scaling, Vol. 1, New York, Seminar Press, 1972 .

55. Wilson, A. G., "The Use of Entropy Maximizing Models," Journal of Transport Economics and Policy III, January 1969.

56. Wilson, A. G., "A Statistical Theory of Spatial Distribution Models," in Quandt, R. E. ed. The Demand for Travel:

Theory and Measurement, Lexington, Health, 1970, pp. 55-82.

57. Bacon, R. W., "An Approach to the Theory of Consumer Shopping Behavior," Urban Studies, 1971.

58. Brush, J. E. and Gauthier, H. L., Service Centers and Consumer Trips, University of Chicago, Department of Geography, Research Paper 113, 1968.

59. Sato, M. G., Methods for Estimating Trip Destinations by Trip Purpose. Chicago Area Transportation Study, Chicago, 1966.

60. Bowlby, S. R., "Spatial Variations in Consuners' Information Levels," Research Report 4, Northwestern University, Transportation Center, Evanston, Illinois, 1972.

61. Hanson, S., "Information Levels and the Intra-Urban Travel Patterns of Swedish Households," Ph. D. Dissertation, Northwestern University, Evanston, Illinois, June 1973.

62. Pillai, K. C. S., Statistical Tables for Tests of Multivariate Hypotheses, Vo1. II, University of the Phillipine Statistical Center, 1959.

63. Kshirsagar, A. M., Multivariate Analysis, Marcel Dekker, Inc., New York, $197 \overline{2 .}$

64. Cochran, W. G., Sampling Techniques, Wiley. \& Sons, 1962.

65. Dial, R., Special Report No. 143, Highway Research Board, pp. 86-87, 1973. 
66. Bock, R. D., "Estimating Multinomial Response Relations," in Bose et al, Essays in Probability and Statistics, University of North Carolina, Chapel Hill, 1968.

67. Myers, R. H., Response Surface Methodology, Allyn and Bacon, Inc., Boston, Mass., 1971.

68. Cherniak, M., "A Statement of the Urban Passenger Transportation Problem;" HRB Bulletin, No. 293.

69. Shunk, G. A., "A Journey to Work: A Singular Basis for Travel Pattern Surveys," Ph. D. Thesis, Purdue University, 1967.

70. Talvitte, A., "Comparison of Probabilistic-Modall Choice Models: Estimation Methods and System Inputs ," Highway Research Record No. 392, HRB, 1972.

71. Talvitte, A., "Aggregate Travel Demand Analysis with Disaggregate or Aggregate Travel Demand Models," Proceedings, Transportation Research Forum, 1973.

72. Discussion Papers, Committee on Travel Behavior and Values, Highway Research Board, Washington, D. C., January 1974.

73. Aitchison, J. and Silvey, S. D., Maximum Likelihood Estimation of Parameters Subject to Restraints," Annals of Mathematical Statistics 29, pp. 813-829, 1958.

74. Plackett, R. L., "A Reduction Formula for Normal Multivariate Integrals," Biometrika, 41.

75. Burnett, P., "Disaggregate Behavioral Models of Travel Decisions other than Mode Choice," Paper presented at the Engineering Foundation Conference on Travel Behavior and Values, at $S$. Berwick, Maine, July 1973.

76. Harman, H. H., Modern Factor Analysis, University of Chicago Press, 1967.

77. Green, P. R. and Carmone, F. J., Multidimensional Scaling: An Introduction and Comparison of Nonmetric Unfolding Techniques," Journal of Marketing Research, Vol. 6, 1969.

78. Golob, T. F., Resource paper on Attitudinal Models, Special Report No. 143, Highway Research Board, pp. 130-145, 1973.

79. Sherret, A. and Wallace III, J. P., Resource paper on Product Attributes, Special Report No. 143, Highway Research Board, pp. 146-174, 1973 .

80. Ruiter, E. R., Special Report No. 143, Highway Research Board, p. 202, 1973 . 
81. Bucklin, L. P., "Trade Area Boundaries: Some Issues in Theory and Methodology," Journal of Marketing Research, 1971.

82. Dobson, R., et al., "Multi-dinensional Scaling of Consumer Rreferences for a Possible Transfortation System: An Application of Two Approaches," General Motors Transportation Research Dept., Warren, Michigan, 1973.

83. Gorman, G., et a1., "Markov Renewal Model of Linked Trip Travel Behavior," Transportation Engineering Journal, 1972.

84. Dobson, R. and Kehoe, J. F., "Disaggregated Behavioral Views of Transportation Attributes," Paper presented at Highway Research Board 53rd - annual meeting, Washington, D. C., January 1974.

85. Torgeson, W. S., Theory and Methods of Scaling, John Wiley \& Sons, New York, 1958 .

86. Bock, R. D., and Jones, L. V., Measurement and Prediction of Iudgement and Choice, Holden-Day, 1968.

87. Marschak, J. "Binary Choice Constraints and Random Utility Indicators" in Mathematical Methods in the Social Sciences, Arrow, Karlin, Suppes eds., Stanford University Press, 1959.

88. Hansen, S., "Mathematical Structure of Disaggregate Choice Models," Resource paper prepared for a Conference on Issues in Behavioral Travel Demand and The Valuation of Travel Time at South Berwick, Maine, July 1973.

89. Rao, C. R., Linear Statistical Inference and its Applications, John Wiley \& Sons, Inc., 1965.

90. Anderson, J. A., "Separate Sample Logistic Discrimination," Bionetrics, 59, pp. 19-35, 1972.

91. Anderson, J. A., "Logistic Discrimination With Medical Applications," in Calcoulos, Discrimination Techniques, 1973.

92. Searle, S. R., Linear Models, Wiley \& Sons, 1971.

93. Scheffé, H., The Analysis of Variance, Wiley \& Sons, 1959.

94. Mantel, M., 'Models for Complex Contingency Tables and Polychotomous Response Curves," Biometrics, 22, pp. 83-110, 1969 .

95. Anderson, T. W., An Introduction to Multivariate Statistical Analysis, p. 348, John Wiley \& Sons, New York, 1958. 
96. Mood, A. M., and Graybill, F. A., Introduction to the Theory Statistics, McGraw-H111, 1963.

97. Adress Coding Guide, Department of Metropolitan Development, Indianapolis, 1970 .

98. Linhart, H., "Techniques for Discriminant-Analysis with Discrete Variables," Metrika, 2, pp. 138-149, 1959.

99. Johns, M. V. Jr., "An Empirical Bayes Approach to Non-parametric Two-way Classification," in Studies in Item Analyses and Prediction, H. Solomon, Editor, Stanford University Press, pp. 221-232, 1961 .

100. Cochran, W. G., and Hopkins, C. E., "Some Classification Problems with Multivariate Qualitative Data," Biometrics, 17 , pp. 10-32, 1961.

101. Martin, D. C., and Bradley, R. A., "Probability Models, Estimation and Classification for Multivariate Dichotomous Populations, Biometrics, 28, pp. 203-225, 1972.

102. Cox, D. R., "Some Procedures Associated with the Logistic Qualitative Response Curve," Research papers in statistics: Festschrift For J. Neyman, F. H. David, Editor, Wiley \& Sons, pp. 55-71, 1966.

103. Day, N. E., and Kerridge D. F., "A General Maximum Likelihood Discriminant," Biometrics, 23, pp. 313-323, 1967.

104. Birch, M. W., "Maximum Likelihood in Three-way Contingency Tables," Journal of the Royal Statistical Society, Series B, 25, pp. 220-233, 1963.

105. Raisbeck, G., Information Theory, M. I.T. Press, 1964.

106. Theil H., Economics and Information Theory, Rand McNally \& Co., Chicago, 1967

107. Theil H., and G. de Wilde,"Parking and Information Value of Surveys," Report No. 6624, Center for Mathematical Studies in Business and Economics, University of Chicago, 1966. 
APPENDICES 
APPENDIX A

SAMPLE CALCULATIONS IN THE ESTIMATION

OF THE PARAMETERS OF A MULTINOMIAL

RESPONSE RELATION MODEL 


\section{APPENDIX A \\ SAMPLE CALCULATIONS IN THE ESTIMATION OF THE PARAMETERS OF A MULTINOMIAL RESPONSE RELATION MODEL}

This Appendix discusses the estimation procedure in the use of the multinomial response relation model for analyzing a contingency table that defines functional zonal shopping destinations for people travelling from zones with an average zonal income of $\$ 7001-\$ 8000$. A discussion of functional destination choice modelling using zonal shopping destinations is given in Appendix B. The functional destination contingency table for three categories each of Zonal Retail Floor Area and Interzonal Airline Distance is shown in Figure A.l.

The main objective is to predict the probability, $p_{j h}$, with which a travel market segment $j(j=1, \ldots, n)$ will select cell $h(h=1, \ldots, m)$ as illustrated in Figure A.1, for which $n=1$ and $m=9$. The probability or likelihood associated with a response pattern (ie the cell frequency being $r_{j h}$ in cell $h$ ) for a market segment $j$ is assumed to follow from the multinomial response law as given in equation 5.1 of Chapter 5 by

$$
L_{j}=\frac{N_{j} !}{r_{j 1} ! r_{j 2} ! \ldots r_{j m} !} \quad p_{j 1}^{r_{j 1}} p_{j 2}^{r_{j 2}} \ldots p_{j m}^{r_{j m}}
$$

The total likelihood of a set of $n$ market segments is given by $\sum_{j=1}^{n} L_{j}$. The maximum likelihood parameter estimation procedure estimates parameters that can be used to determine the probabilities $\mathrm{p}_{j \mathrm{~h}}$ by 
maximizing the total likelihood function.

The probability $\mathrm{p}_{\mathrm{jh}}$ is assumed to be given by the multiple logit model probability law as

$$
P_{j h}=\frac{e^{z h}}{e^{z 1}+e^{z 2} \ldots+e^{z} j}
$$

where $Z_{j h}$ is a multivariate logit defined as

$$
z_{j h}=\underset{\sim j}{x_{j}} \cdot \underset{\sim}{\beta} \cdot \underset{\sim}{x_{q}} \underset{q}{a x t}
$$

where ${\underset{\sim}{j}}_{j}$ is the $j$ th row of a design matrix ${\underset{\sim}{n \times q}}_{n q}$ associated with the market segmentation process and ${ }_{-\mathrm{a}}^{\mathrm{a}}$ is the hth column of the design matrix ${\underset{\sim}{t x m}}_{t}$ corresponding to the classification of the response categories. The $\underset{\sim}{X}$ and $\underset{\sim}{A}$ matrices have been discussed in detail in Chapter 5 . An element of the row vector ${\underset{\sim}{x}}_{j}$ is 0 or 1 according as the effect corresponding to its column position is absent or present when considering the probability associated with response category $h$ of market segment $j$. Similarly the 1 th row element of the column vector $a_{\sim}$ is 0 or 1 according as the effect associated with the 1 th row is absent or present.

Each element $B_{k 1}$ of the matrix $\underset{\sim}{\beta}$ is the parameter corresponding to the kth column of $\underset{\sim}{x}$ and the 1 th row of $\underset{\sim}{A}$.

The applications described in this research develop models for a single market segment so we subsequently will discuss the sample calculations for $n=1$ (ie the $\underset{\sim}{x} \operatorname{matrix}$ is [1]). We therefore replace $p_{j h}$ with $p_{h}$ and $z_{j h}$ with $z_{h}$ and have

$$
P_{h}=\frac{e^{z_{h}}}{e^{z_{1}+e^{z_{2}}+\ldots e^{z_{m}}}}
$$


where

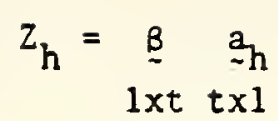

where equation A.4 gives the expression for the probability associated with response category $h$ determined from a linear effect experimental model expression for the multivariate logit $z_{h}$ as indicated above. The 1 th element of $a_{h}$ is 0 or 1 according as the 1 th effect $\beta_{1}$ is absent or present in the definition of response category $h$ in the response matrix $\underset{\text { A. }}{ }$

An extensive discussion has been given in Chapter 5 why a reparameterized form of the model in equation $A .5$ has to be used in the estimation of the multivariate $\operatorname{logits} Z_{h}(h=1, \ldots, m)$. For the application under discussion for which $\mathrm{n}=1$ we have the following linear form for the reparameterized model

$$
Z_{1 \times m}=\Gamma_{1 \times s} \quad I_{s \times m}
$$

where $Z_{1 \times m}$ is a vector of multivariate logits $\Gamma_{1 \times s}$ is a vector of parameters in the reparameterized model discussed further in a later

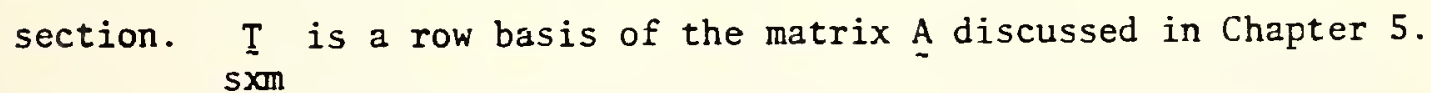
$S$ is the row rank of the matrix $\underset{\sim}{\text { A. }}$

For the contingency table given in Figure A.l the effects of the three Zonal Retail Floor Area are denoted by $F_{1}, F_{2}$, and $F_{3}$ and those of the Interzonal Airline Distance categories by $D_{1}, D_{2}$ and $D_{3}$. The cells of the classification in Figure A.1 are numbered as follows 


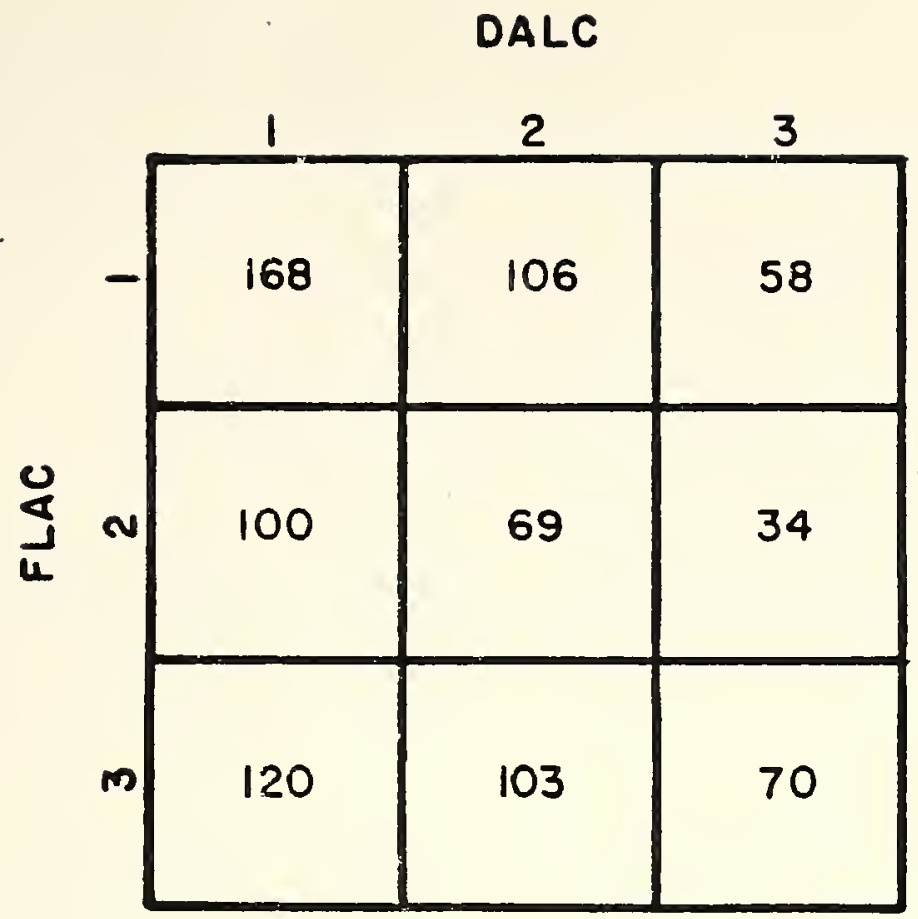

FLAC

1 ZONAL RETAIL FLOOR AREA $\leqslant 150$

$2150<$ ZONAL RETAIL FLOOR AREA $\leq 350$

$3350 \angle$ ZONAL RETAIL FLOOR AREA

EACH ZONAL RETAIL FLOOR AREA UNIT $=1000 \mathrm{sq} . \mathrm{ft}$.

DALC

1 INTERZONAL AIRLINE DISTANCE $\leq 1.5$

$2 \quad 1.5<$ INTERZONAL AIRLINE DISTANCE $\leq 3.5$

$3 \cdot 3.5<$ INTERZONAL AIRLINE DISTANCE

EACH AIRLINE DISTANCE UNIT $=0.833$ miles

FIGURE A.I FUNCTIONAL DESTINATION CLASSIFICATION DEFINED BY ZONAL RETAIL FLOOR AREA AND INTERZONAL AIRLINE DISTANCE FOR AVERAGE ORIGIN ZONE INCOME OF \$700I-\$8000 


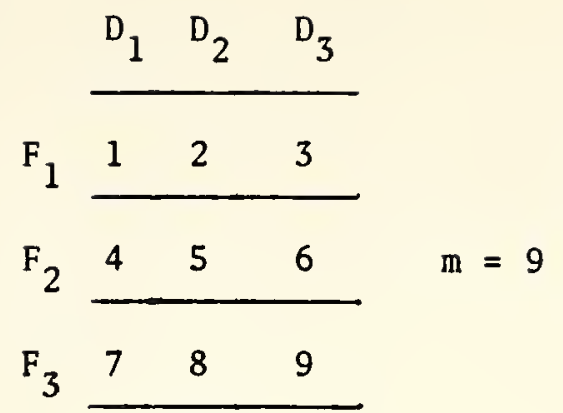

Denoting the general mean effect by $\mu$ the ${\underset{\sim}{7 \times 9}}_{9}$ matrix which considers the general mean and the main effects $F_{1}, F_{2}, F_{3}, D_{1}, D_{2}$ and $D_{3}$ is given by (see Chapter 5):

$$
\begin{aligned}
& \text { cell no.t } 1 \begin{array}{llllllllll}
1 & 2 & 3 & 4 & 5 & 6 & 7 & 8 & 9 & \text { Effect }
\end{array} \\
& \stackrel{A}{7 \times 9}_{1}=\left[\begin{array}{lllllllll}
1 & 1 & 1 & 1 & 1 & 1 & 1 & 1 & 1 \\
1 & 1 & 1 & 0 & 0 & 0 & 0 & 0 & 0 \\
0 & 0 & 0 & 1 & 1 & 1 & 0 & 0 & 0 \\
0 & 0 & 0 & 0 & 0 & 0 & 1 & 1 & 1 \\
1 & 0 & 0 & 1 & 0 & 0 & 1 & 0 & 0 \\
0 & 1 & 0 & 0 & 1 & 0 & 0 & 1 & 0 \\
0 & 0 & 1 & 0 & 0 & 1 & 0 & 0 & 1
\end{array}\right] \begin{array}{l}
\mu \\
F_{1} \\
F_{2} \\
F_{3} \\
D_{1} \\
D_{2} \\
D_{3}
\end{array}
\end{aligned}
$$

The $1 \times 7$ parameter vector $\underline{\beta}$ is given by

$$
\beta_{1 \times 7}=\left[\begin{array}{lllllll}
\mu & F_{1} & F_{2} & F_{3} & D_{1} & D_{2} & D_{3}
\end{array}\right]
$$

Applying the model given in equation A.5, the multivariate logit $Z_{6}$ corresponding to the sixth response category is the product of $\underline{\beta}$ and the sixth column of $\mathrm{A}$ ie

$$
Z_{6}=\left[\begin{array}{lllllll}
\mu & F_{1} & F_{2} & F_{3} & D_{1} & D_{2} & D_{3}
\end{array}\right]\left[\begin{array}{l}
1 \\
0 \\
1 \\
0 \\
0 \\
0 \\
1
\end{array}\right]=\mu+F_{2}+D_{3}
$$


$z_{6}$ as determined above indicates, as expected, that cell 6 is affected by the general mean and the $F_{2}$ and $D_{3}$ main effects. Given that the total sample size $\mathrm{N}$ is constant, if two marginal frequencies are known for each way of classification in Figure A.1, the third marginal frequency can be determined by subtraction. For this reason, each way of classification in a main effects model, contributes 2 to the rank of the matrix $\underset{\sim}{A}$. The rank of $\underset{\sim}{A}$ is therefore 4. A more detailed discussion of the rank of $\underset{\sim}{A}$ is given in Chapter 5. The implication of the rank of

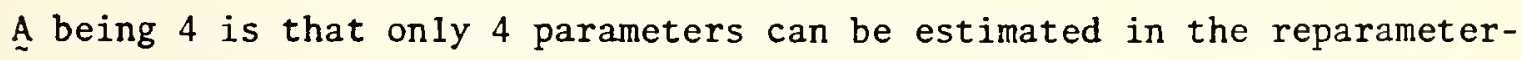
ized main effects model as given in equation A.5.

The relationship between the elements of the $1 \times 4$ parameter vector $\Gamma$ and the $1 \times 7$ parameter vector $\underset{\sim}{\beta}$ depends on the form of the row basis $\underset{\sim}{T}$ of $\stackrel{A}{\sim}$ that is selected for the estimation of $\underset{\sim}{\Gamma}$. The construction of the basis $I$ from contrasts of the effects of each way of classification in a contingency table relative to one category effect was discussed in Chapter 5. The model results are indifferent to the choice of basis, a fact which will be shown by choosing two types of basis $I$ - one with effects considered relative to the first category effect and the other with the effects considered relative to the last category effect of each way of classification.

\section{Basis T Development and Parameter Estimation}

Following the discussion on basis construction in Chapter 5 , the rows of the basis $T$ for the contingency table in Figure A.l are formed from the Kronecker products of the columns of two matrices each of the form $Q_{S \times 3}=\left[1_{3}, \stackrel{C}{3 \times 2}_{3}\right]$ where each $Q$ matrix represents a way of 
classification in Figure A. $1.1_{-3}$ is a $3 \times 1$ column vector each component of which is unity.

$\mathrm{C}_{3 \times 2}$ is a contrast matrix that contrasts the main effect of one category with each of the remaining classes.

If one wishes to estimate parameters relative to the first category effect the rows of the basis $T$ are formed from the Kronecker product of the following matrices:

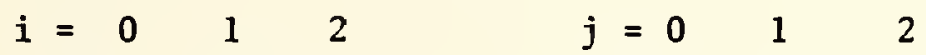

$$
\begin{aligned}
& Q_{1}=\left[\begin{array}{ccc}
1 & -1 / 3 & -1 / 3 \\
1 & 2 / 3 & -1 / 3 \\
1 & -1 / 3 & 2 / 3
\end{array}\right] \quad Q_{2}=\left[\begin{array}{ccc}
1 & -1 / 3 & -1 / 3 \\
1 & 2 / 3 & -1 / 3 \\
1 & -1 / 3 & 2 / 3
\end{array}\right]
\end{aligned}
$$

Denoting the Kronecker product of column $i$ of $Q_{1}$ and column $j$ of $\Omega_{2}$ by $i, j$, the four rows of the $\underset{\sim}{T}$ basis for the main effects model for the contingency table in Figure A.l are given as follows, (assuming $Q_{1}$ and $Q_{2}$ represent Retail Floor Area and Interzonal Distance respectively)

$\begin{array}{ccc}\text { Row } & \begin{array}{c}\text { Kronecker Product } \\ \text { Indices }\end{array} & \text { Effect } \\ 1 & 1,0 & \mathrm{~F}_{2}-\mathrm{F}_{1} \\ 2 & 2,0 & \mathrm{~F}_{3}-\mathrm{F}_{1} \\ 3 & 0,1 & \mathrm{D}_{2}-\mathrm{D}_{1} \\ 4 & 0,2 & \mathrm{D}_{3}-\mathrm{D}_{1}\end{array}$

The resulting $4 \times 9$ basis $\underset{\sim}{\mathrm{T}}$ is shown in Table A.1. The basis given by the computer program is multiplied by the factor that is indicated below the print-out of the matrix T. In subsequent calculations the matrix $T_{\sim}$ printed is divided by the multiplying factor. For the problem 
Table A.1 Sample Calculations for a Multinomial Response Relation Model

FLAC $\times$ DALC for Avg. Income of $\$ 7001-\$ 8000$

T- Matrix

$$
\left[\begin{array}{ccccccccc}
-3 & -3 & -3 & 6 & 6 & 6 & -3 & -3 & -3 \\
-3 & -3 & -3 & -3 & -3 & -3 & 6 & 6 & 6 \\
-3 & 6 & -3 & -3 & 6 & -3 & -3 & 6 & -3 \\
-3 & -3 & 6 & -3 & -3 & 6 & -3 & -3 & 6
\end{array}\right]
$$

The 4 by 9 Matrix has a Factor of 9

$\begin{array}{lllll} & 1 & 2 & 0 & 0 \\ \text { Kronecker Product Indices } & 0 & 0 & 1 & 2\end{array}$

Iteration No. 1

Trial Parameter Matrix - TZ

$0.0000 \quad 0.0000 \quad 0.0000 \quad 0.0000$

Probability Matrix

Column

$\begin{array}{llll}1 & 2 & 3 & 4 \\ 5 & 6 & 7 & 8 \\ 9 & & & \end{array}$

Row 1

$$
\begin{array}{llll}
0.1111 & 0.1111 & 0.1111 & 0.1111 \\
0.1111 & 0.1111 & 0.1111 & 0.1111 \\
0.1111 & & &
\end{array}
$$

First Derivative of Log Likelihood - DTZ

$$
\begin{array}{r}
-73.0000 \\
17.0000 \\
2.0000 \\
-114.0000
\end{array}
$$


Table A.1 Cont.

Second Derivative of Log Likelihood - DDTZ

$\begin{array}{rrrr}-184.0000 & 92.0000 & 0.0000 & 0.0000 \\ 92.0000 & -184.0000 & 0.0000 & 0.0000 \\ 0.0000 & 0.0000 & -184.0000 & 92.0000 \\ 0.0000 & 0.0000 & 92.0000 & -184.0000\end{array}$

Correction To $\mathrm{TZ}$

4.6739 E-01

$1.4130 \mathrm{E}-01$

$3.9855 \mathrm{E}-01$

8.1884 E-01

Estimated Matrix -TZ

$$
\begin{array}{llll}
-0.4674 & -0.1413 & -0.3986 & -0.8188
\end{array}
$$

Iteration No. 2

Trial Parameter Matrix - TZ

$$
\begin{array}{llll}
-0.4674 & -0.1413 & -0.3986 & -0.8188
\end{array}
$$

Probability Matrix

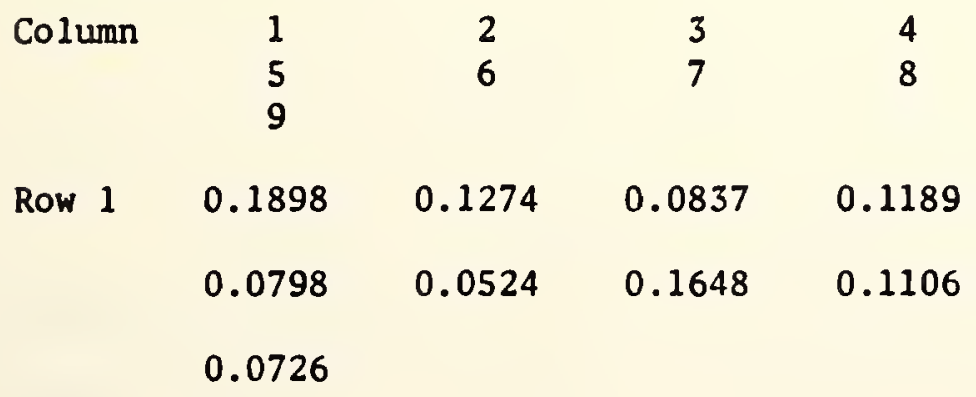


Table A.1 Cont.

First Derivative of Log Likelihood -DTZ

$$
\begin{array}{r}
-4.9691 \\
4.8514 \\
14.8522 \\
-10.8503
\end{array}
$$

Second Derivative of Log Likelihood -DDTZ

$\begin{array}{rrrr}-155.7334 & 72.3744 & 0.0000 & 0.0000 \\ 72.3744 & -187.8713 & 0.0000 & 0.0000 \\ 0.0000 & 0.0000 & -179.5164 & 54.9338 \\ 0.0000 & 0.0000 & 54.9338 & -136.7667\end{array}$

Correction to $\mathrm{TZ}$

$$
\begin{array}{r}
2.4248 \text { E-02 } \\
-1.6482 \text { E-02 } \\
-6.6649 \text { E-02 } \\
5.2564 \text { E-02 }
\end{array}
$$

Estimated Matrix TZ

$$
\begin{array}{llll}
-0.4916 & -0.1248 & -0.3319 & -0.8714
\end{array}
$$

Iteration No. 3

$$
\begin{array}{llll}
-0.4916 & -0.1248 & -0.3319 & -0.8714
\end{array}
$$

Probability Matrix
Column
1
2
6
3
7
4
8
Row 1
0.1877
0.1347
0.0785
0.1148
0.0824
0.0480
0.1657
0.1189
0.0693 
Table A.1 Cont.

First Derivative of Log Likelihood

$$
\begin{aligned}
& -0.0344 \\
& -0.0057 \\
& -0.1647 \\
& -0.1806
\end{aligned}
$$

Second Derivative of Log Likelihood -DDTZ

$\begin{array}{rrrr}-153.2482 & 71.8481 & 0.0000 & 0.0000 \\ 71.8481 & -189.3193 & 0.0000 & 0.0000 \\ 0.0000 & 0.0000 & -184.7159 & 54.4842 \\ 0.0000 & 0.0000 & 54.4842 & -130.4142\end{array}$

Correction to $\mathrm{TZ}$

$$
\begin{aligned}
& 2.9000 \text { E-04 } \\
& 1.4011 \text { E-04 } \\
& 1.4830 \text { E-03 } \\
& 2.0041 \text { E-03 }
\end{aligned}
$$

Estimated Matrix TZ

$$
\begin{array}{llll}
-0.4919 & -0.1250 & -0.3334 & -0.8734
\end{array}
$$

Covariance Matrix for Parameter Vector
7.9377 E-03
3.0124 E-3
0.0000
0.0000
$3.0124 \mathrm{E}-3$
$6.4253 \mathrm{E}-3$
0.0000
0.0000
0.0000
0.0000
6.1746 E-3
2.5796 E-03
0.0000
0.0000
2.5796 E-3
8.7456 E-3

Predicted Frequencies 
Table A.l Cont.

Observed Frequencies

$\begin{array}{lllllllll}168.0 & 106.0 & 58.0 & 100.0 & 69.0 & 34.0 & 120.0 & 103.0 & 70.0\end{array}$

Goodness of Fit CHISQ 8.24 for 4 D.F. 
of Figure A.1 this factor is 9. The Kronecker product indices that went into the development of the basis $\underset{\sim}{T}$ are also indicated in Table A. 1 .

The parameter vector $\Gamma_{\Gamma_{1 \times 4}}$ estimated in the reparameterized main. effects model is given by

$$
\Gamma_{1 \times 4}=\left[\left(F_{2}-F_{1}\right),\left(F_{3}-F_{1}\right),\left(D_{2}-D_{1}\right),\left(D_{3}-D_{1}\right)\right]
$$

The maximum likelihood estimation procedure maximizes the log of the 1 ikelihood function given in equation A.1. The computer program written for this purpose uses the Newton-Raphson gradient technique as discussed between equations 5.13 and 5.15 of Chapter 5 . The estimation procedure uses the first derivative, $\varphi(\underset{\sim}{\Gamma})$ and the second derivative $\Psi(\Gamma)$ of the $\log$ of the likelihood function given in equation A.1.

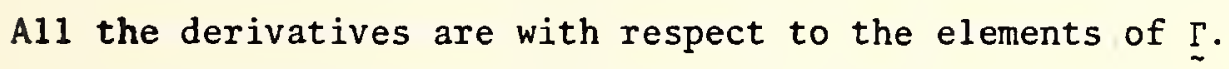

For the problem of Figure A.l under discussion we have from equation 5.9 of Chapter 5 ,

$$
\stackrel{\varphi}{s \times 1}_{\sim}(\Gamma)=\underset{s \times m}{T}(\underset{m \times 1}{r}-N P)
$$

where $\underset{\sim}{r}$ and $\underset{\sim}{\mathrm{P}}$ are, respectively, mxl vectors of observed cell frequencies in the contingency table under consideration and cell probabilities determined from estimated logits in equation A.4. N is the total number of observations or individuals. The other terms in equation A.8 have been previously defined.

The matrix of second derivatives of the $\log$ of the likelihood function in equation A.l is given from equation 5.11 of Chapter 5 by

$$
\underset{s \times s}{\Psi} \underset{\sim}{(\Gamma)}=-N \underset{s \tilde{x} m}{\underset{m}{T}} \underset{\tilde{x} m}{W} \stackrel{T}{\prime}_{m x s}^{\prime}
$$


where $\underset{\sim}{W}$ is the variance - covariance matrix of the estimators of $\mathrm{P}_{\mathrm{h}}$ given by

$$
\underset{m \tilde{x} m}{w}=\left[\begin{array}{cccc}
\mathrm{P}_{1}\left(1-\mathrm{P}_{1}\right) & -\mathrm{P}_{1} \mathrm{P}_{2} & \cdots & -\mathrm{P}_{1} \mathrm{P}_{m} \\
-\mathrm{P}_{2} \mathrm{P}_{1} & \mathrm{P}_{2}\left(1-\mathrm{P}_{2}\right) & -\mathrm{P}_{2} \mathrm{P}_{m} \\
\vdots & & & \vdots \\
-\mathrm{P}_{m} \mathrm{P}_{1} & -\mathrm{P}_{m} \mathrm{P}_{2} & \cdots & \mathrm{P}_{m}\left(1-\mathrm{P}_{m}\right)
\end{array}\right]
$$

For the main effects model for the problem of Figure A.1 $\mathrm{s}=4, \mathrm{~m}=9$.

The following equivalencies in the results given in Table

\section{A. 1 result:}

$$
\begin{aligned}
& \Gamma_{\text {IXs }} \equiv \mathrm{TZ} \\
& \stackrel{\mathrm{p}}{\mathrm{mxl}} \equiv \text { Probability Matrix printed out as a row vector in the } \\
& \varphi(\Gamma) \equiv D T Z \\
& \text { sxl } \\
& \Psi(\underline{\Gamma})=\mathrm{DDTZ} \\
& \text { sXs }
\end{aligned}
$$

The Newton-Raphson estimation procedure uses a trial parameter vector and computes the first and second derivatives of the log of the likelihood function of equation A.l in order to compute corrections to be applied to the assumed parameter vector. The corrected parameter vector becomes the trial parameter vector for the next iteration until convergence according to some assigned tolerance is achieved. In the estimation program used, the tolerance is such that the absolute value of the ratio of the correction to the parameter value mist be less than 0.005 for each element of the estimated parameter vector: 
Given that the trail parameter vector at the ith iteration is $\Gamma_{i}$, the trial logits are given by equation A.5 as:

$$
\hat{z}_{i_{1 \times m}}=\hat{\Gamma}_{i} T
$$

The trial probabilities $P_{h}(h=1, \ldots, m)$ are computed by substituting the elements $z_{h}(h=1, \ldots, m)$ in equation $A .4$. The trial probabilities then form the trial probability vector $\underset{\sim_{i}}{\hat{p}}$ used to compute the $\log$ likelihood first and second derivatives $\varphi\left(\underset{\sim}{\hat{\Gamma}_{i}}\right)$ and $\left.\underset{\underline{T}}{\left(\hat{\Gamma}_{i}\right.}\right)$ respectively in equations A.8 and A.9.

The vector of corrections to the ith trial parameter vector is given by

$$
\delta_{i}=-\underline{\sim}^{-1}\left(\hat{\Gamma}_{i}\right) \varphi\left(\underline{\Gamma}_{i}\right)
$$

The $(i+1)$ th trial parameter vector becomes

$$
\hat{\Gamma}_{i+1}=\hat{\Gamma}_{i}+\delta_{i}
$$

In all the model parameter estimation problems considered the estimation program starts with a trial parameter vector with zero elements for iteration 1 as shown in Table A.1. In the estimation of the parameters for the main effects model for the problem of Figure A.1, convergence is achieved after 3 iterations. The final estimated parameter vector and its covariance matrix are given by the estimation program. The covariance matrix has been shown in Chapter 5 to be given by the negative of the inverse of the matrix of second derivatives of the $\log$ of the likelihood function given in equation A.1. The predicted cell frequencies are given by the product of the total sample size and 
the predicted cell probabilities. The parameters estimated in Table A. 1 are:

$$
\left.\begin{array}{l}
F_{2}-F_{1}=-0.4919 \\
F_{3}-F_{1}=-0.1250 \\
D_{2}-D_{1}=-0.3334 \\
D_{3}-D_{1}=-0.8734
\end{array}\right\}
$$

The goodness-of-fit $\chi^{2}$ value (discussed later) $=8.24$ (4d.f.)

In order to estimate a set of parameters that are relative to the last category effect, a different $T$ basis must be used, developed from Q-matrices (see equation A.6) that include contrast matrices relative to the last category effect.

The appropriate matrices that must replace $Q_{1}$ and $Q_{2}$ in equation A.6 are:

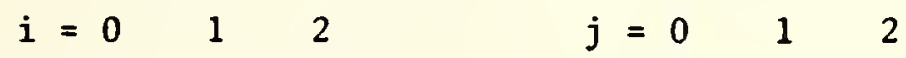

$$
\begin{aligned}
& Q_{1}=\left[\begin{array}{rrr}
1 & 2 / 3 & -1 / 3 \\
1 & -1 / 3 & 2 / 3 \\
1 & -1 / 3 & -1 / 3
\end{array}\right] \quad Q_{2}=\left[\begin{array}{ccc}
1 & 2 / 3 & -1 / 3 \\
1 & -1 / 3 & 2 / 3 \\
1 & -1 / 3 & -1 / 3
\end{array}\right]
\end{aligned}
$$

Using the procedure outlined earlier for developing the basis matrix $\mathrm{T}$, the basis corresponding to the main effects model, where effects are considered relative to the last category is:

$$
\stackrel{T}{4 \times 9}_{4}=1 / 9\left[\begin{array}{ccccccccc}
6 & 6 & 6 & -3 & -3 & -3 & -3 & -3 & -3 \\
-3 & -3 & -3 & 6 & 6 & 6 & -3 & -3 & -3 \\
6 & -3 & -3 & 6 & -3 & -3 & 6 & -3 & -3 \\
-3 & 6 & -3 & -3 & 6 & -3 & -3 & 6 & -3
\end{array}\right]
$$


The parameters estimated using this basis are:

$$
\left.\begin{array}{l}
F_{1}-F_{3}=0.1250 \\
F_{2}-F_{3}=-0.3670 \\
D_{1}-D_{3}=0.8734 \\
D_{2}-D_{3}=0.5400
\end{array}\right\}
$$

Goodness-of-fit $\chi^{2}$ (discussed later) $=8.24$.

We estimate $F_{2}-F_{1}$ and $D_{2}-D_{1}$ from (4d.f.) equation $A .16$ as:

$$
\begin{aligned}
& F_{2}-F_{1}=-0.4920 \\
& D_{2}-D_{1}=-0.3334
\end{aligned}
$$

The predicted cell frequencies given by the parameter vectors whose elements are given in equations A.12 and A.16 are also exactly the same. It is now clear that the modelling results with respect to multivariate logit (and hence cell probability) estimation are invariant with respect to the choice of basis T.

Likelihood Ratio Goodness of fit $\chi^{2}$.

It was shown in Chapter 5 (see equation 5.46) that with large sample maximum likelihood parameter estimation the joint distribution of the parameters tends to a multivariate normal distribution with mean vector $\underset{\sim}{\Gamma}$ and covariance matrix $-\Psi^{-1}[\underset{\sim}{\Gamma}]$. Under this assumption $-2 \times$ the $\log$ of the likelihood function in equation A.1, the likelihood ratio statistic, tends to a $\chi^{2}$ variable with $m-1-s$ degrees of freedom. This goodness of fit $x^{2}$, given by

$$
x^{2}=-2 \sum_{h=1}^{m} r_{h} \log _{e} N \quad \hat{p}_{h} / r_{h}
$$


provides a test for how well an estimated parameter vector provides cell frequencies that come close to the observed frequencies.

Estimation of a Model that includes an Interaction Effect.

The inclusion of an interaction effect in the construction of the A matrix and the basis $\mathrm{T}_{\sim}$ [see earlier sections of this Appendix] were discussed in Chapter 5. Referring to equations A.6 and A.16 the estimation of an interaction $i, j$ in addition to the main effects estimated is accomplished by increasing the row rank of the basis $\mathrm{T}$ by adding a row to the main effects basis formed by the Kronecker product of columns $i$ and $j$ of matrices $Q_{1}$ and $Q_{2}$. An interaction $i$, $j$ in a 2-way contingency table means the interaction between the ith row parameter and the $\mathrm{jth}$ column parameter in the reparameterized model. Hence a 2, 2 interaction in the model developed with equation A.6 is the interaction between $\left(F_{3}-F_{1}\right)$ and $\left(D_{3}-D_{1}\right)$. In the model associated with equation A.16 a 2,2 interaction is the interaction between $\left(\mathrm{F}_{2}-\mathrm{F}_{3}\right)$.

For the model developed from equation A.6 the $5 \times 9$ T basis that includes a 2,2 interaction is given by:

$$
\mathrm{T}_{5 \times 9}=1 / 9 \quad\left[\begin{array}{rrrrrrrrr}
-3 & -3 & -3 & 6 & 6 & 6 & -3 & -3 & -3 \\
-3 & -3 & -3 & -3 & -3 & -3 & 6 & 6 & 6 \\
-3 & 6 & -3 & -3 & -6 & -3 & -3 & 6 & -3 \\
-3 & -3 & 6 & -3 & -3 & 6 & -3 & -3 & 6 \\
1 & 1 & -2 & 1 & 1 & -2 & -2 & -2 & 4
\end{array}\right]
$$

As noted above, this 2.2 interaction is a $\left(\mathrm{F}_{3}-\mathrm{F}_{1}\right)$ by $\left(\mathrm{D}_{3}-\mathrm{D}_{1}\right)$ interaction. The parameters estimated by the resulting model are: 


$$
\begin{array}{ll}
F_{2}-F_{1} & =-0.4919 \\
F_{3}-F_{1} & =-0.0716 \\
D_{2}-D_{1} & =-0.3334 \\
D_{3}-D_{1} & =-0.8938 \\
\left(F_{3}-F_{1}\right) \text { by }\left(D_{3}-D_{1}\right) & =0.4131
\end{array}
$$

Interaction

Goodness of fit $x^{2}$ value $=2.96$ ( 3 d.f.)

A comparison of the predicted and observed response patterns is as follows:

$\begin{array}{llllllllll}\text { Cel1 No. } & 1 & 2 & 3 & 4 & 5 & 6 & 7 & 8 & 9\end{array}$ $\begin{array}{llllllllll}\text { Predicted Frequency } & 160 & 115 & 57 & 98 & 70 & 35 & 130 & 93 & 70\end{array}$ $\begin{array}{llllllllll}\text { Observed Frequency } & 168 & 106 & 58 & 100 & 69 & 34 & 120 & 103 & 70\end{array}$

The reduction in $x^{2}$ value due to the 2,2 interaction compared to the main effects model (see Table A.1) $=8.24-2.96=5.28$ which is significant at the 5 percent level. This significant reduction in goodness of fit $\chi^{2}$ value is accompanied by an improved set of predicted frequencies compared to those in Table A.1.

\section{Model Parameter Estimation Cost}

Though the explanation of the estimation of parameters for a multinomial response relation model may be lengthy, the estimation procedure is very simple and cheap. The models developed in this research rarely cost over 15 cents per run once a compiled version of the estimation computer program is available. The cost of compiling the estimation computer program is less than 40 cents. 
APPENDIX B

FUNCTIONAL ZONAL SHOPPING DESTINATION CHOICE PREDICTION 


\author{
APPENDIX B \\ FUNCTIONAL ZONAL SHOPPING DESTINATION \\ CHOICE PREDICTION*
}

It has been discussed in Chapter 2 why zonal retail floor area or retail employment are inadequate measures of shopping attraction to individuals. The need to agglomerate physical shopping areas, not necessarily along traffic zonal boundaries, and also consider more direct characteristics of shopping areas has been established in Chapters 2 and 6 . There usually is no information on what activities were classified as retail in which case the zonal measures of retail attraction may not give the true picture.

The objections to the use of zonal retail floor area or retail employment are much more serious with respect to the modelling of individual shopping travel behavior than to the modelling of the shopping behavior of groups of people. It should therefore be possible to test a few essential assumptions hitherto used in shopping destination choice modelling with data using zonal measures of shopping travel attraction for broad market segments.

*Al1 multinomial response models discussed in this Appendix estimate parameters relative to the last category. 
The data to be used is on home-based one-way shopping automobile trip data assembled from a 1964 Indianapolis Transportation Study data. Owing to the large number of individuals involved (2772) and the expectation of a random distribution of households in a given zone, the relative geographical location of households and zonal shopping destinations were determined from Zonal Centroid Coordinates. The Zonal Centroids were defined to be approximate centers of the zonal land-use in question. The functional shopping destinations were defined in terms of a cross-classification of Zonal Retail Floor area or employment and interzonal airline distances. Variables available for market segmentation were Average Zonal Income, Accessibility to Zonal Retail Employment, and Percentage single family Dwelling units. The retail relative accessibility measures were determined by Nakkash [ 18 ] for work on zonal trip generation analysis, using friction factors of calibrated gravity models for trip distribution. In spite of the now celebrated objections to the use of the gravity model for such a definition of accessibility, one should get an idea of the effect of relative accessibility by using only broad ranges of Nakkash's measures. The higher the relative retail accessibility measure for a given zone the easier it is for households in that zone to reach retail land-use.

The Monotonicity of the Effects of Shopping Attraction Measures and Distance.

Tables B.1 and B.2 display responses of the total sample to functional zonal shopping destinations defined for Airline Distance with Zonal Retail Floor Area and Zonal Retail Employment respectively. The Airline Distance and Shopping attraction measures are divided into six 
Table B.1. Response Prediction for Functional Destinations Defined by the Crossing of Zonal Retail Floor Area (FLAC) and Airline Distance (DALC) $a, b$

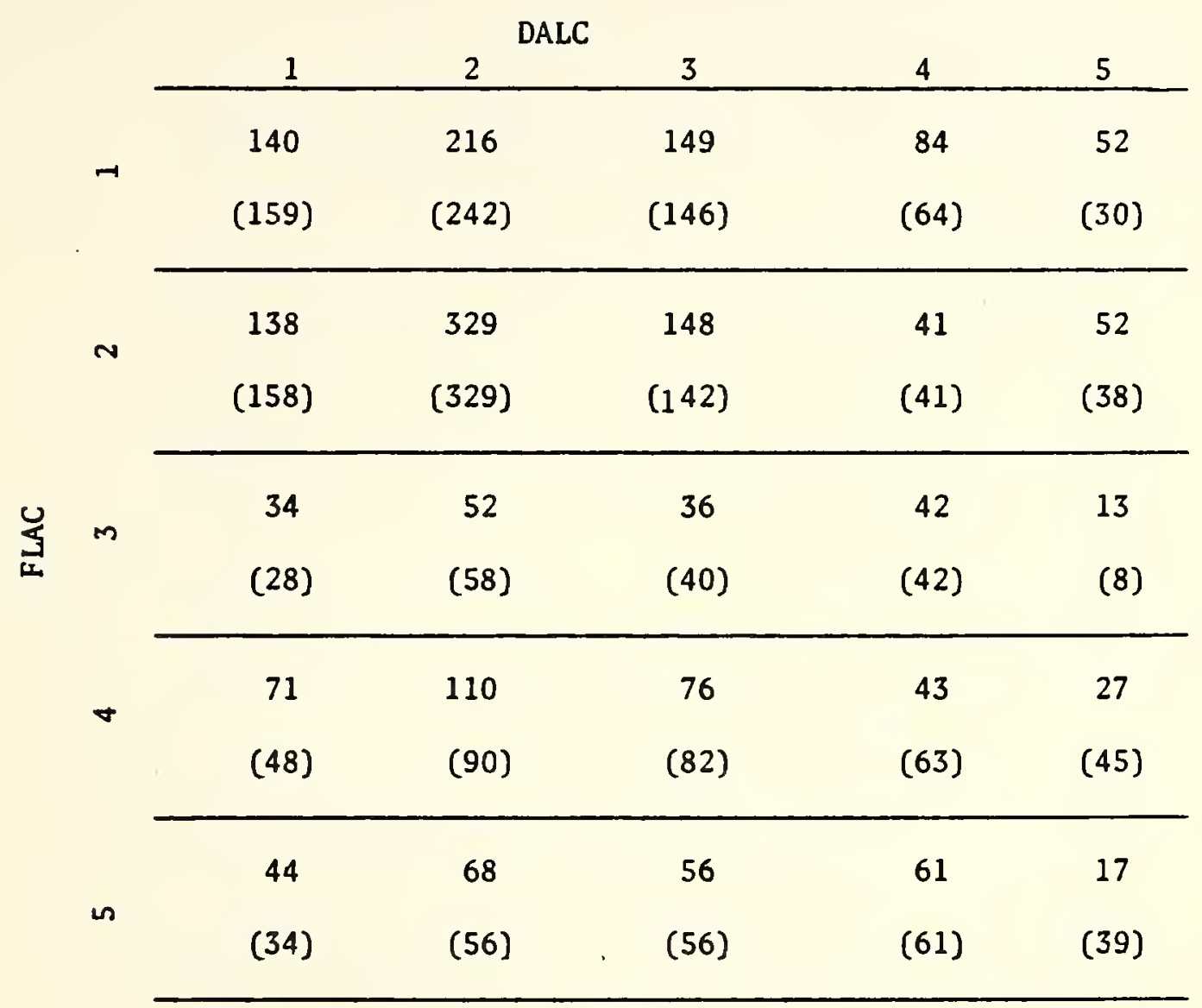

Effects Fitted: Main Effects $+(1,1,(1,3),(2,3),(4,2)$ and $(4,3)$ Interactions

Likelihood Ratio (L.R.) Goodness-of-fit $x^{2}: 91.61$ (11 d.f.) aThe Classification Categories are Defined in Figure B.1 $\mathrm{b}_{\text {Cell }}$ Entries are Predicted Frequencies With the Observed Values in Parenthesis. 
Table B.2. Response Prediction for Functional Destinations Defined by the Crossing of Zonal Retail Employment and Airline Distance $a, b$

DALC

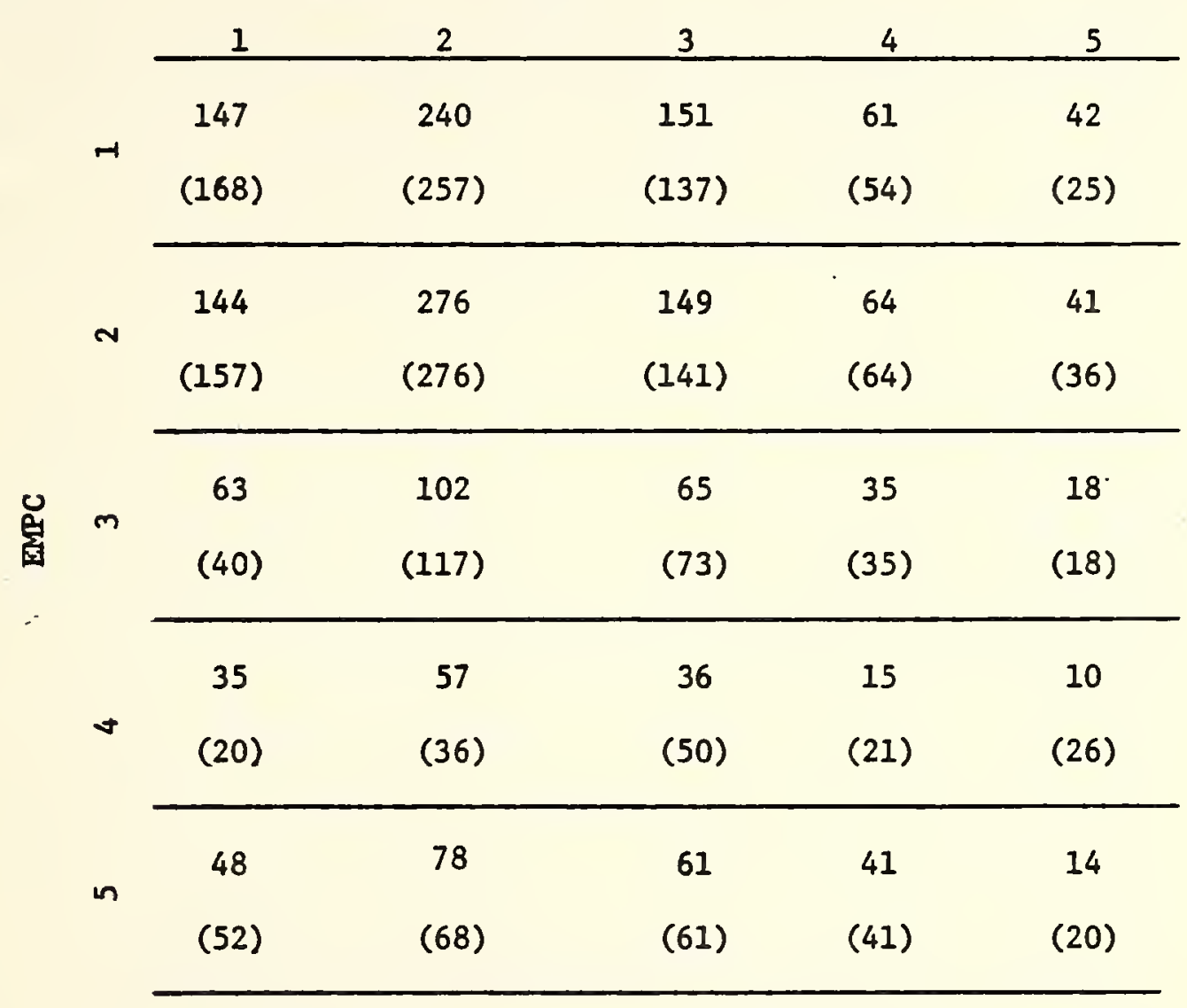

Effects Fitted: Main Effect $+(1,1),(1,3),(2,3),(4,2)$ and $(4,3)$ Interactions

L.R. Goodness-of-fit $\chi^{2}: 74.97$ (11 d.f.)

${ }^{a}$ The Classification Categories are Defined In Figure B:2 ${ }^{b}$ Cell Entries are Predicted Frequencles with Observed Values in Parenthesis. 
categories each at equal successive intervals beyond the first class in each case. The goodness-of-fit $\chi^{2}$ values give an indication of the independence of the factors of classification and the monotonicity in the marginal effects of the factors in the response of the sample to functional zonal shopping destinations. The acute lack of fit implied by the high $\chi^{2}$ values in Tables B.l and B.2 is illustrated in the erratic pattern in the graphical representation of Tables B.1 and B.2 given in Figures B.1 and B.2. Tables B.1 and B.2 show the first 5 categories of each classification.

Table B. 3 shows attempts to fit up to 5 interactions in addition to main effects in the use of the multinomial response relation approach to reproduce the response in the $5 \times 5$ contingency tables in Tables $\mathrm{B} .1$ and B.2. (the multinomial relation approach is discussed in Chapter 5 with a typical example of its estimation procedure given in Appendix A). Al1 the models in Table B.3 were unsuccessful. The reason for the poor fit of the models can be any one or combination of the following:

1. The inadequacy of the shopping opportunity measures used.

2. Regularity or monotonicity of marginal effects not applying over a large number of intervals for shopping attraction and airline distance category variables.

3. The mixing of different market segments that may respond to functional destinations differently.

4. The mixing of local travel with primary urban travel that is of more importance to the transportation engineer, as discussed in Chapter 2. 


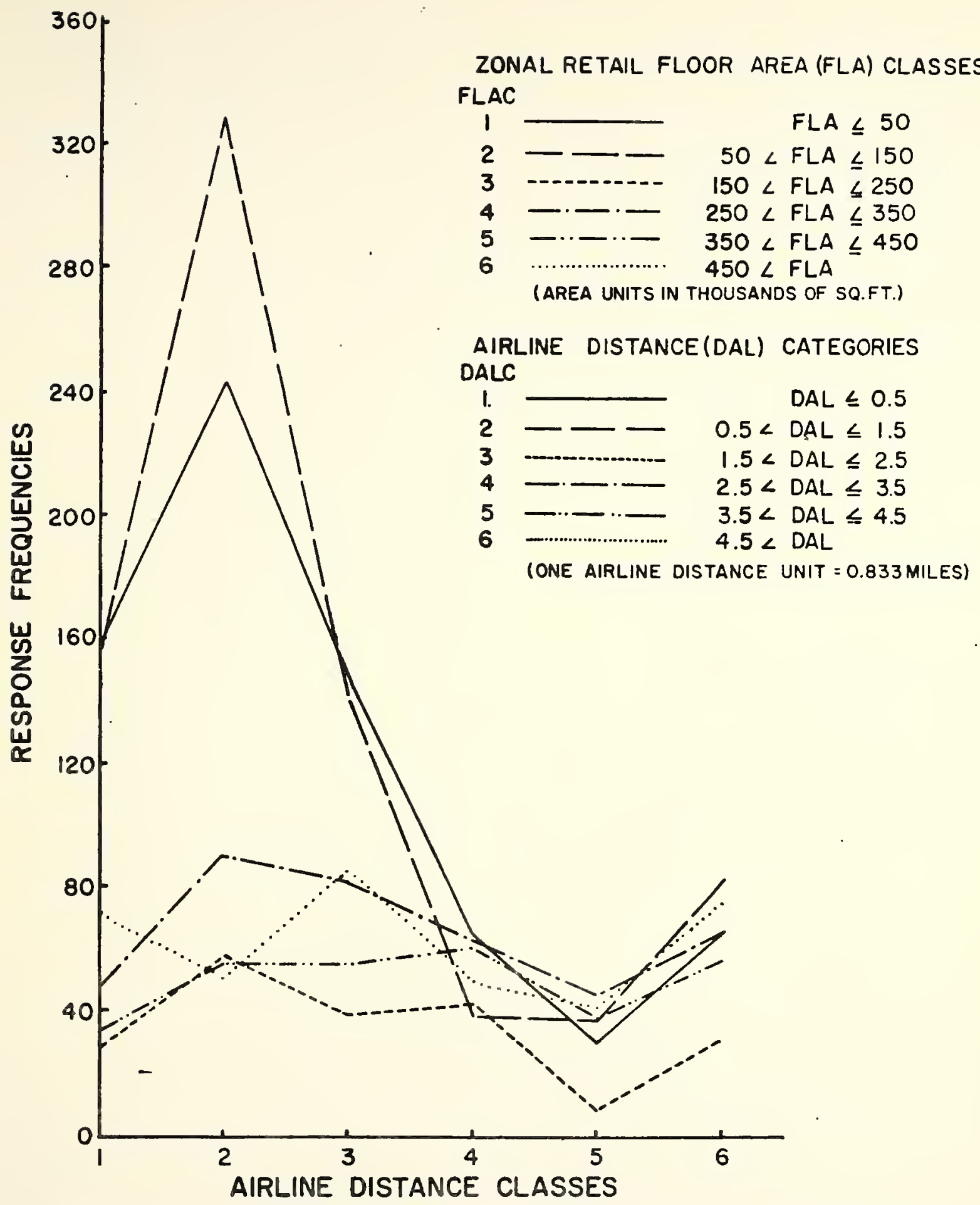

FIGURE B.I RESPONSE FREQUENCY DISTRIBUTIONS FOR ZONAL FUNCTIONAL SHOPPING DESTINATION CHOICE - FLAC $\times$ DALC 


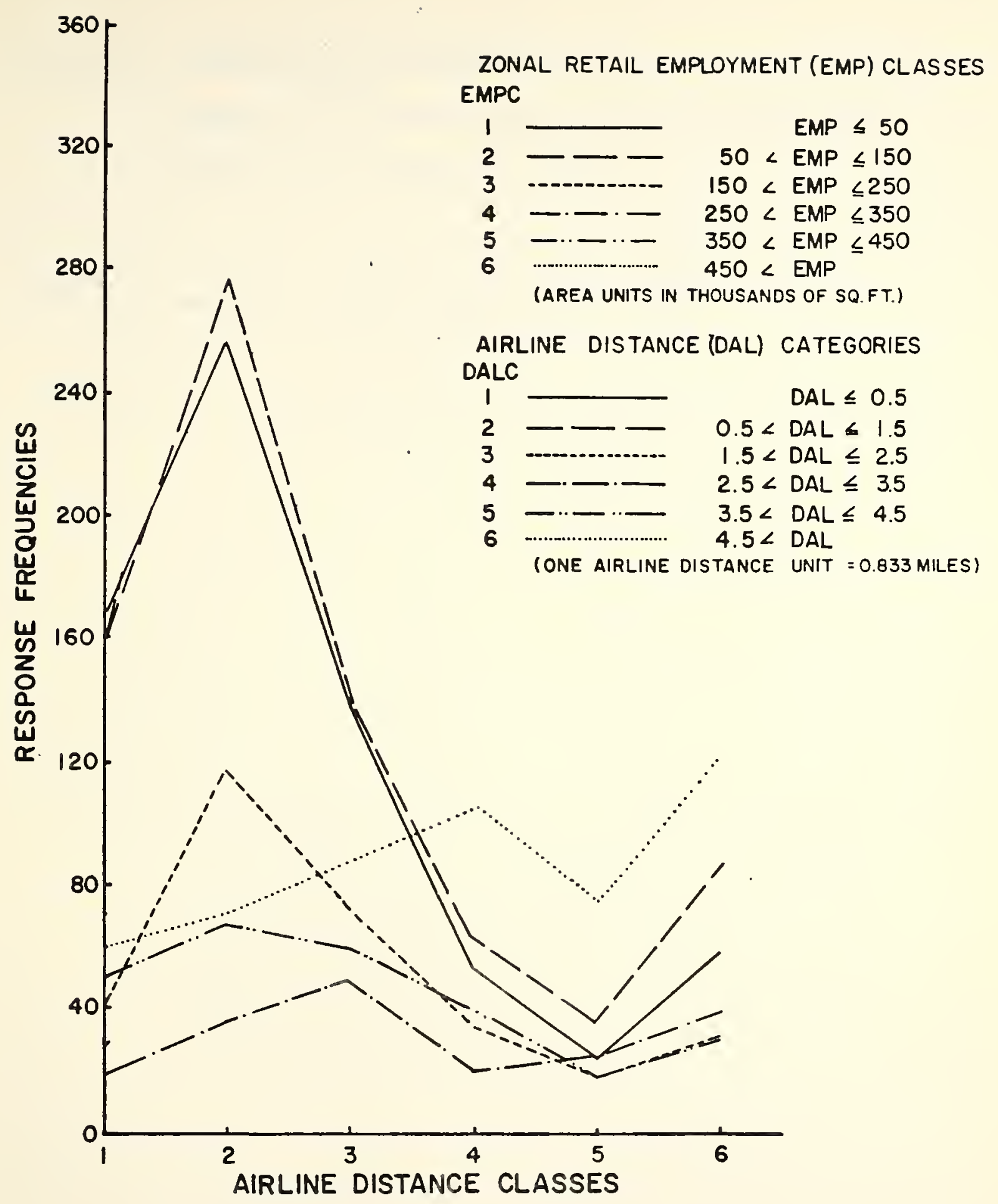

FIGURE B.2 RESPONSE FREQUENCY DISTRIBUTIONS FOR ZONAL FUNCTIONAL SHOPPING DESTINATION CHOICE - EMPC $\times$ DALC 
Table B.3. Likelihood Ratio Goodness-of-fit $\chi^{2}$ Values for Predicting Response of the Total Sample to Functional Destinations Defined in $5 \times 5$ Contingency Tables

Interactions Fitted in
Addition to Main Effect

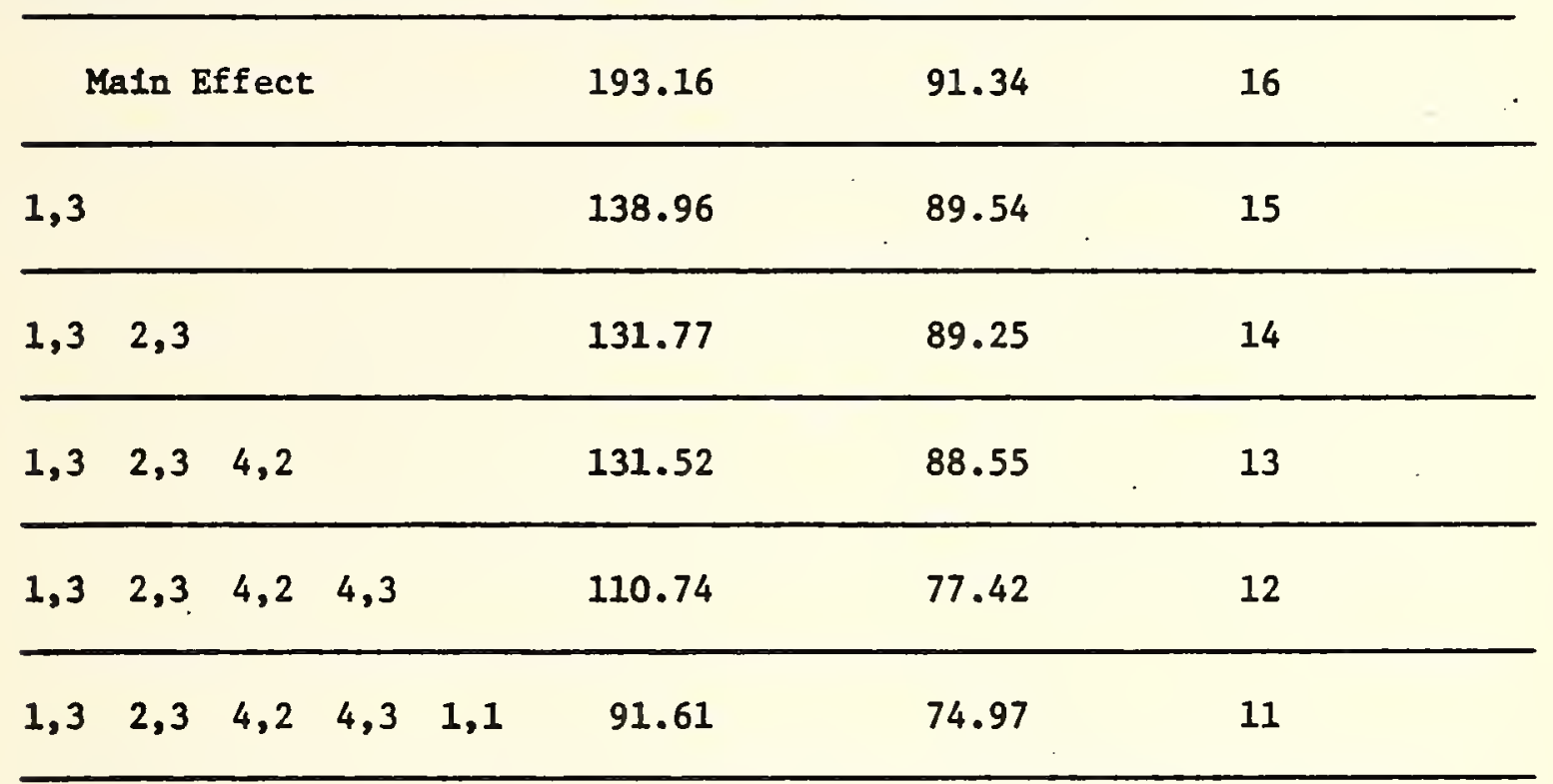

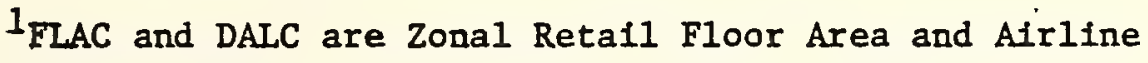
Distance Categories Defined in Figure B.1. ${ }^{2}$ EMPC and DALC are Zonal Retail Employment and Airline Distance Categories Defined in Figure B.2. 
That the first reason should not seriously affect the current investigation has been previously discussed. The second and third possible reasons will be investigated by reducing the number of categories in the factors for defining the functional destinations and also by examining response patterns for different market segments defined with respect to Average Origin Zone Income, Relative Accessibility to Zonal Retail Floor Area, and Percentage Single Family Dwelling Units. The functional destination response patterns for the market segments did not display any consistent patterns even when $4 x 4$ contingency tables (the class values increased by successively equal intervals starting from the first category) were used. It is clear that the failure of the definition of factor categories by successive equal intervals is an indication that spatial separation and shopping destination attraction factors do not have monotonic or regular marginal effects over their domains of occurrence. This brings into serious question the use of distance and attraction variables like retail floor area or retail employment as if such monotonicity prevailed [See Chapter 4].

\section{Functional Destination Prediction}

Further results to be discussed involve $3 \times 3$ functional destinations defined with either Zonal Retail Floor Area or Retail Employment and Airline Distance for which the categories are defined over intervals that are not necessarily equal. The considerably reduced number of categories of shopping attraction and distance measures conforms better to the parsimonious expectation that people do not usually consider large partitions of factors in their response to the urban environment. 
It even leaves room for the use of categories like "regional", "community", and "neighborhood" shopping areas with distance or travel time measures in future functional destination definition. With the reduced numbers of functional destination categories one can use other attributes of shopping areas without making the total number of alternatives in the classification prohibitive.

None of the Relative Accessibility to Retail Floor Area and Percentage Single Family Dwelling Units market segments investigated gave any response patterns that could be reproduced well in all the remaining analyses to be discussed. Since the adequacy of the definition of these factors could be questioned as well, their further use in market segmentation is not discussed. Only Average Origin Zone Income (hereafter referred to as Average Income) will be considered in subsequent market segmentation discussion. Four Average Income categories were defined for market segmentation - (i) $\leq \$ 6000$ (ii) $\$ 6001-\$ 7000$ (iii) $\$ 7001-\$ 8000$ and (iv) $>\$ 8000$. The higher income market segments gave consistently reasonably good results in all cases considered in terms of the level of the goodness-of-fit $\chi^{2}$ value as a test of independence and monotonicity of the factors for defining the functional destination classifications. The Likelihood Ratio goodness-of-fit $x^{2}$ values for various models fitted, using different effects, are summarized in Table B.4.

To attempt to exclude local travel that may not really affect the major transportation network, models were developed where only trips with destination Zone Retail Floor Area greater than 50,000 sq. ft. or with Interzonal Airline Distance greater than 1 distance unit $(0.833$ 


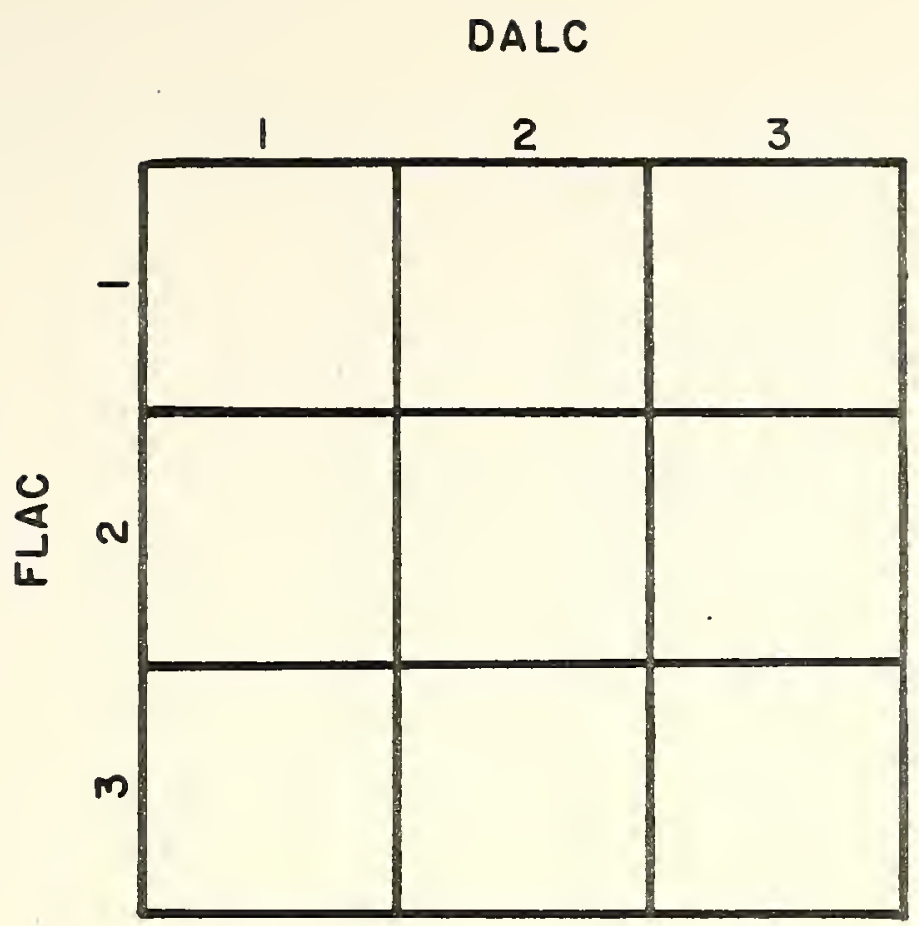

FLAC

1 ZONAL RETAIL FLOOR AREA $\leq 150$

$2150<$ ZONAL RETAIL FLOOR AREA $\leq 350$

$3350<$ ZONAL RETAIL FLOOR AREA

EACH ZONAL RETAIL FLOOR AREA UNIT $=1000 \mathrm{sq} . \mathrm{f} \%$.

DALC

1 AIRLINE DISTANCE $\leq 1.5$

$21.5<$ AIRLINE DISTANCE $\leq 3.5$

$33.5<$ AIRLINE DISTANCE

EACH AIRLINE DISTANCE UNIT $=0.833$ miles

FIGURE B.3 FUNCTIONAL ZONAL SHOPPING DESTINATION CATEGORIES DEFINED BY RETAIL FLOOR AREA AND AIRLINE DISTANCE 


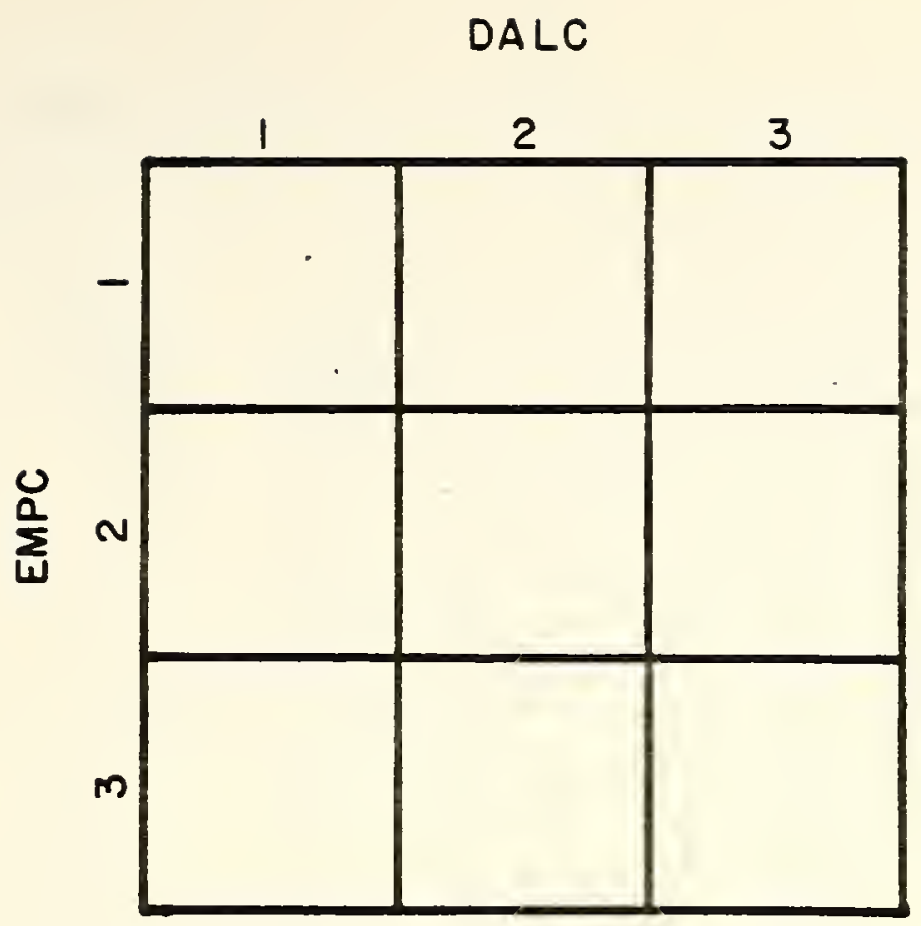

EMPC

1 ZONAL RETAIL EMPLOYMENT $\leq 300$

$2300<$ ZONAL RETAIL EMPLOYMENT $\leq 700$

$3700<$ ZONAL RETAIL EMPLOYMENT

DALC

1 AIRLINE DISTANCE $\leq 1.5$

$2 \quad 1.5<$ AIRLINE DISTANCE $\leq 3.5$

$3 \quad 3.5<$ AIRLINE DISTANCE

EACH AIRLINE DISTANCE UNIT $=0.833$ miles

FIGURE B.4 FUNCTIONAL ZONAL SHOPPING DESTINATION CATEGORIES DEFINED BY RETAIL EMPLOYMENT AND AIRLINE DISTANCE 
Table B.4. Ltkelthood Rat10 Coodnessmof-e1t $\chi^{2}$ Values for Predicting Responses of Subsamples to Runctional Destinations Defined in $3 \times 3$ Contingency Tables, 1,2,3

\begin{tabular}{|c|c|c|c|c|c|c|c|c|c|}
\hline \multirow{2}{*}{$\begin{array}{l}\text { Karket } \\
\text { Segment } \\
\text { (Sample S1ze) }\end{array}$} & \multirow{2}{*}{$\begin{array}{l}\text { Interaction } \\
\text { Fitted In } \\
\text { Model above } \\
\text { Main Effect }\end{array}$} & \multicolumn{8}{|c|}{$\begin{array}{l}\text { Type of Subsample and Contingency Table } \\
\begin{array}{l}\text { Total Raw FLA }>50,000 \mathrm{ft} 2 \text { DAL }>1.0 \mathrm{UnIt} \text { FLA }>50,000 \mathrm{ft}^{2} \\
\text { Sample }\end{array} \\
\text { DAL }>1.0 \text { unft }\end{array}$} \\
\hline & & $\begin{array}{l}\text { FLAC } \\
\mathbf{x} \\
\text { DALC }\end{array}$ & $\begin{array}{l}\text { DMPC } \\
\mathbf{x} \\
\text { DALC }\end{array}$ & $\begin{array}{l}\text { FLAC } \\
x \\
\text { DALC }\end{array}$ & $\begin{array}{l}\text { EMPC } \\
\mathbf{x} \\
\text { DALC }\end{array}$ & $\begin{array}{l}\text { FLAC } \\
\mathbf{x} \\
\text { DALC }\end{array}$ & $\begin{array}{c}\text { EMPC } \\
\mathbf{x} \\
\text { DALC }\end{array}$ & $\begin{array}{l}\text { FLAC } \\
\mathbf{x} \\
\text { DALC } \\
\end{array}$ & $\begin{array}{l}\text { EMPC } \\
x \\
\text { DALC } \\
\end{array}$ \\
\hline $\begin{array}{l}\text { Total } \\
\text { Sample S1ze }\end{array}$ & $\begin{array}{c}- \\
1,1 \\
1,2 \\
2,1 \\
2,2\end{array}$ & $\begin{array}{l}194.04 \\
179.93 \\
186.63 \\
180.27 \\
137.09 \\
2772 \\
\end{array}$ & $\begin{array}{l}179.79 \\
175.73 \\
178.22 \\
163.78 \\
106.28 \\
2772 \\
\end{array}$ & $\begin{array}{l}157.12 \\
143.86 \\
155.99 \\
145.54 \\
121.55 \\
2066 \\
\end{array}$ & $\begin{array}{c}136.16 \\
132.72 \\
135.97 \\
122.16 \\
88.43 \\
2066 \\
\end{array}$ & $\begin{array}{l}82.18 \\
80.22 \\
81.45 \\
81.95 \\
52.79 \\
1912 \\
\end{array}$ & $\begin{array}{l}74.09 \\
73.26 \\
73.98 \\
74.09 \\
39.04 \\
1912 \\
\end{array}$ & $\begin{array}{l}81.03 \\
76.52 \\
80.93 \\
79.50 \\
61.95 \\
1491 \\
\end{array}$ & $\begin{array}{l}67.86 \\
65.26 \\
67.24 \\
67.13 \\
44.91 \\
1491 \\
\end{array}$ \\
\hline $\begin{array}{l}\text { Avg. Income } \\
\geq \$ 6000 \\
\text { Sample S1ze }\end{array}$ & $\begin{array}{l}1,1 \\
1,2 \\
2.1 \\
2,2\end{array}$ & $\begin{array}{r}92.89 \\
88.32 \\
77.76 \\
88.44 \\
64.57 \\
537 \\
\end{array}$ & $\begin{array}{r}80.62 \\
77.32 \\
80.53 \\
74.86 \\
39.51 \\
537 \\
\end{array}$ & $\begin{array}{r}97.44 \\
92.81 \\
84.08 \\
92.92 \\
71.03 \\
382 \\
\end{array}$ & $\begin{array}{r}83.10 \\
79.74 \\
83.09 \\
77.16 \\
43.39 \\
382 \\
\end{array}$ & $\begin{array}{l}33.08 \\
33.01 \\
27.17 \\
32.36 \\
20.60 \\
316 \\
\end{array}$ & $\begin{array}{c}27.38 \\
25.56 \\
27.36 \\
25.85 \\
9.61 \\
316 \\
\end{array}$ & $\begin{array}{l}32.65 \\
32.58 \\
28.08 \\
31.87 \\
21.89 \\
227 \\
\end{array}$ & $\begin{array}{r}24.40 \\
22.70 \\
24.02 \\
22.67 \\
8.30 \\
227 \\
\end{array}$ \\
\hline 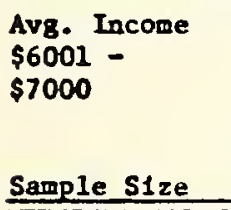 & $\begin{array}{l}- \\
1,1 \\
1,2 \\
2,1 \\
2,2\end{array}$ & $\begin{array}{r}138.45 \\
129.33 \\
137.91 \\
123.30 \\
83.29 \\
757 \\
\end{array}$ & $\begin{array}{c}125.28 \\
123.92 \\
124.55 \\
109.54 \\
70.94 \\
757 \\
\end{array}$ & $\begin{array}{r}103.58 \\
95.49 \\
103.27 \\
92.34 \\
67.97 \\
543 \\
\end{array}$ & $\begin{array}{r}88.02 \\
87.05 \\
87.78 \\
76.05 \\
54.26 \\
543 \\
\end{array}$ & $\begin{array}{l}53.35 \\
46.31 \\
53.33 \\
53.26 \\
32.85 \\
490 \\
\end{array}$ & $\begin{array}{l}50.19 \\
50.16 \\
50.17 \\
49.43 \\
25.56 \\
490\end{array}$ & $\begin{array}{l}39.60 \\
31.42 \\
38.92 \\
39.35 \\
29.13 \\
376\end{array}$ & $\begin{array}{l}34.82 \\
34.55 \\
33.72 \\
33.50 \\
21.54 \\
376 \\
\end{array}$ \\
\hline 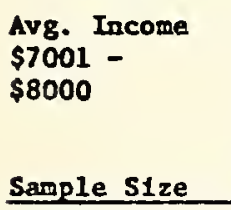 & $\begin{array}{l}- \\
1,1 \\
1,2 \\
2,1 \\
2,2\end{array}$ & $\begin{array}{r}8.24 \\
8.22 \\
6.85 \\
7.74 \\
2.96 \\
828 \\
\end{array}$ & $\begin{array}{c}11.86 \\
11.72 \\
11.78 \\
11.75 \\
5.09 \\
828 \\
\end{array}$ & $\begin{array}{r}8.49 \\
8.36 \\
5.66 \\
7.37 \\
5.17 \\
658 \\
\end{array}$ & $\begin{array}{r}9.60 \\
9.42 \\
9.47 \\
9.13 \\
5.08 \\
658 \\
\end{array}$ & $\begin{array}{l}31.23 \\
31.22 \\
29.25 \\
28.42 \\
22.17 \\
580 \\
\end{array}$ & $\begin{array}{l}23.22 \\
21.98 \\
22.67 \\
23.20 \\
16.52 \\
580 \\
\end{array}$ & $\begin{array}{l}40.71 \\
40.56 \\
37.49 \\
34.94 \\
33.06 \\
469 \\
\end{array}$ & $\begin{array}{l}30.08 \\
27.80 \\
29.99 \\
29.36 \\
24.77 \\
469 \\
\end{array}$ \\
\hline $\begin{array}{l}\text { Avg. Income } \\
>\$ 8000\end{array}$ & $\begin{array}{l}- \\
1,1 \\
1,2 \\
2,1 \\
2,2\end{array}$ & $\begin{array}{l}14.32 \\
13.16 \\
12.42 \\
13.58 \\
13.51 \\
650 \\
\end{array}$ & $\begin{array}{l}10.95 \\
10.73 \\
10.62 \\
9.62 \\
8.84 \\
650 \\
\end{array}$ & $\begin{array}{r}4.03 \\
3.46 \\
3.98 \\
3.67 \\
4.03 \\
483 \\
\end{array}$ & $\begin{array}{r}2.54 \\
2.47 \\
2.35 \\
1.81 \\
2.39 \\
483 \\
\end{array}$ & $\begin{array}{l}1.29 \\
1.28 \\
0.87 \\
1.27 \\
1.27 \\
526 \\
\end{array}$ & $\begin{array}{l}1.34 \\
1.12 \\
1.32 \\
1.32 \\
0.88 \\
526 \\
\end{array}$ & $\begin{array}{l}4.64 \\
3.89 \\
4.55 \\
4.47 \\
4.62 \\
419 \\
\end{array}$ & $\begin{array}{l}2.71 \\
2.69 \\
2.39 \\
2.01 \\
2.59 \\
419 \\
\end{array}$ \\
\hline
\end{tabular}

IFAC and DALC are 2onal Retall Floor Area (FLA) and Afrline Digtance (DAL) Categorlea Defined in Figure B.3

2EMPC and DALC are Zonal Reta1l Employment and Atrline Distance Categorlea Defined in F1gure B.4

$$
\begin{aligned}
& \text { 3d.f. - } 4 \text { for Main Effect Models } \\
& \text { d.f. - } 3 \text { for Main Effect and Single Interaction Models }
\end{aligned}
$$


miles) and where a combination of these two restrictions was used, were considered.

As can be noticed in Table B.4, the Retail Floor Area restriction improves the goodness-of-fit for all cases, making that for the high income market segments extremely good. This supports the contention that local travel should be excluded in model development, as discussed in Chapter 2. It also shows that the shopping behavior of higher income families (with respect to major retail outlet patronage) who usuallylive in outlying areas can be adequately captured by using functional destinations defined with spatial separation and shopping attraction measures. It is quite evident that further shopping opportunity or attraction measures or a more direct definition of such measures is needed particularly for analyzing the shopping behavior of the lower income market segments.

With the Interzonal Airline Distance restriction (excluding trips with interzonal distance less than 1 distance unit $(0.833$ mile)), improvements in goodness-of-fit are achieved, compared to the total raw sample, for all income categories except for the third. This could be because of the means of sample screening or random effects. The nature of the data did not allow a further investigation of this observation. Similar remarks hold for the case where the Retail Floor Area and Airline Distance restrictions were combined.

The ten models that gave good results in functional destination prediction, as discussed above, are sumarized in Tables B.5 - B.14. 
Table B.5, Response Prediction for Functional Destinations Defined by the crossing of Zonal Retall Floor Area and Afrline Distance - Total Raw Sample

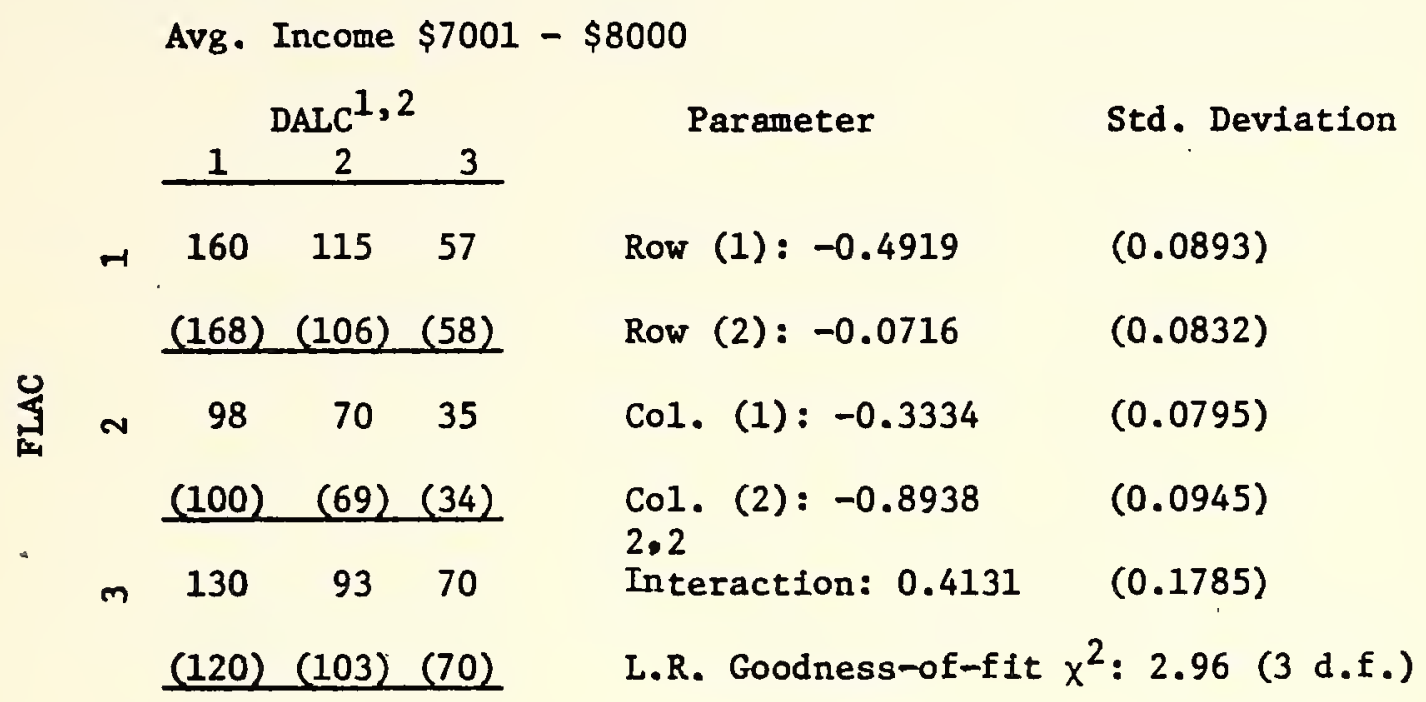

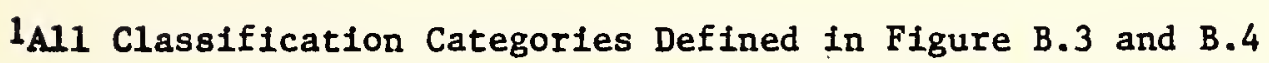

2 Cell Entries are Predicted Frequencles with Observed Values in Parenthesis 
Table B.6. Response Prediction for Functional Destination Defined by the Crossing of Zonal Retail Employment and Airline Distance - Total Raw Sample

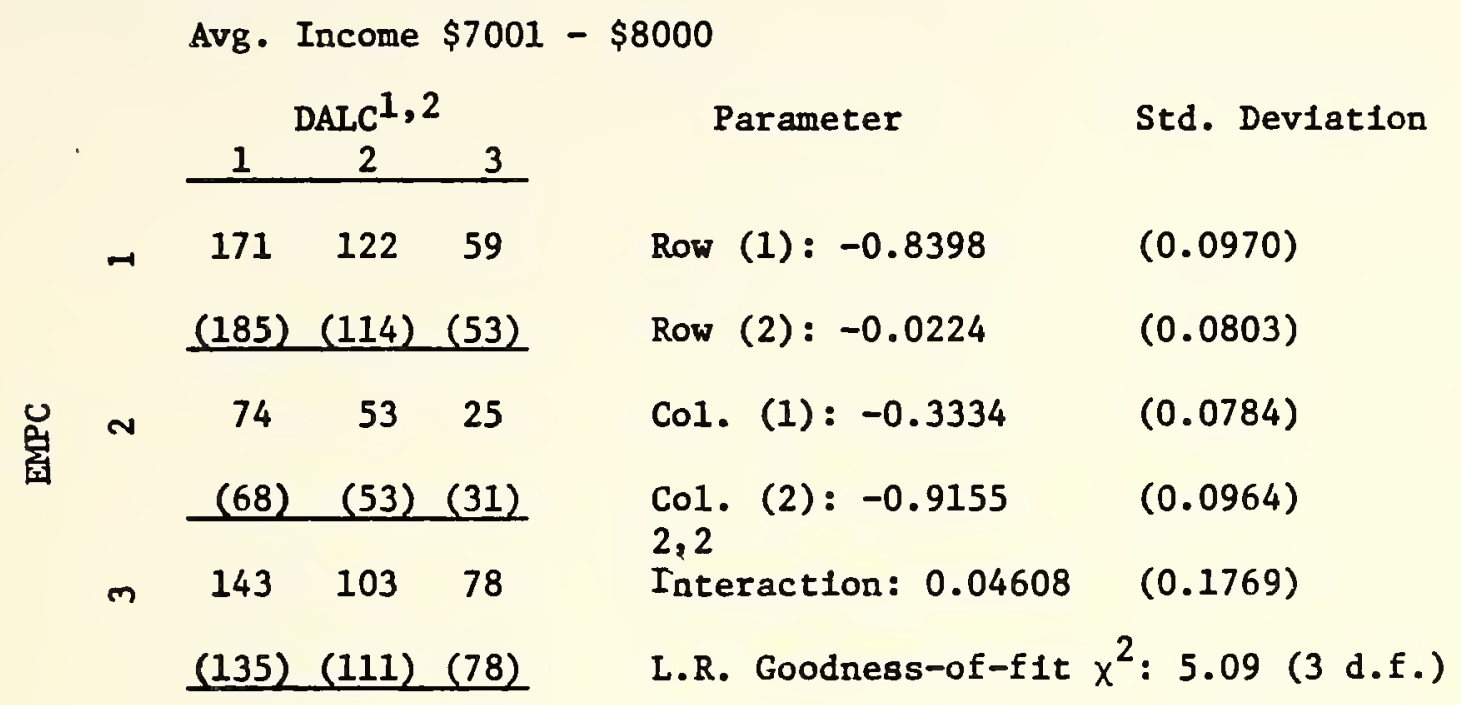

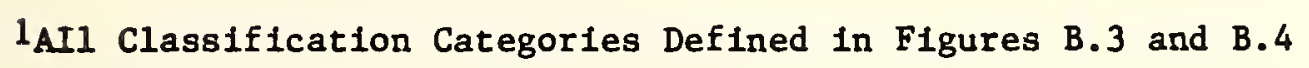

${ }^{2}$ Cell Entries are Predicted Frequencies with Observed Values in Parenthesis 
Table B.7. Response Prediction for Functional Destinations Defined by the Crossing of Zonal Retall Floor Area and Airline Distance - Floor Area > 50,000 sq. ft.

$$
\begin{aligned}
& \text { Avg. Income } \$ 7001-\$ 8000 \\
& \begin{array}{lc}
\multicolumn{3}{c}{\mathrm{DALC}^{\mathrm{I}, 2}} \\
1 & 2 \\
\hline
\end{array} \\
& \begin{array}{lllll}
-1 & 78 & 55 & 29 & \text { Row }(1): 0.2256 \quad(0.1051)
\end{array}
\end{aligned}
$$

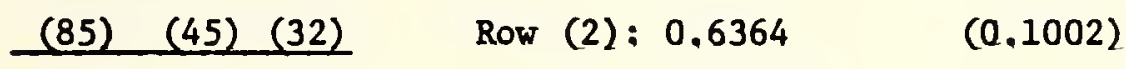

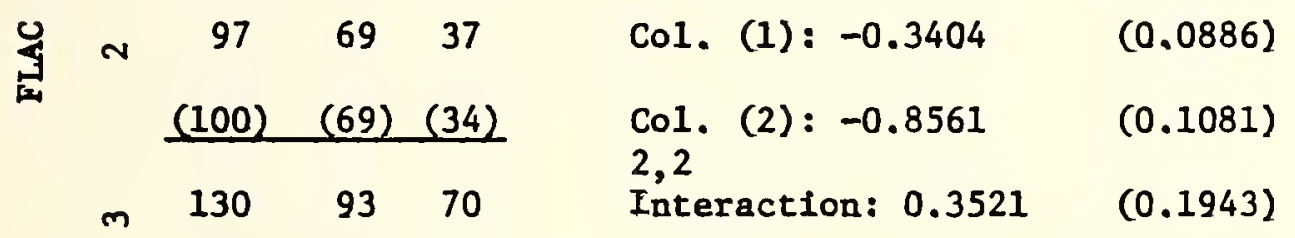

$$
\begin{aligned}
& \text { (120) (103) (70) L.R. Goodness-of-fit } x^{2}: 5.17 \text { (3 d.f.) }
\end{aligned}
$$

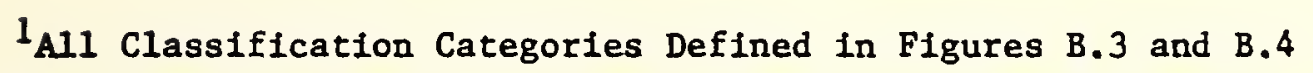
${ }^{2}$ Cell Entries are Predicted Frequencies with Observed Values in Parenthes1s 
Table B.8. Response Prediction for Functional Destinations Defined by the Crossing of Zonal Retail Employment and Airline Distance - Floor Area > 50,000 sq. ft.

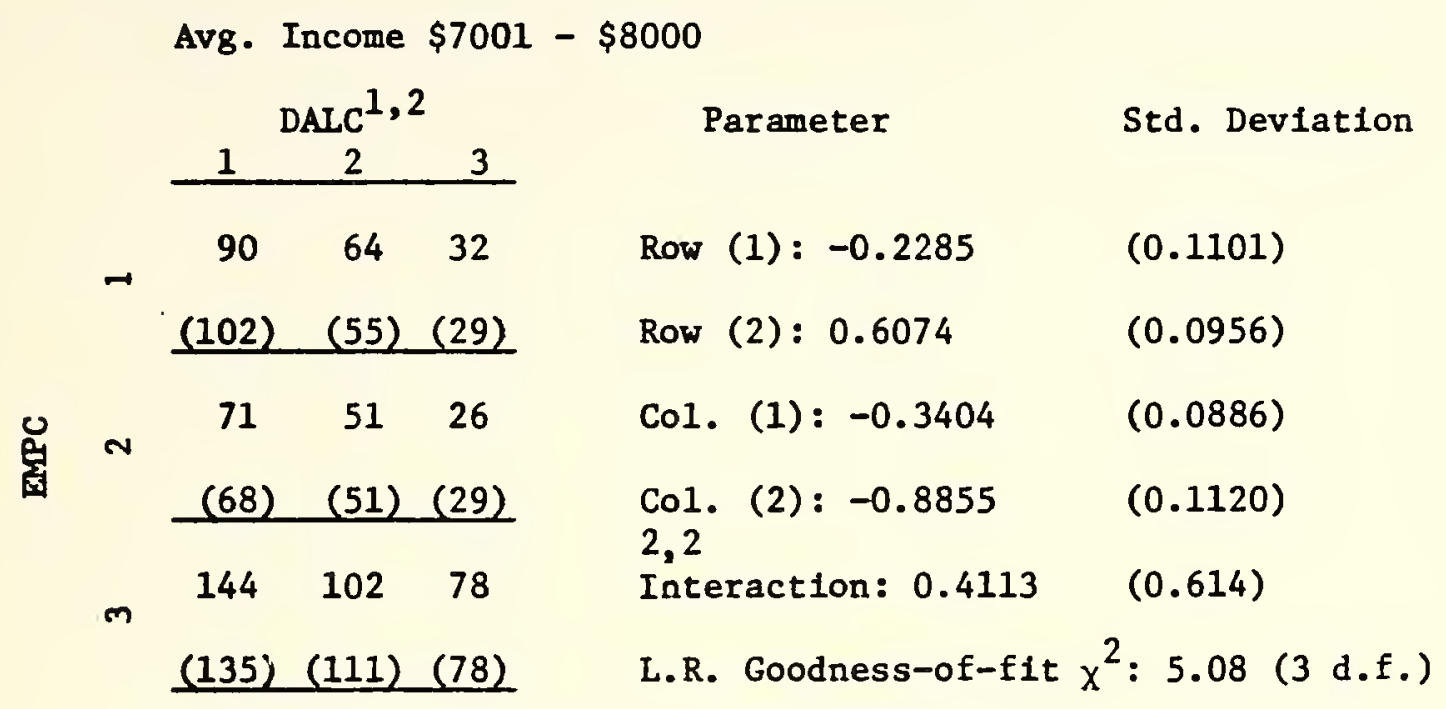

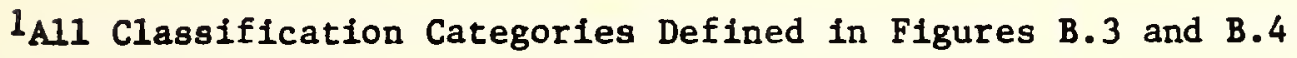

${ }^{2}$ Cell Entries are Predicted Frequencies with Observed Values in Parenthesis 
Table B.9. Response Prediction for Functional Destinations Defined by the Crossing of Zonal Retail Floor Area and Airline D1stance - Floor Area > 50,000 sq. ft.

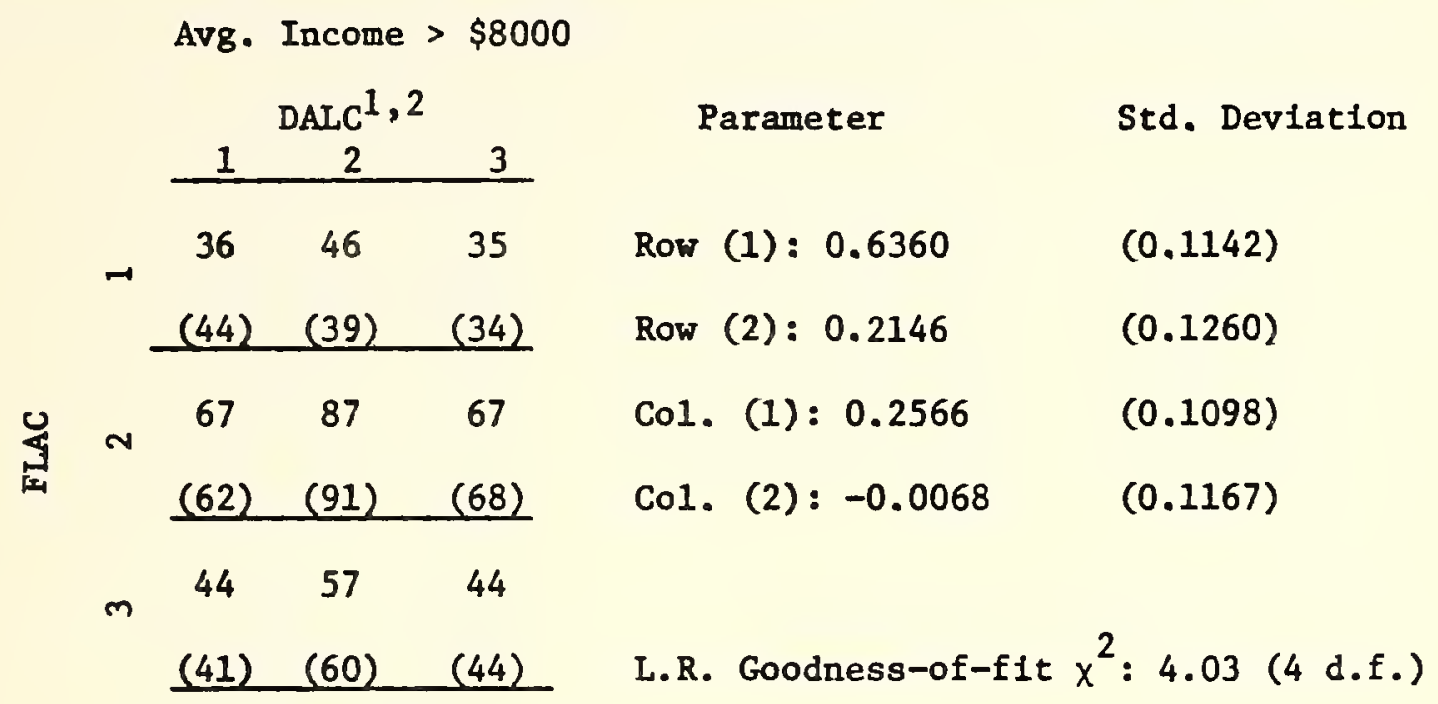

${ }^{1}$ All Classification Categories Defined In Figures B. 3 and B. 4

${ }^{2}$ Cell Entries are Predicted Frequencies with Observed Values in Parenthesis 
Table B.10. Response Prediction for Functional Destinations Defined by the Crossing of Zonal Retail Employment and Airline Distance - Floor Area $>50,000$ sq. ft.

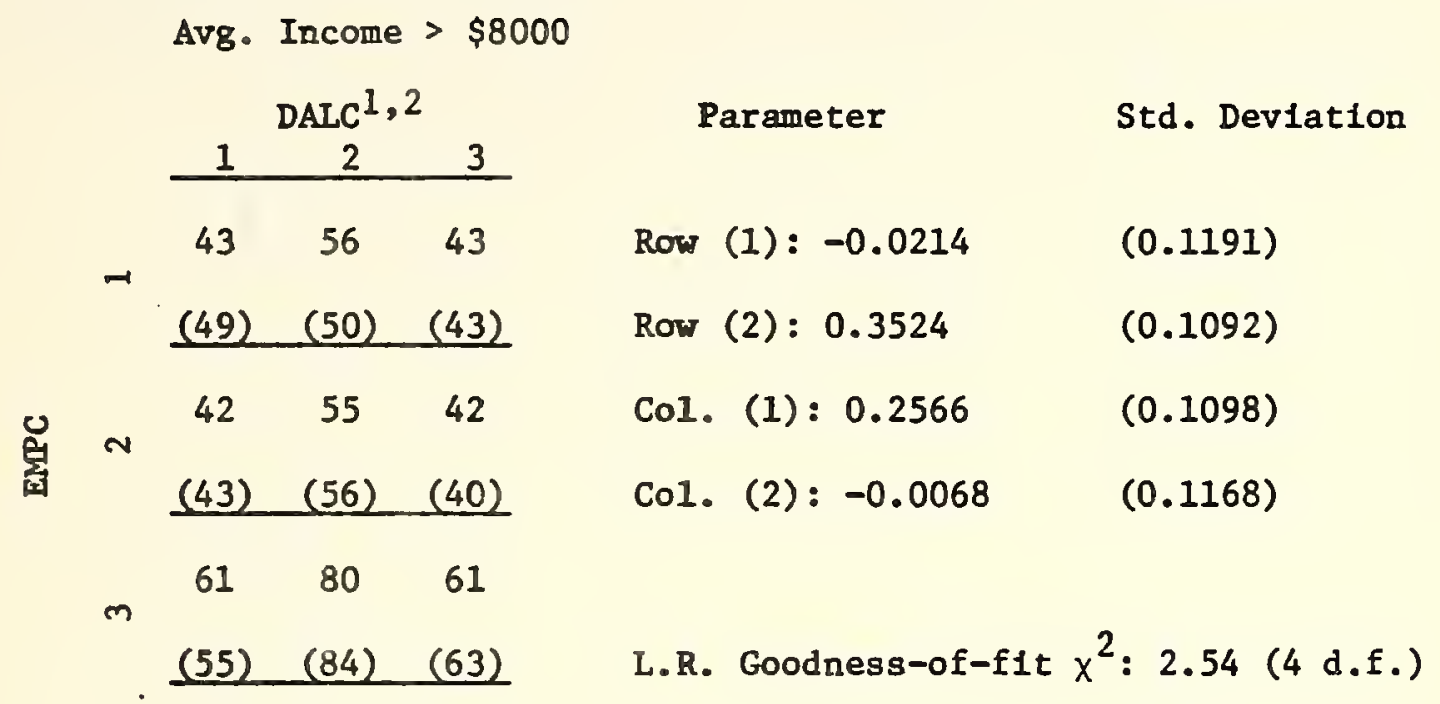

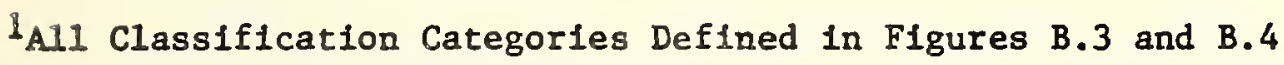

${ }^{2}$ Cell Entries are Predicted Frequencies with Observed Values in Parenthesis 
Table B,11, Response Prediction for Functional Destinations Defined by the Crossing of Zonal Retail Floor Area and Alrline Distance - Afrline Distance > 1.0 unit

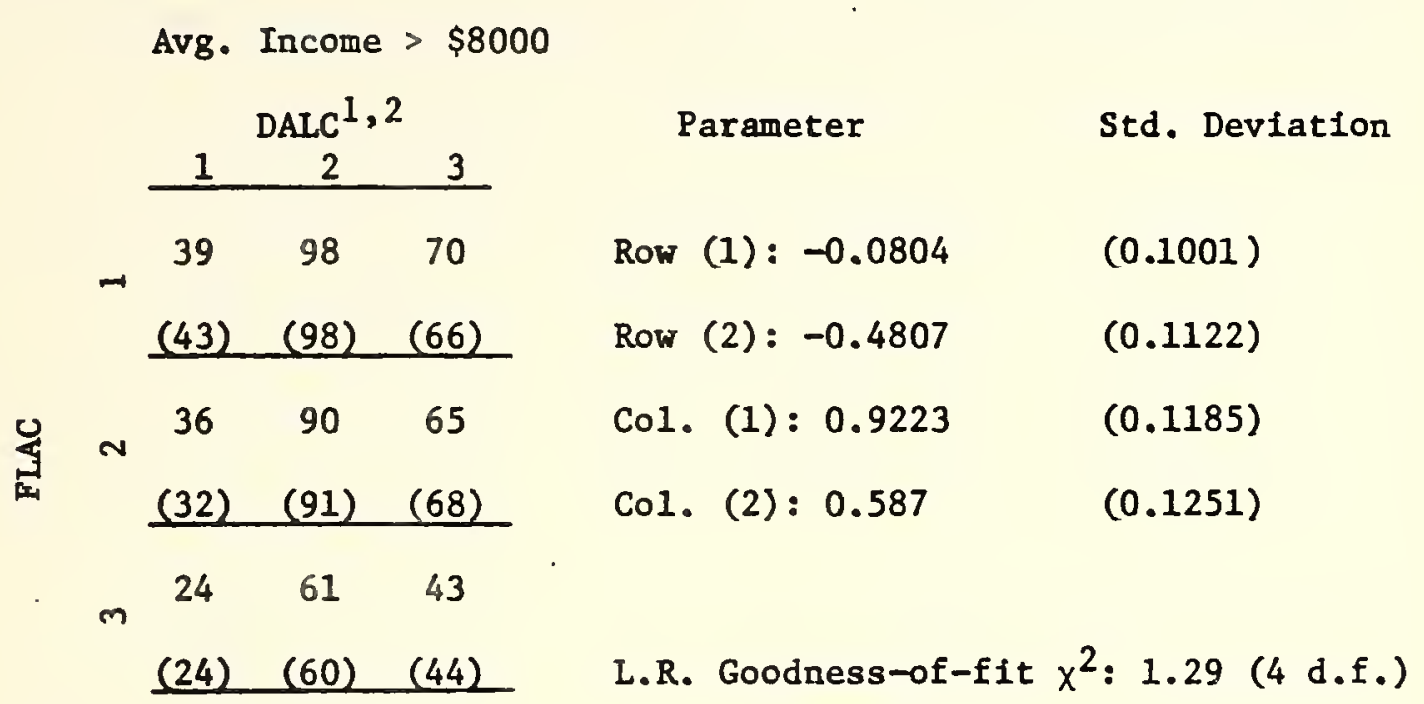

${ }^{1}$ All Classification Categories Defined in Figures B. 3 and B. 4

${ }^{2}$ Cell Entries are Predicted Frequencies with Observed Values in Parenthesis 
Table B, 12. Response Prediction for Functional Destinations Defined by the Crossing of Zonal Retail Exployment and Airline Distance - Airline Distance > 1.0 unit

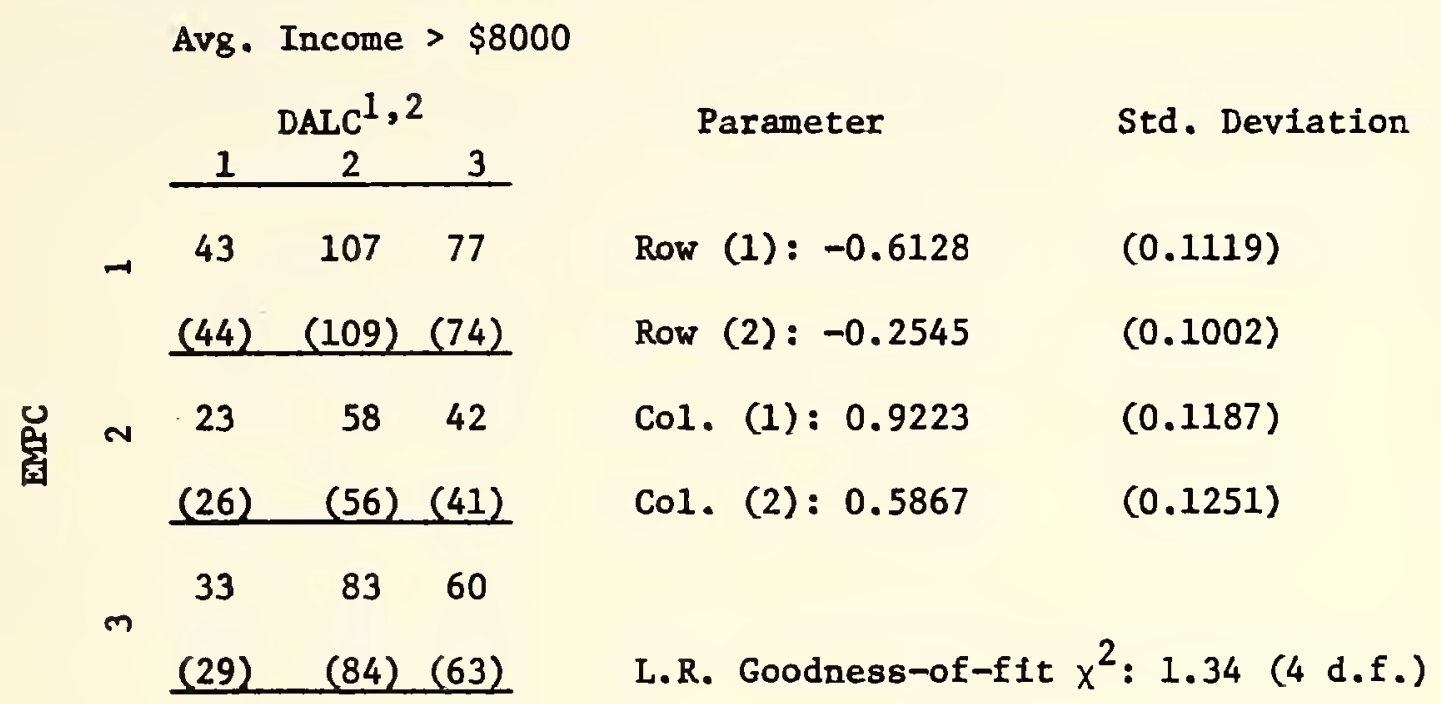

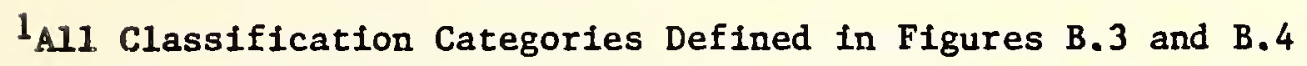

${ }^{2}$ Cell Entries are Predicted Frequencies with Observed Values in Parenthesis 
Table B.13. Response Prediction for Functional Destinations Defined by the Crossing of Zonal Retail Floor Area and Afrline Distance -Floor Area $>50,000 \mathrm{sq}$. ft. - Alrline Distance $>1.0$ unit

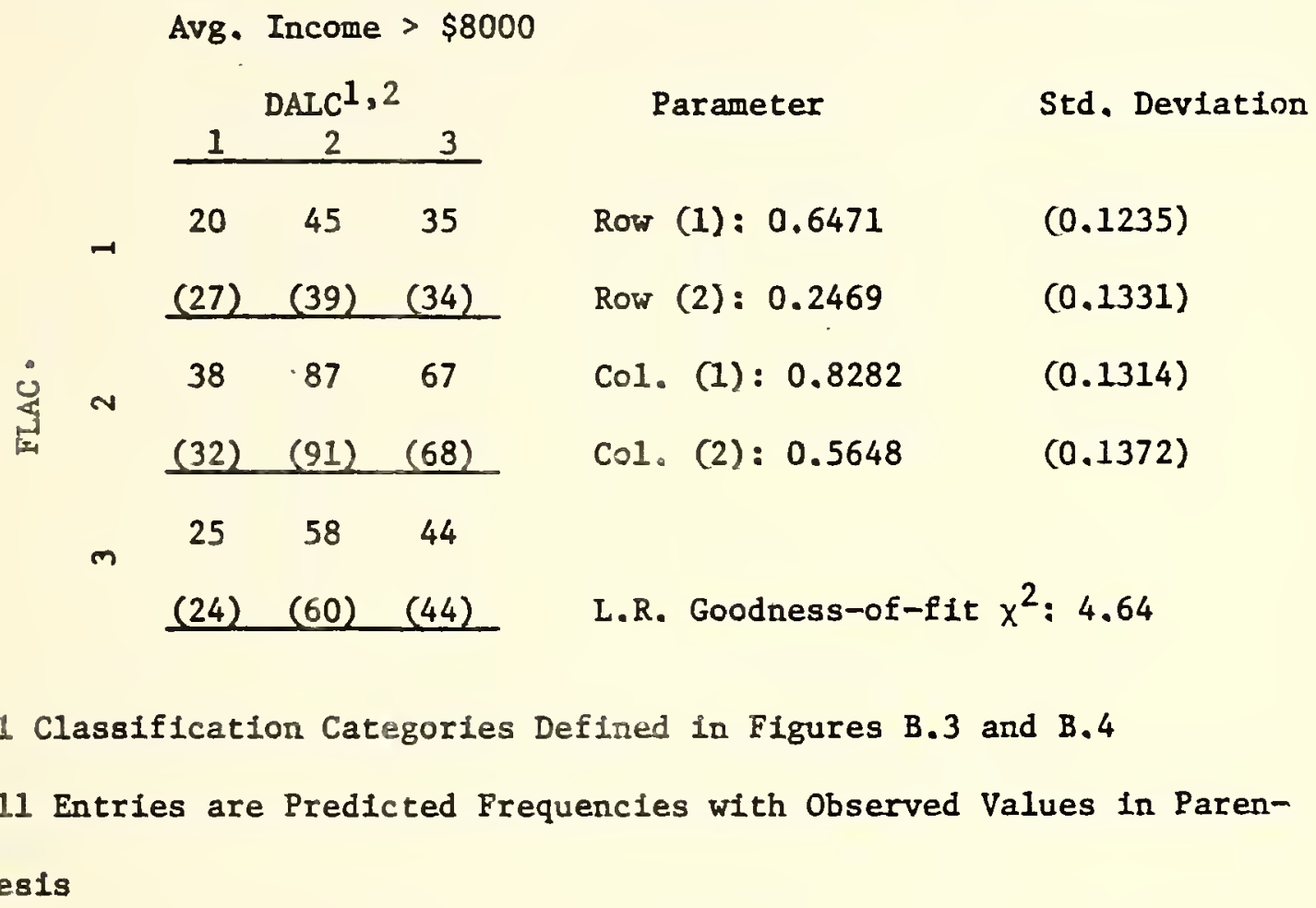


Table B.14. Response Prediction for Functional Destinations Defined by the Crossing of Zonal Retafl Employment and Afrline Distance - Floor Area >50,000 sq. ft. - Airline Distance $>1.0$ unit

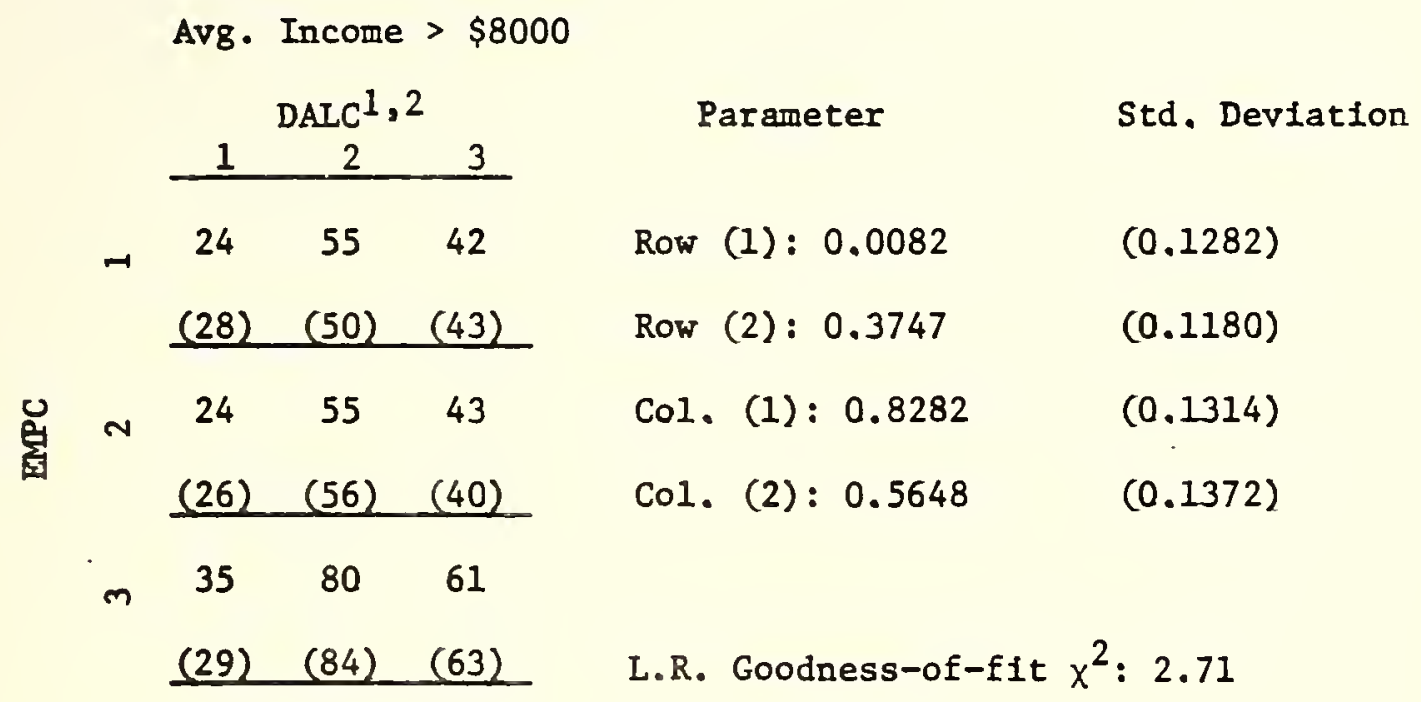

${ }^{1}$ All Classification Categories Defined in Figures B. 3 and B. 4

${ }^{2}$ Cell Entries are Predicted Frequencles with Observed Values in Parenthesis 
Some Further Modelling Considerations

Having now agreed that the shopping behavior of higher income market segments can be sufficiently investigated by using the available zonal data on Retail Floor Area, Employment and Airline Distance, one may now be interested in testing if the 3 rd and 4 th market segments differ in their response patterns and if the patterns are consistent. The first question can be answered by examining Table B.4. It is noticed that where one high income category gives good results the models for the other category are poor. Where both high income market segments have well-fitting models, one achieves that with main effects only while the other does so with main effects and a 2,2 interaction. The need for the market segmentation adopted is therefore justified.

Consistency of Functional Zonal Destination Choice Models

An examination of the signs and magnitudes of parameters estimated for the well-fitting models discussed above (see Tables B.5 to B.14) shows patterns that cannot be easily explained with information available except for the strong likelihood that it is a result of the use of traffic zonal boundaries for defining shopping areas. One would normally expect that, with the exclusion of local travel, the patronage of shopping areas would increase with retail floor area and decrease with distance. Under these conditions one would expect that, in general, the row parameters that correspond to zonal retail floor area effects would be positive and that the column parameters representing interzonal distance effects would be negative. This was not the situation in all 
the models summarized in Tables B.5 to B.14.

Statistical tests were carried out on model parameter vectors, the equality of which for any pair of populations would establish similarity of response patterns. The models that were considered are listed in Table B.15. The multivariate statistical testing procedures used have been presented in Chapter 7 . 70 percent and 50 percent subsamples were taken from the data set used for each model of functional destination choice. The original total sample, the 70 percent subsample, and the 50 percent sub-sample were denoted as populations I, II and III respectively. Comparisons of populations I with II, I with III, and II with III were made for each model. All the tests did not reject the hypothesis that the parameter vectors in all the sub-samples (including the total sample) had the same covariance matrix. However, the inconsistency in the signs of the parameters attributed above to the inadequacy of the use of zonal shopping destinations, prevailed over the models developed to such an extent that the hypothesis of the equality of parameter vectors was rejected in all cases.

The serious inadequacy of the use of zonal shopping areas in functional destination choice prediction discussed above strongly calls for the use of specific shopping areas in functional shopping destination definition, the effectiveness of which has been discussed in Chapter 2 and empirically demonstrated in Chapter 7 . 
Table B.15. Functional Zonal Destination Choice Models Considered In Sub-Sample Analysis

\begin{tabular}{|c|c|c|}
\hline $\begin{array}{l}\text { Functional Zonal } \\
\text { Destination } \\
\text { Classification }\end{array}$ & $\begin{array}{l}\text { Origin Zone } \\
\text { Average Income } \\
\text { For Sub-Sample }\end{array}$ & $\begin{array}{l}\text { Condition for } \\
\text { Subsamples } \\
\text { Selection }, 3\end{array}$ \\
\hline FLAC $\times$ DALC & $\$ 7001-\$ 8000$ & FLA > 50 \\
\hline EMPC $\times$ DALC & $\$ 7001-\$ 8000$ & FLA > 50 \\
\hline FLAC $\times$ DALC & $\begin{array}{c}\text { Greater Than } \\
\$ 8000\end{array}$ & FLA $>50$. \\
\hline EMPC $\times$ DALC & $\begin{array}{c}\text { Greater Than } \\
\$ 8000\end{array}$ & FLA > 50 \\
\hline FLAC $\times$ DALC & $\begin{array}{c}\text { Greater Than } \\
\$ 8000\end{array}$ & $\mathrm{DAL}>1.0$ \\
\hline EMPC $\times$ DALC & $\begin{array}{c}\text { Greater Than } \\
\$ 8000\end{array}$ & DAI $>1.0$ \\
\hline FLAC $\times$ DALC & $\begin{array}{c}\text { Greater Than } \\
\$ 8000\end{array}$ & $\begin{array}{l}\mathrm{FLA}>50 \\
\mathrm{DAL}>1.0\end{array}$ \\
\hline EMPC $\times$ DALC & $\begin{array}{c}\text { Greater Than } \\
\$ 8000\end{array}$ & $\begin{array}{l}\text { FLA }>50 \\
\text { DAL }>1.0\end{array}$ \\
\hline
\end{tabular}

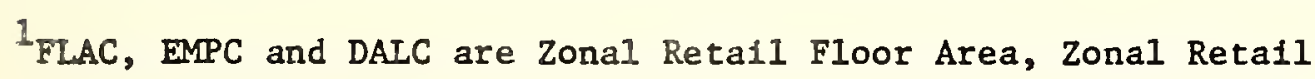

anployment and Inter-zonal Airline Distance Categorles Defined in Figures B.1 and B.2

2FLA is a Zonal Retail Floor Area Unit of 1000 sq. ft.

${ }^{3}$ DAI is an Alrline Distance Unit of 0.833 miles 
VITA

$=$ 
